\title{
Thin Film Cadmium Telluride, Zinc Telluride, and Mercury Zinc Telluride Solar Cells
} NREL/TP-413-4791

\section{Final Subcontract Report} DE92 001237

1 July 1988 - 31 December 1991

T. L. Chu

University of South Florida

Tampa, Florida

NREL technical monitor: H. S. Ullal

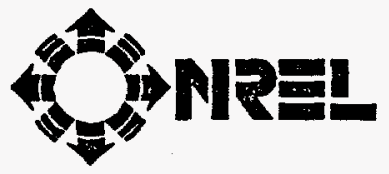

National Renewable Energy Laboratory

(formerly the Solar Energy Research Institute) 1617 Cole Boulevard

Golden, Colorado 80401-3393

A Division of Midwest Research Institute Operated for the U.S. Department of Energy under Contract No. DE-AC02-83CH10093

Prepared under Subcontract No. XL-8-18091-1

April 1992

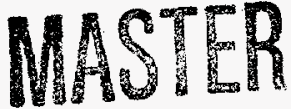


On September 16, 1991 the Solar Energy Institute was designated a national laboratory, and its name was changed to the National Renewable Energy Laboratory.

\section{NOTICE}

This report was prepared as an account of work sponsored by an agency of the United States government. Neither the United States government nor any agency thereof, nor any of their employees, makes any warranty, express or implied, or assumes any legal liability or responsibility for the accuracy, completeness, or usefulness of any information, apparatus, product, or process disclosed, or represents that its use would not infringe privately owned rights. Reference herein to any specific commercial product, process, or service by trade name, trademark, manufacturer, or otherwise does not necessarily constitute or imply its endorsement, recommendation, or favoring by the United States government or any agency thereof. The views and opinions of authors expressed herein do not necessarily state or reflect those of the United States government or any agency thereof.

$$
\begin{gathered}
\text { Printed in the United States of America } \\
\text { Available from: } \\
\text { National Technical Information Service } \\
\text { U.S. Department of Commerce } \\
5285 \text { Port Royal Road } \\
\text { Springfield, VA 22161 }
\end{gathered}
$$

Price: Microfiche A01

Printed Copy A05

Codes are used for pricing all publications. The code is determined by the number of pages in the publication. Information pertaining to the pricing codes can be found in the current issue of the following publications which are generally available in most libraries: Energy Research Abstracts (ERA); Government Reports Announcements and Index (GRA and 1); Scientific and Technical Abstract Reports (STAR); and publication NTIS-PR-360 available from NTIS at the above address. 


\section{DISCLAIMER}

Portions of this document may be illegible electronic image products. Images are produced from the best available original document. 


\section{SUMMARY}

The major objectives of this program on thin film solar cells, supported by the National Renewable Energy Laboratory under Subcontract XL-8-18091-1, are to demonstrate (1) thin film cadmium telluride solar cells with a quantum efficiency of $75 \%$ or higher at $0.44 \mu \mathrm{m}$ and a photovoltaic efficiency of $11.5 \%$ or greater, and (2) thin film zinc telluride and mercury zinc telluride solar cells with a transparency to sub-bandgap radiation of $65 \%$ and a photovoltaic conversion efficiency of $5 \%$ and $8 \%$, respectively.

Efforts during this reporting period have been directed to (1) the deposition of transparent conducting semiconductor (TCS) films by solution-growth and metalorganic chemical vapor deposition (MOCVD) techniques, (2) the deposition of CdTe films by close-spaced sublimination (CSS) and MOCVD techniques, (3) the preparation and evaluation of thin film CdTe solar cells, and (4) the preparation and characterization of thin film $\mathrm{ZnTe}$, $\mathrm{Cd}_{1-x} \mathrm{Zn}_{\mathrm{x}} \mathrm{Te}$, and $\mathrm{Hg}_{1-\mathrm{x}} \mathrm{Zn}_{\mathbf{x}} \mathrm{Te}$ solar cells.

The deposition of CdS films from aqueous solutions has been investigated in detail, and their crystallographic, optical, and electrical properties characterized. Device-quality CdS films of controlled thickness have been prepared reproducibly. Cadmium zinc sulfide $\left(\mathrm{Cd}_{1}\right.$. $Z_{x} n_{x}$ ) films have been deposited by MOCVD, and the effects of the composition of the reaction mixture on the optical and electrical properties investigated. The use of Al-doped $\mathrm{Cd}_{0.7} \mathrm{Zn}_{0.3} \mathrm{~S}$ films as a TCS for II-VI solar cells has been studied. Polycrystalline $\mathrm{ZnSe}$ films have been deposited at $400^{\circ}-500^{\circ} \mathrm{C}$ by MOCVD. The deposited films have high resistivity and negative photoconductivity. The resistivity is reduced and photoconductivity significantly improved by using $\mathrm{Al}$ as a dopant, and the effects of $\mathrm{III} / \mathrm{II}$ and VI/II molar ratios in the reaction mixture on the properties of $\mathrm{ZnSe}$ films determined. The use of Al-doped $\mathrm{ZnSe}$ films as a TCS for II-VI solar cells has been investigated.

CdTe films have been deposited from DMCd and DIPTe at $400^{\circ} \mathrm{C}$ using TEGa and $\mathrm{AsH}_{3}$ as dopants. Intrinsic CdTe films can be n-type (Te vacancies) or p-type (Cd vacancies), depending on the DMCd/DIPTe ratio in the reaction mixture. Ga is readily incorporated into CdTe films; however, low resistivity p-CdTe films have not been obtained. The asdeposited CdS/CdTe (MOCVD) solar cells show poor characteristics which are dramatically improved by post-deposition treatments; solar cells of larger than $1 \mathrm{~cm}^{2}$ area show near $10 \%$ efficiencies. The post-deposition treatments have been studied in detail.

CdTe films deposited by CSS show significantly better microstructure than those by MOCVD. Deep energy states in CdTe films deposited by CSS and MOCVD have been investigated. Thin film solar cells of $1 \mathrm{~cm}^{2}$ area prepared from the solution-grown CdS and CSS CdTe have conversion efficiency of $14.6 \%$ under global AM 1.5 conditions. However, CdTe heterojunction solar cells using other TCS's show relatively poor characteristics.

Thin films of $\mathrm{ZnTe}, \mathrm{Cd}_{1-x} \mathrm{Zn}_{\mathrm{x}} \mathrm{Te}$, and $\mathrm{Hg}_{1-x} \mathrm{Zn}_{\mathrm{x}} \mathrm{Te}$ have been deposited by MOCVD, and their crystallographic, optical, and electrical properties characterized. Heterojunction solar cells show high saturation current density and poor photovoltaic characteristics due to small grain size and poor grain structure of MOCVD films. 


\section{TABLE OF CONTENTS}

Summary

Table of Contents

ii

List of Illustrations

iv

List of Tables

ix

$\begin{array}{lll}\text { Section } 1.0 \text { Introduction } & 1\end{array}$

$\begin{array}{lll}\text { Section } & \text { 2.0 Transparent Conducting Semiconductor Films } & 2\end{array}$

2.1 Cadmium Sulfide Films 3

2.1.1 Solution Growth Process 3

2.1.2 Properties

22 Cadmium Zinc Sulfide $\quad 8$

2.2.1 Solution Growth 9

2.2.2 Metalorganic Chemical Vapor Deposition 9

2.2 .3 Properties

$2.3 \quad$ Zinc Oxide Films 16

$\begin{array}{ll}2.4 & \text { Zinc Selenide Films } \\ \end{array}$

2.4.1 Deposition Process 17

$\begin{array}{ll}2.42 \text { Properties } & 19\end{array}$

Section 3.0 Cadmium Telluride Films and Solar Cells 24

3.1 Metalorganic Chemical Vapor Deposition (MOCVD)

3.1.1 Deposition Process

3.12 Properties of Intrinsic CdTe Films 26

3.13 Properties of Doped CdTe Films 30

3.1.4 Solar Cells 
3.2 Close-Spaced Sublimation (CSS) 40

3.2.1 Deposition Process 41

3.2.2 Solar Cells 44

Section 4.0 Zinc Telluride Films and Solar Cells 48

4.1 Deposition Process : 48

$\begin{array}{lll}4.2 & \text { Properties } & 51\end{array}$

4.3 Solar Cells $\quad 55$

Section 5.0 Cadmium Zinc Telluride Films and Solar Cells 60

$\begin{array}{lll}5.1 & \text { Deposition Process } & 61\end{array}$

$\begin{array}{lll}5.2 & \text { Properties } & 62\end{array}$

$\begin{array}{lll}5.3 & \text { Solar Cells } & 66\end{array}$

$\begin{array}{lll}\text { Section } & 6.0 \text { Mercury Zinc Telluride Films and Solar Cells } & 70\end{array}$

Section 7.0 Conclusions 75

$\begin{array}{lll}\text { Section } & \text { 8.0 Directions for Future Research } & 76\end{array}$

$\begin{array}{lll}\text { Section } 9.0 \text { References } & 77\end{array}$

Section 10.0 Publications and Presentations $\quad 82$

Section 11.0 Students and Associates Supported 85 


\section{LIST OF ILLUSTRATIONS}

Figure 2-1 X-ray diffraction spectrum of a CdS film on a glass substrate.

Figure 2-2 Optical transmission of a CdS film of $1500 \AA$ thickness on glass substrate.

Figure 2-3 Schematic diagram of the apparatus for the MOCVD of II-VI compounds.

Figure 2-4 Deposition rate of $\mathrm{Cd}_{1-x} \mathrm{Zn}_{x} \mathrm{~S}$ films at $375 \cdot \mathrm{C}$ and $425^{\circ} \mathrm{C}$ as a function of $\mathrm{DMCd} / \mathrm{DEZn}$ molar ratio.

Figure 2-5 X-ray diffraction spectrum of a $\mathrm{Cd}_{0.52} \mathrm{Zn}_{0.48} \mathrm{~S}$ film.

Figure 2-6 Bandgap energy of $\mathrm{Cd}_{1-0} \mathrm{Zn}_{\mathrm{x}} \mathrm{S}$ films deposited at $375^{\circ} \mathrm{C}$ and $425^{\circ} \mathrm{C}$ as a function of $\mathrm{DMCd} / \mathrm{DEZn}$ molar ratio.

Figure 2-7 Dark and illuminated resistivity of $\mathrm{Cd}_{1-x} \mathrm{Zn}_{x} \mathrm{~S}$ films deposited at $375^{\circ} \mathrm{C}$ as a function of bandgap energy.

Figure 2-8 Lateral resistivity of aluminum-doped $\mathrm{Cd}_{1-x} \mathrm{Zn}_{x} \mathrm{~S}$ films deposited at $425^{\circ} \mathrm{C}$ in the dark and under illumination.

Figure 2-9 Lateral resistivity of chlorine-doped $\mathrm{Cd}_{1-x} \mathrm{Zn}_{x} \mathrm{~S}$ films deposited at $375^{\circ} \mathrm{C}$ and $425^{\circ} \mathrm{C}$ as a function of bandgap energy.

Figure 2-10 The deposition rate of $\mathrm{ZnSe}$ films at $500^{\circ} \mathrm{C}$ as a function of the $\mathrm{DESe} / \mathrm{DEZn}$ molar ratio in the reaction mixture.

Figure 2-11 The deposition rate of $\mathrm{ZnSe}$ films from a $\mathrm{DESe} / \mathrm{DEZn}=0.7$ reaction mixture as a function of temperature.

Figure 2-12 X-ray diffraction spectrum of a $\mathrm{ZnSe}$ film deposited on a glass substrate at $500^{\circ} \mathrm{C}$.

Figure 2-13 Optical absorption of a $\mathrm{ZnSe}$ film deposited on a glass substrate at $500^{\circ} \mathrm{C}$. 
Figure 2-14 Lateral resistivity of $\mathrm{ZnSe}$ films deposited at various temperatures from a $\mathrm{DESe} / \mathrm{DEZn}=0.7$ reaction mixture in the dark and under illumination with an ELH lamp at $100 \mathrm{~mW} / \mathrm{cm}^{2}$.

Figure 2-15 Lateral resistivity of Al-doped $\mathrm{ZnSe}$ films, in the dark and under illumination, deposited at $500^{\circ} \mathrm{C}$ using a $\mathrm{TMAl} / \mathrm{DEZn}=0.03$, as a function of DESe/DEZn ratio in the reaction mixture.

Figure 2-16 Lateral resistivity of Al-doped $\mathrm{ZnSe}$ films, in the dark and under illumination, deposited at $500^{\circ} \mathrm{C}$ having a DESe $/ D E Z n=0.7$, as a function of TMAl concentration in the reaction mixture.

Figure 3-1 The deposition rate of CdTe films as a function of DMCd/DIPTe molar ratio in the reaction mixture.

Figure 3-2 Junction photovoltage spectra of graphite/n-CdTe/ $\mathrm{SnO}_{2}: \mathrm{F} /$ glass and graphite $/ \mathrm{p}-\mathrm{CdTe} / \mathrm{SnO}_{2}: \mathrm{F} /$ glass structures.

Figure 3-3 Lateral resistivity of CdTe films versus the reactant composition in the dark and under illumination with an ELH lamp at $100 \mathrm{~mW} / \mathrm{cm}^{2}$.

Figure 3-4 Photoluminescence spectra of CdTe films at $4.2 \mathrm{~K}$ deposited by using various DMCd/DIPTe molar ratios in the reaction mixture.

Figure 3-5 Lateral resistivity of Ga-doped CdTe films, in the dark and under illumination with an ELH lamp at $100 \mathrm{~mW} / \mathrm{cm}^{2}$, versus TEGa concentration in the reaction mixture.

Figure 3-6 Carrier concentration in Ga-doped CdTe films versus TEGa/DMCd molar ratio in the reaction mixture.

Figure 3-7 Photoluminescence spectra of Ga-doped CdTe films at $4.2 \mathrm{~K}$ deposited by using TEGa/DMCd molar ratios of 0.009 (A), $0.03(\mathrm{~B})$, and $0.05(\mathrm{C})$ in the reaction mixture.

Figure 3-8 Junction photovoltage spectra of two graphite/CdTe/ $\mathrm{SnO}_{2}: \mathrm{F} /$ glass structures deposited with TEGa/DMCd molar ratios of 0.009 (A) and 0.03 (B). 
Figure 3-9 Lateral resistivity of As-doped CdTe films, in the dark and under illumination with an ELH lamp at $100 \mathrm{~mW} / \mathrm{cm}^{2}$, versus $\mathrm{AsH}_{3}$ concentration in the reaction mixture.

Figure 3-10 Photoluminescence spectra of As-doped CdTe films at $4.2 \mathrm{~K}$ deposited by using a $\mathrm{AsH}_{3} / \mathrm{DIPTe}$ molar ratio of 0.45 and DMCd/DIPTe molar ratios of (A) $0.34,(B) 0.68,(C)$ 1.0, (D) 2.0, and (E) 3.0.

Figure 3-11 Junction photovoltage spectra of a CdS/CdTe junction structure before (A) and after (B) the $\mathrm{CdCl}_{2}$ treatment.

Figure 3-12 Current-voltage characterization of a CdTe (i MOCVD) $/ \mathrm{CdS} / \mathrm{SnO}_{2}$; $\mathrm{F} /$ glass solar cell under global AM 1.5 conditions.

Figure 3-13 The quantum efficiency of the CdS/CdTe solar cells shown in Figure 3-12.

Figure 3-14 Photoluminescence spectra of (1) an as-deposited $\mathrm{CdTe}(\mathrm{MOCVD}) / \mathrm{CdS} / \mathrm{SnO}_{2} \cdot \mathrm{F} /$ glass structure, illuminated from the CdTe (A) and the glass (C) surfaces, and (2) a $\mathrm{CdCl}_{2}$ treated structure illuminated from the CdTe (B) and the glass (D) surfaces.

Figure 3-15 DLTS spectra of a CdS/CdTe junction structure before and after the $\mathrm{CdCl}_{2}$ treatment.

Figure 3-16 Schematic diagram of the apparatus for the deposition of CdTe films by the CSS technique.

Figure 3-17 Deposition rate of CdTe films as a function of argon pressure in the CSS process.

Figure 3-18 Scanning electron micrographs of the chemically etched surface of a CdTe films deposited by CSS (upper) and MOCVD (lower) techniques.

Figure 3-19 X-ray diffraction spectra of CdTe films deposited by CSS (left) and MOCVD (right) techniques.

Figure 3-20 Dark current-voltage characteristics of a $\mathrm{CdTe}(\mathrm{CSS}) / \mathrm{CdS} / \mathrm{SnO}_{2}: \mathrm{F} /$ glass solar cell. 
Figure 3-21 Current-voltage characteristics of a CdTe(CSS)/CdS/

$\mathrm{SnO}_{2}: \mathrm{F} /$ glass solar cell under global AM 1.5 conditions.

Figure 3-22 The quantum efficiency of the CdS/CdTe solar cell shown in Figure 3-21.

Figure 4-1 Schematic diagram of the deposition chamber for the photoenhanced metalorganic chemical vapor deposition of $\mathrm{ZnTe}$ films.

Figure 4-2 Junction photovoltage spectra of two $\mathrm{ZnTe} / \mathrm{CdS} / \mathrm{SnO}_{2}: \mathrm{F} /$ glass structures prepared from (A) as-deposited CdS, and (B) heat treated CdS.

Figure 4-3 Open-circuit voltage of $\mathrm{ZnTe} / \mathrm{CdS} / \mathrm{SnO}_{2}: \mathrm{F} /$ glass structures as a function of the reactant composition used for the deposition of $\mathrm{ZnTe}$.

Figure 4-4 X-ray diffraction spectrum of a $\mathrm{ZnTe}$ film deposited on a glass substrate at $350^{\circ} \mathrm{C}$.

Figure 4-5 Lateral resistivity of $\mathrm{ZnTe}$ films versus the reactant composition in the dark and under illumination with ELH lamps at $100 \mathrm{~mW} / \mathrm{cm}^{2}$.

Figure 4-6 Lateral electrical resistivity of arsenicdoped $\mathrm{ZnTe}$ films versus the $\mathrm{AsH}_{3} / \mathrm{DIPTe}$ molar ratio in the reaction mixture.

Figure 4-7 Lateral resistivity of an As-doped $\mathrm{ZnTe}$ film as a function of temperature.

Figure 4-8 Photoluminescence spectra of ZnTe films at $4.2 \mathrm{~K}$ deposited at $350^{\circ} \mathrm{C}$ using various DEZn/DIPTe molar ratios in the reactor mixture and As-doped $\mathrm{ZnTe}$ films.

Figure 4-9 Photoluminescence spectrum of an As-doped ZnTe films at $4.2 \mathrm{~K}$.

Figure 4-10 Dark current-voltage characteristics of a thin film $\mathrm{ZnSe} / \mathrm{ZnTe}$ solar cell.

Figure 4-11 Current-voltage characteristics of thin film $\mathrm{ZnSe} / \mathrm{ZnTe}$ and $\mathrm{Cd}_{0.7} \mathrm{Zn}_{0.3} \mathrm{~S} / \mathrm{ZnTe}$ solar cells under illumination with ELH lamps at $100 \mathrm{~mW} / \mathrm{cm}^{2}$. 
Figure 5-1 X-ray diffraction spectrum of a $\mathrm{Cd}_{0.53} \mathrm{Zn}_{0.47} \mathrm{Te}$ film.

Figure 5-2 Optical absorption coefficients of $\mathrm{Cd}_{1-x} \mathrm{Zn}_{\mathbf{x}} \mathrm{Te}$ films with different concentrations of $\mathrm{ZnTe}$.

Figure 5-3 Bandgap energy - composition relation of $\mathrm{Cd}_{1-x} \mathrm{Zn}_{\mathrm{x}} \mathrm{Te}$ films.

Figure 5-4 Junction photovoltage spectrum of a graphite/ $\mathrm{p}-\mathrm{Cd}_{1-x} \mathrm{Zn}_{\mathrm{x}} \mathrm{Te} / \mathrm{CdS} / \mathrm{SnO}_{2} /$ glass structure.

Figure 5-5 Lateral resistivity of $\mathrm{Cd}_{0.8} \mathrm{Zn}_{0.2} \mathrm{Te}$ films as a function of $\mathrm{AsH}_{3}$ concentration in the reaction mixture.

Figure 5-6 Bandgap energy of $\mathrm{Cd}_{1-\mathrm{z}} \mathrm{Zn}_{2} \mathrm{Te}$ films as a function of DMCd/DEZn ratio in the reaction mixture using fixed DMCd flow rate and II/VI ratio.

Figure 5-7 Bandgap energy of $\mathrm{Cd}_{1-x} \mathrm{Zn}_{x} \mathrm{Te}$ films as a function of $\mathrm{II} / \mathrm{VI}$ ratio in the reaction mixture using fixed DMCd flow rate and DMCd/DEZn ratio.

Figure 5-8 Illuminated current-voltage characteristics of a thin film $\mathrm{Cd}_{0.75} \mathrm{Zn}_{0.25} \mathrm{Te}(\mathrm{Eg}=1.65 \mathrm{eV}) / \mathrm{Cd}_{0.7} \mathrm{Zn}_{0.3} \mathrm{~S}$ $(\mathrm{Eg}=2.8 \mathrm{eV})$ solar cell.

Figure 5-9 Illuminated current-voltage characteristics of a thin film CdTe $/ \mathrm{Cd}_{0.7} \mathrm{Zn}_{0.3} \mathrm{Te} / \mathrm{Cd}_{0.7} \mathrm{Zn}_{0.3}$ S solar cell.

Figure 6-1 Bandgap energy of $\mathrm{Hg}_{1-x} \mathrm{Zn}_{x} \mathrm{Te}$ films as a function of substrate temperature.

Figure 6-2 Bandgap energy of $\mathrm{Hg}_{1-x} \mathrm{Zn}_{\mathrm{x}} \mathrm{Te}$ films as a function of DIPTe/DMZn molar ratio in the reaction mixture.

Figure 6-3 Lateral resistivity of $\mathrm{Hg}_{1-x} \mathrm{Zn}_{x} \mathrm{Te}$ films on glass substrates in the dark and under illumination with ELH lamps at $100 \mathrm{~mW} / \mathrm{cm}^{2}$.

Figure 6-4 Resistivity of $\mathrm{Hg}_{0.25} \mathrm{Zn}_{0.75} \mathrm{Te}$ films as a function of $\mathrm{AsH}_{3}$ concentration in the reaction mixture.

Figure 6-5 Illuminated current-voltage characteristics of a thin film $\mathrm{Hg}_{0.25} \mathrm{Zn}_{0.75} \mathrm{Te} / \mathrm{Cd}_{0.7} \mathrm{Zn}_{0.3} \mathrm{~S}$ solar cell. 


\section{LIST OF TABLES}

Table 2-1 Properties of selected II-VI compounds and TCS.

Table 2-2 Powder diffraction data of hexagonal and cubic CdS using $\mathrm{CuK}_{\alpha}$ radiation.

Table 4-1 Powder diffraction data of $\mathrm{ZnTe}$. 


\section{SECTION 1.0}

\section{INTRODUCTION}

This is the Final Technical Report of a research program "Thin Film Cadmium Telluride, Zinc Telluride, and Mercury Zinc Telluride Solar Cells" covering the period July 1988 to December 1991, supported by the National Renewable Energy Laboratory under Subcontract XI-8-18091-1. The major objectives of this subcontract are to demonstrate (1) thin film cadmium telluride solar cells with a quantum efficiency of $75 \%$ or higher at 0.44 $\mu \mathrm{m}$ and a photovoltaic efficiency of $11.5 \%$ or greater, and (2) thin film zinc telluride and mercury zinc telluride solar cells with a transparency to sub-bandgap radiation of $65 \%$ and a photovoltaic conversion efficiency of $5 \%$ and $8 \%$, respectively.

Polycrystalline thin film cadmium telluride (CdTe) is a most promising photovoltaic material. Thin film CdTe solar cells are usually of the heterojunction configuration and are prepared by the successive deposition of a transparent conducting semiconductor (TCS) film, a p-CdTe film, and ohmic contact on $\mathrm{SnO}_{2}: \mathrm{F}$ coated glass substrates. While cadmium sulfide (CdS) is the commonly used TCS for thin film CdTe solar cells, a larger bandgap TCS is more desirable. The electrical resistivity and homogeneity of CdTe films and the ohmic contact/CdTe interface resistance are extremely important for obtaining high efficiency solar cells.

The achievable efficiency of a single junction polycrystalline thin film solar cell is limited to about $18 \%$. The efficiency can be significantly increased by using two cells in tandem. The optimum bandgap energy for the upper and lower cells are $1.65-1.75 \mathrm{eV}$ and $1.0-1.1$ $\mathrm{eV}$, respectively. The upper cell has not been extensively investigated.

During the course of this subcontract, efforts have been directed to the following tasks:

- The deposition and characterization of TCS films: (1) CdS films from an aqueous solution, and (2) $\mathrm{Cd}_{1-\mathrm{zn}} \mathrm{Zn}, \mathrm{ZnSe}, \mathrm{ZnO}$, and $\mathrm{SnO}_{2}$ films by metalorganic chemical vapor deposition (MOCVD).

- The deposition, doping, and characterization of CdTe films by MOCVD, and the fabrication and evaluation of homojunction and heterojunction solar cells.

- The optimization of the deposition of p-CdTe films by close-spaced sublimination (CSS), and the preparation and characterization of thin film TCS/CdTe (CSS) solar cells.

- The deposition of $\mathrm{ZnTe}, \mathrm{Cd}_{1-x} \mathrm{Zn}_{\mathrm{x}} \mathrm{Te}$, and $\mathrm{Hg}_{1-x} \mathrm{Zn}_{\mathrm{x}} \mathrm{Te}$ films and characterization of heterojunction solar cells.

The experimental procedures used in these tasks and the results obtained are discussed in the following sections. 


\section{TRANSPARENT CONDUCTING SEMICONDUCTOR FILMS}

High conductivity large bandgap semiconductor films have major applications in many optoelectronic devices. For example, thin film II-VI solar cells are usually of the heterojunction configuration, and a transparent conducting semiconductor (TCS) is used as the heterojunction partner. The known TCSs, non-stoichiometric or doped oxides and sulfides, are of n-type conductivity, and a p-type absorber must be used. The conversion efficiency of the heterojunction solar cells depends on the compatibility of the physical and chemical properties of the TCS and the absorber. The electron affinity, lattice parameter, and thermal expansion coefficient of the TCS should be similar to those of the absorber. Any difference in electron affinities of the absorber and the TCS will result in band discontinuities. A reduction in open-circuit voltage results from a larger electron affinity of the TCS, and a reduction in short-circuit current results from a larger electron affinity of the absorber. The mismatch in lattice parameters and thermal expansion coefficients result in the formation of interface states.

The properties of CdTe and several TCSs are summarized in Table 2-1. Cadmium sulfide is the commonly used window material for efficient thin film CdTe solar cells. However, the bandgap energy of CdS is only $2.42 \mathrm{eV}$, and $0.1 \mu \mathrm{m}$ of CdS films will absorb $36 \%$ of the incident radiation with energy greater than the bandgap energy. This becomes more undesirable for absorbers of larger bandgap energy, such as the upper member of a two solar cell tandem structure, and TCSs of larger bandgap energy should be explored.

Table 2-1. Properties of selected II-VI compounds and TCS

\begin{tabular}{|c|c|c|c|c|}
\hline Semiconductor & $\begin{array}{l}\text { Energy } \\
\text { Gap, eV }\end{array}$ & $\begin{array}{c}\text { Lattice } \\
\text { Constants, A }\end{array}$ & $\begin{array}{c}\text { TEC } \\
\times 10^{-6} \cdot \mathrm{C}^{-1}\end{array}$ & $\begin{array}{c}\text { Electron } \\
\text { Affinity, eV }\end{array}$ \\
\hline CdTe (cubic) & 1.44 (d) & 6.477 & 5.5 & 4.28 \\
\hline $\mathrm{ZnTe}$ (cubic) & $2.2 \dot{5}$ (d) & 6.104 & 8 & 3.53 \\
\hline CdS (hex) & 2.42 (d) & $\begin{array}{l}a=4.137 \\
c=6.716\end{array}$ & $\begin{array}{l}5.0 \text { ( } \perp c \text {-axis }) \\
2.5 \text { (//c-axis) }\end{array}$ & 4.5 \\
\hline $\mathrm{ZnO}$ & 3.3 (d) & $\begin{array}{l}a=3.25 \\
c=3.21\end{array}$ & $\begin{array}{l}4.8 \\
2.9\end{array}$ & 4.35 \\
\hline $\mathrm{ZnSe}$ (cubic) & 2.67 (d) & 5.669 & 7 & \\
\hline ZnS (hex) & $3.66(d)$ & $\begin{array}{l}a=3.819 \\
c=6.256\end{array}$ & $\begin{array}{r}5.9-6.5 \text { (//c-axis) } \\
4.5 \text { ( } 1 c \text {-axis) }\end{array}$ & 3.9 \\
\hline $\mathrm{nO}_{2}: \mathrm{F}$ & $3.9-4.6$ & 6.7 & & 4.8 \\
\hline
\end{tabular}


In this program, the deposition and properties of cadmium sulfide (CdS), cadmium zinc sulfide $\left(\mathrm{Cd}_{1-x} \mathrm{Zn}_{\alpha} \mathrm{S}\right)$, zinc oxide $(\mathrm{ZnO}, \mathrm{Eg}=3.3 \mathrm{eV})$, and zinc selenide $(\mathrm{ZnSe}, \mathrm{Eg}=2.67 \mathrm{eV})$ films have been investigated. Although CdS has a relatively low bandgap energy, the absorption of above-gap radiation by CdS can be reduced by reducing the thickness of CdS. Cadmium zinc sulfide has a tunable bandgap energy in the range of 2.42-3.66 eV. The use of these TCSs for thin film CdTe and higher bandgap energy II-VI solar cells are discussed in Sections 3, 4, 5, and 6.

\subsection{CADMIUM SULFIDE FILMS}

The commonly used techniques for the deposition of CdS films include vacuum evaporation, chemical vapor deposition, chemical spraying, and solution growth. The deposition of CdS films from an aqueous solution is a low-cost and scalable technique for the manufacture of thin film solar cells. This technique has been reported by several authors [1-5]; however, the effects of the process parameters are not well understood. Further, the use of solutiongrown CdS films for photovoltaic devices has been studied only to a limited extent. For example, thin film $\mathrm{CdS} / \mathrm{Cu}_{2} \mathrm{~S}$ solar cells were made by the deposition of multi-layers of $\mathrm{CdS}$ films (maximum thickness of CdS obtainable from a single deposition is limited to a few tenths of a micrometer) on $\mathrm{Al}, \mathrm{Zn}$, and Mo substrates followed by immersion in a $\mathrm{CuCl}$ solution. The photovoltaic characteristics of the cells were poor; the highest open-circuit voltage, short-circuit current density and conversion efficiency were $0.3 \mathrm{~V}, 2.7 \mathrm{~mA} / \mathrm{cm}^{2}$, and $0.13 \%$, respectively.

\subsubsection{Solution Growth Process}

The reaction between a Cd-salt (acetate, fluoride, chloride, bromide, or iodide), an $\mathrm{NH}_{4}$-salt, ammonia, and thiourea $\left[\mathrm{CS}\left(\mathrm{NH}_{3}\right)_{2}\right]$ in an aqueous solution has been used for the deposition of CdS films. Ammonia is a complexing agent, thiourea furnishes $\mathrm{S}^{-}$, and the $\mathrm{NH}_{4}$-salt serves as a buffer. The various reactions involved and their equilibrium constants at room temperature are as follows:

$$
\begin{array}{lll}
\mathrm{NH}_{3}+\mathrm{H}_{2} \mathrm{O} \neq \mathrm{NH}_{4}^{+}+\mathrm{OH}^{-} & \text {(1) } & \mathrm{K}_{1}=1.8 \times 10^{-5} \\
\mathrm{Cd}^{++}+2 \mathrm{OH}^{-} \neq \mathrm{Cd}(\mathrm{OH})_{2}(\mathrm{~S}) & \text { (2) } \mathrm{K}_{2}=1.88 \times 10^{14} \\
\mathrm{Cd}^{++}+4 \mathrm{NH}_{3} \neq \mathrm{Cd}\left(\mathrm{NH}_{3}\right)_{4}^{++} & \text {(3) } \mathrm{K}_{3}=3.6 \times 10^{6} \\
\left(\mathrm{NH}_{2}\right)_{2} \mathrm{CS}+2 \mathrm{OH}^{-} \neq \mathrm{S}^{-}+2 \mathrm{H}_{2} \mathrm{O}+\mathrm{H}_{2} \mathrm{CN}_{2} & \text { (4) } \\
\mathrm{Cd}^{++}+\mathrm{S}^{*} \neq \mathrm{CdS}(\mathrm{s}) & \text { (5) } & \mathrm{K}_{\mathrm{s}}=7.1 \times 10^{28}
\end{array}
$$

Qualitatively, in the presence of sufficient $\mathrm{NH}_{3}$, the $\mathrm{Cd}$ salt exists predominantly in the form of $\mathrm{Cd}\left(\mathrm{NH}_{3}\right)_{4}{ }^{++}$. The room temperature equilibrium constant of reaction (4) is very small. When the concentration product of $\mathrm{Cd}^{++}$and $\mathrm{S}^{*}$ in solution exceeds the solubility product of CdS, $1.4 \times 10^{-29}, \mathrm{CdS}$ precipitates. The rate of formation of CdS is determined by the concentration of $\mathrm{Cd}^{++}$provided by $\mathrm{Cd}\left(\mathrm{NH}_{3}\right)_{4}{ }^{++}$and the concentration of $\mathrm{S}^{*}$ from the 
hydrolysis of $\left(\mathrm{NH}_{2}\right)_{2} \mathrm{CS}$. The rate of hydrolysis of $\left(\mathrm{NH}_{2}\right)_{2} \mathrm{CS}$ depends on the $\mathrm{pH}$ and temperature of the solution. At $80^{\circ} \mathrm{C}$, for example, the rate constants of hydrolysis are 3.8 $\times 10^{-3}$ and $8.2 \times 10^{-3}$ at $\mathrm{pH}$ of 13 and 13.7 , respectively. These constants become $1.1 \times 10^{-2}$ and $2.5 \times 10^{-2}$, respectively, when the solution temperature is increased to $100^{\circ} \mathrm{C}$. The presence of an $\mathrm{NH}_{4}$-salt in solution shifts the equilibrium position of reaction (1), increasing the concentration $\mathrm{Cd}\left(\mathrm{NH}_{3}\right)_{4}{ }^{++}$and reducing the concentration of $\mathrm{Cd}^{++}$. The equilibrium position of reaction (4) is also shifted, reducing the concentration of $S^{*}$. As a result, the rate of formation of $\mathrm{CdS}$ is reduced. The use of an excess of ammonia increases the $\mathrm{pH}$ of the solution, promoting the formation of $\mathrm{S}^{*}$; however, the concentration of $\mathrm{Cd}\left(\mathrm{NH}_{3}\right)_{4}^{++}$is also increased, reducing the concentration of $\mathrm{Cd}^{++}$and the rate of $\mathrm{CdS}$ formation. Thus, the rate of formation of CdS can be adjusted by varying the concentrations of ammonia and the $\mathrm{NH}_{4}$-salt in solution. Further, the equilibrium constants of all reactions are temperature dependent. The hydrolysis of $\left(\mathrm{CH}_{2}\right)_{2} \mathrm{CS}$ is greatly enhanced as temperature increases. The temperature of the solution can therefore also be used to control the rate of CdS formation.

In addition to ammonia, triethanolamine, $\mathrm{N}\left(\mathrm{CH}_{2} \mathrm{CH}_{2} \mathrm{OH}\right)_{3}$, (TEA) has also been used as the complexing agent for cadmium [4]. A $100 \mathrm{ml}$ solution containing $10 \mathrm{ml}$ of $1 \mathrm{M} \mathrm{CdAc}, 5 \mathrm{ml}$ of $7.4 \mathrm{M}$ TEA, $10 \mathrm{ml}$ of $1 \mathrm{M}$ thiourea, and $10 \mathrm{ml}$ of $13.4 \mathrm{M}$ ammonia was used. It was claimed that the use of TEA promoted the formation of uniform, adherent, and thicker films of cadmium chalcogenide, even at room temperature. However, this observation is not in agreement with the stability constant of $\mathrm{Cd}(\mathrm{TEA})^{++}$:

$$
\mathrm{Cd}^{++}+\mathrm{TEA} \rightleftharpoons \mathrm{Cd}(\mathrm{TEA})^{++} \quad(6) \quad \mathrm{K}_{6}=7.2 \times 10^{3}
$$

Since the solution contains a higher concentration of ammonia than TEA, the larger stability constant of $\mathrm{Cd}\left(\mathrm{NH}_{3}\right)_{4}{ }^{++}, 3.6 \times 10^{6}$, equation (3), indicates that $\mathrm{Cd}(\mathrm{TEA})^{++}$is not a dominant species in the above solution.

The formation of $\mathrm{CdS}$ can take place beterogeneously on the substrate surface, depositing $\mathrm{CdS}$, or homogeneously in solution, producing CdS precipitate. The homogeneous process is highly undesirable since the adsorption of CdS particles on the substrate surface yields powdery and non-adherent films. The homogeneous process may be suppressed by using conditions for the formation of CdS at low rates, such as low concentrations of Cd-salt and thiourea, high concentrations of $\mathrm{NH}_{3}$ and $\mathrm{NH}_{4}$-salt, low temperature, etc. In the heterogeneous process, nucleation on the substrate surface results from the preferential adsorption of $\mathrm{Cd}^{++}$or $\mathrm{S}^{*}$ followed by the addition of $\mathrm{S}^{*}$ or $\mathrm{Cd}^{++}$ions. The heterogeneous process may be prompted by preparing the substrate surface conducive to nucleation, such as chemical etching of the glass surface. The nucleation of CdS on the surface of a crystalline substrate is easier than that of an amorphous substrate. Also, the Cd-salt and thiourea are utilized more efficiently as the homogeneous process is suppressed.

Many experiments on the deposition of CdS films have been carried out under a wide range of conditions. The apparatus used for the deposition process has been described in a previous report [6]. Aqueous solutions containing (1) $\mathrm{CdAc}$ or $\mathrm{CdCl}_{2}$ in the concentration range of (5-100) x $10^{-4} \mathrm{M}$, (2) $\mathrm{NH}_{4} \mathrm{Ac}, \mathrm{NH}_{4} \mathrm{~F}$, or $\mathrm{NH}_{4} \mathrm{Cl}$ in the concentration range of (2.5100) $\times 10^{-3} \mathrm{M},(3)$ thiourea in the concentration range of (5-100) $\times 10^{-4} \mathrm{M}$, and (4) ammonia 
in the concentration range of $0.05-1 \mathrm{M}$ bave been used. The fluoride and chloride were used in order to determine if $\mathrm{F}$ and $\mathrm{Cl}$, with tetrahedral covalent radii of 0.64 and $0.99 \AA$, respectively, can be incorporated into CdS (covalent radius of S:1.04 A) for the control of carrier concentration. The solution is always vigorously stirred to facilitate the diffusion of $\mathrm{Cd}^{++}$and $\mathrm{S}^{-}$to the substrate surface. The temperature of the solution is maintained at $50^{\circ}-90^{\circ} \mathrm{C}$ during the deposition process. In a typical experiment, glass or $\mathrm{SnO}_{2}: \mathrm{F} /$ glass substrates are thoroughly cleaned in the usual manner and suspended vertically in an aqueous solution of $\mathrm{CdAc}_{2}\left(10^{-3} \mathrm{M}\right), \mathrm{NH}_{4} \mathrm{Ac}(0.02 \mathrm{M}), \mathrm{NH}_{4} \mathrm{OH}(0.4 \mathrm{M})$, and $\left(\mathrm{NH}_{2}\right)_{2} \mathrm{CS}(5$ $\left.x 10^{-3} \mathrm{M}\right)$ at $85^{\circ} \mathrm{C}$ under constant stirring. The solution has a pH of $9.05-9.10$, and shows no immediate change in appearance. After 10-15 minutes, the solution becomes slightly yellow, and a thin film deposit appears on the substrate surface. The deposition process is completed after about one hour. The average deposition rate is $20-30 \AA / \mathrm{min}$. The quality of the CdS film is strongly affected by the initial nucleation process. For example, CdS films of $1000 \AA$ or less in thickness deposited on glass substrates with a smooth surface are usually discontinuous, and the continuity of the CdS film can be greatly improved by etching the glass surface with hydrofluoric acid. The nucleation of $\mathrm{CdS}$ on $\mathrm{SnO}_{2}$-coated glass substrates takes place readily, and continuous CdS films of about $500 \AA$ thickness can be readily deposited. During the deposition process, particular care was taken to minimize dust particles and other particulates; these contaminants are the major cause of pinholes in the films.

\subsubsection{Properties}

The CdS films deposited on $\mathrm{SnO}_{2}: \mathrm{F} /$ glass substrates are highly adherent. To evaluate the large number of process parameters affecting the properties of deposited CdS films, a simple criterion of the quality of the films has been developed. CdS is soluble in diluted hydrochloric acid; the rate of dissolution is a measure of the porosity, impurity content, and bond strain in the film. An acid concentration of $0.3 \mathrm{M}$ was used for this purpose. As an example, CdS films deposited at high rates $(100 \AA / m i n$ or higher) always show considerably higher dissolution rates (more than $200 \mathrm{~A} / \mathrm{min}$ ) than those deposited at low rates (60-90 $\AA / m i n$ for films deposited at $10-20 \AA / m i n)$. The as-deposited CdS films can be densified by heating in $\mathrm{He}$ at $300^{\circ} \mathrm{C}$ as shown by the reduction in the dissolution rate. For example, the dissolution rate of a CdS film has been found to be reduced from $90 \AA / \mathrm{min}$ to $50 \mathrm{~A} / \mathrm{min}$ after heating in $\mathrm{He}$ at $300^{\circ} \mathrm{C}$.

The crystallographic properties of solution-grown CdS films have been investigated by the $x$-ray diffraction technique using $\mathrm{CuK}_{\mathrm{a}}$ radiation. CdS exists in two crystalline modifications: the hexagonal (wurtzite) phase and the cubic (zincblende) phase. The hexagonal phase is believed to be the stable modification between $25^{\circ}$ and $900^{\circ} \mathrm{C}$. Polycrystalline hexagonal and cubic CdS of random orientation are known to show many strong $\mathrm{x}$-ray diffraction peaks; the relative intensities and the $d$ values are summarized in Table 2.2. The CdS films deposited on glass substrates typically show very simple spectrum, while the CdS powder precipitated in the solution șhows many diffraction peaks associated with both cubic and 
Table 2-2. Powder diffraction data of hexagonal and cubic CdS using $\mathrm{CuK}_{\boldsymbol{\alpha}}$ radiation

\author{
Hexagonal CdS
}

\begin{tabular}{lccc}
\multicolumn{1}{c}{ d } & I & hkl & $2 \theta$ \\
3.583 & 75 & 100 & 24.8 \\
3.36 & 60 & 002 & 26.5 \\
3.160 & 100 & 101 & 28.2
\end{tabular}

2.90

2.450

2.068

2.058

1.898

1.791

1.761

1.753

1.680

1.679

1.581

1.453

1.337

$\begin{array}{lll}45 \quad 112 & 51.9\end{array}$ $\begin{array}{lll}25 & 102 & 36.6\end{array}$

$\begin{array}{lll}55 & 110 & 43.7\end{array}$

$\begin{array}{lll}80 & 220 & 43.9\end{array}$

$\begin{array}{lll}60 & 311 & 52.1\end{array}$

$\begin{array}{lll}10 & 222 & 54.56\end{array}$

$\begin{array}{lll}4 & 004 & 54.6\end{array}$

$\begin{array}{lll}8 & 202 & 58.3\end{array}$

$\begin{array}{lll}18 & 200 & 50.9\end{array}$
Cubic CdS

$\begin{array}{lll}40 & 200 & 30.8\end{array}$

$\begin{array}{lll}100 & 111 & 26.5\end{array}$

$\begin{array}{lll}20 & 400 & 64.0\end{array}$

$\begin{array}{lll}30 & 331 & 70.3\end{array}$

hexagonal phases. The x-ray diffraction spectrum of a CdS film grown on a glass substrate is shown in Figure 2-1, where a single diffraction peak at $2 \theta=26.5^{\circ}$ is observed. This diffraction peak can be associated with the (002) reflection of hexagonal CdS or the (111) reflection of the cubic modification. The preferred orientation of the CdS film may be attributed, at least in part, to the nucleation process.

The optical absorption of solution-grown CdS films was measured using a Varian Model Cary 17D spectrophotometer. The films deposited from solutions of various compositions showed essentially the same absorption characteristics. Figure 2-2 shows the transmission spectrum of a CdS film of about $1500 \AA$ in thickness deposited on a glass substrate. The change in optical transmission at the band edge is more gradual in films of less than 1000 $\AA$ thickness. The above-gap transmission agrees well with those estimated from the known absorption coefficients of CaS. The optical bandgap energy deduced from the $\alpha^{2}$ ( $\alpha$ is the absorption coefficient) versus energy plot is $2.35-2.37 \mathrm{eV}$. 


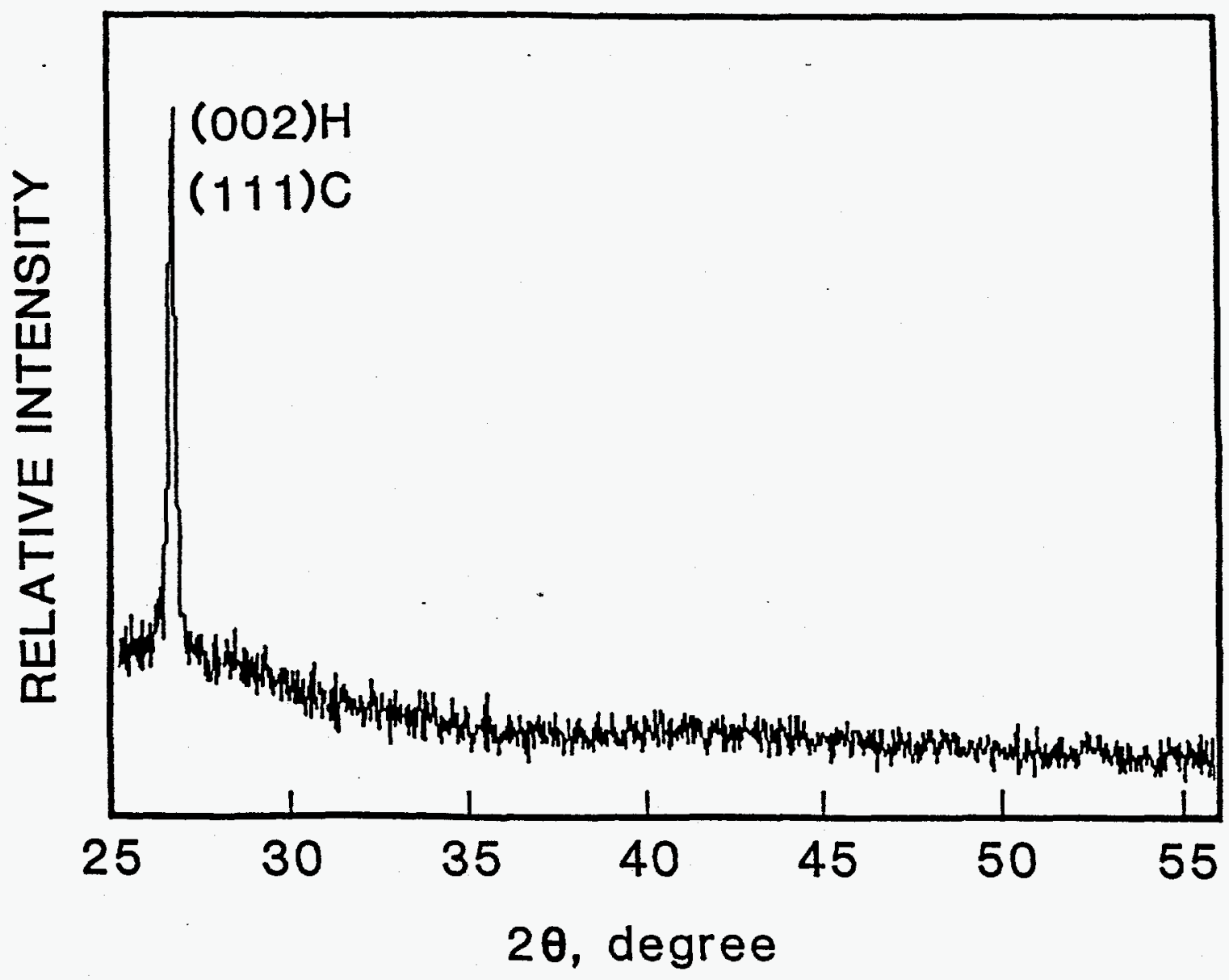

Figure 2-1. X-ray diffraction spectrum of a CdS film on a glass substrate

The electrical resistivity of CdS films is an important factor affecting the -solar cell characteristics. The lateral electrical resistivity of CdS films deposited on glass substrates was measured at room temperature using a potential probe technique. Four colinear contacts were made to the film using a Ga-In alloy. The current is passed through the outer contacts, and the potential drop measured across the two inner contacts. The lateral resistivity of CdS films was also measured under illumination with ELH lamps at 100 $\mathrm{mW} / \mathrm{cm}^{2}$, equivalent to AM 1.5. The increase in conductivity under illumination is due to the excess carriers in the grains introduced by the absorption of above bandgap radiation and the lowering of potential barriers at grain boundaries. The photoconductivity ratio, i.e. the ratio of dark resistivity to illuminated resistivity, is a convenient criterion of the quality of CdS. The resistivity of CdS under illumination is also important for the operation of the solar cells. The dark resistivity of as-deposited CdS films of $1000 \AA$ thickness is usually on the order of $10^{4} \cdot 10^{5} \mathrm{ohm}-\mathrm{cm}$, and the photoconductivity ratio is in the range of 50-1,000. This type of CdS film is suitable for solar cell purposes. 


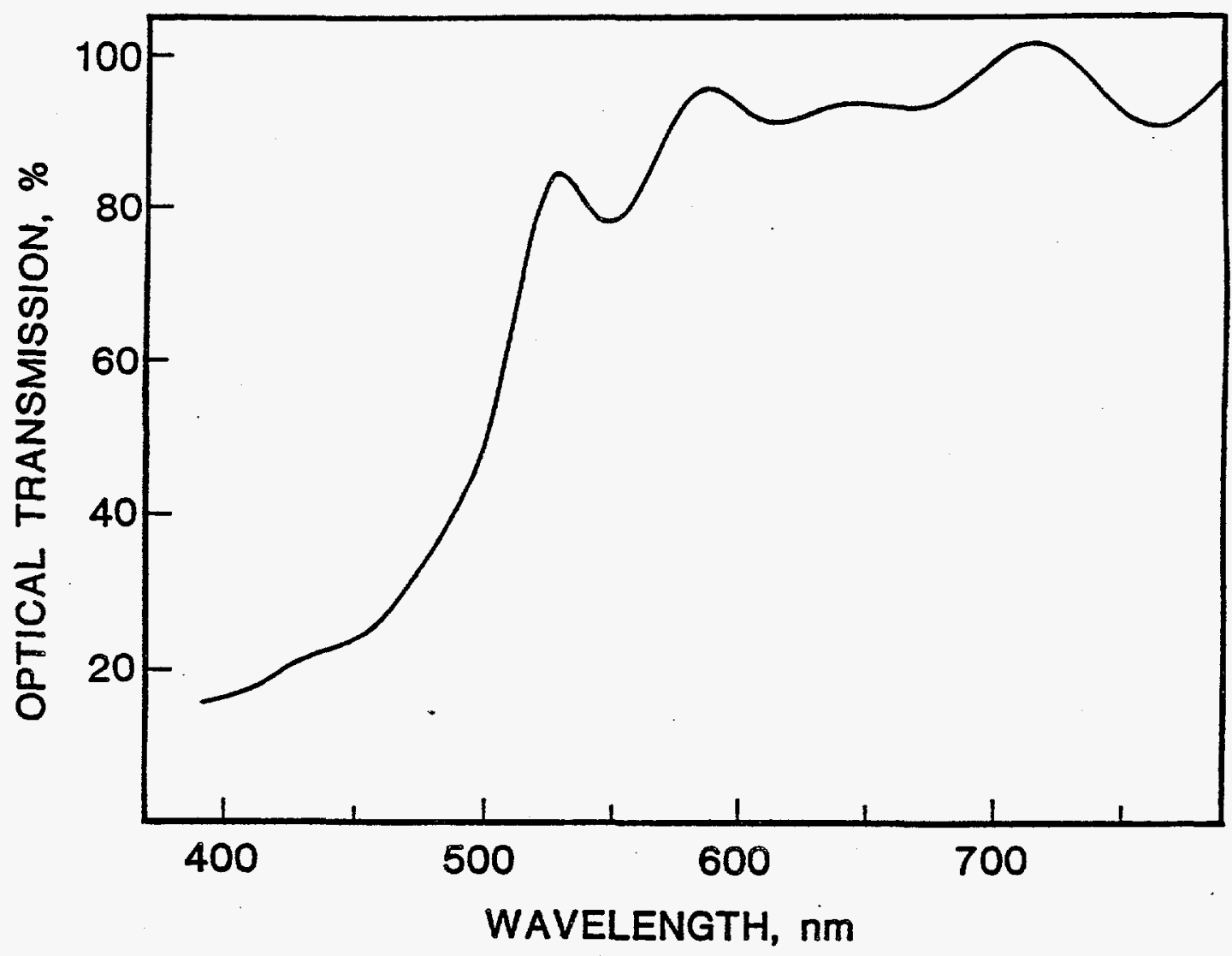

Figure 2-2. Optical transmission spectrum of a CdS film of $1400 \AA$ thickness on a $\mathrm{SnO}_{2}: \mathrm{F} /$ glass substrate

\subsection{CADMIUM ZINC SULFIDE FILMS}

The bandgap energy of CdS can be increased by the incorporation of $\mathrm{ZnS}$. $\mathrm{ZnS}$ is also a direct-gap semiconductor with a room temperature bandgap energy of $3.66 \mathrm{eV}$; however, dopants cannot be readily incorporated into $\mathrm{ZnS}$. $\mathrm{CdS}$ and $\mathrm{ZnS}$ form a continuous series of solid solutions, $\mathrm{Cd}_{1-x} \mathrm{Zn}_{\mathrm{x}} \mathrm{S}$. The bandgap energy of $\mathrm{Cd}_{1-x} \mathrm{Zn}_{\mathrm{x}} \mathrm{S}$ can be controlled in the range of the binary bandgaps. Single crystals of $\mathrm{Cd}_{1-x} \mathrm{Zn}_{\mathrm{x}} \mathrm{S}$ have been grown from the melt; a closed system was used because of the high dissociation pressure of $\mathrm{CdS}$ and $\mathrm{ZnS}$ at the melting point. Thin films of $\mathrm{Cd}_{1-x} \mathrm{Zn}_{\mathrm{x}} \mathrm{S}$ have been deposited by the vacuum evaporation technique using $\mathrm{CdS}$ and $\mathrm{ZnS}$ sources [7]; the bandgap energy and lattice parameter of $\mathrm{Cd}_{1-}$ $\mathrm{Zn}_{\mathrm{x}} \mathrm{S}$ have been found to be essentially a linear function of composition, and the resistivity increases from less than $1 \mathrm{ohm}-\mathrm{cm}$ for CdS to greater than $10^{10} \mathrm{ohm}-\mathrm{cm}$ for $\mathrm{ZnS}$. The resistivity of $\mathrm{Cd}_{\mathrm{l}-\mathrm{x}} \mathrm{Zn}_{\mathrm{x}} \mathrm{S}$ (up to $\mathrm{x}=0.3$ ) has been reduced to about $2 \mathrm{ohm}-\mathrm{cm}$ by using In as a dopant during the evaporation process [8]. The incorporation of dopants into $\mathrm{Cd}_{1-x} \mathrm{Zn}_{x} \mathrm{~S}$ becomes increasingly difficult as the $\mathrm{ZnS}$ concentration increases. Thin films of $\mathrm{Cd}_{1-x} \mathrm{Zn}_{\mathbf{x}} \mathrm{S}$ have also been deposited by (1) the sublimation of CdS and ZnS in a hydrogen flow [9], (2) the reaction of cadmium acetate, zinc acetate, and thiourea in an ammoniacal solution [10], and (3) the spray pyrolysis technique using $\mathrm{Zn}$-salt, Cd-salt, and thiourea. In this program, 
the use of solution growth technique for the deposition of $\mathrm{Cd}_{1-x} \mathrm{Zn}_{x} \mathrm{~S}$ films was investigated briefly with no success, and major efforts were directed to the metalorganic chemical vapor deposition (MOCVD) process.

\subsubsection{Solution Growth}

The growth of $\mathrm{ZnS}$ films from an ammonia solution of a zinc salt and thiourea is similar to that of CdS films; however, the reactions for $\mathrm{ZnS}$ deposition differ significantly in equilibrium constants from those for CdS deposition.

$$
\begin{aligned}
& \mathrm{Zn}^{++}+2 \mathrm{OH}^{-} \nRightarrow \mathrm{Zn}(\mathrm{OH})_{2}(\mathrm{~S}) \\
& \mathrm{Zn}^{++}+4 \mathrm{NH}_{3} \nRightarrow \mathrm{Zn}\left(\mathrm{NH}_{3}\right)_{4}^{++} \\
& \mathrm{Zn}^{++}+\mathrm{S}^{-} \nRightarrow \mathrm{ZnS}(\mathrm{S})
\end{aligned}
$$

$$
\begin{aligned}
& K_{7}=1.3 \times 10^{16} \\
& K_{8}=5 \times 10^{8} \\
& K_{9}=3.4 \times 10^{24}
\end{aligned}
$$

A comparison of equations (8) and (9) with equations (3) and (5) indicates that $\mathrm{Zn}\left(\mathrm{NH}_{3}\right)_{4}{ }^{++}$ is more stable than $\mathrm{Cd}\left(\mathrm{NH}_{3}\right)_{4}{ }^{++}$and that $\mathrm{CdS}$ is more stable than $\mathrm{ZnS}$. By combining equations ( 3 ) and (5) and equations (8) and (9), one obtains:

$$
\begin{array}{lll}
\mathrm{Cd}\left(\mathrm{NH}_{3}\right)_{4}{ }^{++}+\mathrm{S}^{=} & \Rightarrow \mathrm{CdS}(\mathrm{S})+4 \mathrm{NH}_{3} & \text { (10) } \mathrm{K}_{10}=2 \times 10^{22} \\
\mathrm{Zn}\left(\mathrm{NH}_{3}\right)_{4}{ }^{++}+\mathrm{S}^{=} & \mathrm{ZnS}(\mathrm{S})+4 \mathrm{NH}_{3} & \text { (11) } \mathrm{K}_{11}=7 \times 10^{15}
\end{array}
$$

Qualitatively, in a solution containing ammonia and thiourea at equilibrium, the concentration of $\mathrm{Zn}\left(\mathrm{NH}_{3}\right)_{4}{ }^{++}$is about $3 \times 10^{6}$ times higher than that of $\mathrm{Cd}\left(\mathrm{NH}_{3}\right)_{4}{ }^{++}$, and the concentration of $\mathrm{Zn}^{++}$is about $2 \times 10^{4}$ times higher that that of $\mathrm{Cd}^{++}$. Thus, when an ammoniacal solution of $\mathrm{Cd}$ and $\mathrm{Zn}$ salts is treated with thiourea, CdS will precipitate preferentially. Several experiments were carried out to determine the possibility of depositing $\mathrm{Cd}_{1-\mathrm{z}} \mathrm{Zn}_{\mathrm{r}} \mathrm{S}$ films from an aqueous solution. The process parameters include the $\mathrm{Zn}^{++} / \mathrm{Cd}^{++}$ratio, the $\left(\mathrm{Zn}^{++}+\mathrm{Cd}^{++}\right) /\left(\mathrm{NH}_{2}\right)_{2} \mathrm{CS}$ ratio, the concentrations of ammonia and ammonium salt, and the solution temperature. Since CdS has a much lower solubility product than $\mathrm{ZnS}$, a large $\mathrm{Zn}^{++} / \mathrm{Cd}^{++}$ratio is necessary to yield $\mathrm{Cd}_{1-x} \mathrm{Zn}_{\mathbf{x}} \mathrm{S}$ films. Using a $\mathrm{Zn}^{++} / \mathrm{Cd}^{++}$ratio of as high as 50, the deposited film was shown to be CdS from optical transmission measurements. Thus, the deposition of $\mathrm{Cd}_{1-x} \mathrm{Zn}_{\mathrm{x}} \mathrm{S}$ films from an aqueous solution does not appear to be feasible unless a complexing agent can be found that the $\mathrm{Cd}$ complex is considerably more stable than the $\mathrm{Zn}$ complex.

\subsubsection{Metalorganic Chemical Vapor Deposition}

During the past few years, the metalorganic chemical vapor deposition (MOCVD) technique has been used extensively for the epitaxial growth of II-VI compounds, and mercury cadmium telluride in particular, on single crystalline substrates. The thermal instability of metalorganic compounds permits the use of relatively low temperatures for the growth process, and the composition of the deposited film can be controlled by adjusting the 
composition of the metalorganic mixture. Thus, the MOCVD technique is well-suited for the deposition of ternary II-VI compounds, such as $\mathrm{Cd}_{1-x} \mathrm{Zn}_{x} \mathrm{~S}$ and $\mathrm{Cd}_{1-x} \mathrm{Zn}_{x} \mathrm{Te}$.

The apparatus for the MOCVD of II-VI binary and ternary compounds is shown schematically in Figure 2-3. It consists of two parts: a gas-handling system and a reaction tube. This set-up has been used for the deposition of CdTe, $\mathrm{ZnSe}, \mathrm{ZnTe}, \mathrm{Cd}_{1-x} \mathrm{Zn}_{\mathrm{x}} \mathrm{S}$, and $\mathrm{Cd}_{1-\mathrm{K}} \mathrm{Zn}$ Te films on heated substrates in a $\mathrm{H}_{2}$ atmosphere. The source materials include dimethylcadmium (DMCd), diethylzinc (DEZn), diethylselenium (DESe), diisopropyltellurium (DIPTe), and propylmercaptan ( $\mathrm{PM}, \mathrm{C}_{3} \mathrm{H}_{8} \mathrm{~S}$ ). Triethylaluminum (TEAl) and triethylgallium (TEGa) are used as n-type dopants, and a $\mathrm{H}_{2}-\mathrm{AsH}_{3}$ mixture containing $100 \mathrm{ppm}$ of $\mathrm{AsH}_{3}$ is used as the p-type dopant. Except $\mathrm{AsH}_{3}$, all source materials are liquids at room temperature and are introduced into the reaction tube by passing measured amounts of hydrogen through the liquids. The composition of the reaction mixture is then determined by the flow rates of hydrogen through the metalorganics and the reaction tube. The reaction tube is made of fused silica of $5.5 \mathrm{~cm} \mathrm{ID}$. Glass, $\mathrm{SnO}_{2}: \mathrm{F} /$ glass, and other types of coated glass are used as substrates. $\mathrm{SnO}_{2}: \mathrm{F}$ coated glass, with a sheet resistance of about 10 ohms per square, obtained through the courtesy of Watkin-Johnson, Inc., are used as ohmic or rectifying contacts to the deposited films. The substrates are supported on a silicon carbide-coated graphite susceptor in the reaction tube, and the susceptor heated externally with an if generator. A thermocouple inserted into the interior of the susceptor was used to monitor the temperature of the substrates. The important process parameters are the substrate temperature and the composition and flow rates of reaction species.

The MOCVD of $\mathrm{Cd}_{1-x} \mathrm{Zn}_{\mathrm{x}} \mathrm{S}$ films has been carried out with the objective of controlling the composition and resistivity of these films. The source materials are DMCd, DEZn, and PM, with TMAl and octyl chloride $\left(\mathrm{OC}_{3} \mathrm{C}_{8} \mathrm{H}_{17} \mathrm{Cl}\right)$ as dopants. Adherent films of $\mathrm{Cd}_{1-x} \mathrm{Zn}_{2} \mathrm{~S}$ have been deposited on glass substrates at $375^{\circ}$ and $425^{\circ} \mathrm{C}$, where the vapor pressures of CdS and $\mathrm{ZnS}$ are negligible. The $\mathrm{ZnO}: \mathrm{F}$ coating was found to be stable toward the reaction mixture. However, the $\mathrm{SnO}_{2}: \mathrm{F}$ coating is reactive toward the reaction mixture, resulting in the deposition of defective films. This problem has been overcome by using a $\mathrm{ZnO}: \mathrm{F}$ interlayer, as described in Section 2.2.3.

The deposition rate and properties of $\mathrm{Cd}_{1-x} \mathrm{Zn}_{x} \mathrm{~S}$ film depend on the substrate temperature and the composition and flow rate of the reaction mixture; the DMCd/DEZn and $\mathrm{PM} /(\mathrm{DMCd}+\mathrm{DEZn})$ (referred to as VI/II ratio hereafter) molar ratios strongly affect the deposition rate and incorporation of dopants. Since $\mathrm{Cd}_{1-x} \mathrm{Zn}_{\mathrm{x}} \mathrm{S}$ films of $0.05-0.1 \mu \mathrm{m}$ thickness are used in heterojunction devices, the process parameters are selected to yield relatively low deposition rates. Figure $2-4$ shows the deposition rate of $\mathrm{Cd}_{1-x} \mathrm{Zn}_{\mathrm{x}} \mathrm{S}$ films at $375^{\circ}$ and $425^{\circ} \mathrm{C}$ as a function of the DMCd/DEZn molar ratio in the reaction mixture. The flow rate of PM was $6.3 \times 10^{-5} \mathrm{~mol} / \mathrm{min}$, and the total flow rate of DMCd and DEZn was $1.6 \times 10^{-5} \mathrm{~mol} / \mathrm{min}$, corresponding to a VI/II molar ratio of 4 . The deposition rate at $425^{\circ}$ is higher than that at $375^{\circ} \mathrm{C}$, indicating that the deposition process is most likely controlled by the surface kinetics. At each temperature, the deposition rate of $\mathrm{Cd}_{1-\mathrm{x}} \mathrm{Zn}_{\mathrm{x}} \mathrm{S}$ films increases with increasing DMCd/DEZn molar ratio in the reaction mixture, indicating that $\mathrm{CdS}$ is formed more readily than $\mathrm{ZnS}$. This variation of deposition rate of $\mathrm{Cd}_{1-x} \mathrm{Zn}_{\mathbf{x}} \mathrm{S}$ with composition is more pronounced at the higher temperature due to the ease of 
incorporation of $\mathrm{ZnS}$. Also, the deposition rate of $\mathrm{Cd}_{1-2} \mathrm{Zn}_{2} \mathrm{~S}$ at $425^{\circ} \mathrm{C}$ remains essentially the same if the VI/II molar ratio is decreased to 2, while that at $375^{\circ} \mathrm{C}$ is reduced at lower $\mathrm{VI} / \mathrm{II}$ ratios, indicating a smaller degree of decomposition of $\mathrm{PM}$ at $375^{\circ} \mathrm{C}$.

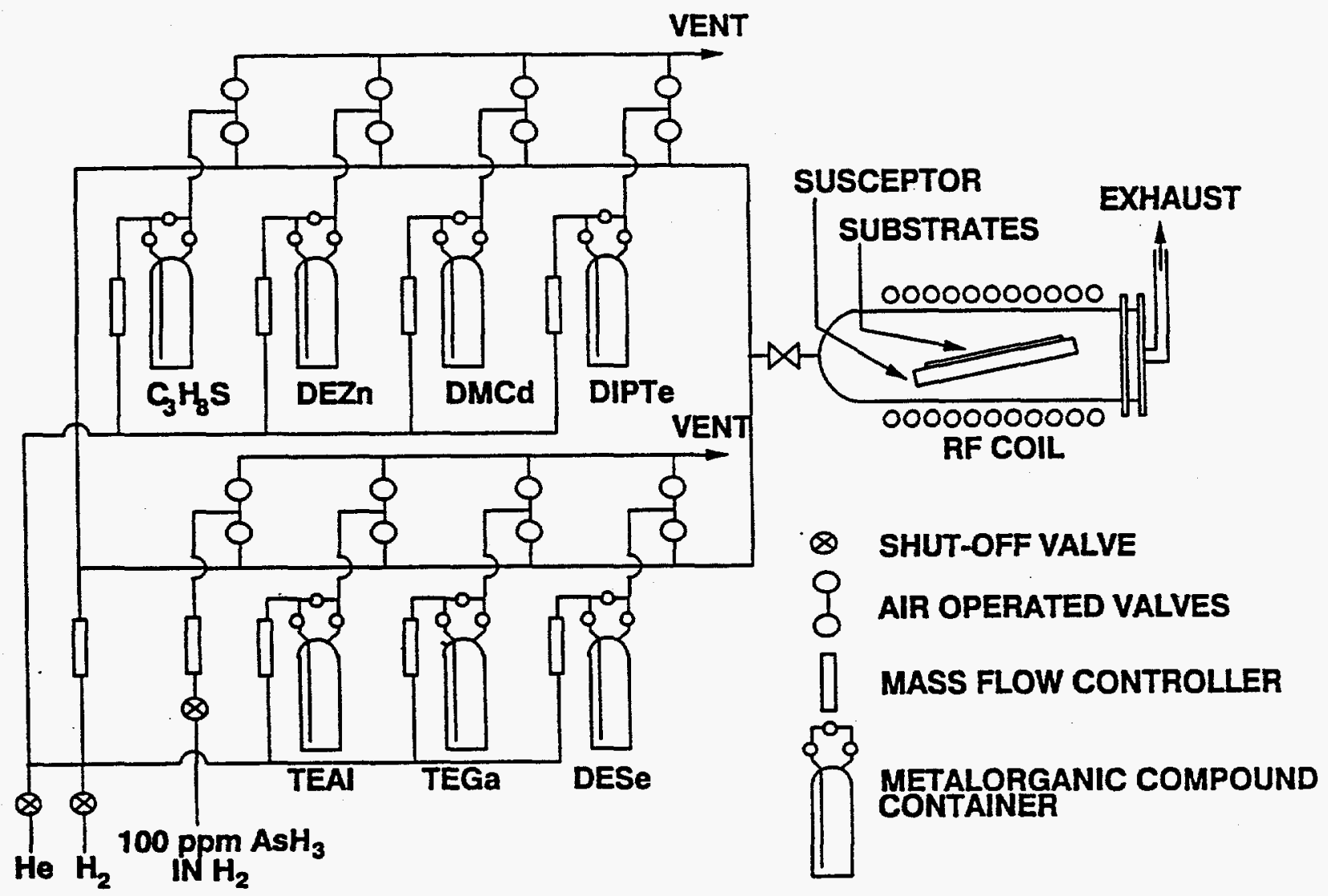

Figure 2-3. Schematic diagram of the apparatus for the MOCVD of II-VI compounds

\subsubsection{Properties}

All deposited $\mathrm{Cd}_{1-x} \mathrm{Zn}_{\mathrm{n}} \mathrm{S}$ films are polycrystalline consisting of submicron grains. The crystallinity and composition of deposited films were determined by the x-ray diffraction technique. $\mathrm{CdS}$ and $\mathrm{ZnS}$ are polymorphoric with the stable modification crystallizing in the wurtzite structure. The lattice parameters are $a_{0}=4.136 \AA$ and $c_{0}=6.713 \AA$ for hexagonal $\mathrm{CdS}$, and $\mathrm{a}_{\mathrm{o}}=3.820 \AA$ and $\mathrm{c}_{\mathrm{o}}=6.260 \AA$ for hexagonal $\mathrm{ZnS}$. Polycrystalline CdS and $\mathrm{ZnS}$ of random orientation are known to show many strong $x$-ray diffraction peaks. For example, hexagonal CdS shows diffraction peaks associated with $\{100\},\{002\},\{101\},\{110\},\{103\}$, $\{112\}$ reflections with "d" values of $3.583,3.360,3.160,2.068,1.898$, and $1.761 \AA$ and relative intensities of $75,60,100,55,40$, and 45 respectively. Since the lattice parameter of $\mathrm{Cd}_{\mathrm{I}-\mathrm{x}} \mathrm{Zn}_{\mathrm{x}} \mathrm{S}$ films follows the Vegard law, the composition of $\mathrm{Cd}_{1-x} \mathrm{Zn}_{x} \mathrm{~S}$ films can be

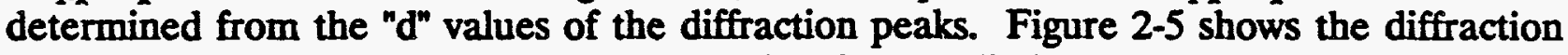
spectrum of a $\mathrm{Cd}_{1-x} \mathrm{Zn}_{x} \mathrm{~S}$ film obtained by using $\mathrm{CuK}_{e}$ radiation, where only one diffraction 
peak with a $2 \theta$ value of $27.44^{\circ}$ corresponding to a "d" value of $3.248 \AA$ is present. The absence of diffraction peaks associated with $\mathrm{CdS}$ and $\mathrm{ZnS}$ indicates that this film is a single phase material. The presence of only $\{002\}$ reflection suggests that this film has a very strong $\{002\}$ preferred orientation. The composition of the film deduced from the " $\mathrm{d}$ " value corresponds to $\mathrm{Cd}_{0.52} \mathrm{Zn}_{0.48} \mathrm{~S}$.

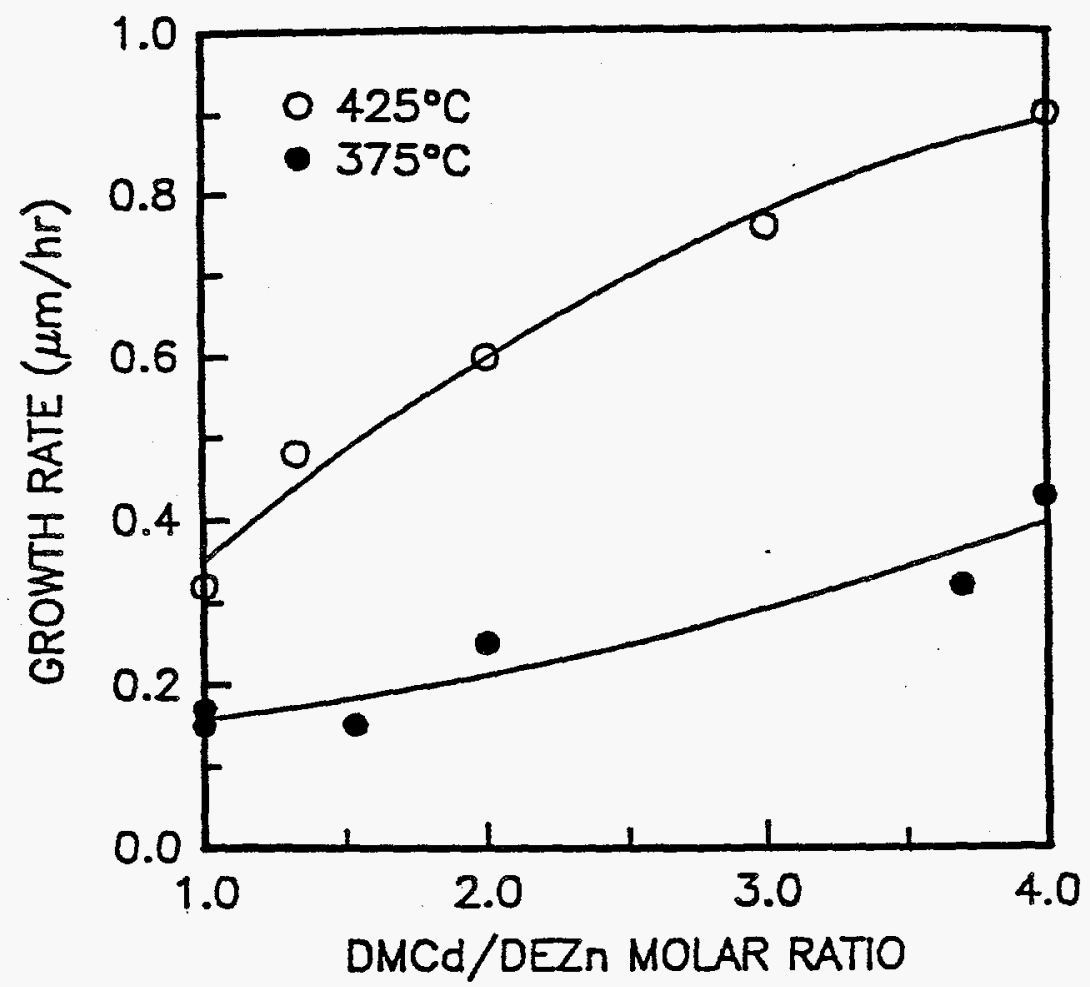

Figure 2-4. Deposition rate of $\mathrm{Cd}_{1-x} \mathrm{Zn}_{\mathrm{x}} \mathrm{S}$ films at $375^{\circ} \mathrm{C}$ and $425^{\circ} \mathrm{C}$ as a function of $\mathrm{DMCd} / \mathrm{DEZn}$ molar ratio

The bandgap energy of $\mathrm{Cd}_{1-x} \mathrm{Zn}_{x} \mathrm{~S}$ films at room temperature was determined by optical absorption measurements. $\mathrm{Cd}_{1-x} \mathrm{Zn}_{2} \mathrm{~S}$ is of direct bandgap; the optical bandgap energy can be deduced from the linear plot of the square of the absorption coefficient versus the photon energy near the band edge. The optical absorption of $\mathrm{Cd}_{1-x} \mathrm{Zn}_{\mathrm{x}} \mathrm{S}$ films on glass or coated glass substrates was measured on a Cary $17 \mathrm{D}$ spectrophotometer. The bandgap energy of $\mathrm{Cd}_{1-x} \mathrm{Zn}_{\mathrm{x}} \mathrm{S}$ films depends strongly on the substrate temperature and the composition and flow rate of the reaction mixture. Figure 2-6 shows the bandgap energy of $\mathrm{Cd}_{1-x} \mathrm{Zn}_{\mathrm{x}} \mathrm{S}$ films deposited at $375^{\circ}$ and $425^{\circ} \mathrm{C}$ as a function of the $\mathrm{DMCd} / \mathrm{DEZn}$ molar ratio in the reaction mixture. The flow rate of PM was maintained at $6.3 \times 10^{-5} \mathrm{~mol} / \mathrm{min}$ and the VI/II molar ratio was 4. At each temperature, the variation of bandgap energy with the DMCd/DEZn ratio is more pronounced at low DMCd/DEZn ratios, due to the ease of formation of CdS. At a given composition of the reaction mixture, the film deposited at $425^{\circ} \mathrm{C}$ has a higher bandgap energy than that at $375^{\circ} \mathrm{C}$, indicating the increased extent of $\mathrm{ZnS}$ formation with increasing temperature. All films show a subgap transmission of higher than $90 \%$. 


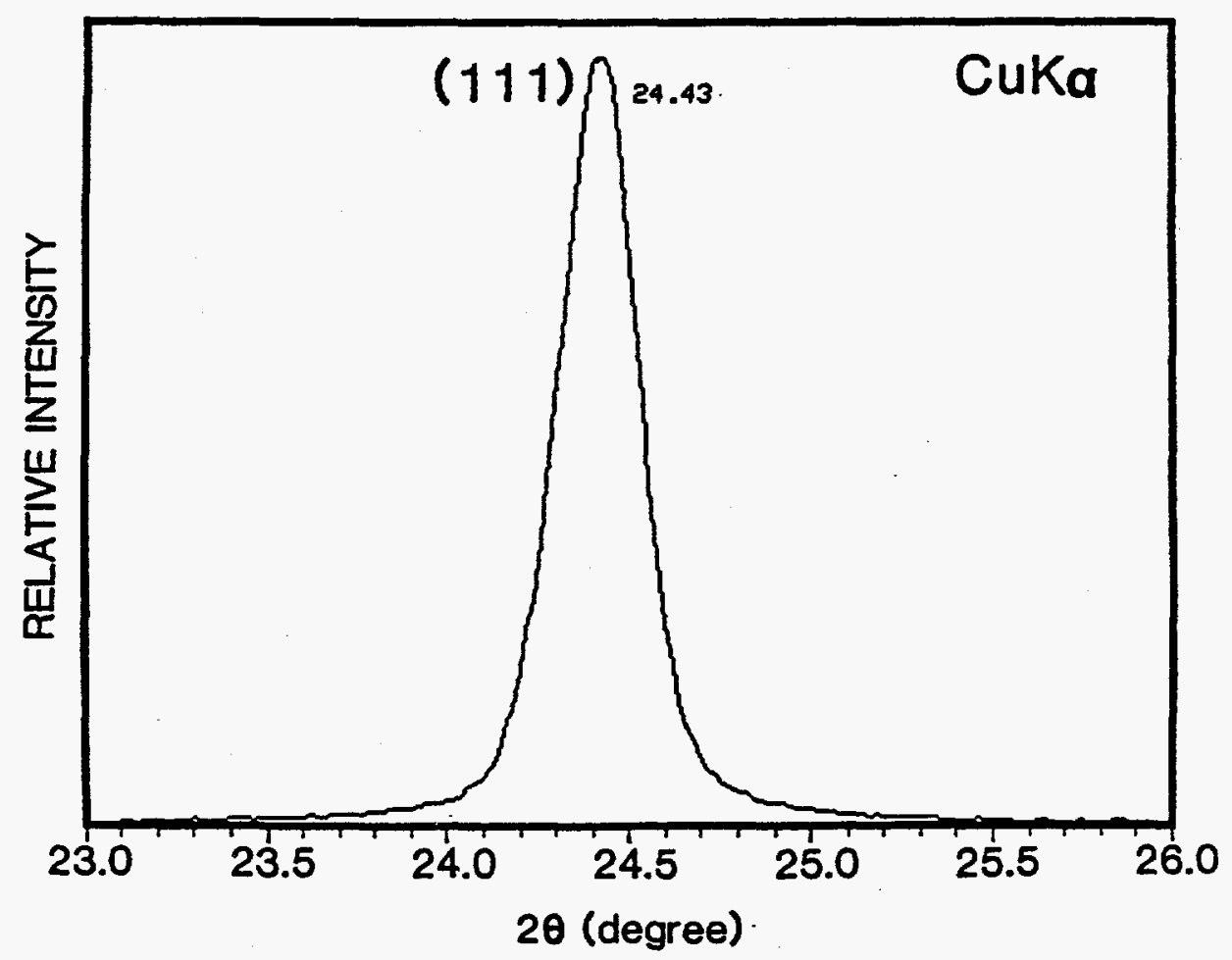

Figure 2-5. X-ray diffraction spectrum of a $\mathrm{Cd}_{1-x} \mathrm{Zn}_{\mathbf{x}} \mathrm{S}$ film

The lateral resistivity of $\mathrm{Cd}_{1-x} \mathrm{Zn}_{\mathrm{x}} \mathrm{S}$ films on glass substrates was measured at room temperature using the potential probe technique and Ga-In contacts. Because of the low current level associated with the high sheet resistance of $\mathrm{Cd}_{1-x} \mathrm{Zn}_{\mathrm{x}} \mathrm{S}$, the measurements were carried out in a screened enclosure. The lateral resistivity of $\mathrm{Cd}_{1-\mathrm{Z}} \mathrm{Zn}_{2} \mathrm{~S}$ films was also measured under illumination with ELH lamps at $100 \mathrm{~mW} / \mathrm{cm}^{2}$. Figure 2-7 shows the dark lateral resistivity of $\mathrm{Cd}_{1-x} \mathrm{Zn}_{x} \mathrm{~S}$ films, deposited at $375^{\circ} \mathrm{C}$ without intentional doping using a VI/II molar ratio of 4 , as a function of the bandgap energy. The dark resistivity is about $10^{3} \mathrm{ohm}-\mathrm{cm}$ for $\mathrm{CdS}$ and increases rapidly as the concentration of $\mathrm{ZnS}$ increases, exceeding $10^{8} \mathrm{ohm}-\mathrm{cm}$ at a bandgap energy of about $2.8 \mathrm{eV}$. The VI/I ratio in the reaction mixture affects the bandgap energy of deposited films but has no measurable effect on the lateral resistivity. The photoconductivity $\mathrm{Cd}_{1-x} \mathrm{Zn}_{2} \mathrm{~S}$ films depends strongly on the composition of the films. For example, the photoconductivity ratio, i.e. the ratio of the conductivity under illumination to the dark conductivity, is $20-40$ for films with a bandgap energy of less than about $2.6 \mathrm{eV}$ and decreases with increasing bandgap energy. The photoconductivity ratio in films with bandgap energy greater than about $2.8 \mathrm{eV}$ becomes smaller than unity indicating the generation of multi-charged centers above the Fermi level.

The lateral resistivity of $\mathrm{Cd}_{1-x} \mathrm{Zn}_{x}$ S films can be reduced by using trimethylaluminum (TMAl) or octyl chloride (OC) as a dopant during the deposition process. The extent of dopant incorporation depends strongly on the composition of the solid solution. Figure 2-8 shows the lateral resistivity of $\mathrm{Al}$-doped $\mathrm{Cd}_{1-\mathrm{x}} \mathrm{Zn}_{x} \mathrm{~S}$ films deposited at $425^{\circ} \mathrm{C}$ as a function of the 


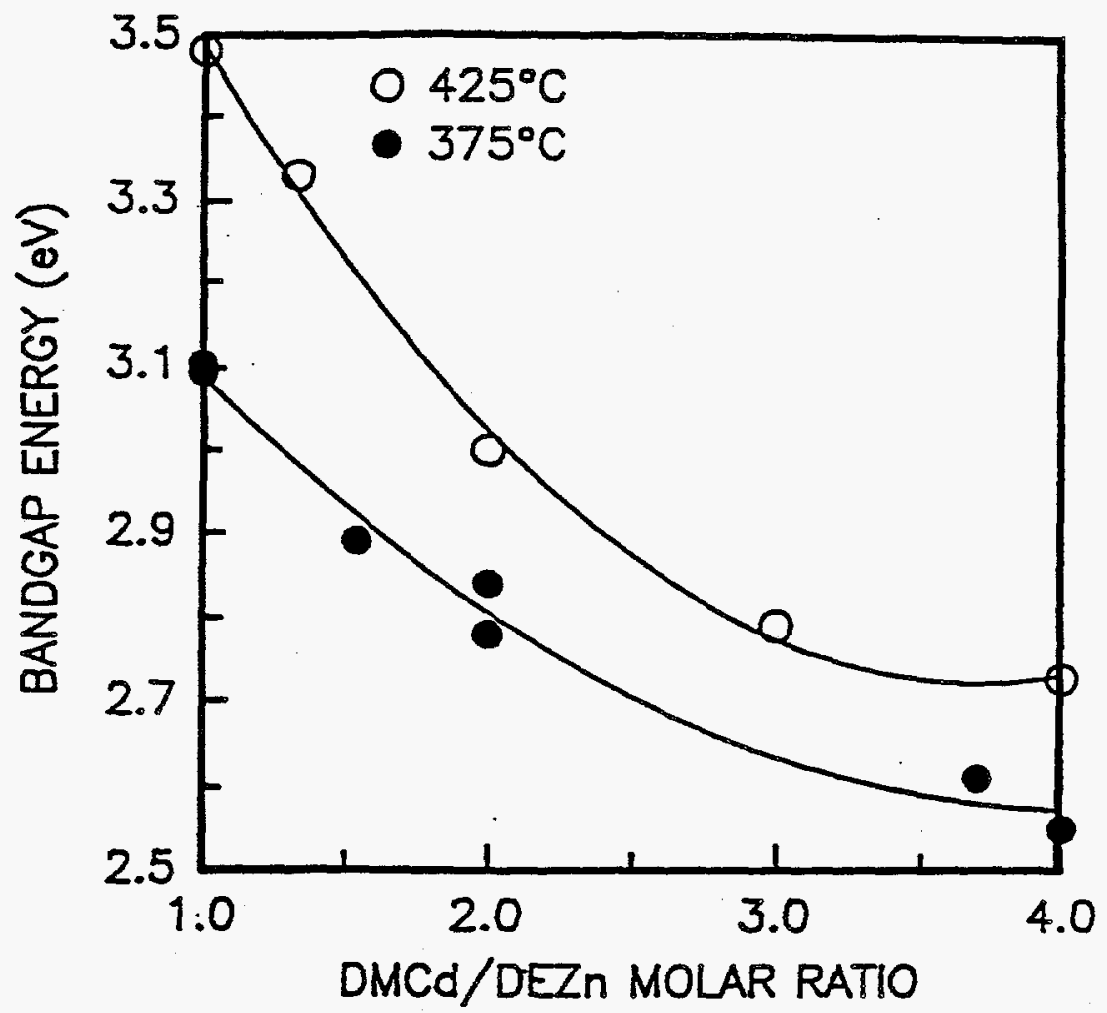

Figure 2-6. Bandgap energy of $\mathrm{Cd}_{1-x} \mathrm{Zn}_{\mathrm{x}} \mathrm{S}$ films deposited at $375^{\circ} \mathrm{C}$ and $425^{\circ} \mathrm{C}$ as a function of $\mathrm{DMCd} / \mathrm{DEZn}$ molar ratio

bandgap energy of the films. These films were deposited by using a PM flow rate of $6.3 \times 10^{5} \mathrm{~mol} / \mathrm{min}$ a V1/II molar ratio of 2 , and a TMAl/II ratio of 0.016 . Al can be incorporated into all $\mathrm{Cd}_{1-x} \mathrm{Zn}_{\mathrm{S}} \mathrm{S}$ films; however, the incorporation of $\mathrm{Al}$ becomes more difficult as the bandgap energy increases. The photoconductivity ratio also decreases in films with bandgap energy higher that about $3 \mathrm{eV}$ and becomes less than unity at still higher bandgap energies. The use of the group VII dopants, such as octyl chloride, is less effective. At small $\mathrm{Cl} / \mathrm{S}$ ratios, such as $0.03-0.06$, the resistivity of $\mathrm{Cd}_{1-x} \mathrm{Zn}_{2} \mathrm{~S}$ films is essentially unaffected. Figure 2-9 shows the lateral resistivity of $\mathrm{Cd}_{1 \cdot 0} \mathrm{Zn}_{x} \mathrm{~S}$ films deposited at $375^{\circ} \mathrm{C}$ and $425^{\circ} \mathrm{C}$ as a function of bandgap energy. These films were deposited by using a PM flow rate of $6.3 \times 10^{-5} \mathrm{~mol} / \mathrm{min}$, a VI/II molar ratio of 2 for films deposited at $425^{\circ} \mathrm{C}$ and 4 for films deposited at $375^{\circ} \mathrm{C}$ and a $\mathrm{Cl} / \mathrm{S}$ ratio of 03 . At a given composition, the film deposited at $425^{\circ} \mathrm{C}$ is of higher resistivity than that at $375^{\circ} \mathrm{C}$, and the photoconductivity of the films is also higher. In contrast to Al-doped $\mathrm{Cd}_{1-x} \mathrm{Zn}_{\mathrm{x}} \mathrm{S}$ films, the photoconductivity ratio of Cl-doped films is always greater than unity. Using $\mathrm{Al}$ or $\mathrm{Cl}$ as a dopant, $\mathrm{Cd}_{1 \times x} \mathrm{Zn}_{x} \mathrm{~S}$ films with bandgap energy of up to about $2.9 \mathrm{eV}$ and with resistivity suitable for most devices can be deposited. 


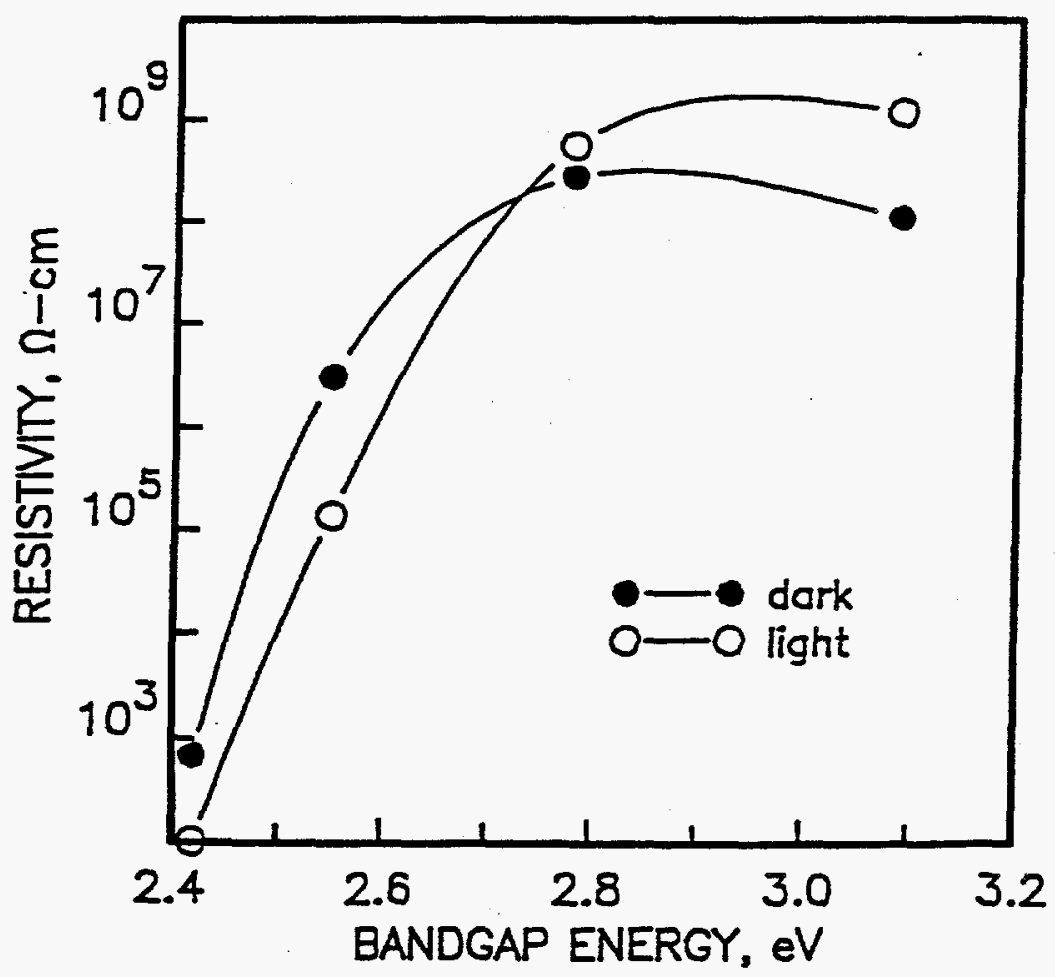

Figure 2-7. Dark and illuminated resistivity of $C d_{1-x} \mathrm{Zn}_{2} \mathrm{~S}$ films deposited at $375^{\circ} \mathrm{C}$ as a function of bandgap energy

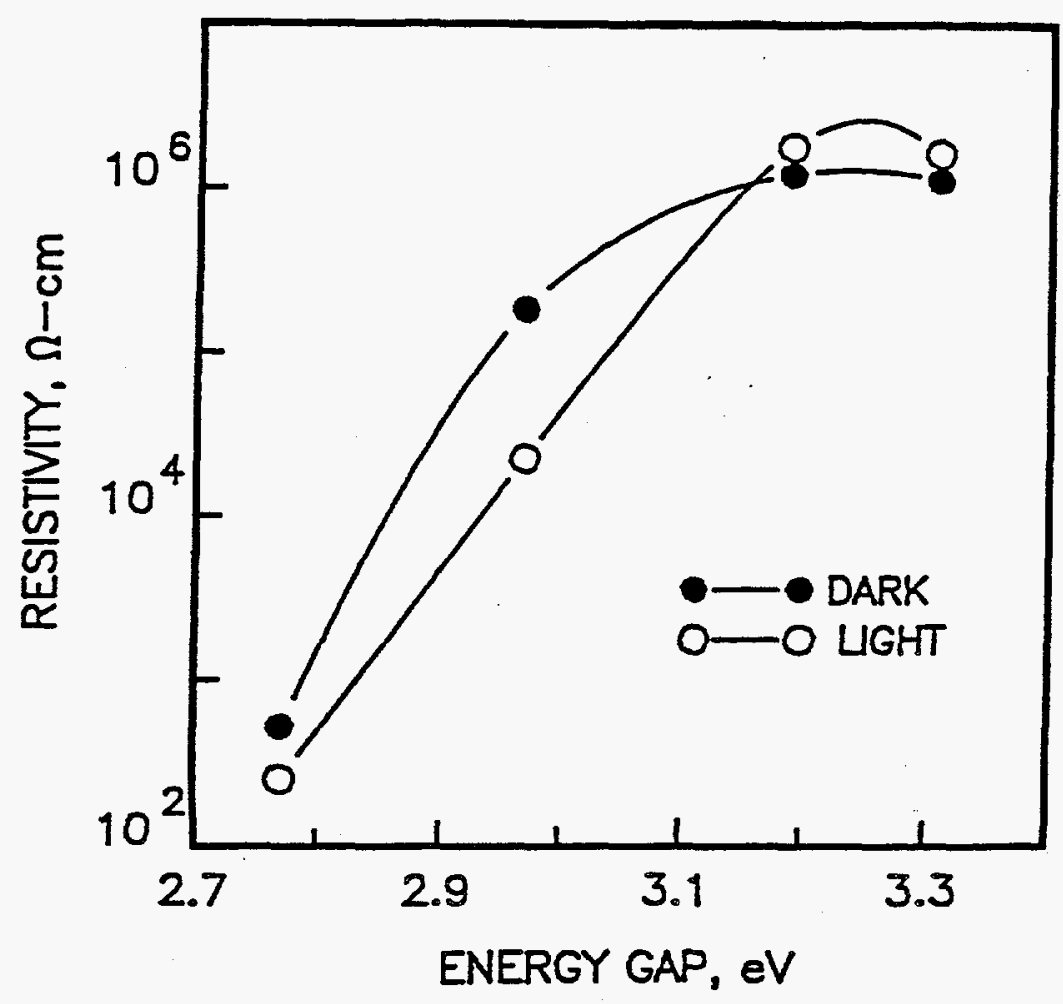

Figure 2-8. Lateral resistivity of aluminum-doped $\mathrm{Cd}_{1-x} \mathrm{Zn}_{\mathrm{x}} \mathrm{S}$ films deposited at $425^{\circ} \mathrm{C}$ in the dark and under illumination 


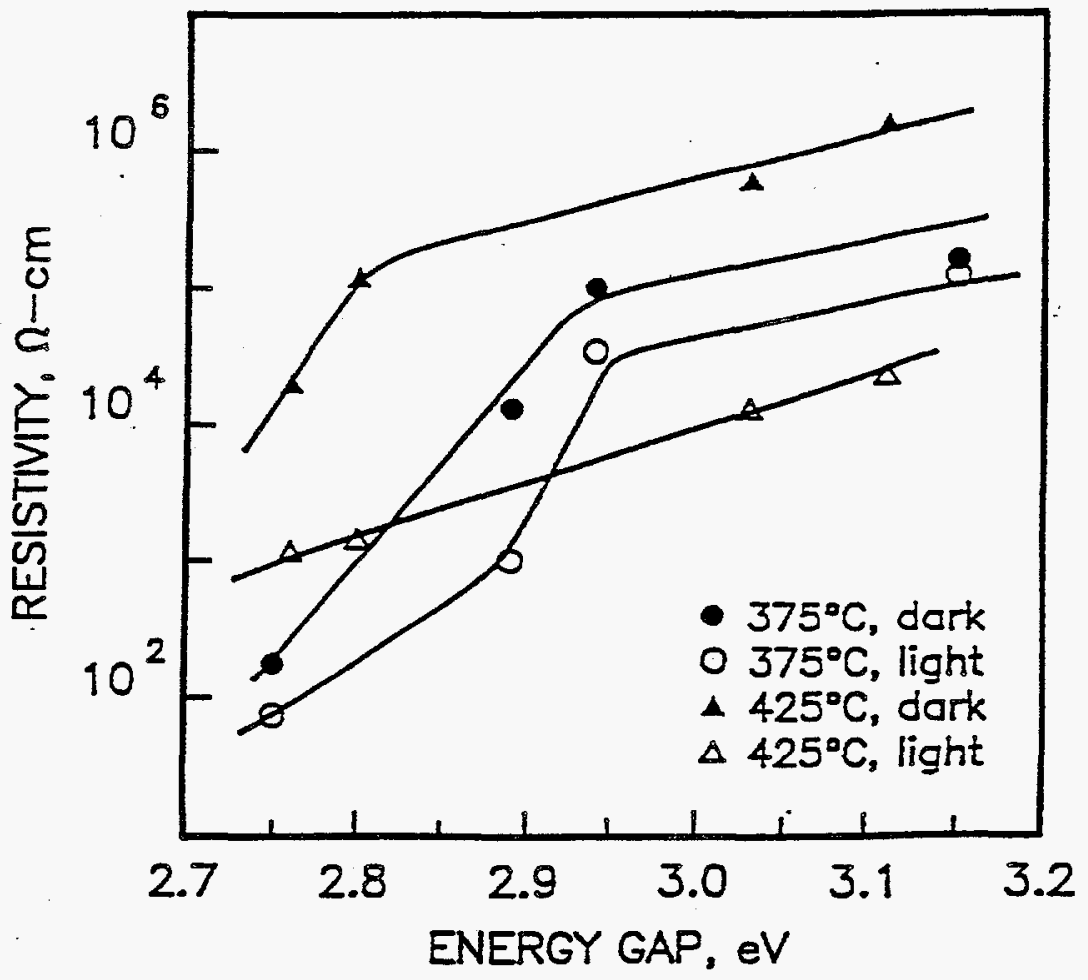

Figure 2-9. Lateral resistivity of Chlorine-doped $\mathrm{Cd}_{1-x} \mathrm{Zn}_{\mathbf{x}} \mathrm{S}$ films deposited at $375^{\circ}$ and $425^{\circ} \mathrm{C}$ as a function of bandgap energy

\subsection{ZINC OXIDE FILMS}

Zinc oxide films have numerous applications in electro-optic, piezoelectric, and photoconductive devices. They have been used as windows for thin film cadmium telluride solar cells [11]. MOCVD is the most commonly used non-vacuum technique for the deposition of $\mathrm{ZnO}$ films; low resistivity films can be deposited at relatively low temperatures by the oxidation of diethylzinc (DEZn) with oxygen or alcohols using Al or F compounds as a dopant [12-14].

In this program, the reaction of DEZn with ethanol $\left(\mathrm{C}_{2} \mathrm{H}_{5} \mathrm{OH}\right)$ has been used for the deposition of $\mathrm{ZnO}$ films on glass or $\mathrm{SnO}_{2}: \mathrm{F} /$ glass substrates at $350^{\circ}-400^{\circ} \mathrm{C}$ in a He flow. The typical flow rates are $4 \ell / \mathrm{min}, 3.5 \times 10^{-5} \mathrm{~mole} / \mathrm{min}$, and $6.6 \times 10^{-4} \mathrm{~mole} / \mathrm{min}$, for $\mathrm{He}$, $\mathrm{DEZn}$, and $\mathrm{C}_{2} \mathrm{H}_{5} \mathrm{OH}$, respectively. The deposition rate of $\mathrm{ZnO}$ is approximately $170 \AA / \mathrm{min}$ at $350^{\circ} \mathrm{C}$, and the resistivity of deposited films can be reduced to $10^{-3} \mathrm{ohm}-\mathrm{cm}$ by using hexafluoropropene $\left(\mathrm{C}_{3} \mathrm{~F}_{6}\right)$ at a flow rate of $10 \mathrm{ml} / \mathrm{min}$ as a dopant. However, $\mathrm{F}$-doped $\mathrm{ZnO}$ films were found to be unstable upon heating at $600^{\circ} \mathrm{C}$ in an inert atmosphere; the resistivity increased more than one thousand folds. Aluminum-doped $\mathrm{ZnO}$ films deposited at $350^{\circ} \mathrm{C}$ by using TMAl as a dopant were found to be stable; their resistivity, typically $10^{-3}$ ohm-cm, remained unchanged after heating at $600^{\circ}$ in a $\mathrm{He}$ atmosphere. 


\subsection{ZINC SELENIDE FILMS}

Zinc selenide ( $\mathrm{ZnSe}$ ), a direct gap semiconductor with a room temperature bandgap energy of $2.67 \mathrm{eV}$, has long been considered as a promising optoelectronic material. For example, $\mathrm{ZnSe}$ has been used successfully as a window for thin film CuInSe ${ }_{2}$ solar cells with a $10 \%$ conversion efficiency [15]. During the sixties, bulk crystals and homo- and heteroepitaxial films (on GaAs and Ge substrates) of $\mathrm{ZnSe}[16,17]$ were grown, at $800^{\circ}-900^{\circ} \mathrm{C}$ and $500^{\circ}$ $600^{\circ} \mathrm{C}$, respectively, by the chemical transport of polycrystalline $\mathrm{ZnSe}$ using $\mathrm{HCl}, \mathrm{HBr}$, or $I_{2}$ as a transport agent. The grown crystals were always n-type due to self-compensation. $\mathrm{P}-\mathrm{n}$ junction devices were made from $\mathrm{ZnSe}-\mathrm{ZnTe}$ solid solutions; $\mathrm{ZnSe}_{\mathrm{x}} \mathrm{Te}_{1-\mathrm{x}}$ is $\mathrm{p}$-type at $x \leq 0.6$ and can be doped to low resistivity n-type or p-type in the composition range of $0.4 \leq x \leq 0.5$ [18]. Heteroepitaxial and polycrystalline films of $\mathrm{ZnSe}$ have also been grown by the direct combination of the elemental vapors at $650^{\circ}-850^{\circ} \mathrm{C}[19,20]$ and by closespaced vapor transport at $400^{\circ}-750^{\circ} \mathrm{C}$ [21]. The chemical transport technique is not entirely satisfactory for the deposition of $\mathrm{ZnSe}$ films with controlled properties for photovoltaic applications. During the past few years, metalorganic chemical vapor deposition (MOCVD) has been used successfully for the heteroepitaxial growth of $\mathrm{ZnSe}$ films at relatively low temperatures, $250^{\circ}-500^{\circ} \mathrm{C}$ [22-25]. The p-type doping of ZnSe by nitrogen using ammonia as a dopant has also been established [25,26]. Further, $\mathrm{ZnSe}$ is miscible with $\mathrm{ZnS}$ (Eg = 3.66. eV) [27], thus extending the usefulness of $\mathrm{ZnSe}$ to higher energies.

In this program, thin films of $\mathrm{ZnSe}$ have been deposited on glass and conductive oxidecoated glass substrates by MOCVD using the reaction of diethylzinc (DEZn) and diethylselenium (DESe) in a hydrogen atmosphere with the objective of using $\mathrm{ZnSe}$ as a heterojunction partner, or window, in II-VI thin film solar cells. The structural, optical, and electrical properties of $\mathrm{ZnSe}$ films have been characterized, and the electrical resistivity of $\mathrm{n}-\mathrm{ZnSe}$ films controlled by using an appropriate dopant.

\subsubsection{Deposition Process}

DEZn and DESe are thermally unstable, permitting the use of relatively low temperatures for the deposition of ZnSe films. The use of low substrate temperature could minimize the density of native defects and is thus advantageous. However, the composition of the reaction mixture must be such that no free $\mathrm{Zn}$ or Se deposits on the substrate.

The substrates used for the deposition of $\mathrm{ZnSe}$ films were glass and $\mathrm{SnO}_{2}: \mathrm{F}$ coated glass, where the $\mathrm{SnO}_{2}$ coating is used to reduce the sheet resistance of $\mathrm{ZnSe}$. However, $\mathrm{SnO}_{2}$ films were found to be reactive toward the reaction species used for the deposition of $\mathrm{ZnSe}$, and $\mathrm{ZnO}: \mathrm{F} /$ glass or $\mathrm{ZnO}: \mathrm{F} / \mathrm{SnO}_{2}: \mathrm{F} /$ glass were used as the substrates. To control the resistivity of ZnSe films, group VII (octyl chloride and octyl bromide) and group III (trielthylaluminum, TMAl) compounds were used as dopants; aluminum occupies the $\mathrm{Zn}$ sites, and the group VII elements occupy the Se sites. All starting materials were liquids at room temperature and were introduced into the reaction tube, a fused silica tube of 5.5 $\mathrm{cm}$ ID, by bubbling measured amounts of hydrogen through the liquids. The composition of the reaction mixture was then determined by the flow rates of hydrogen through $\mathrm{DEZn}$, DESe, the reaction tube, and the dopants. The substrates were supported on a silicon carbide coated graphite susceptor in the reaction tube, and the susceptor heated externally 
with an if generator. A thermocouple inserted into the interior of the susceptor was used to monitor the temperature of the substrates. The flow rates of hydrogen and DEZn were $4.5 \mathrm{l} / \mathrm{min}$ and $3.5 \times 10^{-5} \mathrm{moles} / \mathrm{min}$, respectively, and the flow rate of DESe was varied to yield a DESe/DEZn molar ratio (referred to as the VI/II ratio hereafter) of 0.5-2.0.

Figure 2-10 shows the deposition rate of $\mathrm{ZnSe}$ films at $500^{\circ} \mathrm{C}$ as a function of the VI/II ratio in the reaction mixture. At low VI/II ratios, the deposition rate of $\mathrm{ZnSe}$ increases linearly with increasing concentration of DESe and remains essentially constant, $3.7 \mu \mathrm{m} / \mathrm{hr}$,

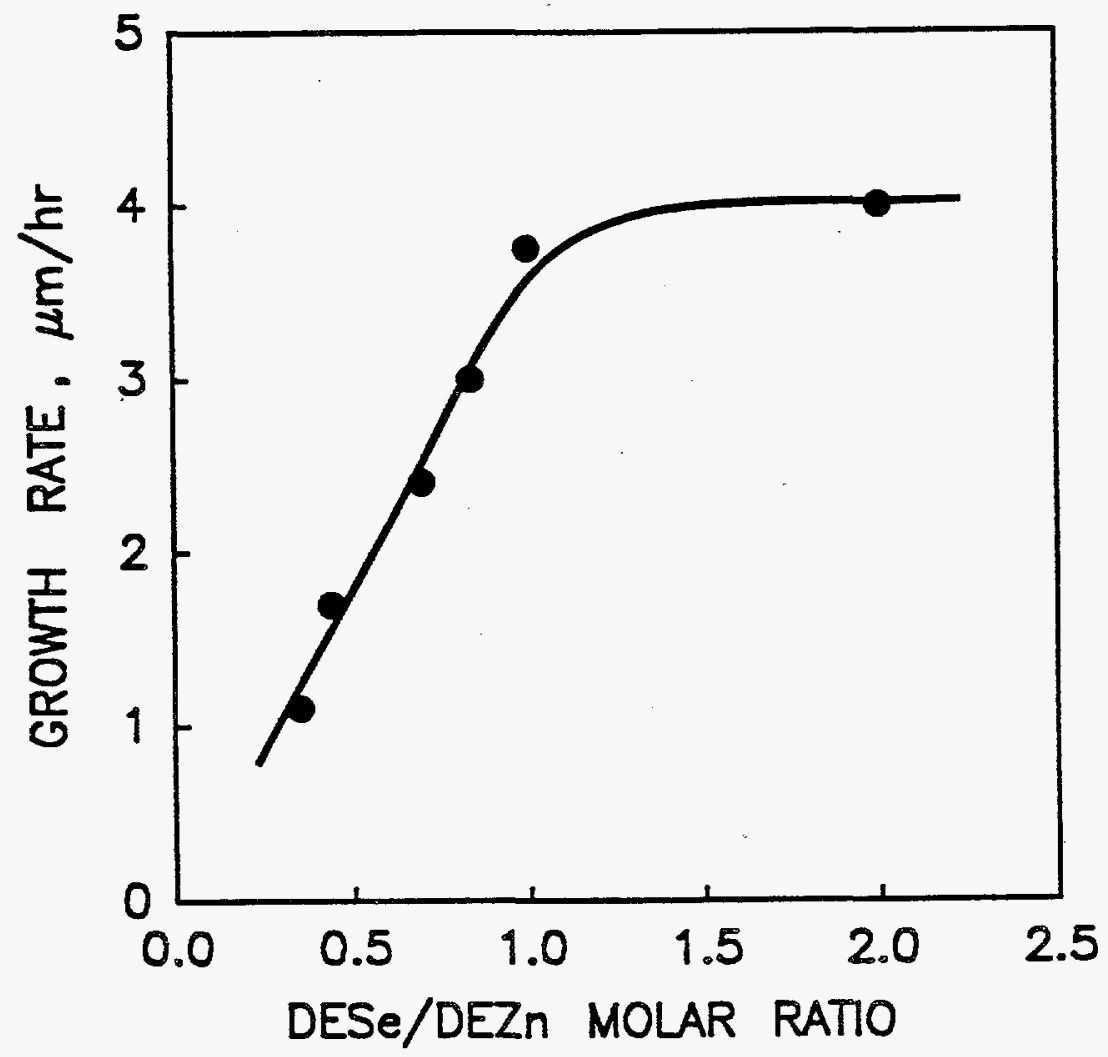

Figure 2-10. The deposition rate of $\mathrm{ZnSe}$ films at $500^{\circ} \mathrm{C}$ as a function of the DESe/DEZn molar ratio in the reaction mixture

when the VI/II ratio exceeds unity. These results indicate that DEZn and DESe have similar stabilities at $500^{\circ} \mathrm{C}$. Figure 2-11 shows the deposition rate of $\mathrm{ZnSe}$ films as a function of temperature using a VI/II ratio of 0.7 in the reaction mixture; this ratio was selected on the basis of the photoconductivity ratio of doped $\mathrm{ZnSe}$ films. At low temperatures, the deposition rate increases exponentially with temperature, from $0.3 \mu \mathrm{m} / \mathrm{hr}$ at $360^{\circ} \mathrm{C}$ to $1.0 \mu \mathrm{m} / \mathrm{hr}$ at $400^{\circ} \mathrm{C}$ and $2.3 \mu \mathrm{m} / \mathrm{hr}$ at $450^{\circ} \mathrm{C}$, indicating that the deposition process is surface reaction controlled in this temperature range. The activation energy deduced from the slope of the linear plot is about $0.9 \mathrm{eV}$; this low activation energy is related to the thermal instability of the metalorganics. As the temperature is further increased, the deposition rate levels off, indicating that the transport of reaction species 


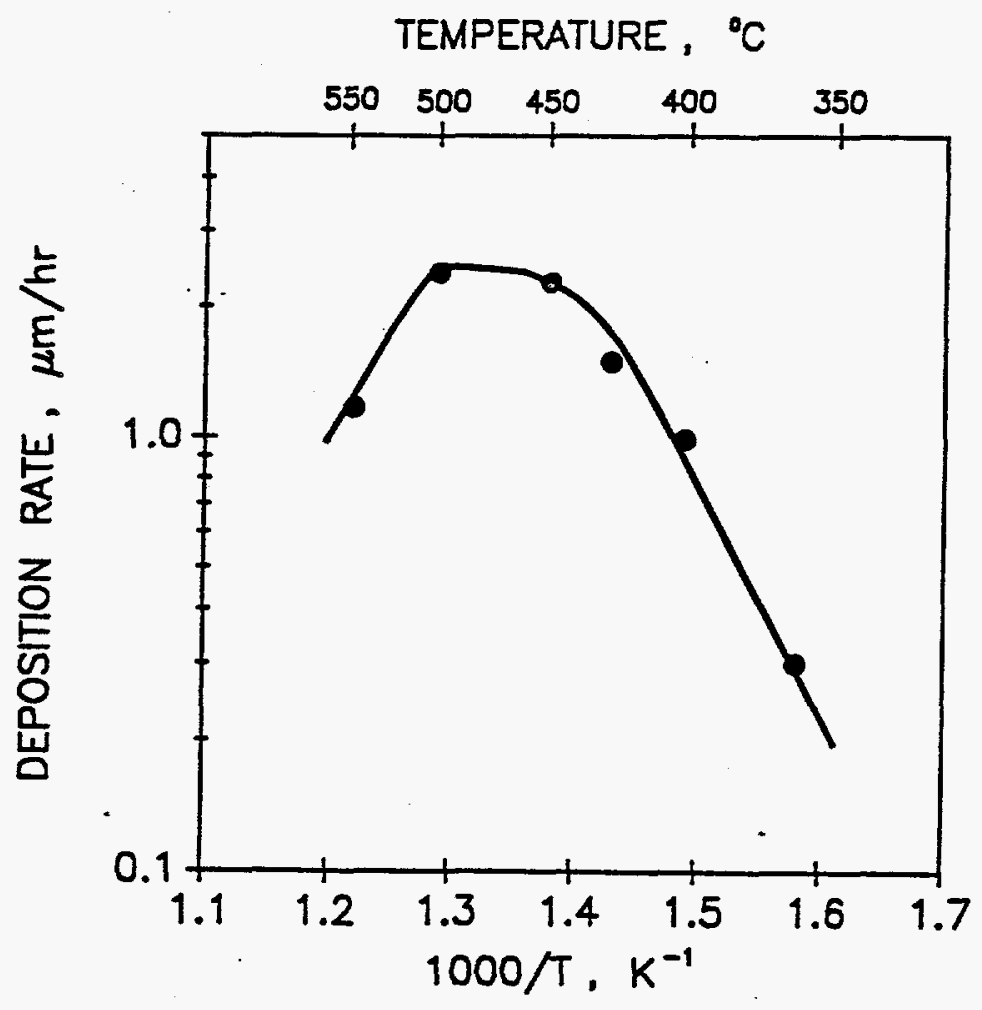

Figure 2-11. The deposition rate of $\mathrm{ZnSe}$ films from a $\mathrm{DESe} / \mathrm{DEZn}=0.7$ reaction mixture as a function of temperature

becomes the dominant process. At still higher temperatures, the deposition rate decreases due to the increased contribution of the gas phase reaction. Most of the $\mathrm{ZnSe}$ films in this work were deposited at $500^{\circ} \mathrm{C}$.

\subsubsection{Properties}

The deposited $\mathrm{ZnSe}$ films are adherent to the glass and $\mathrm{ZnO}: \mathrm{F} /$ glass substrates and are polycrystalline consisting of sub-micrometer size grains. The grain boundaries can be delineated by etching the surface with a $\mathrm{K}_{2} \mathrm{Cr}_{2} \mathrm{O}_{7}-\mathrm{HNO}_{3}-\mathrm{AgNO}_{3}$ solution. The grains are columnar in structure as shown by the fractured and etched vertical cross sections.

The crystallographic properties of $\mathrm{ZnSe}$ films deposited on glass substrates were determined by the $\mathrm{x}$-ray diffraction technique. Polycrystalline ZnSe powder of random orientation is known to show three strong diffraction peaks associated with $\{111\},\{220\}$, and $\{311\}$ reflections with relative intensities of 100,70 , and 44 , respectively. The diffraction spectra of $\mathrm{ZnSe}$ films were obtained by scanning $2 \theta$ in the range of $25^{\circ}$ to $55^{\circ} \mathrm{C}$. The $\mathrm{ZnSe}$ films deposited at $500^{\circ} \mathrm{C}$ show a strong preferred $\{111\}$ orientation, Figure 2-12. However, films deposited at $400^{\circ} \mathrm{C}$ become more random oriented, and $\{220\}$ and $\{311\}$ reflections become significant. 


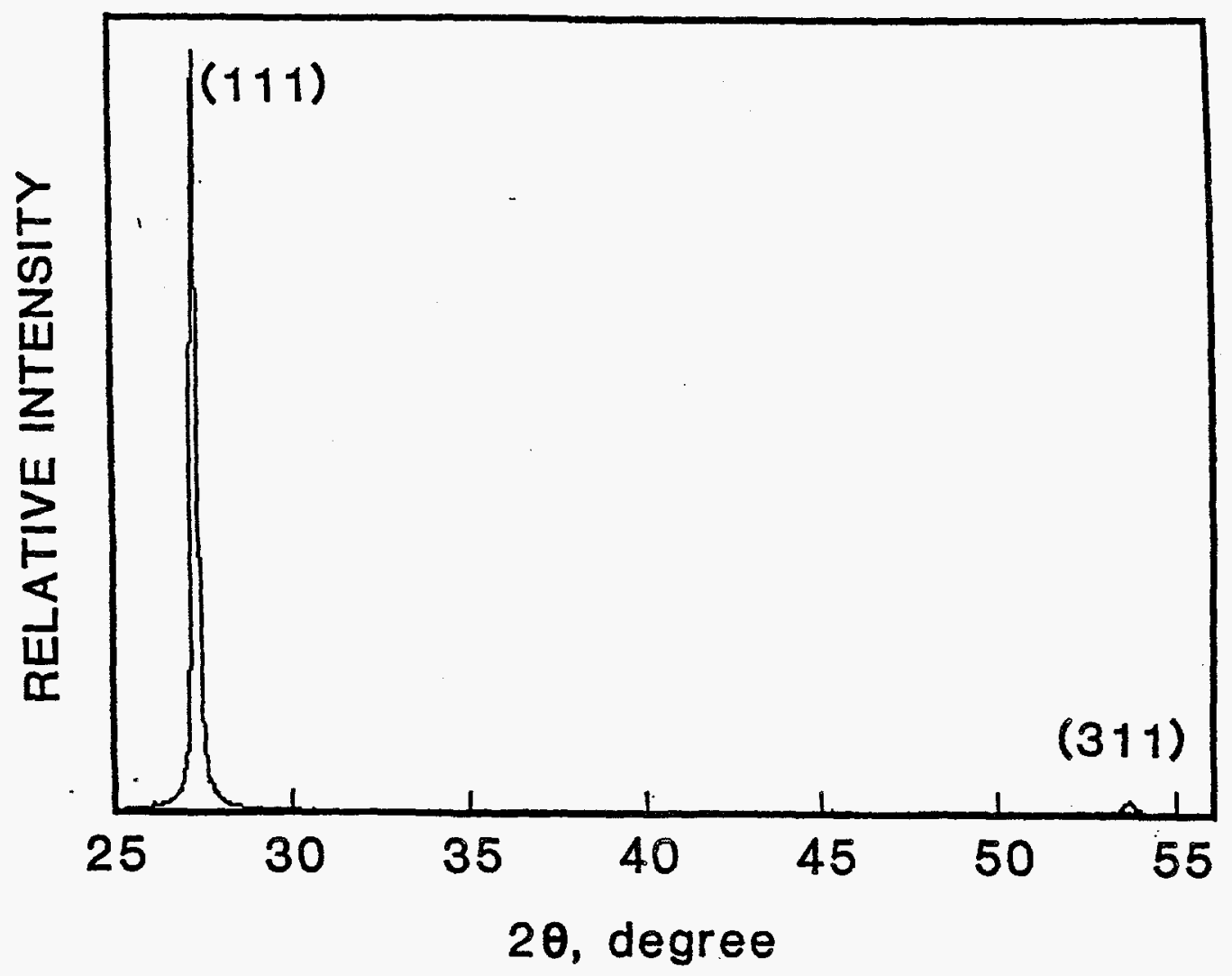

Figure 2-12. X-ray diffraction spectrum of a $\mathrm{ZnSe}$ film deposited on a glass substrate at $500 \cdot \mathrm{C}$

The optical transmission of $\mathrm{ZnSe}$ films deposited on glass substrates was measured on a Cary 17D spectrophotometer. After the reflection corrections, the sub-bandgap transmission is approximately $90 \%$ in films of $6000-8000 \AA$ in thickness. Figure 2-13 shows the $\alpha^{2}$ ( $\alpha$ is the absorption coefficient) vs E plot near the bandedge, and an optical bandgap of $2.69 \mathrm{eV}$ was deduced, essentially the same as the bandgap energy of single crystalline material.

All ZnSe films deposited on glass substrates are n-type and have high electrical resistivity. The lateral resistivity of $\mathrm{ZnSe}$ films on glass substrates was measured at room temperature using a coplanar configuration. Four colinear contacts to the films were made by using a Ga-In alloy. The current is passed through the outer contacts, and the potential drop measured across the two inner contacts. The lateral resistivity of $\mathrm{ZnSe}$ films was also measured under illumination with ELH lamps at $100 \mathrm{~mW} / \mathrm{cm}^{2}$, equivalent to the AM 1.5 condition. Figure 2-14 shows the lateral resistivity of $\mathrm{ZnSe}$ films, in the dark and under illumination, deposited in the temperature range of $350^{\circ} \mathrm{C}-550^{\circ} \mathrm{C}$ without intentional doping from a VI/II $=0.7$ reaction mixture. The lateral resistivity is determined by the carrier concentration in the grains and by the potential barriers at grain boundaries. The observed variation of dark lateral resistivity with deposition temperature is most likely related to the variation of defect concentration in the grains rather than the grain boundary contribution, since the grain boundary resistance is expected to increase at lower temperatures due to smaller grain size. Although the grain boundary resistance is expected to decrease under illumination due to the lowering of potential barriers by the photogenerated carriers, the 


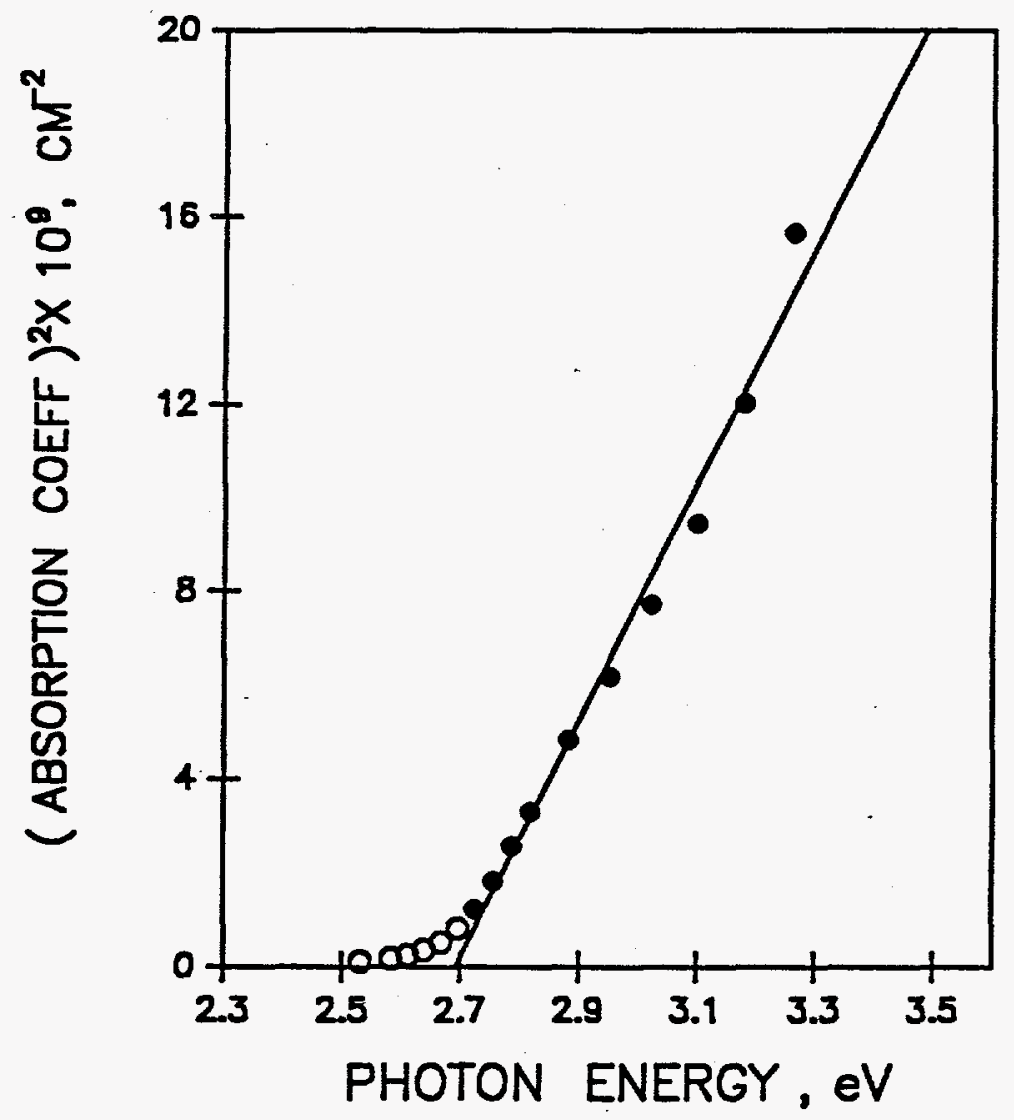

Figure 2-13. Optical absorption of a $\mathrm{ZnSe}$ film deposited on a glass substrate at $500^{\circ} \mathrm{C}$

illuminated resistivity is always higher than the dark resistivity. This less than unity photoconductivity ratio, sometimes referred to as negative photoconductivity, has been observed in numerous materials and is most likely due to the generation of multi-charged centers above the Fermi level [28]. All ZnSe films deposited under a wide range of reaction mixture composition and substrate temperature show photoconductivity ratios of less than unity.

The photoconductivity ratio of ZnSe films can be increased by using group VII (octyl bromide and octyl chloride) or group III (trimethylaluminum, TMAl) compounds during the deposition process. The incorporation of $\mathrm{Br}$ or $\mathrm{Cl}$ into $\mathrm{ZnSe}$ is very limited even at dopant/DESe molar ratios of up to 0.2 , due presumably to the thermal stability of octyl bromide and octyl chloride. While the dark resistivity of $\mathrm{ZnSe}$ films changed very little 


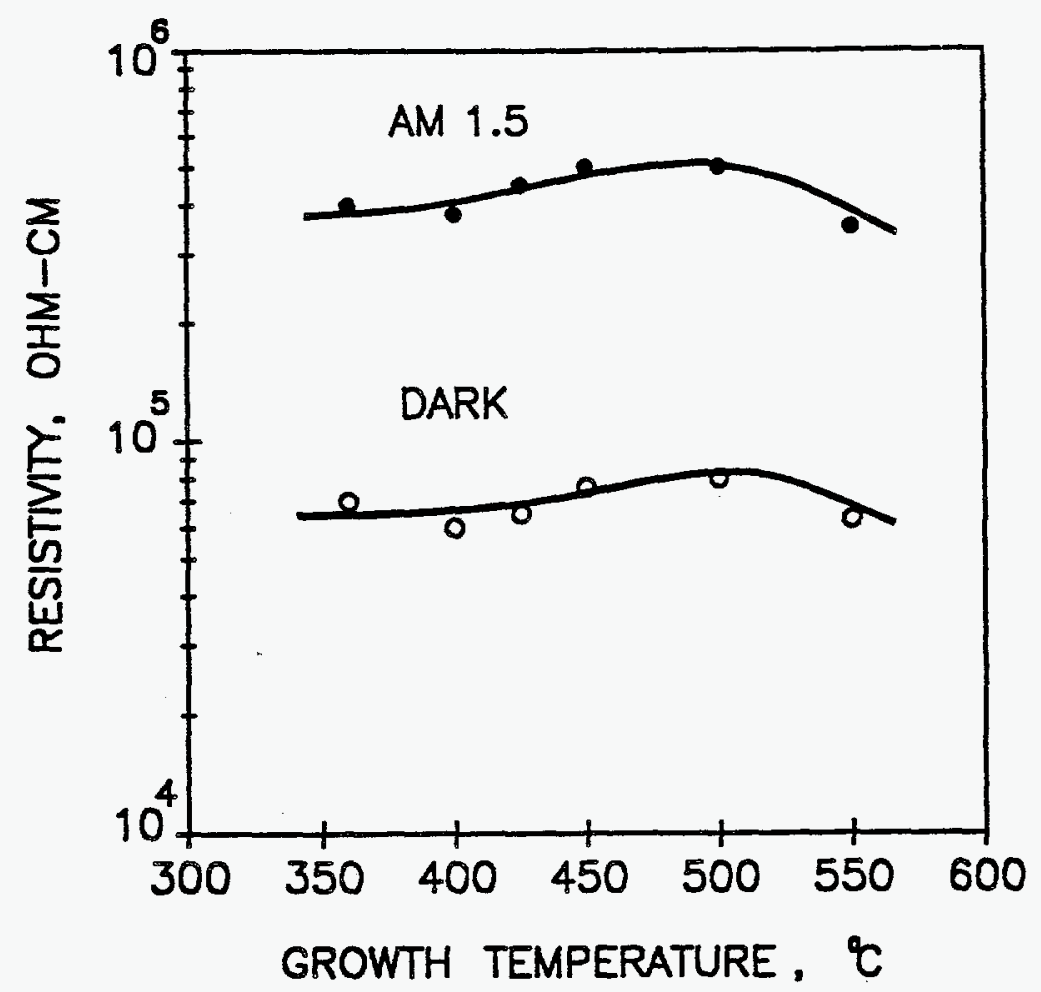

Figure 2-14. Lateral resistivity of $\mathrm{ZnSe}$ films deposited at various temperatures from a $\mathrm{DESe} / \mathrm{DEZn}=0.7$ mixture in the dark and under illumination with an ELH lamp at $100 \mathrm{~mW} / \mathrm{cm}^{2}$

when using $\mathrm{Br}$ or $\mathrm{Cl}$ as a dopant, the resistivity under illumination is significantly reduced, and photoconductivity ratios of up to 10 have been observed. The incorporation of $\mathrm{Al}$ into $\mathrm{ZnSe}$ is more efficient than that of $\mathrm{Br}$ or $\mathrm{C}$. The photoconductivity ratio of Al-doped films depends on the composition of the reaction mixture. Figure 2-15 shows the lateral resistivity of Al-doped $\mathrm{ZnSe}$ films, in the dark and under illumination, deposited at $500^{\circ} \mathrm{C}$ from reaction mixtures having a TMAl/DEZn ratio of 0.03 and various VI/II ratios. While the dark resistivity is relatively independent of the VI/II ratios, the illuminated resistivity varies strongly with the VI/II ratio, and the maximum photoconductivity ratio of approximately 2,000 is observed at a VI/II ratio of about 0.7 . Although a large VI/II ratio would favor the incorporation of $\mathrm{Al}$, the measured resistivity shows no such dependence. Figure 2-16 shows the lateral resistivity of Al-doped $\mathrm{ZnSe}$ films, in the dark and under illumination, deposited at $500^{\circ} \mathrm{C}$ from reaction mixtures having a $\mathrm{VI} / \mathrm{II}$ ratio of 0.7 and various concentrations of TMAl. At low TMAl concentrations, the dark and illuminated resistivities decrease with increasing TMAl/DEZn ratio, and photoconductivity ratios of about 1,000 and higher are observed at TMAl/DEZn ratios of higher than about 0.02. The Al-doped ZnSe films deposited at $500^{\circ} \mathrm{C}$ from reaction mixtures having a VI/II ratio of 0.7 and TMAl/DEZn ratios of $0.025-0.035$ are suitable as the "window" for thin film II-VI heterojunction solar cells. Such films of $1000-2000 \AA$ thickness make negligible contribution to the series resistance of the device under illumination. 


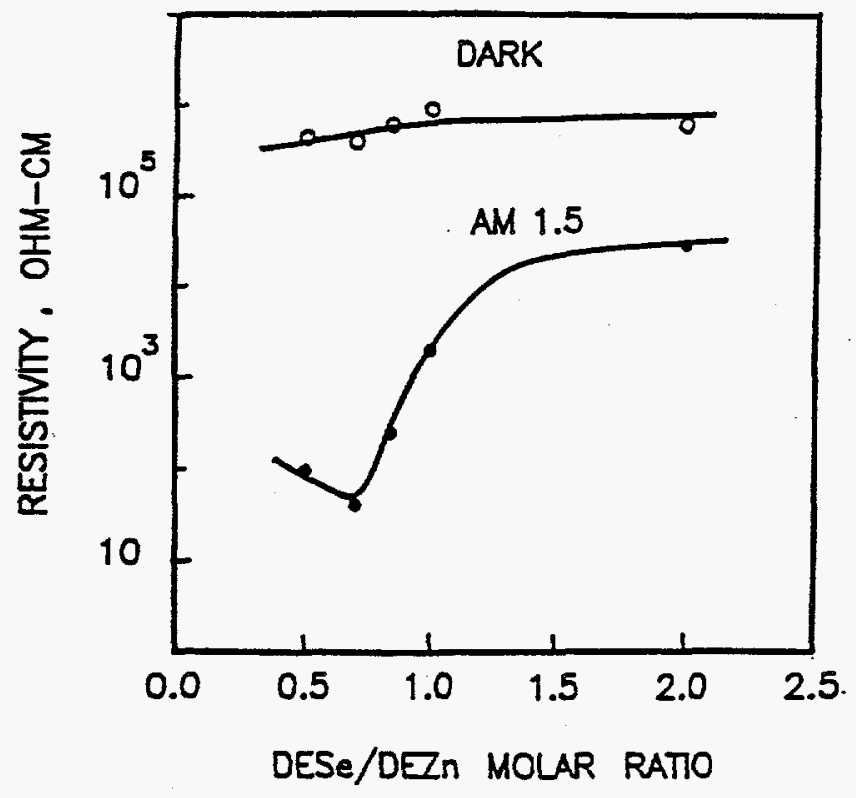

Figure 2-15. Lateral resistivity of Al-doped $\mathrm{ZnSe}$ films, in the dark and under illumination, deposited at $500^{\circ} \mathrm{C}$ using a TMAl/DEZn $=0.03$, as a function of DESe/DEZn ratio in the reaction mixture

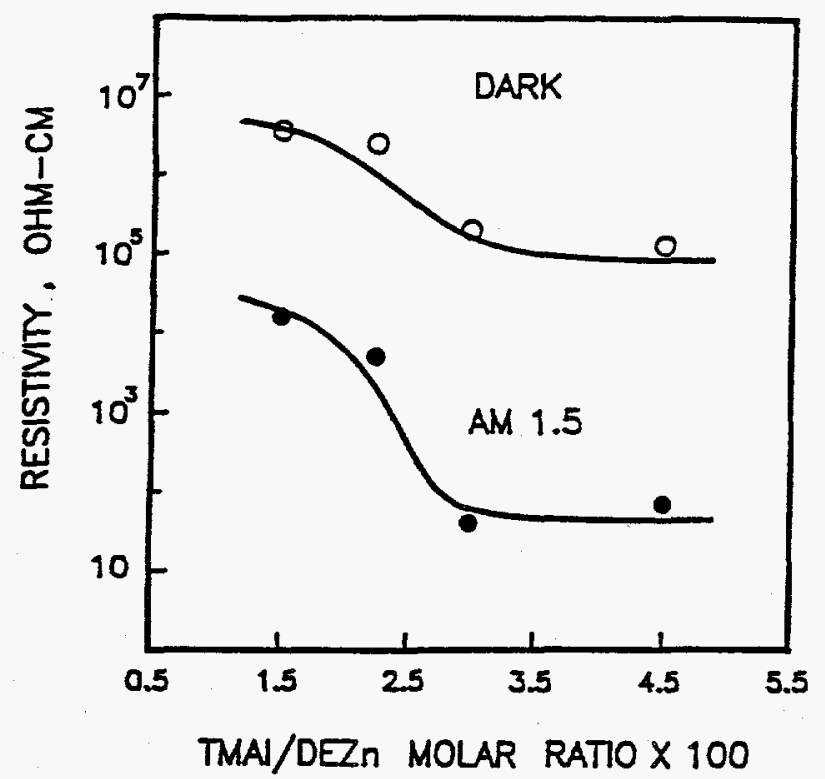

Figure 2-16. Lateral resistivity of $\mathrm{Al}$-doped $\mathrm{ZnSe}$ films, in the dark and under illumination, deposited at $500^{\circ} \mathrm{C}$ having a DESe/DEZn $=0.7$, as a function of TMAl concentration in the reaction mixture 


\section{SECTION 3.0}

\section{CADMIUM TELLURIDE FILMS AND SOLAR CELLS}

Several techniques have been developed for the deposition of CdTe films for efficient solar cells. They include close-spaced sublimation (CSS), chemical vapor deposition (CVD), spraying, screen-printing, electrodeposition, and metalorganic chemical vapor deposition (MOCVD). In this program, the CSS and MOCVD techniques have been used for the deposition of CdTe films. The CSS technique requires relatively high temperatures and is capable of depositing CdTe films at high rates. The MOCVD technique is a low temperature process and is, in principle, capable of controlling the composition of deposited films. However, the control of dopant concentration and distribution in polycrystalline CdTe films by MOCVD has not been explored. The use of low temperatures is advantageous in that self-compensation and native defects could be reduced, and that the absorber-window interface reactions could be minimized. It is believed that the results on MOCVD solar cells could provide information on the ultimate efficiency of thin film solar cells.

\subsection{METALORGANIC CHEMICAL VAPOR DEPOSITION (MOCVD)}

During the past few years, the metalorganic chemical vapor deposition (MOCVD) technique has been used for the epitaxial growth of CdTe, and to a lesser extent, the deposition of polycrystalline CdTe films [29,30]. However, very little information on the doping and properties of MOCVD CdTe films is known. In this program, CdTe films have been deposited on glass, $\mathrm{SnO}_{2}: \mathrm{F} /$ glass, and $\mathrm{CdS} / \mathrm{SnO}_{2}: \mathrm{F} /$ glass substrates by $\mathrm{MOCVD}$ using the reaction between dimethylcadmium (DMCd) and diisopropyltellurium (DIPTe) in a hydrogen atmosphere. The structural, optical, and electrical properties of these films have been investigated. Also, group III and group V compounds have been used as the n-type and p-type dopant during the MOCVD of CdTe films, and the properties of doped films characterized. Thin film homo- and heterojunctions have also been prepared, and their photovoltaic properties measured.

\subsubsection{Deposition Process}

The apparatus used for the MOCVD of CdTe films from DMCd and DIPTe has been shown in Figure 2-3. To control the carrier concentration in CdTe films, trimethylaluminum (TMAl) and triethylgallium (TEGa) were used as n-type dopants, and triethylantimony (TESb) and a $\mathrm{H}_{2}-\mathrm{AsH}_{3}$ mixture containing $100 \mathrm{ppm} \mathrm{AsH}_{3}$ were used as p-type dopants during the MOCVD process. DMCd, DIPTe, TMAl, TEGa, and TESb, with vapor pressures of $28.4,3.3,8.7,4.4$, and $2.9 \mathrm{Torr}$, respectively, at $20^{\circ} \mathrm{C}$, were introduced into the reaction tube, a fused silica tube of $5.5 \mathrm{~cm} \mathrm{mD}$, by bubbling measured amounts of hydrogen through the liquids. The composition of the reaction mixture was then determined by the flow rates of hydrogen through the liquids and the reaction tube. The substrates, glass, $\mathrm{SnO}_{2}: \mathrm{F} /$ glass, or $\mathrm{CdS} / \mathrm{SnO}_{2}: \mathrm{F} /$ glass, were supported on a silicon carbide coated graphite susceptor in the reaction tube, and the susceptor heated externally with an if generator. A 
thermocouple inserted into the interior of the susceptor was used to monitor the temperature of the substrates. The flow rates of hydrogen and DIPTe were $4.5 \mathrm{l} / \mathrm{min}$ and $3.6 \times 10^{-5} \mathrm{moles} / \mathrm{min}$, respectively, and the flow rate of $\mathrm{DMCd}$ was varied to yield DMCd/DIPTe molar ratios of 0.34-2. Figure 3-1 shows the deposition rate of CdTe films at $350^{\circ} \mathrm{C}$ and $400^{\circ} \mathrm{C}$ as a function of the DMCd/DIPTe molar ratio in the reaction mixture.

The deposition rate at $400^{\circ} \mathrm{C}$ is higher than that at $350^{\circ} \mathrm{C}$ indicating that the deposition rate is kinetically controlled in this temperature range. At $400^{\circ} \mathrm{C}$, the deposition rate of CdTe increases linearly with increasing DMCd concentration in the reaction mixture at DMCd/DIPTe molar ratios below approximately 0.6. The deposition rate remains essentially constant, $4.3 \mu \mathrm{m} / \mathrm{hr}$, at higher DMCd/DIPTe ratios. The CdTe film deposited at a DMCd/DIPTe molar ratio of 0.51 is essentially stoichiometric, as shown below, indicating the greater thermal stability of DIPTe. The deposition rate at high DMCd/DIPTe ratios is limited by the concentration of DIPTe in the reaction mixture and thus remains unchanged. On the basis of the deposition rate and the susceptor area, DMCd is estimated to be more than $90 \%$ decomposed under the conditions used here. The extent of decomposition of DIPTe is about $50 \%$.

The DMCd/DIPTe molar ratio is also an important parameter in the deposition of doped CdTe films. Since the group III element occupies the Cd position in the CdTe lattice, the incorporation of the donor will be facilitated by the presence of a high concentration of $\mathrm{Cd}$ vacancies, i.e. by using a reaction mixture with a small DMCd/DIPTe molar ratio, which would yield p-type CdTe without intentional doping. Similarly, a large DMCd/DIPTe molar ratio should be used for the deposition of p-type CdTe films.

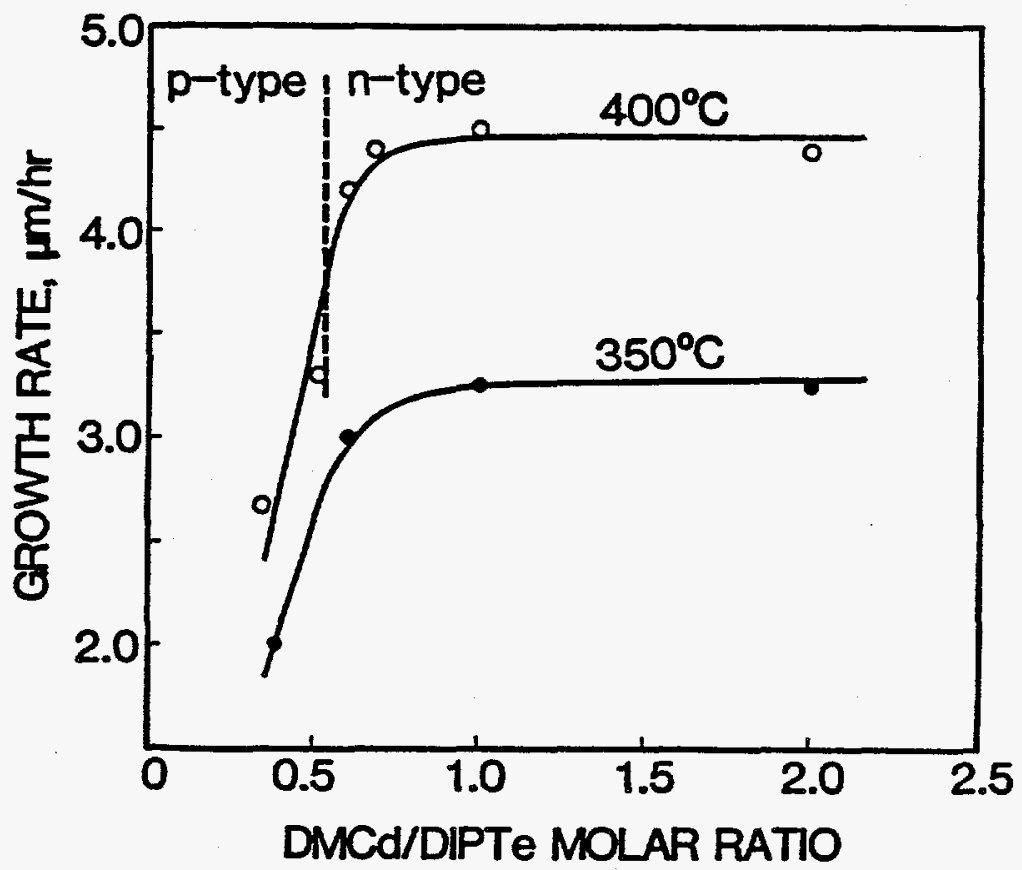

Figure 3-1 The deposition rate of CdTe films as a function of DMCd/DIPTe molar ratio in the reaction mixture 


\subsubsection{Properties of Intrinsic CdTe Films}

The deposited CdTe films are adherent to the glass and $\mathrm{SnO}_{2}: \mathrm{F} /$ glass substrates. The films are polycrystalline consisting of densely-packed grains with an average grain size of about $1 \mu \mathrm{m}$. The grains are columnar in structure as shown by the fractured and etched vertical cross sections.

The crystallographic properties of $\mathrm{CdTe}$ films deposited on glass and $\mathrm{SnO}_{2}: \mathrm{F} /$ glass substrates were determined by the $\mathrm{x}$-ray diffraction technique. Polycrystalline CdTe powder of random orientations is known to show three strong diffraction peaks associated with $\{111\},\{220\}$, and $\{311\}$ reflections with relative intensities of 100,62 , and 28 , respectively. The diffraction spectra of CdTe films were obtained by scanning $2 \theta$ in the range of $20^{\circ}$ to $60^{\circ}$. All CdTe films deposited on glass and $\mathrm{SnO}_{2}: \mathrm{F} /$ glass substrates under a wide range of conditions show essentially identical diffraction spectra with a strong preferred $\{111\}$ orientation. This is in contrast with the random orientation of CdTe films deposited by the direct combination of elemental vapors on the substrate surface at $550^{\circ} \mathrm{C}$ [31].

The optical absorption of CdTe films deposited on glass substrates was measured on a Cary 17D spectrophotometer. The sub-bandgap transmission is approximately $85 \%$ in films of about $1 \mu \mathrm{m}$ thickness. The optical bandgap energy deduced from the $\alpha^{2}$ ( $\alpha$ is the absorption coefficient) versus $E$ plot near the bandedge is about $1.50 \mathrm{eV}$.

All CdTe films deposited on glass substrates with no intentional doping have high electrical resistivity. Their conductivity type cannot be readily determined by conventional thermoelectric probes. The conductivity type of CdTe films was deduced from junction photovoltage spectroscopy by using films of $2-3 \mu \mathrm{m}$ thickness deposited on $\mathrm{SnO}_{2}: \mathrm{F} /$ glass substrates. Graphite paste was applied to the surface of the CdTe film to form a graphite $/ \mathrm{CdTe} / \mathrm{SnO}_{2}: \mathrm{F} /$ glass structure, and silver paste was used as an ohmic contact to $\mathrm{SnO}_{2}$. The junction photovoltage spectrum was then measured in the wavelength range of 500-1000 nm by illuminating the glass surface with a tungsten-halogen lamp. The graphite/n-CdTe and $\mathrm{p}-\mathrm{CdTe} / \mathrm{SnO}_{2}$ junctions are known to be rectifying, and the n$\mathrm{CdTe} / \mathrm{SnO}_{2}$ and $\mathrm{p}-\mathrm{CdTe} /$ graphite junctions are essentially ohmic. In a graphite/n$\mathrm{CdTe} / \mathrm{SnO}_{2}: \mathrm{F} /$ glass structure, the short wavelength radiation is strongly absorbed in $\mathrm{n}-\mathrm{CdTe}$ near the $\mathrm{SnO}_{2} / \mathrm{n}-\mathrm{CdTe}$ interface, and most carriers generated by short wavelength radiation are not collected at the graphite/n-CdTe junction. In a graphite $/ \mathrm{p}-\mathrm{CdTe} / \mathrm{SnO} \mathrm{O}_{2}: \mathrm{F} /$ glass structure, the carrier generation by the short wavelength radiation occurs in p-CdTe near the $\mathrm{p}-\mathrm{CdTe} / \mathrm{SnO}_{2}$ junction, and these carriers are collected at the junction. Thus, the graphite/p-CdTe/SnO $2: \mathrm{F} /$ glass structures show considerably better response in the short wavelength region than graphite $/ \mathrm{n}-\mathrm{CdTe} / \mathrm{SnO} \mathrm{O}_{2}: \mathrm{F} /$ glass structures. This is illustrated in Figure 3-2. The shape of these spectra depends, of course, on the thickness of the CdTe films.

The conductivity type of $\mathrm{CdTe}$ films deposited on $\mathrm{SnO}_{2}: \mathrm{F} /$ glass substrates at $400^{\circ} \mathrm{C}$ without intentional doping was determined as a function of the DMCd/DIPTe molar ratio in the reaction mixture by the junction photovoltage technique. The nearly stoichiometric films can be p-type due to Cd vacancies or n-type due to Te vacancies. At DMCd/DIPTe molar 


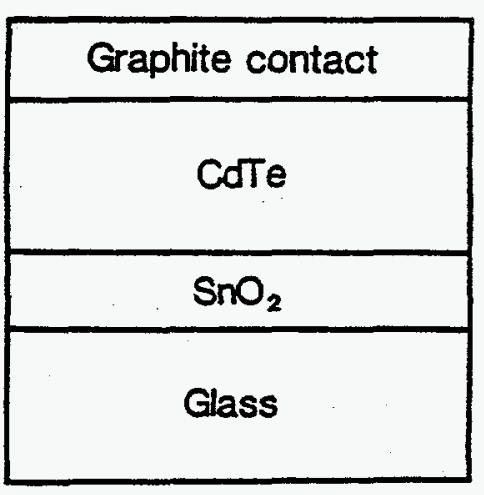

$\uparrow \uparrow \uparrow \uparrow \uparrow \uparrow \uparrow$

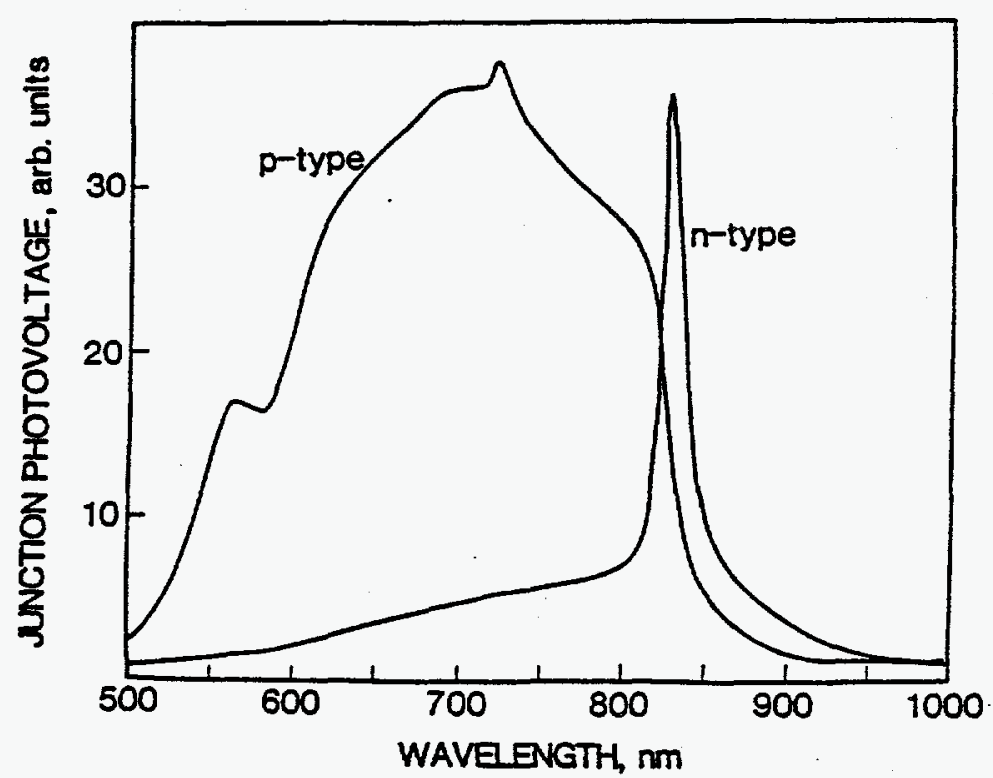

Figure 3-2 Junction photovoltage spectra of graphite/n-CdTe/SnO $\mathrm{O}_{2}: \mathrm{F} /$ glass and graphite/p-CdTe/SnO $2: \mathrm{F} /$ glass structures

ratios of about 0.51 or lower, the deposited films were all p-type. The deposited films became n-type at higher DMCd/DIPTe ratios. Thus, the change in conductivity type of nearly stoichiometric films takes place over a narrow range of the reactant composition. The conductivity change in CdTe films deposited at $350^{\circ} \mathrm{C}$ occurs at a higher DMCd/DIPTe ratio because of the greater stability of DIPTe. A similar behavior has been observed in the deposition of CdTe films by the direct combination of elemental vapors, where the n-p - transmission occurs at a vapor phase $\mathrm{Cd} / \mathrm{Te}$ ratio of about 1.1 at a deposition temperature of $575^{\circ} \mathrm{C}$ [32]. The vapor phase composition is different from the solid phase composition because of the higher vapor pressure of Cd. In MOCVD films, the solid phase composition is related to the vapor phase composition by the relative thermal stability of DMCd and DIPTe.

The lateral resistivity of CdTe films on glass substrates was measured by the conventional potential probe technique using graphite contacts. Because of the low current level associated with the high sheet resistance of CdTe, the measurements were carried out in a screened enclosure. The dark lateral resistivity of all CdTe films has been found to be $10^{7}$ $10^{8} \mathrm{ohm} / \mathrm{cm}$, with slight dependence on the DMCd/DIPTe molar ratio in the reaction mixture, as shown in Figure 3-3. This is due predominately to the columnar structure of CdTe films and the potential barriers at the grain boundaries, where the grain boundary resistance is many times higher than the resistance of the grains. Under illumination with ELH lamps at $100 \mathrm{~mW} / \mathrm{cm}^{2}$, the lateral resistivity is reduced by a factor of $100-300$, also shown in Figure 3-3, due to the reduction of potential barriers at grain boundaries. 


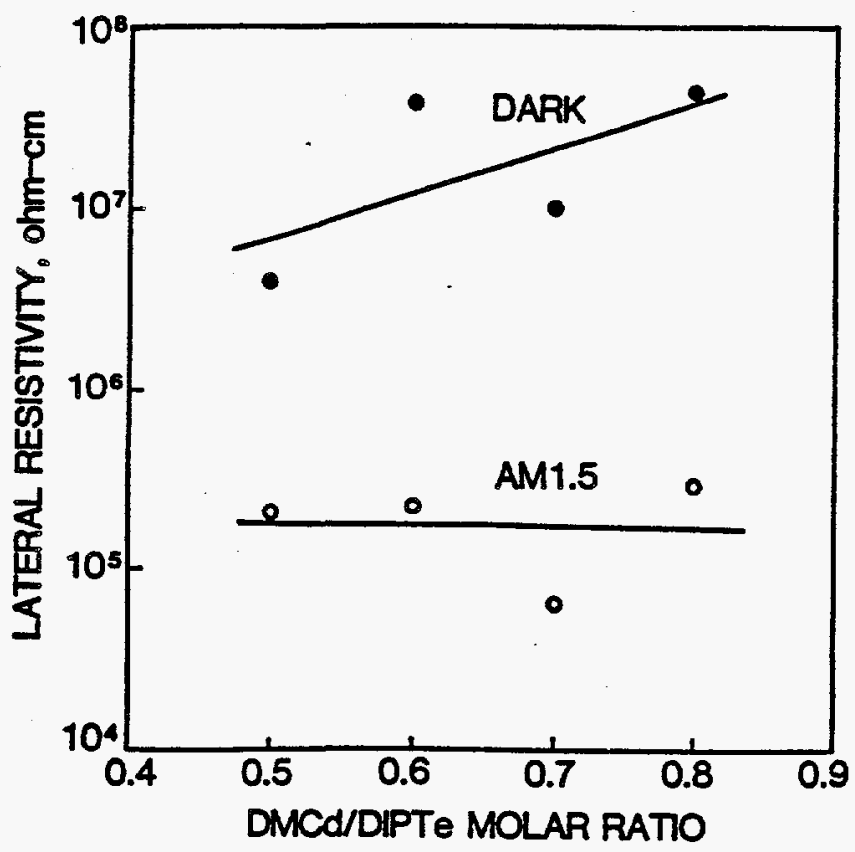

Figure 3-3 Lateral resistivity of CdTe films versus the reactant composition in the dark and under illumination with an ELH lamp at $100 \mathrm{~mW} / \mathrm{cm}^{2}$

The photoluminescence of CdTe films deposited from reaction mixtures with various DMCd/DIPTe molar ratios was measured at $4.2 \mathrm{~K}$. Very little information on the photoluminescence of polycrystalline CdTe films is available. The effect of oxygen on the luminescence of CdS/CdTe thin films has been reported [33]. A donor-acceptor transition $(1.521 \mathrm{eV}$ at $4.2 \mathrm{~K}$ ) was observed only at the CdS/CdTe interface of samples prepared in an oxygen atmosphere. The samples were supported on a copper holder immersed in liquid helium in a Janis cryogenic Dewar, and its temperature was monitored by a silicon diode. Excitation was provided by a mechanically chopped $(1 \mathrm{k} \mathrm{Hz})$ radiation from an argon ion laser with a $484 \mathrm{~nm}$ interference filter. Luminescence from the sample was optically focused onto the slit of a Spex Model 1704 spectrometer, and the slit width of the spectrometer was selected to yield energy resolution of $0.5 \mathrm{meV}$ or better in the luminescent spectra. The signal was detected with a silicon p-i-n detector and processed with a lock-in amplifier. The spectrometer and the detector system were interfaced with a data acquisition system.

CdTe films deposited at $350^{\circ} \mathrm{C}$ show very broad luminescent bands in the $800-900 \mathrm{~nm}$ range, indicating a high density of gap states. Films deposited at $400^{\circ} \mathrm{C}$ show intense and welldefined luminescent bands. Figure 3-4 shows the luminescent spectra of four CdTe films deposited with DMCd/DIPTe molar ratios of 0.34 (p-type), 0.42 (p-type), 0.51 (essentially stoichiometric), and 0.59 (n-type). Four bands at $778 \mathrm{~nm}(1.59 \mathrm{eV}), 840 \mathrm{~nm}(1.47 \mathrm{eV}), 903$ $\mathrm{nm}(1.37 \mathrm{eV})$, and $932 \mathrm{~nm}(1.33 \mathrm{eV})$ are present. Since the four samples differ principally in the concentration of $\mathrm{Cd}$ and $\mathrm{Te}$ vacancies and their complexes, the differences in the photoluminescence spectra are most likely to be associated with these defects. The photoluminescence spectra of many CdTe bulk crystals and epitaxial films have been reported. In epitaxial CdTe films, several near bandedge emission lines have been ascribed to free exciton, donor-bound exciton, ionized donor-bound exciton, acceptor-bound exciton, 


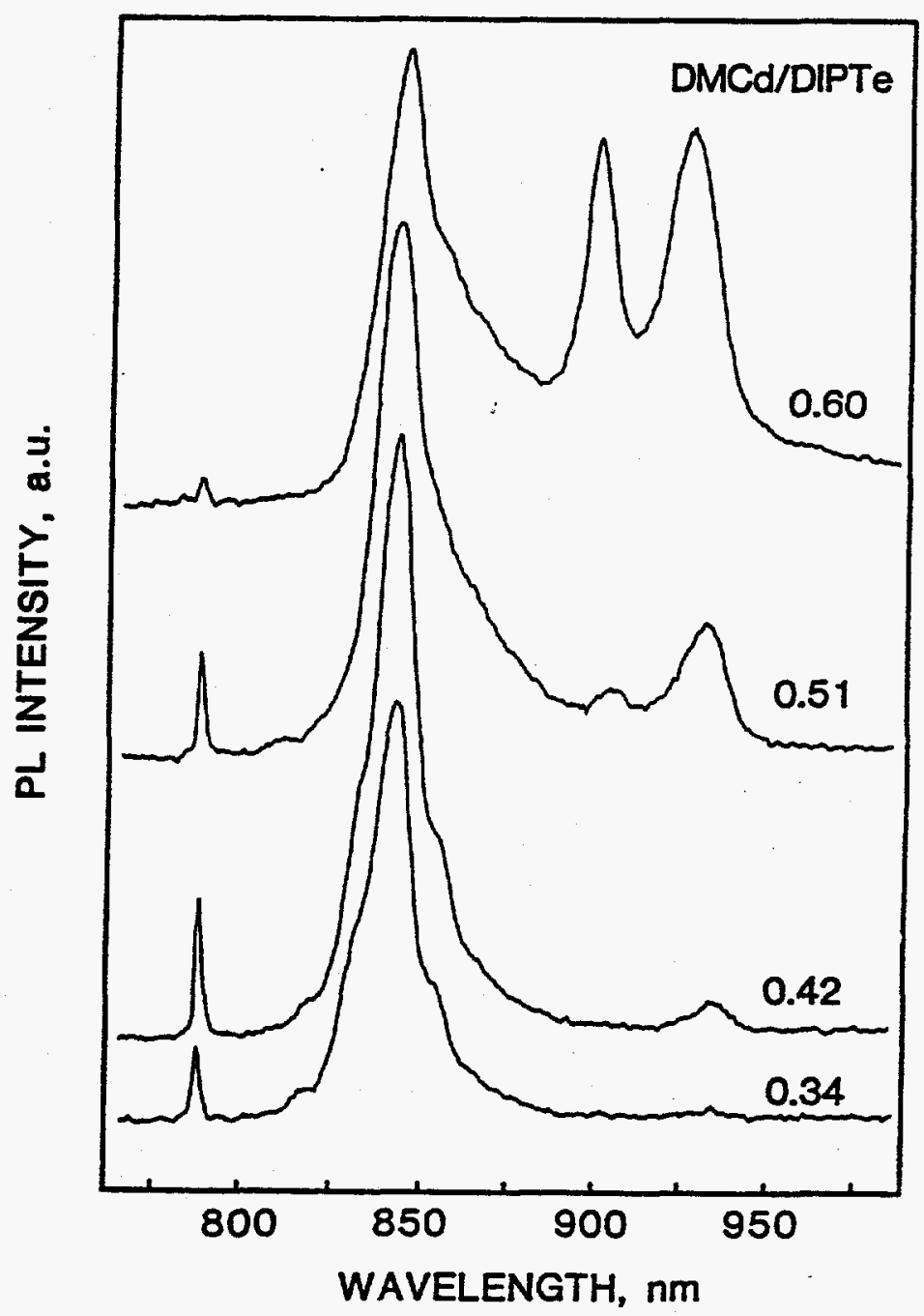

Figure 3-4 Photoluminescence spectra of CdTe films at $4.2 \mathrm{~K}$ deposited by using various DMCd/DIPTe molar ratios in the reaction mixture

donor-like structural defects, impurity defect complexes, etc. [34-36]. A defect related band at $1.476 \mathrm{eV}$ has also been observed; this band decreased in intensity as the growth temperature increased. Due to the complexity of defect interactions in crystalline CdTe, the nature of the defect states in the luminescence spectrum in single crystalline CdTe has not been definitively identified. In polycrystalline CdTe films on glass substrates, the $778 \mathrm{~nm}$ band decreases greatly in intensity as the DMCd/DIPTe molar ratio exceeds about 0.5 and is most likely to be associated with a conduction band-shallow acceptor transition. The other three bands in the observed spectra are associated with states of relatively large ionization energy. The intensity of the $840 \mathrm{~nm}$ band is relatively independent of the DMCd/DIPTe ratio in the reaction mixture and could be associated with a chemical impurity. As the CdTe films become n-type at higher DMCd/DIPTe ratios, the 903 and 932 $\mathrm{nm}$ bands appear. They are presumably associated with $\mathrm{Te}$ vacancies or its complexes. 


\subsubsection{Properties of Doped CdTe Films}

During the early stage of this program, TMAl was used as an n-type dopant during the MOCVD of CdTe at $400^{\circ} \mathrm{C}$. The extent of Al incorporation was found to be very small even at TMAl/DMCd molar ratios of up to 0.18 due to the thermal stability of TMAl. TEGa is thermally more unstable than TMAl and is a more effective dopant. Figure 3-5 shows the lateral resistivity of Ga-doped CdTe films in the dark and under illumination with an ELH lamp at $100 \mathrm{~mW} / \mathrm{cm}^{2}$ as a function of the TEGa/DMCd molar ratio in the reaction mixture. These films were deposited by using flow rates of DMCd and DIPTe at $1.6 \times 10^{-5}$ and $3.6 \times 10^{-5} \mathrm{~mole} / \mathrm{min}$, respectively, corresponding to a DMCd/DIPTe molar ratio of 0.45 . Without intentional doping, a reaction mixture of this composition would yield p-CdTe films. When TEGa is introduced into the reaction mixture, the resistivity of CdTe films is determined by the extent of decomposition of TEGa, the incorporation of $\mathrm{Ga}$ into $\mathrm{Cd}$ positions, and self-compensation. At TEGa/DMCd molar ratios of $1 \%$ or less, the dark and illuminated resistivities of $\mathrm{Ga}$-doped CdTe films are similar to those of CdTe films without intentional doping. This is related to the compensation of incorporated $\mathrm{Ga}$ by residual acceptors in CdTe. The resisitivity of CdTe films decreases rapidly as the concentration of TEGa increases and levels off at a TEGa/DMCd ratio of about 0.08 . The photoconductivity ratio of Ga-doped CdTe films depends on the TEGa/DMCd ratio and is in the range of $10^{2}-10^{4}$. To determine the carrier concentration in Ga-doped CdTe films, silver was evaporated onto the surface of $\mathrm{n}-\mathrm{CdTe} / \mathrm{SnO}_{2}: \mathrm{F} /$ glass structures to form Schottky barriers, and the capacitance-voltage relation measured at $3 \mathrm{k} \mathrm{Hz}$. The carrier concentration in CdTe films has been found to be a linear function of the TEGa/DMCd molar ratio in the reaction mixture, as shown in Figure 3-6. Only a very small fraction, on the order of $10^{-5}$, of the TEGa in the reaction mixture becomes electrically active in CdTe films.

The Ga-doped CdTe films were also characterized by photoluminescence and junction photovoltage measurements. The photoluminescence was measured at $4.2 \mathrm{~K}$ by using an argon ion laser with a $484 \mathrm{~nm}$ interference filter, chopped at $1 \mathrm{kHz}$, as the excitation source. Figure 3-7 shows the luminescence spectra of three Ga-doped CdTe films deposited with a DMCd/DIPTe molar ratio of 0.42 and TEGa/DMCd ratios of $0.009,0.03$, and 0.05 . The spectrum of the film deposited with a TEGa/DMCd ratio of 0.009 , curve $\mathrm{A}$, shows three bands at $778(1.59 \mathrm{eV}), 839(1.48 \mathrm{eV})$, and $937 \mathrm{~nm}(1.32 \mathrm{eV})$, similar to that of an undoped film deposited with a DMCd/DIPTe molar ratio of 0.51, Figure 3-4. When the TEGa/DMCd molar ratio is increased, the intensity of the $778 \mathrm{~nm}$ band decreases, the 839 and $937 \mathrm{~nm}$ bands disappear, and several overlapping bands centered at about $862 \mathrm{~nm}$ are observed, as shown in curve B of Figure 3-7, where the CdTe film was deposited at a TEGa/DMCd ratio of 0.03 . As the TEGa/DMCd ratio further increases, curve $C$, the 862 nm band further broadens, and the $778 \mathrm{~nm}$ band decreases in intensity. At still higher $\mathrm{TEGa} / \mathrm{DMCd}$ ratios, the luminescence spectrum remains essentially the same. The deep levels associated with the broad band are related to the donor complexes; similar bands have been observed in Ga- and In-doped CdTe crystals [37]. 


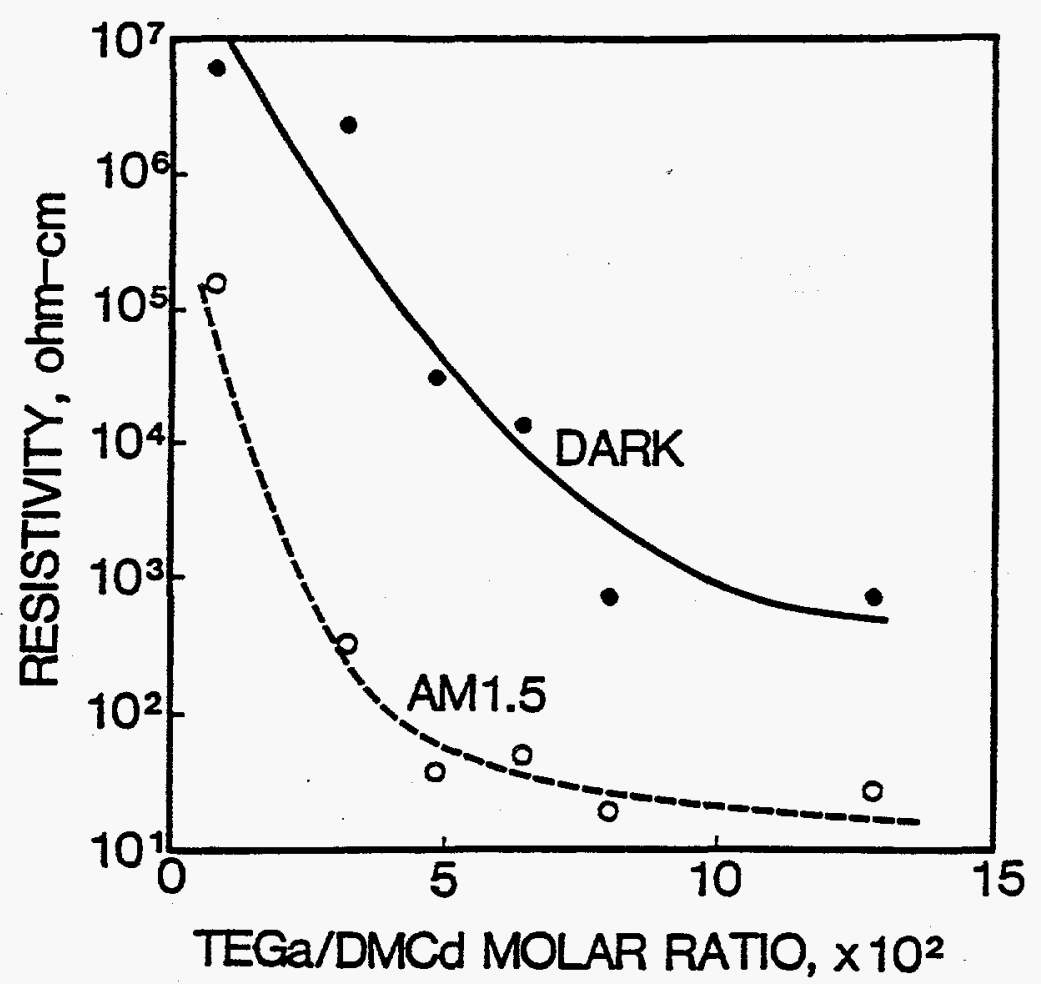

Figure 3-5 Lateral resistivity of Ga-doped CdTe films, in the dark and under illumination with an ELH lamp at $100 \mathrm{~mW} / \mathrm{cm}^{2}$, versus TEGa concentration in the reaction mixture

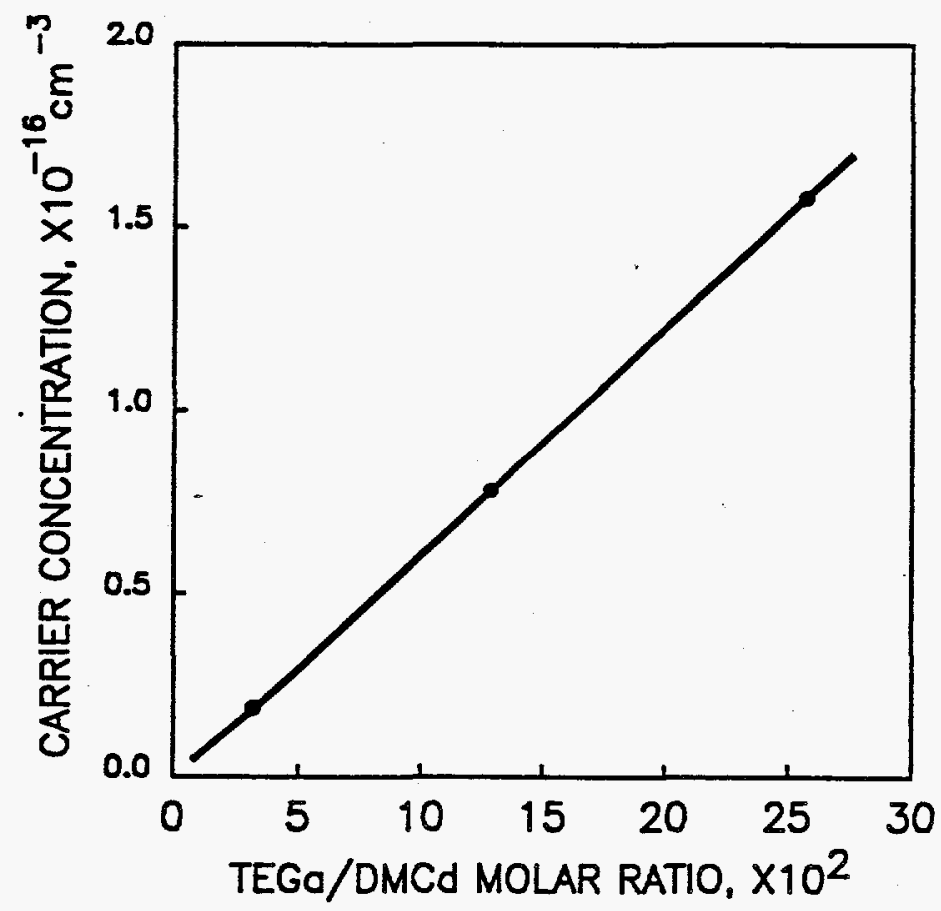

Figure 3-6 Carrier concentration in Ga-doped CdTe films versus TEGa/DMCd molar ratio in the reaction mixture 


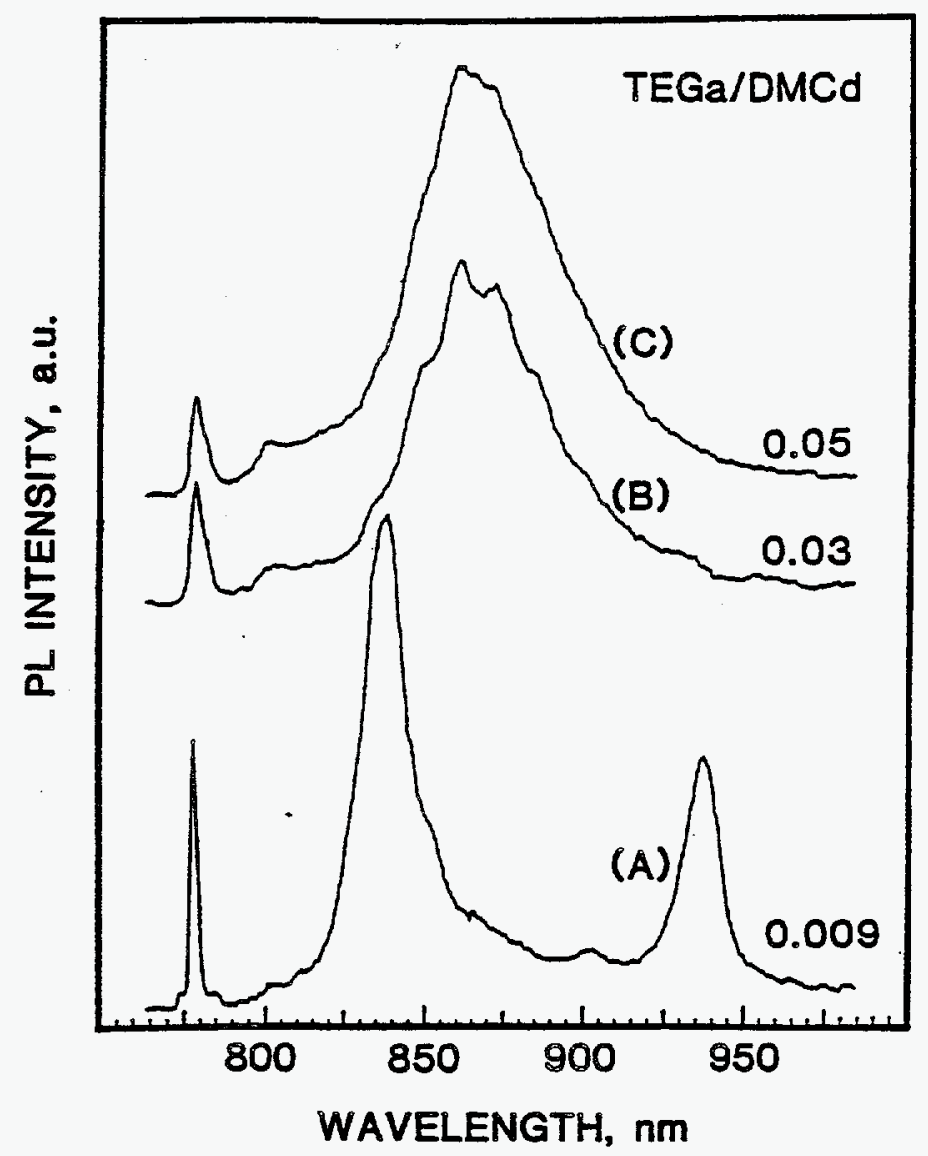

Figure 3-7 Photoluminescence spectra of Ga-doped CdTe films at 4.2 $\mathrm{K}$ deposited by using TEGa/DMCd molar ratios of 0.009 (A), 0.03 (B), and 0.05 (C) in the reaction mixture

CdTe films of 2-3 $\mu \mathrm{m}$ thickness deposited on $\mathrm{SnO}_{2}: \mathrm{F} /$ glass substrates were used to measure junction photovoltage spectrum. Graphite paste was applied to the surface of the CdTe film to form a graphite/CdTe/ $\mathrm{SnO}_{2}: \mathrm{F} /$ glass structure, and silver paste was used as an ohmic contact to $\mathrm{SnO}_{2}$. The junction photovoltage spectrum was then measured in the wavelength range of 500-1000 nm by illuminating the glass surface with a tungsten-halogen lamp. Figure 3-8 shows the junction photovoltage spectra of two graphite/CdTe(Ga-doped)/SnO $2: \mathrm{F} /$ glass structures, where the CdTe films were deposited with TEGa/DMCd molar ratios of 0.009 and 0.03. It is apparent that Ga-doped CdTe films deposited at low concentrations of TEGa remain p-type. The bandgap energy deduced from the extrapolation of the junction photovoltage spectrum near the band edge is $1.45 \pm 0.01 \mathrm{eV}$ for both films.

As-doped CdTe films have been deposited at $400^{\circ} \mathrm{C}$ from DMCd-DIPTe reaction mixtures. In the absence of arsine, the reaction mixtures with DMCd/DIPTe molar ratios of 0.51 and higher would yield n-CdTe films. Figure 3-9 shows the lateral resistivity of As-doped CdTe films deposited with a DMCd/DIPTe molar ratio of 2.0 as a function of the $\mathrm{AsH}_{3} / \mathrm{DIPTe}$ ratio in the reaction mixture. When the reaction mixture has a very low $\mathrm{AsH}_{3} / \mathrm{DIPTe}$ ratio, 


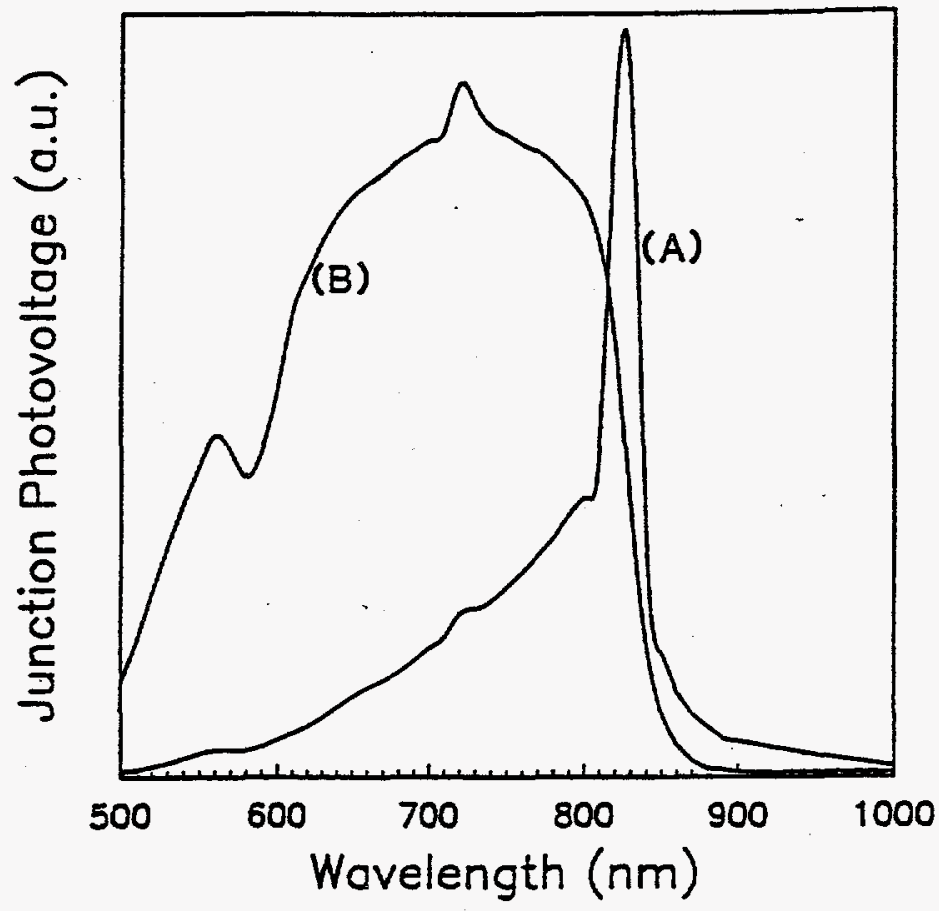

Figure 3-8 Junction photovoltage spectra of two graphite/CdTe/SnO structures deposited with TEGa/DMCd molar ratios of 0.009 (A) and 0.03 (B)

such as $5 \times 10^{-4}$, the deposited CdTe film is n-type as shown by junction photovoltage spectroscopy. In contrast to Ga-doping, the incorporation of As does not significantly reduce the resistivity of $\mathrm{CdTe}$ films. All As-doped samples show high photoconductivity ratios, $10^{2}-10^{3}$. At similar $\mathrm{AsH}_{3} / \mathrm{DIPTe}$ and TEGa/DMCd molar ratios, the extent of As incorporation into CdTe is expected to be less than that of $\mathrm{Ga}$ because of the greater thermal stability of $\mathrm{AsH}_{3}$.

The As-doped CdTe films were characterized by photoluminescence measurements. The intrinsic p-CdTe films show two major luminescence bands at $778 \mathrm{~nm}(1.59 \mathrm{eV})$ and $840 \mathrm{~nm}$ $(1.47 \mathrm{eV})$. The intrinsic $\mathrm{n}-\mathrm{CdTe}$ filmis show three luminescent bands at $840(1.47 \mathrm{eV}), 903$ $(1.37 \mathrm{eV})$, and $932 \mathrm{~nm}(1.33 \mathrm{eV})$; the latter two bands have been ascribed to states associated with Te vacancies or its complexes (Section 3.1.2). The addition of a small amount of $\mathrm{AsH}_{3}$ to the reaction mixture, $\mathrm{AsH}_{3} / \mathrm{DIPTe}$ ratio of $5 \times 10^{-4}$ for example, resulted in essentially no change in the luminescent spectrum due to compensation of incorporated As by residual donors in CdTe. The spectra change significantly at higher $\mathrm{AsH}_{3} / \mathrm{DIPTe}$ molar ratios. Figure 3-10 shows the effect of the DMCd/DIPTe molar ratio on the luminescence of As-doped CdTe films. These films were deposited by using a DIPTe flow rate of $3.6 \times 10^{-5} \mathrm{~mol} / \mathrm{min}$, a $\mathrm{AsH}_{3} / \mathrm{DIPTe}$ molar ratio of 0.45 , and DMCd/DIPTe molar ratios of $0.34,0.68,1.0,2.0$, and 3.0. Without $\mathrm{AsH}_{3}$, the film deposited with a DMCd/DIPTe ratio of 0.34 would be p-type, and the others would be n-type. The $840 \mathrm{~nm}$ band in intrinsic $n$ - and p-films is extinguished by the incorporation of As. An intense luminescent band at about $820 \mathrm{~nm}(1.50 \mathrm{eV})$ appears in the sample deposited with a $\mathrm{DMCd} / \mathrm{DIPT}$ ratio of 0.34 , curve A. A similar band has also been observed in As-doped 


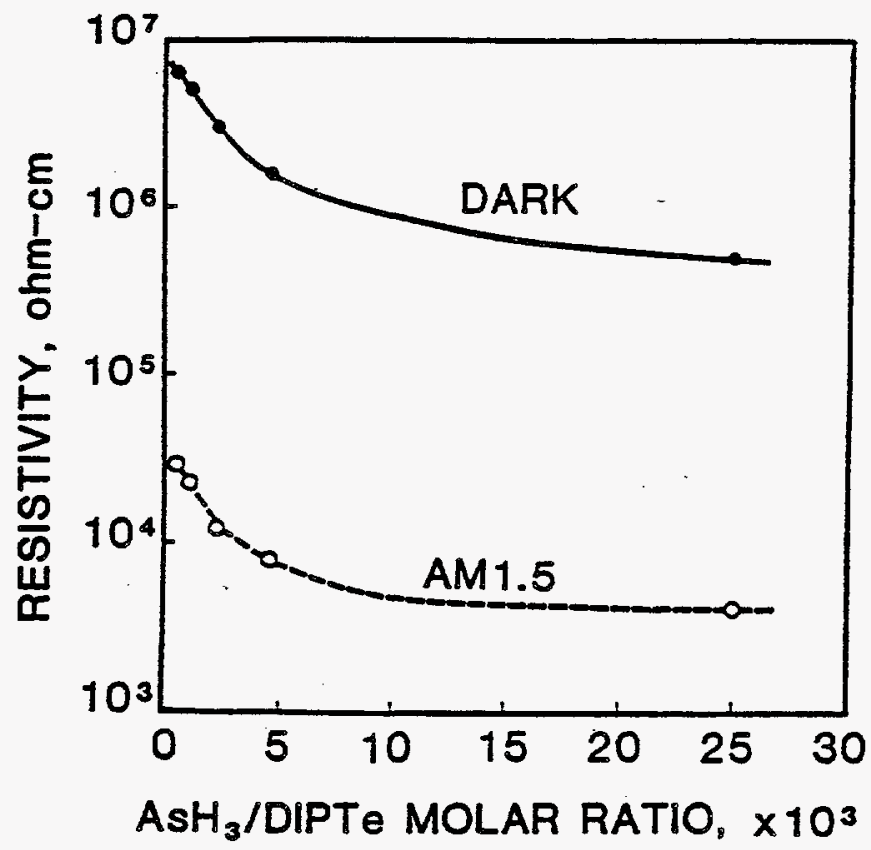

Figure 3-9 Lateral resistivity of As-doped CdTe films, in the dark and under illumination with an ELH lamp at $100 \mathrm{~mW} / \mathrm{cm}^{2}$, versus $\mathrm{AsH}_{3}$ concentration in the reaction mixture

bulk CdTe and As-doped epitaxial CdTe grown by molecular beam epitaxy; this band is associated with the donor-acceptor pair emission. The $820 \mathrm{~nm}$ band is shifted to lower energies as the DMCd/DIPTe ratio in the reaction mixture is increased, curves B, C, D, and E. The 903 and $932 \mathrm{~nm}$ bands associated with the Te vacancies in intrinsic $\mathrm{n}-\mathrm{CdTe}$ are also extinguished by As incorporation.

\subsubsection{Solar Cells}

The CdS/CdTe heterojunction solar cells were prepared by the successive in-situ deposition of 3-4 $\mu \mathrm{m}$ of intrinsic or As-doped CdTe films at $400{ }^{\circ} \mathrm{C}$ and $0.1-0.2 \mu \mathrm{m}$ of As-doped ZnTe at $300^{\circ} \mathrm{C}$ onto $\mathrm{CdS} / \mathrm{SnO}_{2}: \mathrm{F} /$ glass substrates. The CdS film was about $0.1 \mu \mathrm{m}$ in thickness and was briefly etched in diluted hydrochloric acid immediately before being placed in the reaction chamber. Prior to the deposition process, the substrate was heated in $\mathrm{H}_{2}$ at $400^{\circ} \mathrm{C}$ to minimize the extrinsic CdS/CdTe interface states. The in-situ cleaning of the CdS surface strongly affects the properties of the CdS/CdTe junction [38]. With in-situ cleaning, the current-transport process across the junction is controlled by a thermally activated process. Without in-situ cleaning, tunneling makes an important contribution to the interface recombination at temperatures below room temperature. The $\mathrm{p}^{+}$-ZnTe film serves as a low resistance contact to $\mathrm{p}-\mathrm{CdTe}$, and a Ni contact to $\mathrm{ZnTe}$ was deposited by electron beam evaporation. Mesa devices of about $1 \mathrm{~cm}^{2}$ area were prepared by masking and etching; the contact to $\mathrm{SnO}_{2}$ was made using In-solder. The current voltage characteristics of the heterojunctions were measured in the dark and under illumination with ELH lamps at 100 $\mathrm{mW} / \mathrm{cm}^{2}$. A large number of devices were made from intrinsic $\mathrm{p}-\mathrm{CdTe}$ and As-doped CdTe 


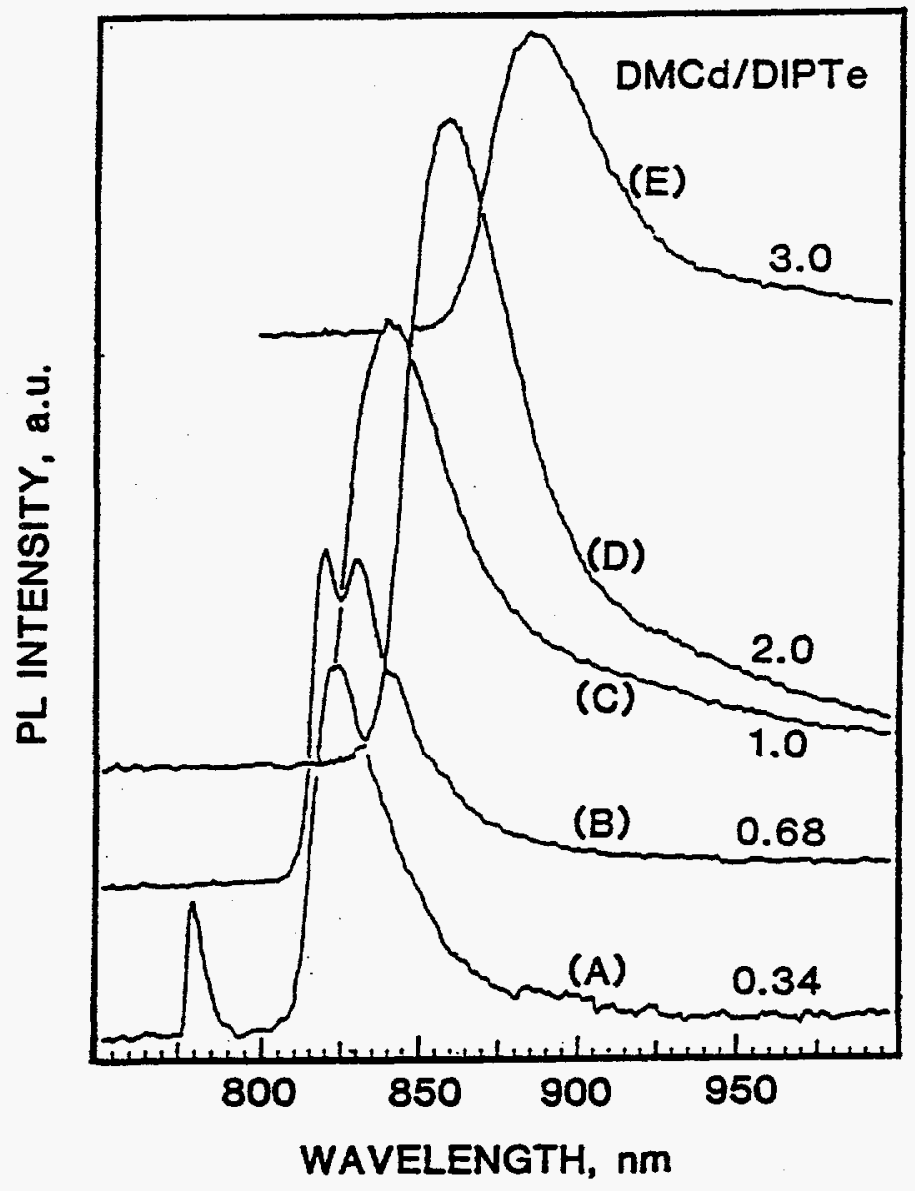

Figure 3-10 Photoluminescence spectra of As-doped CdTe films at 4.2 K deposited by using a AsH H $_{3}$ DIPTe molar ratio of 0.46 and DMCd/DIPTe molar ratios of (A) $0.34,(B) 0.68,(C) 1.0$, (D) 2.0 , and (E) 3.0

films. The saturation current density and diode quality factor measured in the dark are typically $3 \times 10^{-8} \mathrm{~A} / \mathrm{cm}^{2}$ and 1.75 , respectively. Under illumination, the open-circuit voltage is about $530 \mathrm{mV}$, the short-circuit current density is approximately $18 \mathrm{~mA} / \mathrm{cm}^{2}$, the fill factor is $54 \%$, and the shunt resistance under illumination is $200 \mathrm{ohm}-\mathrm{cm}^{2}$. These results suggest that the high saturation current and shunt resistance are related to the poor junction quality and are reflected in the low open-circuit voltage and low fill factor. The poor junction characteristics could be related to the small grain size in MOCVD CdTe films and to the relatively low temperature used in the MOCVD of CdTe. At $400^{\circ} \mathrm{C}$, the reaction between $\mathrm{CdTe}$ and CdS is negligible, and the mismatch in the properties of CdS and CdTe results in a high density of intrinsic interface states. To improve the electrical characteristics of the $\mathrm{CdS} / \mathrm{CdTe}$ junctions, the cadmium chloride $\left(\mathrm{CdCl}_{2}\right)$ treatment was used.

The use of $\mathrm{CdCl}_{2}$ has been known to play an important role in the fabrication of efficient CdS/CdTe solar cells for many years $[39,40,41]$. In the screen printing process, for example, $\mathrm{CdCl}_{2}$ is used as a flux for the sintering of CdS and CdTe films. The sintering of $\mathrm{CdCl}_{2}-$ containing CdS films at $500^{\circ} \mathrm{C}$ has been found to produce significant densification and grain 


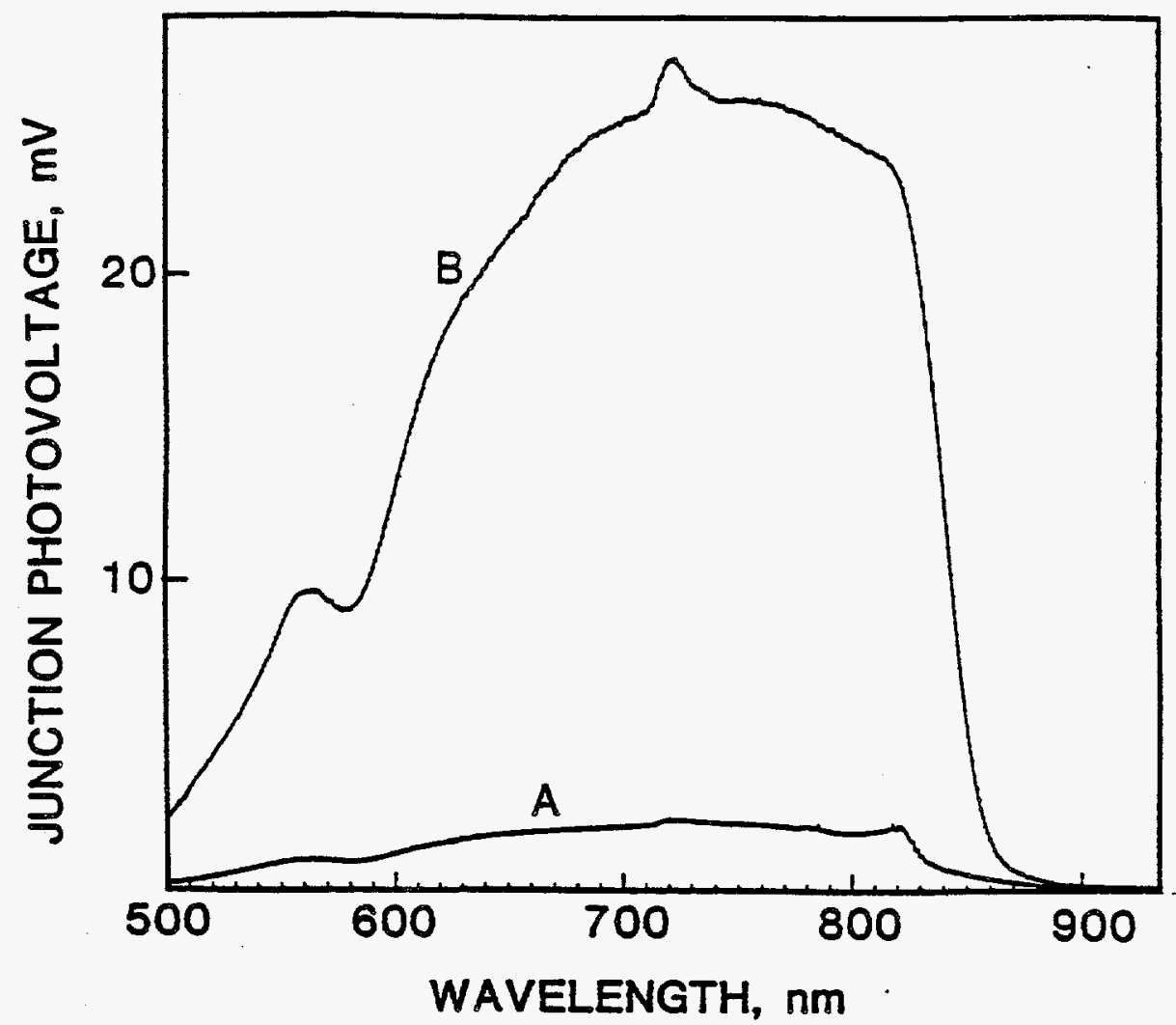

Figure 3-11 Junction photovoltage spectra of a CdS/CdTe junction structure before (A) and after (B) the $\mathrm{CdCl}_{2}$ treatment

growth [42]. The treatment of MBE-grown CdTe films with a methanol solution of $\mathrm{CdCl}_{2}$ followed by heating in air at $400^{\circ} \mathrm{C}$ has been found to increase the grain size of $\mathrm{CdTe}$ and to increase the barrier height of the CdS/CdTe junction [43]. It is also known that $\mathrm{CdS} / \mathrm{CdTe}$ solar cells made from CdTe films of sub-micrometer grain size by electrodeposition and vacuum evaporation require the $\mathrm{CdCl}_{2}$ treatment to achieve reasonable conversion efficiencies.

To carry out the $\mathrm{CdCl}_{2}$ treatment, the CdS/CdTe structures were prepared without the $\mathrm{ZnTe}$ contact, since $\mathrm{ZnTe}$ tends to react with $\mathrm{CdCl}_{2}$ at high temperatures. Subsequently, a $\mathrm{Cu}$ or $\mathrm{Hg}$-doped graphite paste was used as the contact to CdTe. Upon heating, interlayers of $\mathrm{Cu}_{2} \mathrm{Te}$ or $\mathrm{Hg}_{1-x} \mathrm{Cd}_{2} \mathrm{Te}$ of high carrier concentrations are readily formed, facilitating the formation of a low resistance contact. Mesa devices were then prepared. The $\mathrm{CdCl}_{2}$ treatment has been found to significantly improve the magnitude of junction photovoltage as shown in Figure 3-11, where the junction photovoltage spectra of a junction structure before and after $\mathrm{CdCl}_{2}$ treatment are shown. Since the junction photovoltage is measured under open-circuit conditions, the integrated area under the spectrum is related to the open-circuit voltage. When a CdS/n-CdTe structure is subjected to the $\mathrm{CdCl}_{2}$ treatment, the n-CdTe is converted to p-type as shown by junction photovoltage spectroscopy. This is due to the incorporation of oxygen, a shallow acceptor in CdTe, during the heat treatment. The saturation current density and the diode quality factor of $\mathrm{CdCl}_{2}$ 


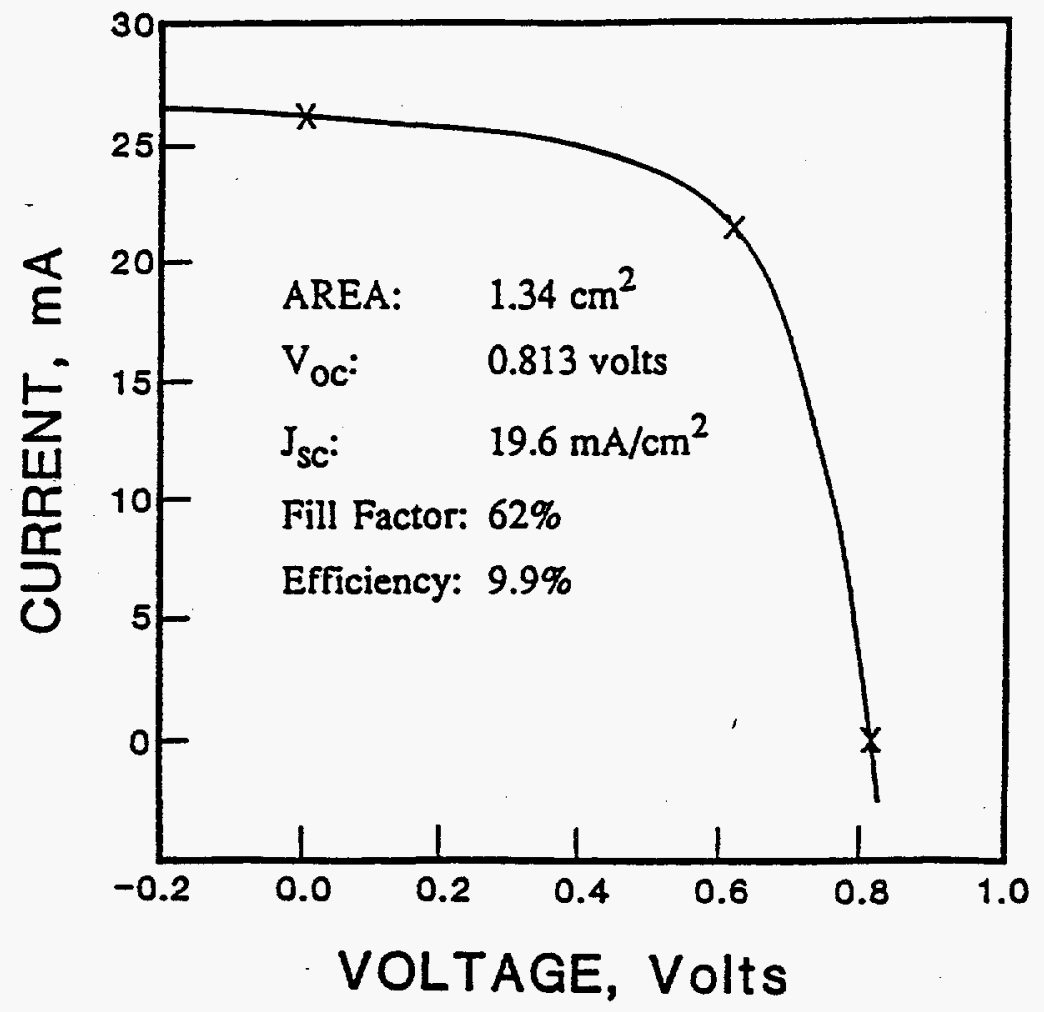

Figure 3-12 Current-voltage characteristics of a CdTe (i,MOCVD)/CdS/SnO glass solar cell under global AM 1.5 conditions

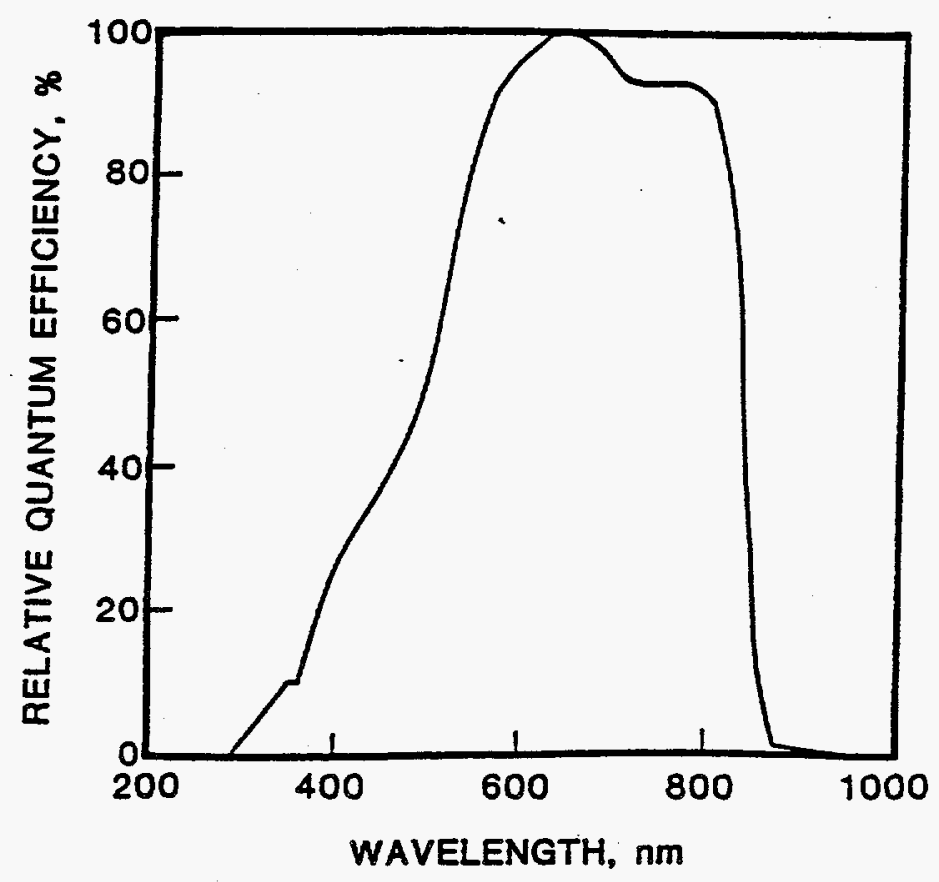

Figure 3-13 The quantum efficiency of the CdS/CdTe solar cell shown in Figure 3-12 
treated junction structures are typically $1.5 \times 10^{-10} \mathrm{~A} / \mathrm{cm}^{2}$ and 1.7 , respectively. Considerable improvements in the photovoltaic parameters have also been observed. Figure 3-12 shows the illuminated current-voltage characteristics of a CdS/CdTe solar cells of $1.3 \mathrm{~cm}^{2}$ area under global AM 1.5 conditions measured at the National Renewable Energy Laboratory. The open-circuit voltage, short-circuit current density, and fill factor are $0.813 \mathrm{~V}, 19.6$ $\mathrm{mA} / \mathrm{cm}^{2}$, and $62 \%$, respectively, corresponding to a conversion efficiency of $9.9 \%$. The shunt resistant under illumination is about $650 \mathrm{ohm}-\mathrm{cm}^{2}$. This is believed to be the first report of a near $10 \%$ large area CdS/CdTe solar cell prepared from MOCVD CdTe. The quantum efficiency of the above solar cell, also measured at the Solar Energy Research Institute, is shown in Figure 3-13. The relatively low quantum efficiency in the blue region suggests that a reduction in the thickness of CdS film could improve the conversion efficiency of the solar cell.

The $\mathrm{CdCl}_{2}$ treated junction structures show a lower carrier concentration in $\mathrm{CdTe}$ as compared with the as-deposited structures. The hole concentration in the $\mathrm{CdCl}_{2}$ treated structures, deduced from capacitance-voltage measurements, is (1-3) $\times 10^{14} \mathrm{~cm}^{-3}$, as compared with about $10^{15} \mathrm{~cm}^{-3}$ in as-deposited structures (the C-V measurements on asdeposited structures were not precise because of the excessive noise).

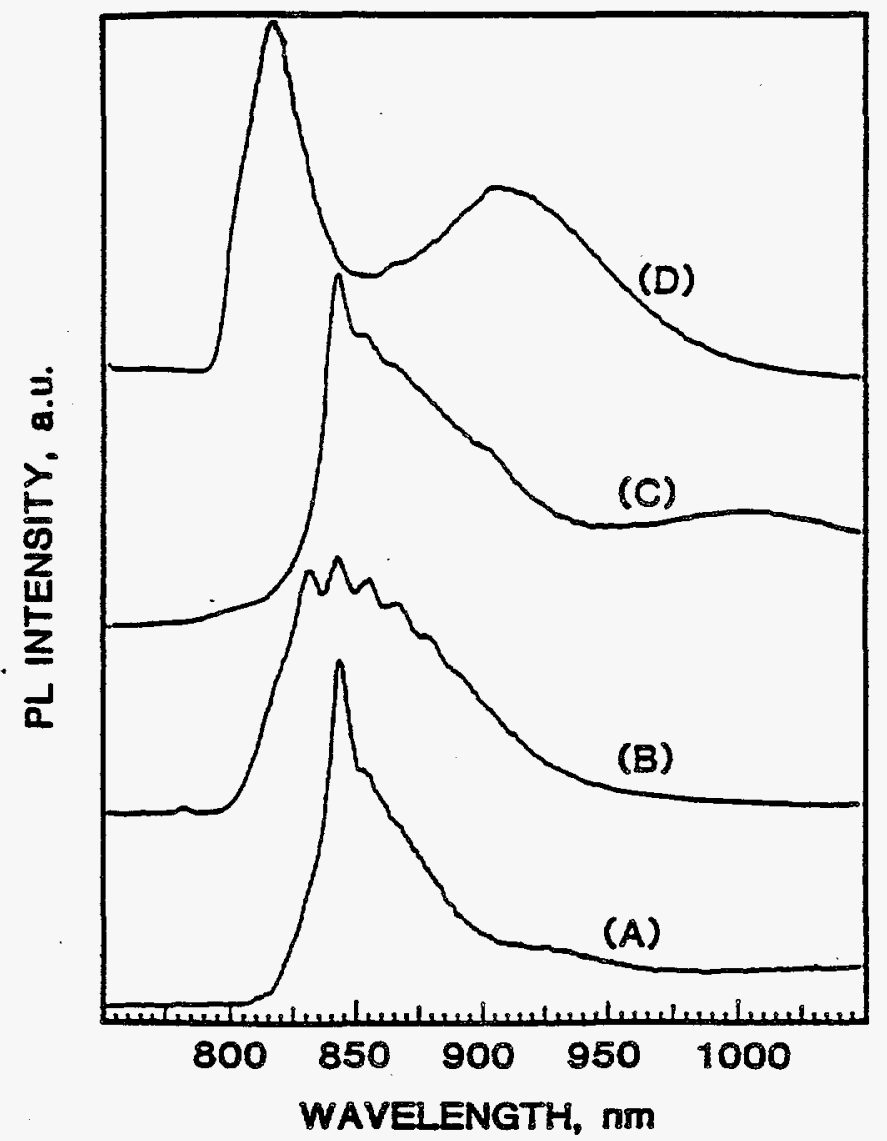

Figure 3-14 Photoluminescence spectra of (1) an as-deposited $\mathrm{CdTe}(\mathrm{MOCVD}) / \mathrm{CdS} / \mathrm{SnO}_{2}: \mathrm{F} /$ glass structure, illuminated from the $\mathrm{CdTe}(\mathrm{A})$ and the glass (C) surfaces, and (2) a $\mathrm{CdCl}_{2}$ treated structure illuminated from the CdTe (B) and the glass (D) surfaces 
The effect of the $\mathrm{CdCl}_{2}$ treatment of CdS/CdTe solar cells has been investigated using photoluminescence and DLTS measurements. Figure 3-14 shows the luminescence spectra of as-deposited and $\mathrm{CdCl}_{2}$ treated $\mathrm{CdTe} / \mathrm{CdS} / \mathrm{SnO}_{2}: \mathrm{F} /$ glass structures obtained by impinging the $484 \mathrm{~nm}$ radiation from an argon ion laser on the surface of CdTe and on the surface of glass. When the CdTe surface is illuminated, essentially all laser radiation is absorbed by CdTe since the thickness of CdTe, 3-4 $\mu \mathrm{m}$, is much larger than the absorption length of $\mathrm{CdTe}$ at $484 \mathrm{~nm}$. When the glass surface is illuminated, the laser radiation is absorbed by the CdS film, the CdS/CdTe interface region, and the portion of CdTe near the interface. The luminescence spectrum obtained by exciting the CdTe surface of the as-deposited structure, curve A, consists of several overlapping bands with the major band at $840 \mathrm{~nm}$. This band is present in all intrinsic $n$ - and p-CdTe films. When the glass surface of the asdeposited structure is illuminated, the spectrum is essentially unchanged except that a weak, broad band appears at about $1000 \mathrm{~nm}$, curve $C$. Thus, the CdS film and the CdS/CdTe interface make negligible contribution to the luminescence spectrum. After $\mathrm{CdCl}_{2}$ treatment, the $840 \mathrm{~nm}$ band in the as-deposited structure becomes several overlapping bands, curve B, which have been shown to be present in bulk CdTe crystals annealed in a $\mathrm{Cd}$ atmosphere [44]. This result suggests the incorporation of $\mathrm{Cd}$ into the CdTe film during $\mathrm{CdCl}_{2}$ treatment. The $\mathrm{CdCl}_{2}$ treatment also resulted in pronounced change in the spectrum by exciting the glass surface of the structure, curve $D$. The $840 \mathrm{~nm}$ band is shifted to higher energy, and more importantly, a broad band at about $900 \mathrm{~nm}$ is observed. This band must be associated with the $\mathrm{CdS} / \mathrm{CdTe}$ interface. Presumably, the $\mathrm{CdCl}_{2}$ treatment induced a reaction between $\mathrm{CdS}$ and $\mathrm{CdTe}$ at the interface producing a thin interlayer of $\mathrm{CdS}_{\mathrm{x}} \mathrm{Te}_{1-x}$ which accounts for the $900 \mathrm{~nm}$ band. The formation of this interlayer causes the movement of the heterojunction from the metallurgical interface into CdTe, improving the electrical characteristics of the CdS/CdTe junction.

The effects of $\mathrm{CdCl}_{2}$ treatment on the properties of $\mathrm{CdS} / \mathrm{CdTe}$ structures were also evaluated by DLTS measurements. Figure 3-15 shows the DLTS spectra of a CdS/CdTe junction structure before and after $\mathrm{CdCl}_{2}$ treatment. The data were obtained with a reverse bias of $2.0 \mathrm{~V}$ pulsed to $0.0 \mathrm{~V}$ for $10 \mathrm{msec}$, and the spectra obtained with a rate window of $80 \mathrm{sec}^{-1}$. In the as-deposited sample, a hole trap is located at $\mathrm{Ev}+0.52 \mathrm{eV}$ with a density of $6 \times 10^{12} \mathrm{~cm}^{-3}$. After the $\mathrm{CdCl}_{2}$ treatment, this state is replaced by one at $\mathrm{Ev}+0.63 \mathrm{eV}$ with a density of $2 \times 10^{12} \mathrm{~cm}^{-3}$. This state has also been observed in $\mathrm{CdCl}_{2}$ treated MBEgrown CdS/CdTe and is presumably related to doubly-ionized Cd vacancies or singly-ionized cadmium vacancy-halogen complexes, such as $\left(\mathrm{V}_{\mathrm{Cd}} \mathrm{Cl}\right)^{-1}$.

Thin film CdTe homojunctions were prepared by the successive in-situ deposition of 0.1 $0.2 \mu \mathrm{m}$ of Ga-doped CdTe and 3-4 $\mu \mathrm{m}$ of As-doped CdTe films at $400{ }^{\circ} \mathrm{C}$ and $0.1-0.2 \mu \mathrm{m}$ of $\mathrm{p}^{+}-\mathrm{ZnTe}$ film at $300^{\circ} \mathrm{C}$ onto $\mathrm{SnO}_{2}: \mathrm{F} /$ glass substrates. The $\mathrm{CdTe}: \mathrm{Ga} / \mathrm{SnO}_{2}: \mathrm{F}$ structure is known to have an ohmic interface. After the deposition of $\mathrm{Ni}$ contact to $\mathrm{ZnTe}$, mesa devices were prepared by masking and etching in the same manner described previously. The homojunction structures have been found to have a saturation current density of about $4 \times 10^{-8} \mathrm{~A} / \mathrm{cm}^{2}$ and a diode quality factor of 1.88 , similar to the as-deposited heterojunctions. Under illumination, the open-circuit voltage and short-circuit current density are 


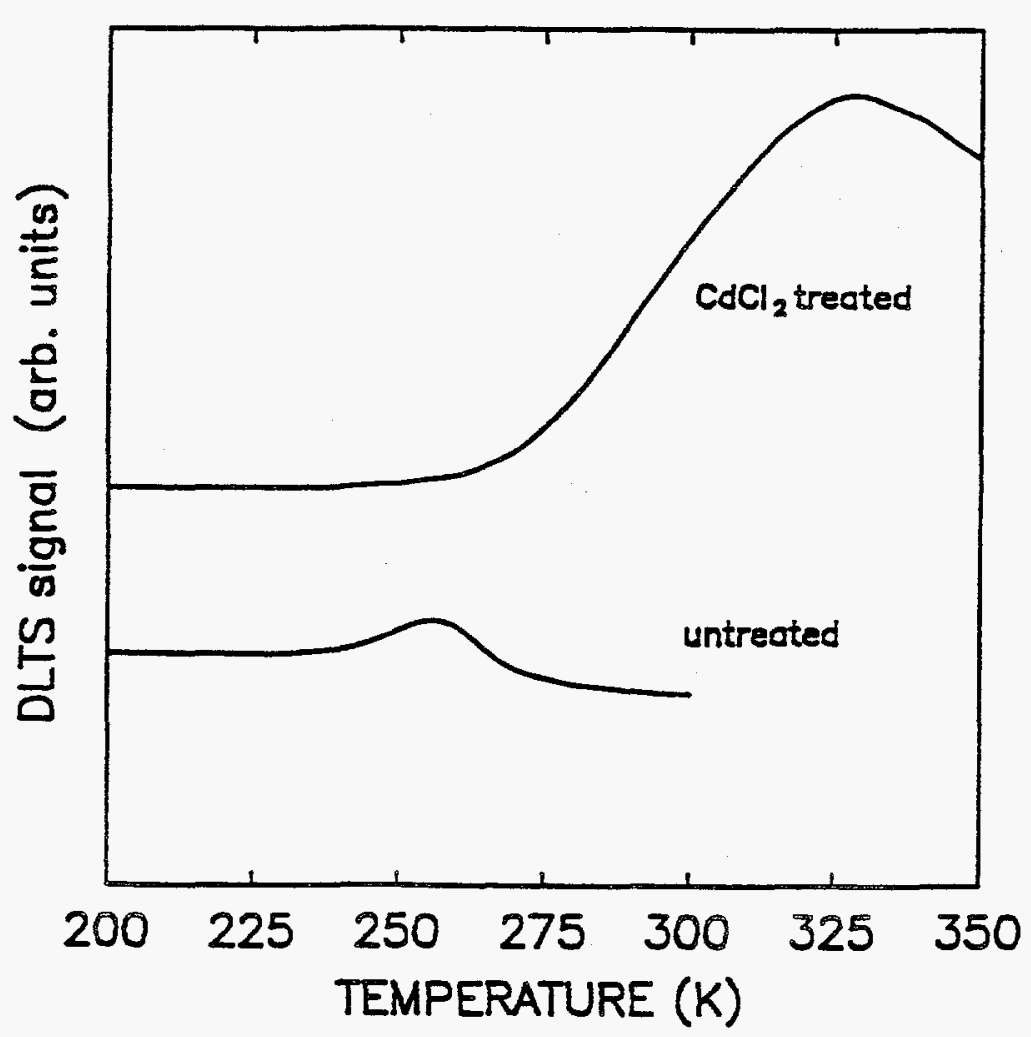

Figure 3-15 DLTS spectra of a CdS/CdTe junction structure before and after the $\mathrm{CdCl}_{2}$ treatment

approximately $480 \mathrm{mV}$ and $15 \mathrm{~mA} / \mathrm{cm}^{2}$, respectively. The relatively poor characteristics are presumably related to the poor microstructure of MOCVD CdTe films. Attempts to improve the junction characteristics by $\mathrm{CdCl}_{2}$ treatment were not successful due to the disturbance of the homojunction structure by $\mathrm{CdCl}_{2}$.

\subsection{CLOSE-SPACED SUBLIMATION (CSS)}

The deposition of CdTe films by the close-spaced sublimation (CSS) technique is based on the reversible dissociation of CdTe at high temperatures:

$$
2 \operatorname{CdTe}(\mathrm{s})=\mathrm{Cd}(\mathrm{g})+\mathrm{Te}_{2}(\mathrm{~g})
$$

The source material is maintained at a higher temperature than the substrate. The source CdTe dissociates into its elements, which recombine on the substrate surface depositing CdTe films. The dissociation pressure of CdTe at a given temperature is defined by the relation:

$$
K_{C d T e}(T)=\left(p^{\circ} C_{d}\right)\left(p^{\circ}{ }_{T e_{2}}\right)^{1 / 2}
$$


where the $p^{\circ} s$ are the equilibrium partial pressures at temperature $T$. The $p^{\circ} s$ increase exponentially with increasing temperature. The equilibrium partial pressure of $\mathrm{Te}_{2}$ has been calculated to be $2.6 \times 10^{-7}, 7.8 \times 10^{-6}$, and $1.2 \times 10^{-4} \mathrm{~atm}$. at $500^{\circ}, 600^{\circ}$, and $700^{\circ} \mathrm{C}$, respectively (the equilibrium partial pressure of $\mathrm{Cd}$ at a given temperature is twice that of $\mathrm{Te}_{2}$ ). Thus, the rate of $\mathrm{CdTe}$ deposition depends strongly on the source temperature and the gas pressure in the reaction tube.

\subsubsection{Deposition Process}

The substrates used for the deposition of $\mathrm{CdTe}$ films were: Corning 7059 glass, $\mathrm{SnO}_{2}: \mathrm{F} /$ glass (sheet resistance of about 10 ohms per square, prepared by the thermal oxidation of tetramethyltin with oxygen using Freon as a dopant), and $\mathrm{TCS} / \mathrm{SnO}_{2}: \mathrm{F} /$ glass (the $\mathrm{SnO}_{2}: \mathrm{F}$ films were used to reduce the sheet resistance of the TCS film; CdS, $\mathrm{ZnO}, \mathrm{ZnSe}$, and $\mathrm{SnO}_{2}$ were used as TCSs).

The apparatus used for the deposition of CdTe films by the CSS technique is shown schematically in Figure 3-16. The substrate and source, separated by $0.1-0.2 \mathrm{~cm}$ and supported by appropriate holders, were enclosed in a controlled atmosphere in a fused silica tube provided with gas inlet and outlet tubes. They were maintained at desired temperatures by using quartz lamps, and thermocouples inserted into the holders were used to control their temperatures (due to the location of the thermocouples, the true temperature of the source is lower than the temperature indicated by the thermocouple, and that of the substrate is higher than the temperature indicated by the thermocouple). Since

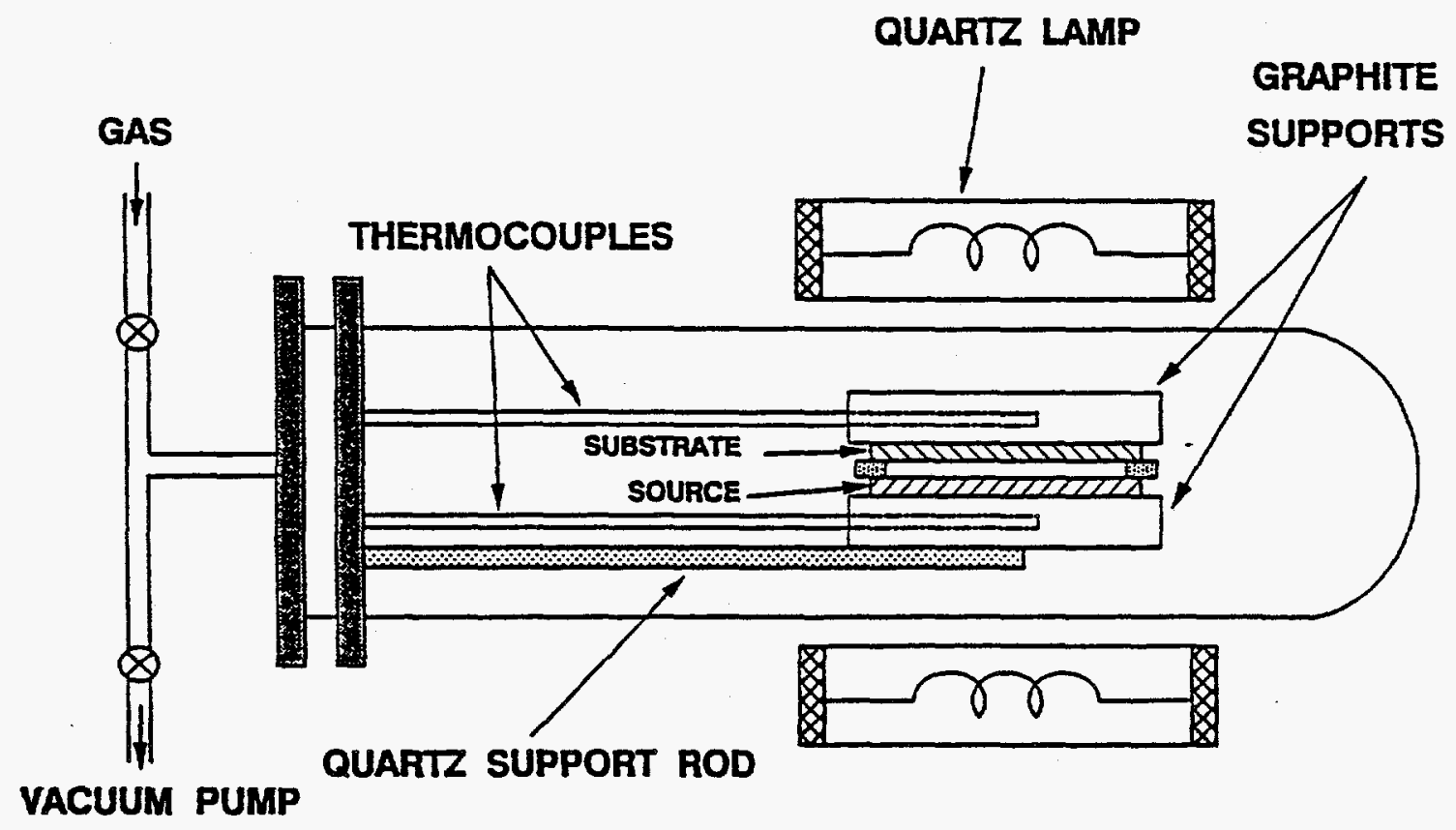

Figure 3-16 Schematic diagram of the apparatus for the deposition of CdTe films by the CSS technique 
the spacing between the source and substrate is less than a few percent of the dimension of the substrate, the material transport conditions are largely independent of conditions elsewhere in the system. The CSS process is essentially diffusion-limited, and the closespacing of source and substrate provides direct transport of each component of the source across the space to the substrate.

The CSS technique involves several interrelated parameters, such as the temperatures of the source and the substrate, the separation between the source and the substrate, ambience in the reaction tube, the pressure in the reaction tube, the composition of the source material, etc. For example, the pressure in the reaction tube is important in determining the rate of deposition; at a given source temperature, the sublimation rate increases rapidly as the pressure in the reaction tube is reduced from the atmospheric pressure. Thus, the rate of deposition may be controlled by controlling the pressure in the reaction tube while other parameters are held constant. Figure 3-17 shows the deposition rate of CdTe films as a function of the reciprocal argon pressure in the reaction tube, where the substrate and source were separated by $2 \mathrm{~mm}$, and their temperatures were $600^{\circ}$ and $680^{\circ} \mathrm{C}$, respectively. The deposition rate of CdTe films is inversely proportional to the pressure in the reaction tube and can be varied between 0.5 to $3 \mu \mathrm{m} / \mathrm{min}$. The linear relation between deposition rate and reciprocal pressure is also observed in a $\mathrm{He}$ atmosphere. Under the same conditions, the deposition rate of CdTe films in $\mathrm{He}$ is nearly twice of that in Ar due presumably to the fact that the thermal conductivity of $\mathrm{He}$ is about ten times of the conduc-

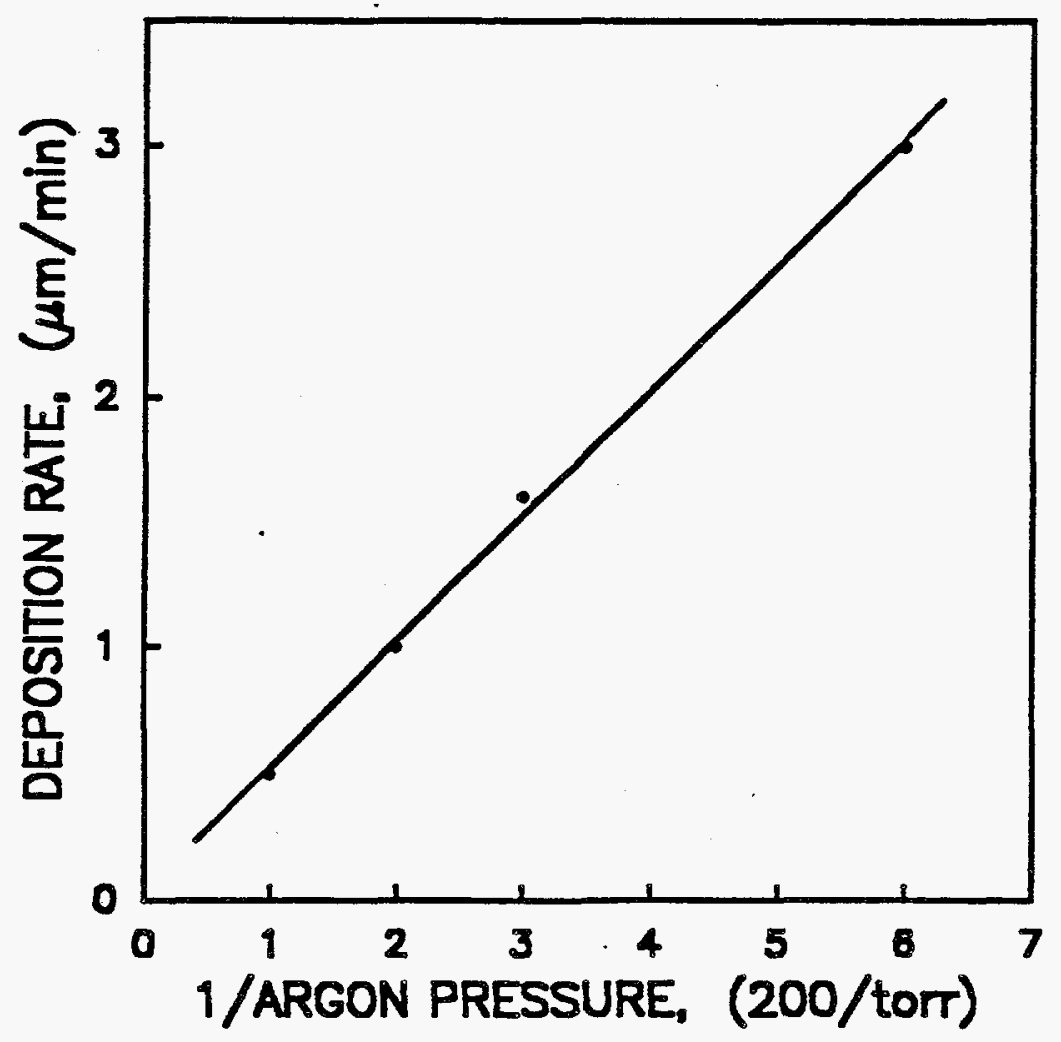

Figure 3-17 Deposition rate of CdTe films as a function of argon pressure in the CSS process 
tivity of Ar. The deposition rate of CdTe films also depends strongly on the source temperature since the rate of sublimination of the CdTe source is a major factor determining the rate of deposition. Using 30 Torr of $\mathrm{Ar}$ in the reaction tube and maintaining substrate temperature at $80^{\circ} \mathrm{C}$ below the source temperature, the deposition rate is an exponential function of the source temperature, being -3.3 and $1.7 \mu \mathrm{m} / \mathrm{min}$ at source temperatures of $680^{\circ}$ and $650^{\circ} \mathrm{C}$, respectively.

The microstructure of CdTe films is determined by the substrate temperature, sourcesubstrate temperature gradient, and the crystallinity of the substrate. In general, the grain size increases with increasing substrate temperature and increasing film thickness. For example, the grain size increases from about $1 \mu \mathrm{m}$ in films deposited at $500^{\circ} \mathrm{C}$ to $2-3 \mu \mathrm{m}$ in films deposited at $550^{\circ} \mathrm{C}$ and to $3-5 \mu \mathrm{m}$ in films deposited at $600^{\circ} \mathrm{C}$. The films also show improved grain structures with well-developed faces as the deposition temperature is increased. CdTe films deposited by CSS show considerably larger grains than those by MOCVD because of the higher temperature used in the CSS process. Figure 3-18 shows the scanning electron micrographs of the chemically etched surface of CdTe films deposited by CSS and MOCVD techniques; etching of the as-deposited surface of CdTe films with a $\mathrm{K}_{2} \mathrm{Cr}_{2} \mathrm{O}_{7}+\mathrm{H}_{2} \mathrm{SO}_{4}$ solution makes the grain boundaries more distinguishable. The microstructure of CdTe films deposited by CSS is significantly better than that by MOCVD, average grain size being $4-5 \mu \mathrm{m}$ and $1-2 \mu \mathrm{m}$ in CSS and MOCVD films, respectively. The crystallographic properties of CdTe films were determined by the x-ray diffraction technique using $\mathrm{CuK} \alpha$ radiation. Polycrystalline CdTe powder of random orientation is known to show three strong diffraction peaks associated with $\{111\},\{220\}$, and $\{311\}$ reflections with relative intensities of 100,62 , and 28 , respectively. The diffraction spectra of CdTe films were obtained by scanning $2 \theta$ in the range of $20^{\circ}-50^{\circ}$. Figure $3-19$ shows
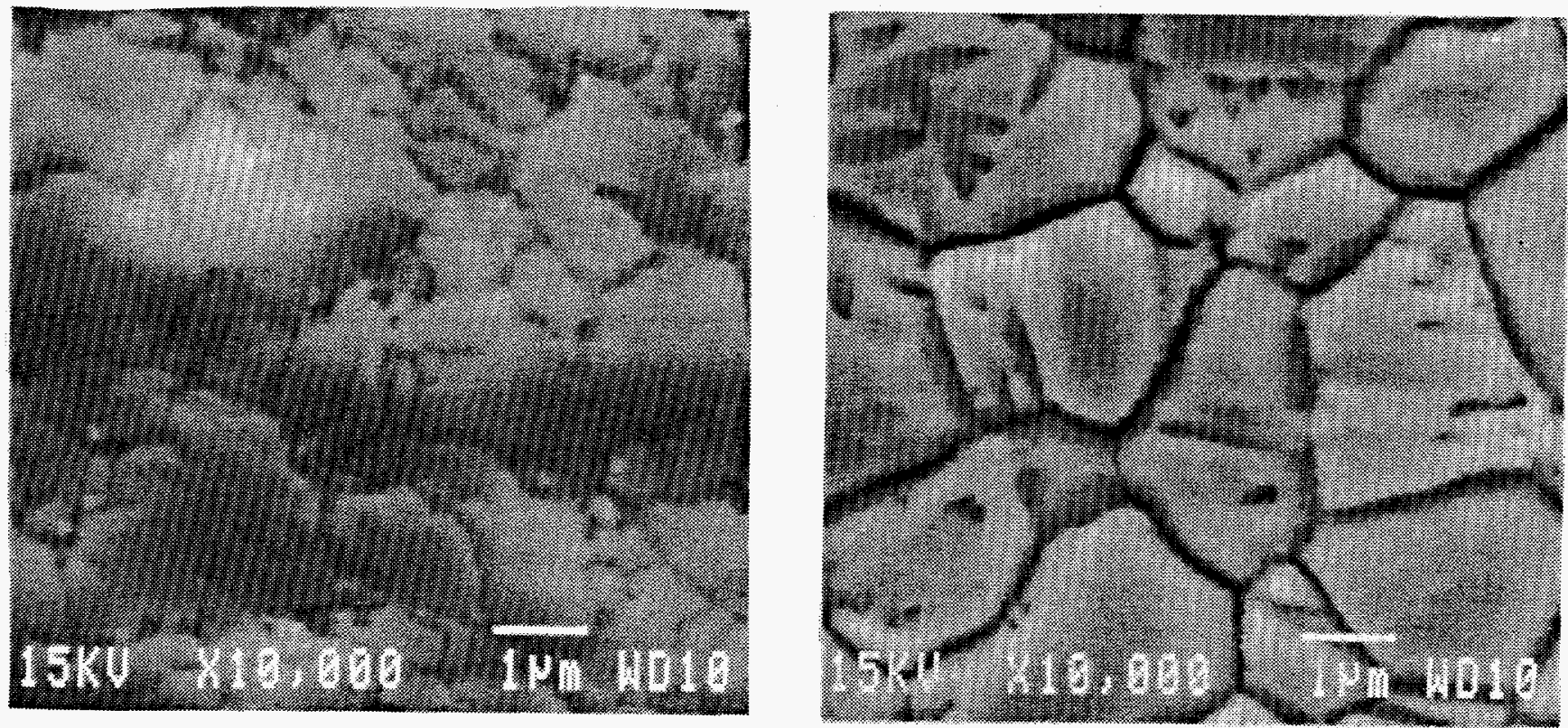

Figure 3-18 Scanning electron micrographs of the chemically etched surface of CdTe films deposited by CSS (left) and MOCVD (right) techniques. 
the diffraction spectra of CdTe films deposited by CSS and MOCVD techniques. While the CdTe films deposited by MOCVD shows a strong $\{111\}$ preferred orientation, that by CSS is of random orientation. This difference is again due to the difference in deposition temperature.

\subsubsection{Solar Cells}

Thin film CdTe solar cells have been prepared by the deposition of CdTe films on four window materials: $\mathrm{CdS}, \mathrm{ZnO}, \mathrm{ZnSe}$, and $\mathrm{SnO}_{2}$. The $\mathrm{CdS} / \mathrm{CdTe}$ cells are significantly superior to others in characteristics.
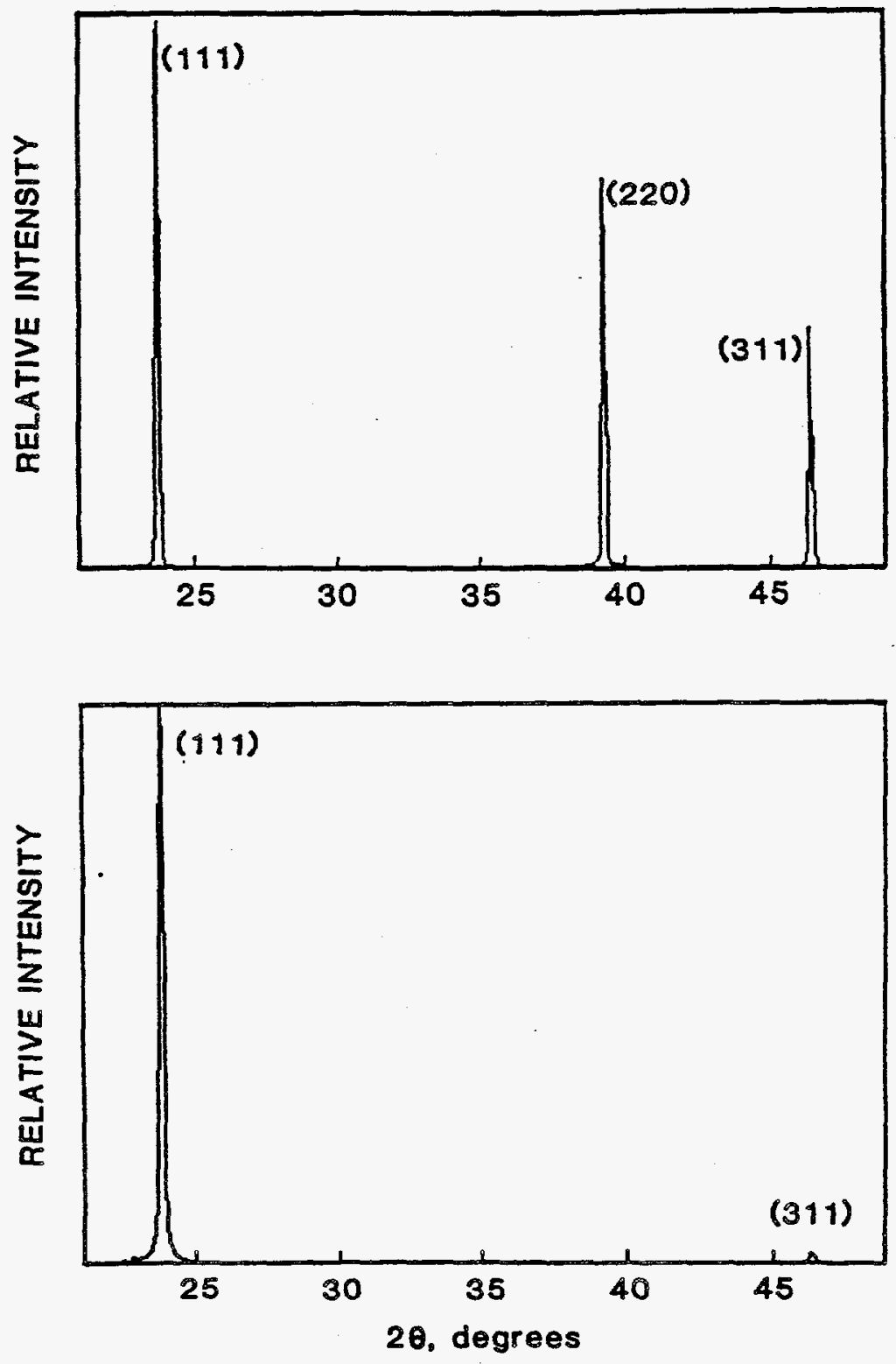

Figure 3-19 X-ray diffraction spectra of CdTe films deposited by CSS (upper) and MOCVD (lower) techniques. 
CdS films of $500-800 \AA$ thickness grown on $\mathrm{SnO}_{2}: \mathrm{F} /$ glass substrates from an aqueous solution were used as substrates for the deposition of p-CdTe films by CSS. Because of the relatively high rate of the CSS process, 3-4 minutes are sufficient for the deposition of $4-5 \mu \mathrm{m}$ of CdTe. Ohmic contacts to CdTe were made by the deposition of $\mathrm{p}^{+} \cdot \mathrm{ZnTe}$ at $300^{\circ} \mathrm{C}$ (Section 4.1) or by using a graphite paste doped with $\mathrm{Cu}^{++}$or $\mathrm{Hg}^{++}$, followed by heat treatment. Figure 3-20 shows the dark current-voltage characteristics of a typical solar cell, where the saturation current density and diode quality factor are approximately $6 \times 10^{-11} \mathrm{~A} / \mathrm{cm}^{2}$ and 1.65 , respectively. The illuminated characteristics of many solar cells of larger than $1 \mathrm{~cm}^{2}$ area have been measured under global AM 1.5 conditions at the Solar Energy Research Institute; conversion efficiencies higher than $13.5 \%$ have been obtained. The glass surface of the multilayer structure is highly reflective, the reflection loss (specular and diffuse) is nearly $10 \%$ in the $300.900 \mathrm{~nm}$ range, depending on wavelength. By using $\mathrm{MgF}_{2}$ as the antireflection coating, the conversion efficiency of a solar cell has been increased to $14.6 \%$, as shown in Fig. 3-21. The quantum efficiency of this solar cell is shown in Fig. 3-22.

The conversion efficiency of CdS/CdTe solar cells with the CdTe film deposited by CSS is considerably higher than that by MOCVD due mainly to the difference in the structure of CdTe films. CdTe films deposited by the CSS technique show considerably larger grains and better microstructures than those by the MOCVD technique, and as a result, the CdS/CdTe (CSS) junctions have significantly lower saturation current density than CdS/CdTe (MOCVD) junctions.

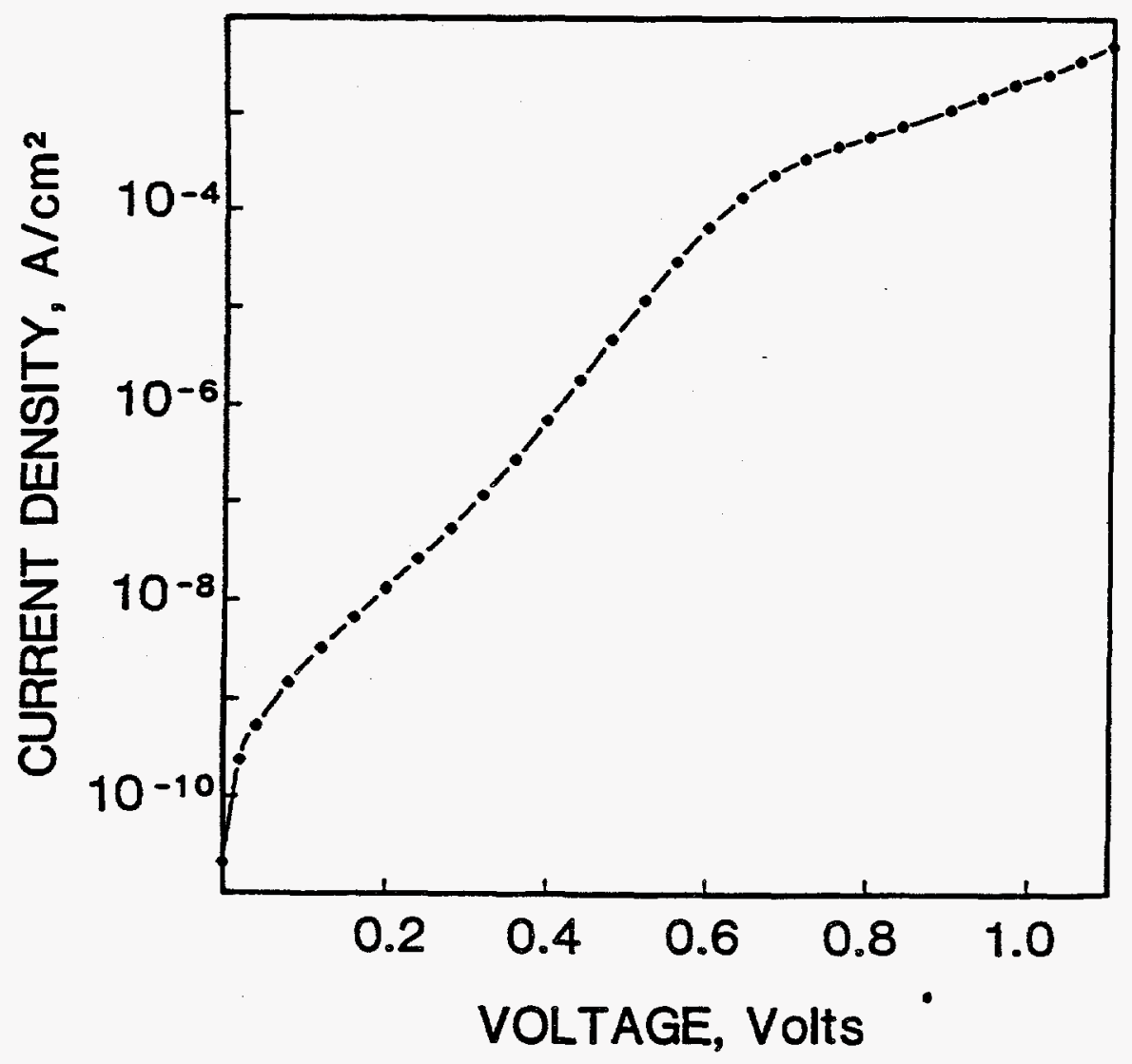

Figure 3-20 Dark current-voltage characteristics of a CdTe (CSS)/CdS/SnO $:$ F/glass solar cell. 


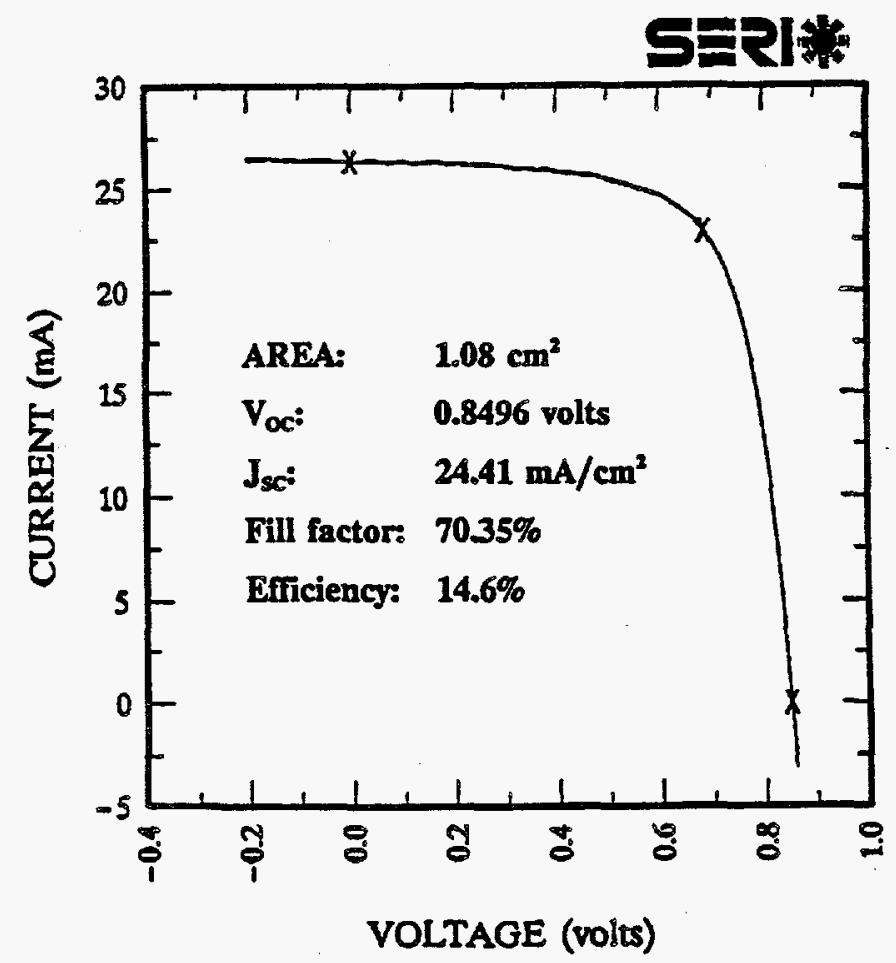

Figure 3-21 Current-voltage characteristics of a CdTe(CSS)/CdS/SnO $2: \mathrm{F} / \mathrm{glass} / \mathrm{MgF}_{2}$ solar cell under global AM 1.5 conditions.

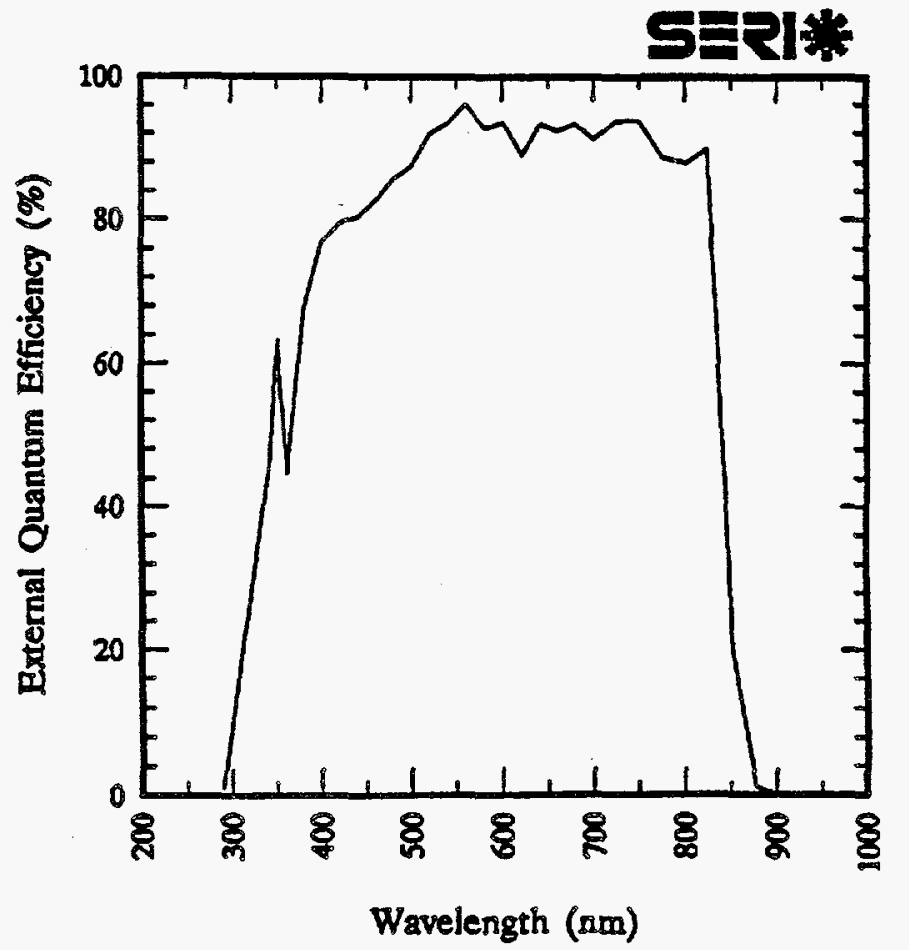

Figure 3-22 The quantum efficiency of the CdS/CdTe solar cell shown in Figure 3-21. 
Thin film CdTe solar cells prepared by using other TCS's, such as $\mathrm{ZnO}, \mathrm{ZnSe}$, and $\mathrm{SnO}_{2}$, have considerably lower photovoltage, $650 \mathrm{mV}$ or lower, than CdS/CdTe solar cells. The high conversion efficiency of CdS/CdTe solar cells appears to be related to the interface reaction between $\mathrm{CdS}$ and CdTe. The formation of $\mathrm{CdS}_{\mathrm{x}} \mathrm{Te}_{1-\mathrm{x}}$ shifts the electrical junction from the metallurgical interface into CdTe, thus improving the electrical and photovoltaic characteristics of the junction.

The deep energy states in CdTe films deposited by CSS have been measured by using a Polaron S 4600 Modular DLTS system. The Cds/CdTe junction was reverse biased at $4 \mathrm{~V}$ and the spectra measured with various rate windows. Three major states with activation energies of $0.46,0.79$, and $0.85 \mathrm{eV}$ have been observed. Their densities are relatively low, on the order of $10^{13} \mathrm{~cm}^{-3}$. 


\section{SECTION 4.0}

\section{ZINC TELLURIDE FILMS AND SOLAR CELLS}

Zinc telluride ( $\mathrm{ZnTe}$ ), a direct gap semiconductor with a room temperature bandgap energy of $2.25 \mathrm{eV}$, is a promising photonic material. Single crystals of $\mathrm{ZnTe}$ have been grown from the melt, from a tellurium or a zinc chloride solution, and from the vapor phase. They always exhibit p-type conductivity due to the high degree of self-compensation of incorporated donors by native defects. ZnTe crystals are readily doped by shallow acceptors, such as phosphorus and arsenic with activation energies of 63 and $73 \mathrm{meV}$, respectively.

Zinc telluride is a potential thin film photovoltaic material. Although its bandgap energy is too high as an absorber for solar cells, the solid solutions of $\mathrm{ZnTe}$ and $\mathrm{HgTe}$ or CdTe with bandgap energies of $1.65-1.75 \mathrm{eV}$ are promising candidates for the upper cell of a two-cell tandem structure. Also, the simplicity of the fabrication of thin film $\mathrm{ZnTe}$ heterojunction solar cells could be most economical when used in conjunction with a 1.0 $1.1 \mathrm{eV}$ cell. However, very limited information on $\mathrm{ZnTe}$ films is available. The deposition of $\mathrm{ZnTe}$ films by the direct combination of elemental vapors [46], vacuum evaporation, and close-spaced vapor transport [47] has been reported. In this program, $\mathrm{ZnTe}$ films have been prepared by metalorganic chemical vapor deposition (MOCVD) and photoenhanced metalorganic chemical vapor deposition (PEMOCVD), with emphasis on the latter. Their structural, optical, and electrical properties have been characterized. The experimental procedures and results are discussed in this section.

\subsection{DEPOSITION PROCESS}

Thin films of II-VI compounds can be deposited at relatively low temperatures by metalorganic chemical vapor deposition (MOCVD) because of the thermal instability of the metalorganic precursors [48]. Further, nearly all metalorganic precursors absorb strongly in the far ultraviolet region [49] by single or multi-photon processes, resulting in the excitation of these molecules to higher electronic states or their dissociation to free radicals. The products of photo-excitation or photo-dissociation then react chemically with other species, reducing the temperature required for the dissociation process. The PEMOCVD process has been used for the expitaxial growth of several II-VI compounds, such as mercury telluride and mercury cadmium telluride [50,51].

The reaction between dimethylzinc (DMZn) or diethylzinc (DEZn) and diisopropyltellurium (DIPTe), has been used for the deposition of $\mathrm{ZnTe}$ films on the surface of heated substrates in $\mathrm{H}_{2}$ under atmospheric pressure. Arsine $\left(\mathrm{AsH}_{3}\right)$ was used as a dopant to control the electrical resistivity of $\mathrm{ZnTe}$ films. The substrates included Corning 7059, fluorine-doped tin oxide-coated glass ( $\mathrm{SnO}_{2} \circ \mathrm{F} /$ glass), and cadmium sulfide coated $\mathrm{SnO}_{2} \circ \mathrm{F} /$ glass, all of $3 \mathrm{x}$ $3 \mathrm{~cm}$ in area. CdS films were deposited on $\mathrm{SnO}_{2}: \mathrm{F} /$ glass substrates by the solution growth process (Section 2.1). A p-n beterojunction can be conveniently formed by depositing $\mathrm{ZnTe}$ films on a CdS-coated substrate. The ultraviolet radiation was provided by a $3 \mathrm{~kW}$ 
microwave-excited $\mathrm{Hg}$-Xe light source with a high spectral irradiance in the far ultraviolet region, about $450 \mathrm{~W}$ in the wavelength range of $200-300 \mathrm{~nm}$. The reaction chamber for the deposition process, made of fused silica, is shown schematically in Figure 4-1. It is equipped with a $3^{\text {n }}$ diameter Suprasil II window, gas inlet and outlet tubes, and purging gas for minimizing the deposition on the window. The substrates were supported on a silicon or silicon carbide-coated graphite block, heated by a tungsten-halogen quartz lamp. A thermocouple with its tip in contact with the surface of the substrate was used to control the substrate temperature. The organic precursors were introduced into the reaction chamber by using hydrogen as a carrier gas. The important process parameters are the substrate temperature and the composition and flow rate of the reaction mixture. The deposition experiments were carried out at substrate temperatures in the range of $270^{\circ}-350^{\circ} \mathrm{C}$. Because of the use of relatively low temperatures, the composition of the reaction mixture is important in that no free $\mathrm{Zn}$ or $\mathrm{Te}_{2}$ deposits on the substrate. $\mathrm{ZnTe}$ is a stable compound with negligible dissociation pressure at $350^{\circ} \mathrm{C}$ or below. If an excess of $\mathrm{DEZn}, \mathrm{DMZn}$, or DIPTe is present in the reaction mixture, the partial pressure of the excess of that element must be less than its equilibrium vapor pressure at the substrate temperature to prevent its deposition on the substrate surface. It is also important that the formation of $\mathrm{ZnTe}$ takes place predominately on the substrate surface, and the homogeneous nucleation can be minimized by using low concentrations of the organic precursors in the reaction mixture.

In all deposition experiments, the flow rate of hydrogen was $4.5 \mathrm{\ell} / \mathrm{min}$, the partial pressure of DEZn (or DMZn) was fixed at $1.5 \times 10^{-4} \mathrm{~atm}$, and the partial pressure of DIPTe was

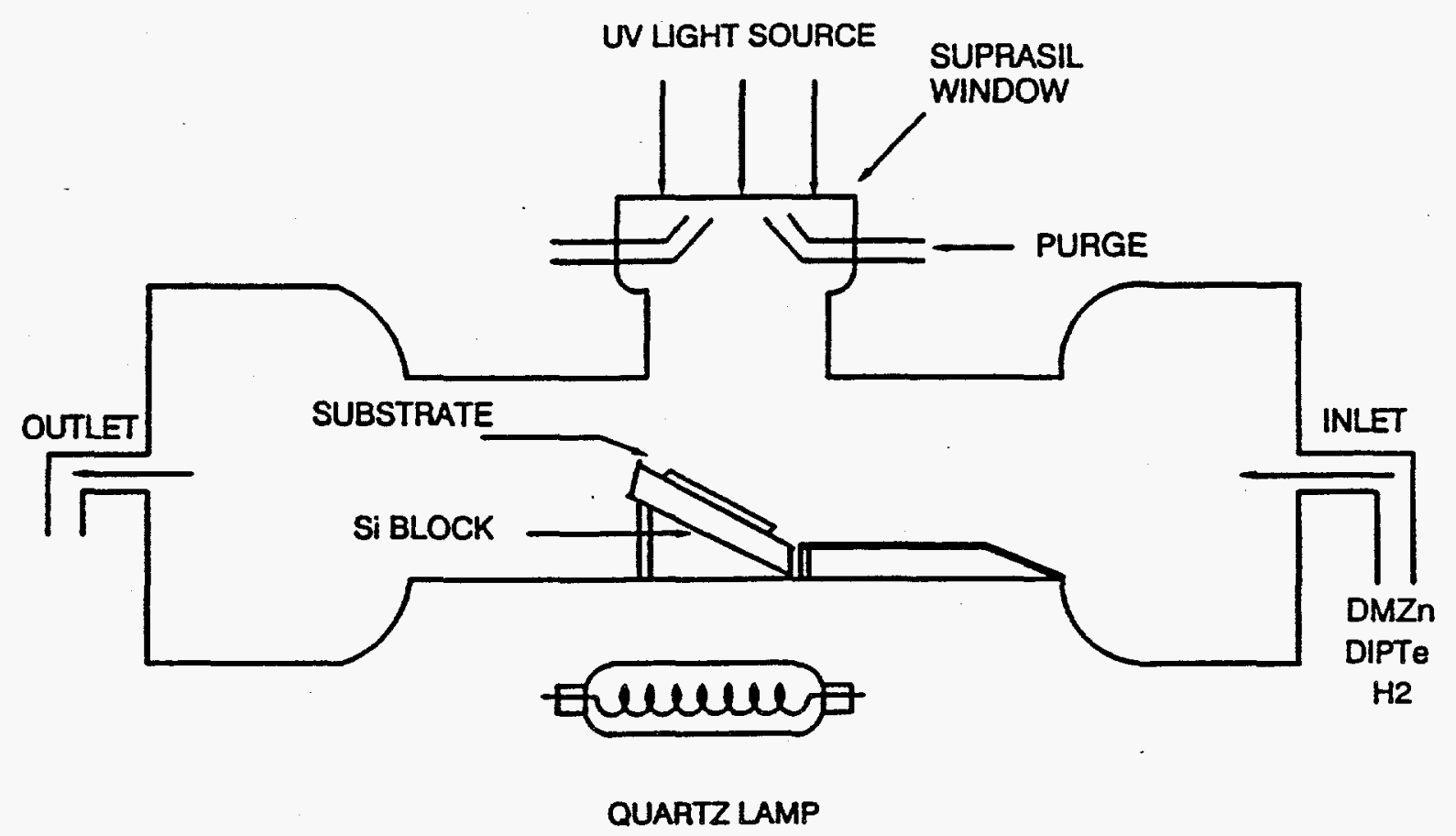

Figure 4-1 Schematic diagram of the deposition chamber for the photoenhanced metalorganic chemical vapor deposition of $\mathrm{ZnTe}$ films 
varied in the range of $1.25 \times 10^{-4}-3 \times 10^{-4}$ atm, yielding a DEZn/DIPTe molar ratios of 0.5 - 1.2. The flux of photons with wavelength in the $200-300 \mathrm{~nm}$ range is many times higher than the flux of organic precursors at the substrate surface.

The $\mathrm{SnO}_{2}: \mathrm{F} /$ glass substrates were found to be unstable at $350^{\circ} \mathrm{C}$ under the conditions used due mainly to the reduction of $\mathrm{SnO}_{2}$. The $\mathrm{CdS} / \mathrm{SnO}_{2}: \mathrm{F} /$ glass substrates must be heated at $400^{\circ} \mathrm{C}$ or higher before the deposition of $\mathrm{ZnTe}$ films to minimize the interface reaction, as shown by junction photovoltage measurements. Graphite paste was applied to the surface of a $\mathrm{ZnTe}$ film deposited on a $\mathrm{CdS} / \mathrm{SnO}_{2}: \mathrm{F} /$ glass substrate to form a graphite/ $\mathrm{ZnTe} / \mathrm{CdS} / \mathrm{SnO}_{2} \cdot \mathrm{F} /$ glass structure, where the graphite $/ \mathrm{ZnTe}$ and $\mathrm{CdS} / \mathrm{SnO}_{2}$ junctions are ohmic, and silver paste was used as an ohmic contact to $\mathrm{SnO}_{2}$. Figure 4-2 shows the junction photovoltage spectra of two $\mathrm{ZnTe} / \mathrm{CdS} / \mathrm{SnO}_{2}: \mathrm{F} /$ glass samples in the wavelength range of 500-1000 $\mathrm{nm}$ obtained by illuminating the glass surface with a tungsten-halogen lamp (the CdS film is essentially transparent because of its small thickness, 800 to $1000 \AA$ ). Sample A was prepared by depositing $\mathrm{ZnTe}$ films on an as-deposited CdS surface whereas in sample $\mathrm{B}$, the $\mathrm{CdS} / \mathrm{SnO}_{2}: \mathrm{F} /$ glass substrate was heated at $400^{\circ} \mathrm{C}$ prior to deposition. The

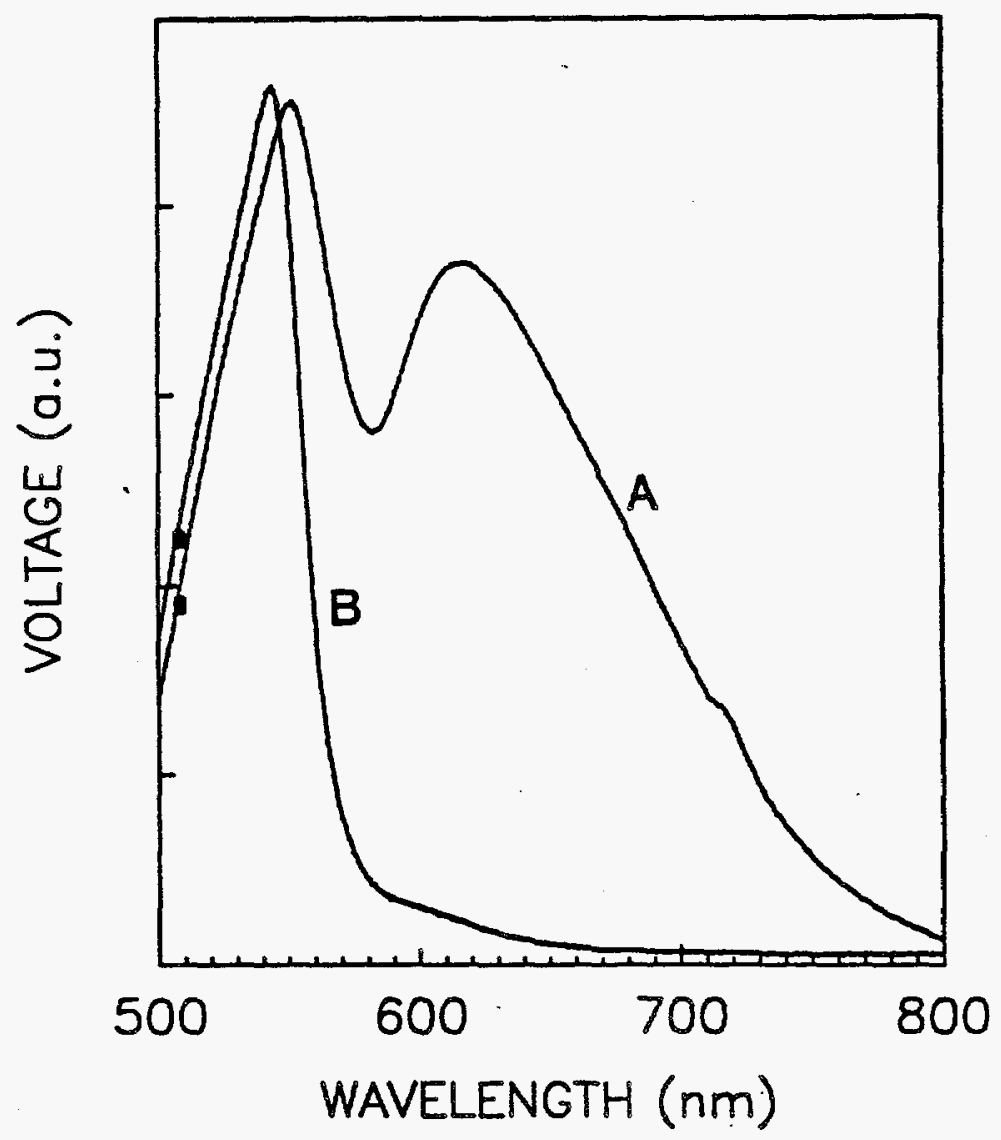

Figure 4-2 Junction photovoltage spectra of two $\mathrm{ZnTe} / \mathrm{CdS} / \mathrm{SnO}_{2}: \mathrm{F} /$ glass structures prepared from (A) as-deposited CdS, and (B) heat treated CdS 
Junction photovoltage spectrum of the $\mathrm{ZnTe} / \mathrm{CdS}$ structure is determined mainly by the properties of $\mathrm{ZnTe}$, such as optical absorption spectrum, depletion region width, minority carrier diffusion length, etc. Since the minority carrier diffusion length in the $\mathrm{ZnTe}$ film is presumably smaller than the absorption length, the carriers generated by longer wavelength radiation is not completely collected. Thus, the photoresponse near the bandedge does not show an abrupt cut-off as in single crystalline material. However, the bandgap energy can be estimated from the photon energy at which the photoresponse changes abruptly. The bandgap energy of $\mathrm{ZnTe}$ films in sample B deduced from the junction photovoltage spectrum is about $2.15 \mathrm{eV}$. However, the photoresponse cut-off in the spectrum of sample $\mathrm{A}$ is more gradual and is considerably lower than the bandgap energy of $\mathrm{ZnTe}$, indicating a chemical reaction between $\mathrm{CdS}$ and $\mathrm{ZnTe}$ during the deposition process. Apparently, the solution grown CdS is chemically reactive, and its reactivity is reduced by heat treatment.

At $350^{\circ} \mathrm{C}$ and a DEZn partial pressure of $1.5 \times 10^{-4} \mathrm{~atm}$, the deposition rate of $\mathrm{ZnTe}$ films is $2-3 \mu \mathrm{m} / \mathrm{hr}$ depending on the DEZn/DIPTe molar ratio in the reaction mixture. The deposition rate of $\mathrm{ZnTe}$ films from $\mathrm{DMZn}$ and DIPTe is similar, although $\mathrm{DMZn}$ is more stable than $\mathrm{DEZn}$, indicating that $\mathrm{DMZn}$ and $\mathrm{DEZn}$ decompose to a similar extent in this photoenhanced process. The deposition rate of $\mathrm{ZnTe}$ at $270^{\circ} \mathrm{C}$ is lower than that at $350^{\circ} \mathrm{C}$ due to the greater stability of DIPTe.

The optimum composition of the reaction mixture for the deposition of $\mathrm{ZnTe}$ films was determined from the open-circuit voltage measurements of $\mathrm{ZnTe} / \mathrm{CdS} / \mathrm{SnO}_{2}: \mathrm{F} /$ glass structures. The electrical properties of the $\mathrm{ZnTe} / \mathrm{CdS}$ heterojunction is determined mainly by the quality of the $\mathrm{ZnTe}$ film since the carrier concentration in CdS is considerably higher. The open-circuit voltage of the heterojunctions was measured by illuminating the glass surface with an ELH lamp at $100 \mathrm{~mW} / \mathrm{cm}^{2}$. Figure 4-3 shows the open-circuit voltage of $\mathrm{ZnTe} / \mathrm{CdS}$ heterojunctions deposited at $350^{\circ} \mathrm{C}$ as a function of the DMZn/DIPTe molar ratio in the reaction mixture. The observed photovoltage is significantly lower than one would expect from the bandgap energy of $\mathrm{ZnTe}$. This is due presumably to the large difference in the electron affinity of CdS $(4.5 \mathrm{eV})$ and $\mathrm{ZnTe}(3.5 \mathrm{eV})$, resulting in a conduction band discontinuity of $1 \mathrm{eV}$. The barrier height, and therefore the photovoltage at the junction is reduced. Nevertheless, the open-circuit voltage provides a reasonable comparison of the quality of $\mathrm{ZnTe}$ films prepared under different conditions.

The maximum open-circuit voltage is observed in a $\mathrm{ZnTe}$ film deposited with a $\mathrm{DMZn/DIPTe}$ molar ratio of about 0.9 , which is presumably the optimum composition of the reaction mixture for the deposition process.

\subsection{PROPERTIES}

The ZnTe films deposited by PEMOCVD are adherent to the substrates and are essentially stoichiometric within experimental errors of electron microprobe analysis. The films are polycrystalline with submicrometer size grains, and the grains do not show any crystallographic features. They have a columnar structure, as observed from the etched vertical cross-sectioned surfaces. 


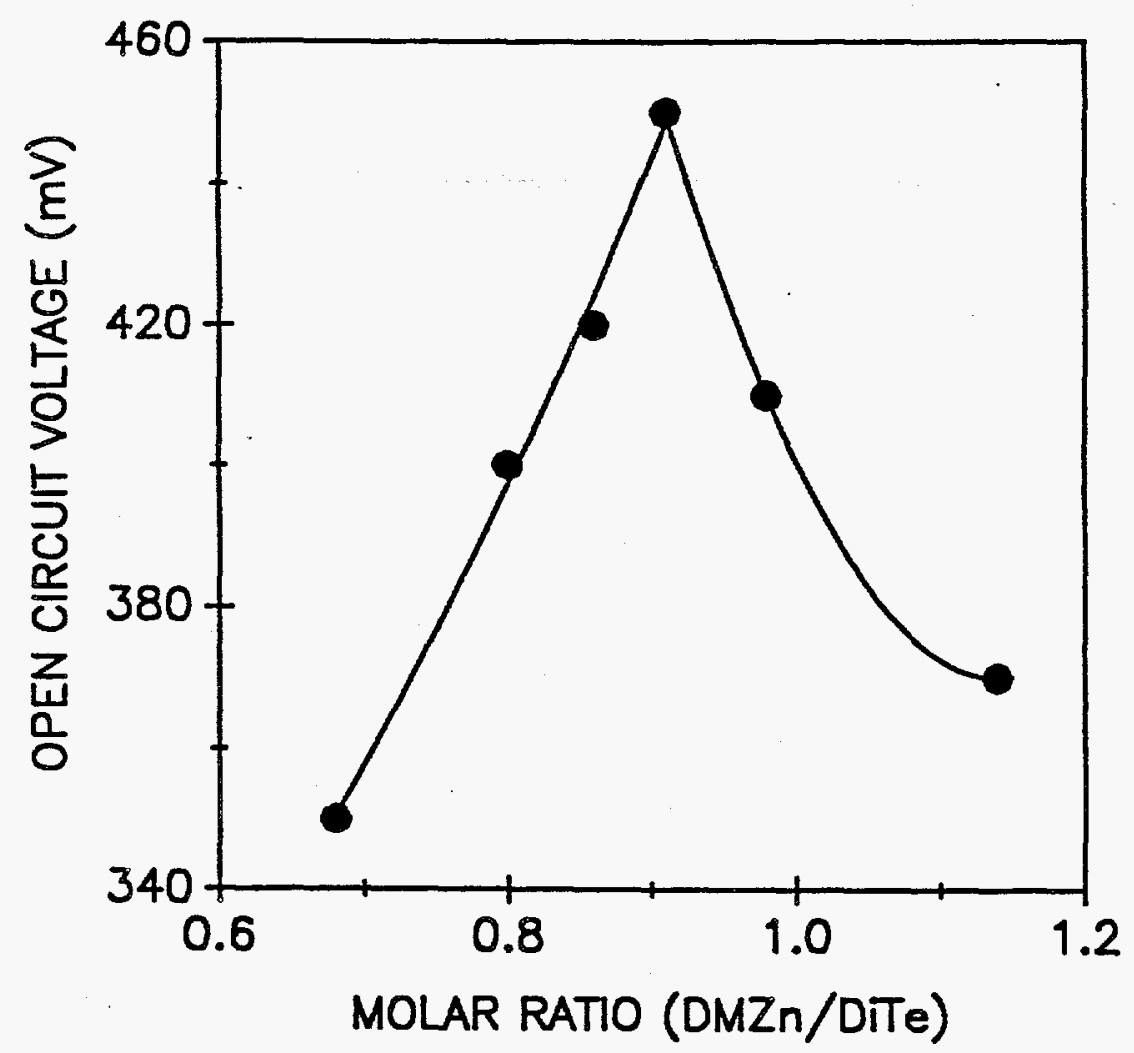

Figure 4-3 Open-circuit voltage of $\mathrm{ZnTe} / \mathrm{CdS} / \mathrm{SnO}_{2}: \mathrm{F} /$ glass structures as a fuction of the reactant composition used for the deposition of $\mathrm{ZnTe}$

The crystallographic properties of $\mathrm{ZnTe}$ films were determined by the x-ray diffraction technique using $\mathrm{CuK} \alpha$ radiation. $\mathrm{ZnTe}$ crystallizes in the zincblende structure. Polycrystalline $\mathrm{ZnTe}$ powder of random orientation is known to show a number of diffraction peaks, as summarized in Table 4-1. The diffraction spectra of $\mathrm{ZnTe}$ films were obtained by scanning $2 \theta$ in the range of $20^{\circ}-60^{\circ}$. A typical spectrum is shown in Figure $4-4$, where the (111) diffraction is particularly strong, indicating a preferred $\{111\}$ orientation.

The optical absorption of $\mathrm{ZnTe}$ films deposited on glass substrates was measured at room temperature using a Varian Model Cary 17D spectrophotometer. The transmission of subbandgap radiation is about $80 \%$ due mainly to the reflection loss at the $\mathrm{ZnTe} /$ glass interface. The optical bandgap energy of $\mathrm{ZnTe}$, deduced from the square of the absorption coefficient versus photon energy plot, is $2.23 \mathrm{eV}$.

All ZnTe films are of p-type conductivity. The dark lateral resistivity of $\mathrm{ZnTe}$ films deposited on glass substrates at $350^{\circ} \mathrm{C}$ was measured by the conventional potential probe technique using graphite paste contacts. The measurements were carried out in a screened enclosure because of the high sheet resistance of $\mathrm{ZnTe}$ films. All films deposited with no intentional doping have high lateral resistivity, $10^{7}-10^{8} \mathrm{ohm}-\mathrm{cm}$, essentially independent of the DEZn/DIPTe molar ratio in the reaction mixture, as shown in Figure 4-5, where the 
Table 4-I Powder diffraction data of ZnTe

d hil $\quad$ I/Io

$\begin{array}{llc}3.523 & 111 & 100 \\ 3.051 & 200 & 10 \\ 2.159 & 220 & 80 \\ 1.840 & 311 & 35 \\ 1.762 & 222 & 4 \\ 1.526 & 400 & 8 \\ 1.4003 & 331 & 14 \\ 1.3645 & 420 & 4 \\ 1.2456 & 422 & 10\end{array}$

effects of illumination and heat treatment are also shown. ELH lamps were used to illuminate the sample at an irradiance of $100 \mathrm{~mW} / \mathrm{cm}^{2}$. The dark resistivity/illuminated resistivity ratios are relatively low, about 20 , in all as-deposited $\mathrm{ZnTe}$ films, and the maximum photoconductivity ratio is observed in $\mathrm{ZnTe}$ films deposited at a DMZn/DIPTe molar ratio of about 0.9 , similar to the results of the open-circuit voltage measurements of $\mathrm{ZnTe} / \mathrm{CdS}$ heterojunctions. The resistivity of as-deposited $\mathrm{ZnTe}$ films has been found to

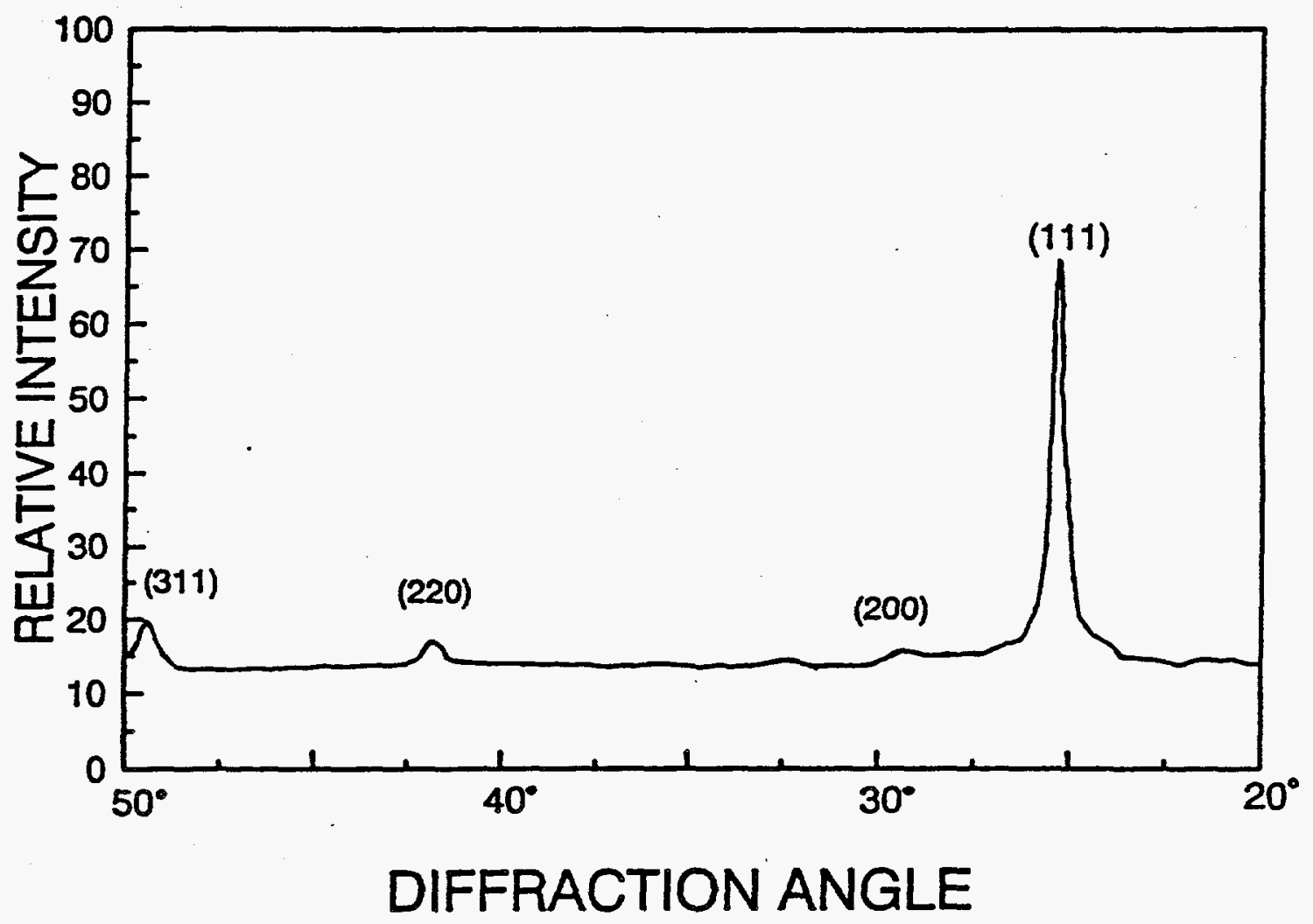

Figure 4-4 X-ray diffraction spectrum of a ZnTe film deposited on a glass substrate at $350^{\circ} \mathrm{C}$ 
be reduced by heat treatment in a helium atmosphere, and the photoconductivity ratio also increased. This is due presumably to the diffusion of interstitial $\mathrm{Zn}$ or $\mathrm{Te}$ atoms to lattice positions.

The lateral resistivity of $\mathrm{ZnTe}$ films can be significantly reduced by using $\mathrm{AsH}_{3}$ as a dopant during the deposition process. Figure 4-6 shows the resistivity of As-doped $\mathrm{ZnTe}$ films, deposited at $350^{\circ} \mathrm{C}$ at a DEZn/DIPTe molar ratio of about 0.9 as a function of the concentration of $\mathrm{AsH}_{3}$ in the reaction mixture. ZnTe films with dark resistivities of $10 \mathrm{ohm}$ $\mathrm{cm}$ or lower have been deposited. Figure 4-7 shows the temperature dependence of the resistivity of an As-doped film in the temperature range of $300-400 \mathrm{~K}$. Two activation energies, 0.11 and $0.33 \mathrm{eV}$, were deduced. Neglecting the temperature dependence of hole mobility, which is small in the temperature range under consideration [52], these activation energies may be correlated with the ionization processes. The $0.11 \mathrm{eV}$ energy is presumably associated with the ionization of $\mathrm{As}$ in $\mathrm{ZnTe}$, and the $0.33 \mathrm{eV}$ energy is most likely to be associated with grain boundaries.

The photoluminescence of $\mathrm{ZnTe}$ films deposited from reaction mixtures with various $\mathrm{DMZn} / \mathrm{DIPT}$ molar ratios was measured at $4.2 \mathrm{~K}$, using the apparatus described in Section 3.1.2. Figure 4-8 shows the luminescence spectra of four $\mathrm{ZnTe}$ films deposited at $350^{\circ} \mathrm{C}$ by using DMZn/DIPTe molar ratios of $0.65,0.83,1.03$, and 1.29. The films deposited with a

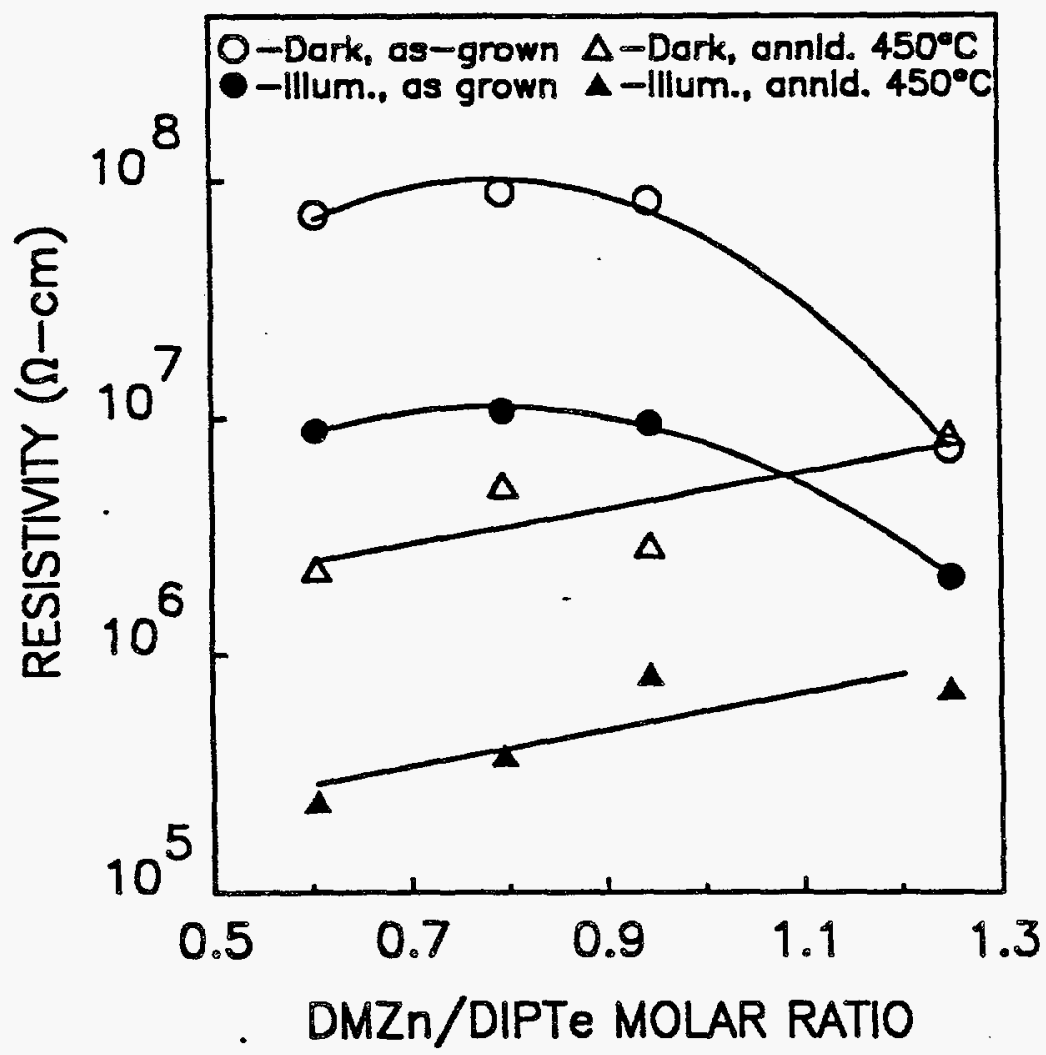

Figure 4-5 Lateral resistivity of $\mathrm{Zn}$ 'Te films versus the reactant composition in the dark and under illumination with ELH lamps at $100 \mathrm{~mW} / \mathrm{cm}^{2}$ 
ratio of higher than about 0.9 presumably contain zinc interstitials or tellurium vacancies and those deposited with a ratio of lower than about 0.9 presumably contain zinc vacancies or tellurium interstitials. Four bands at about $540,570,590$, and $650 \mathrm{~nm}$ are observed. The bands at 540 and $590 \mathrm{~nm}$ are present in all films and are presumably associated with common defects and impurities. The band at $570 \mathrm{~nm}$ has the highest intensity in the film deposited with a DMZn/DIPTe molar ratio of 0.69 and is presumably due to transitions involving $\mathrm{Zn}$ vacancies, and its intensity decreases with increasing molar ratio. The intensity of the band at $650 \mathrm{~nm}$ decreases with decreasing DMZn/DIPTe molar ratios, similar to that observed in $\mathrm{ZnTe}$ films grown on GaAs substrates by molecular beam epitaxy. All these bands become indistinguishable in arsenic doped ZnTe films, and only a broad band appears at about $830 \mathrm{~nm}$ due to banding of dopant atoms, as shown in Figure 4-9.

\subsection{SOLAR CELLS}

The bandgap energy of $\mathrm{ZnTe}$ at room temperature is $2.25 \mathrm{eV}$, and the short-circuit current density of an ideal ZnTe solar cell under global AM 1.5 conditions is about $9.4 \mathrm{~mA} / \mathrm{cm}^{2}$. Efficient thin film $\mathrm{ZnTe}$ heterojunction solar cells require window materials with large bandgap energy. The TCS's used in this work included $\mathrm{SnO}_{2}, \mathrm{ZnO}, \mathrm{Cd}_{0.7} \mathrm{Zn}_{0.3} \mathrm{~S}(\mathrm{Eg} \sim 2.8$ $\mathrm{eV}$ ), and $\mathrm{ZnSe}$. $\mathrm{SnO}_{2}$ and $\mathrm{ZnO}$, with bandgap energy of 4.4 and $3.3 \mathrm{eV}$, respectively, are

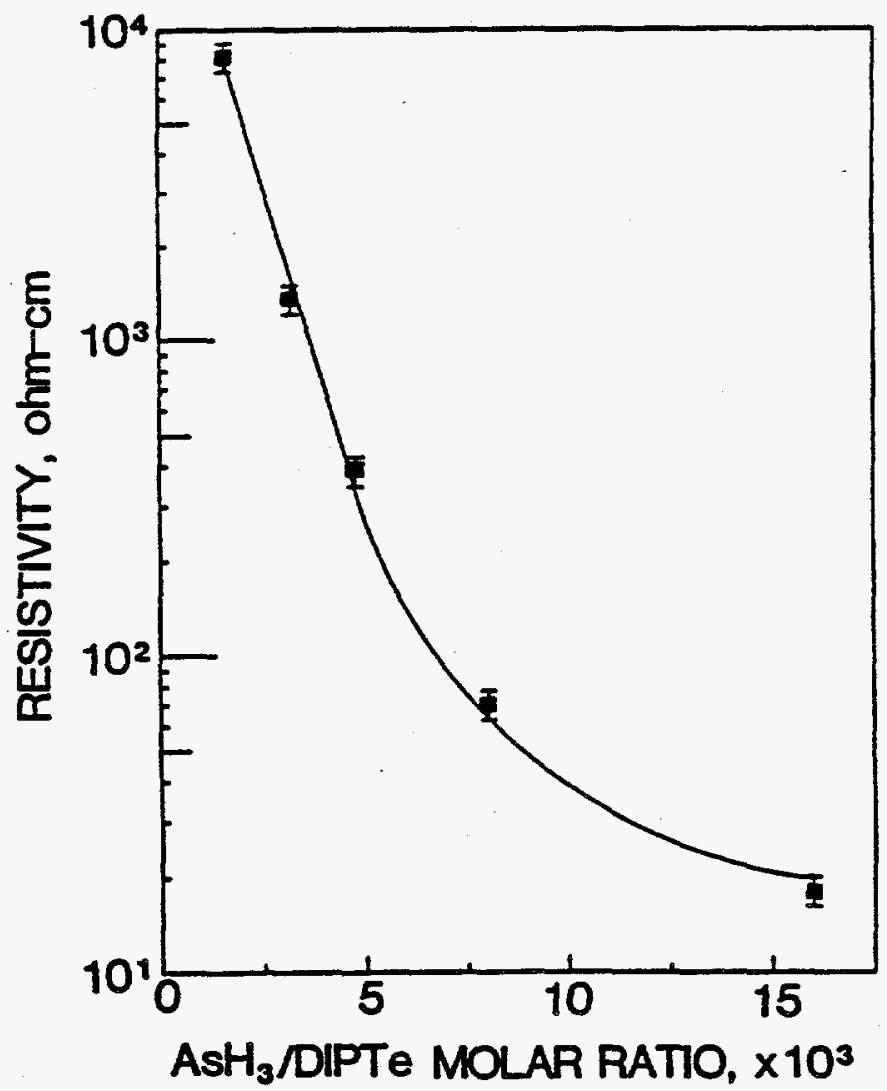

Figure 4-6 Lateral electrical resistivity of arsenic-doped $\mathrm{ZnTe}$ films versus the $\mathrm{AsH}_{3} /$ DIPTe molar ratio in the reaction mixture 


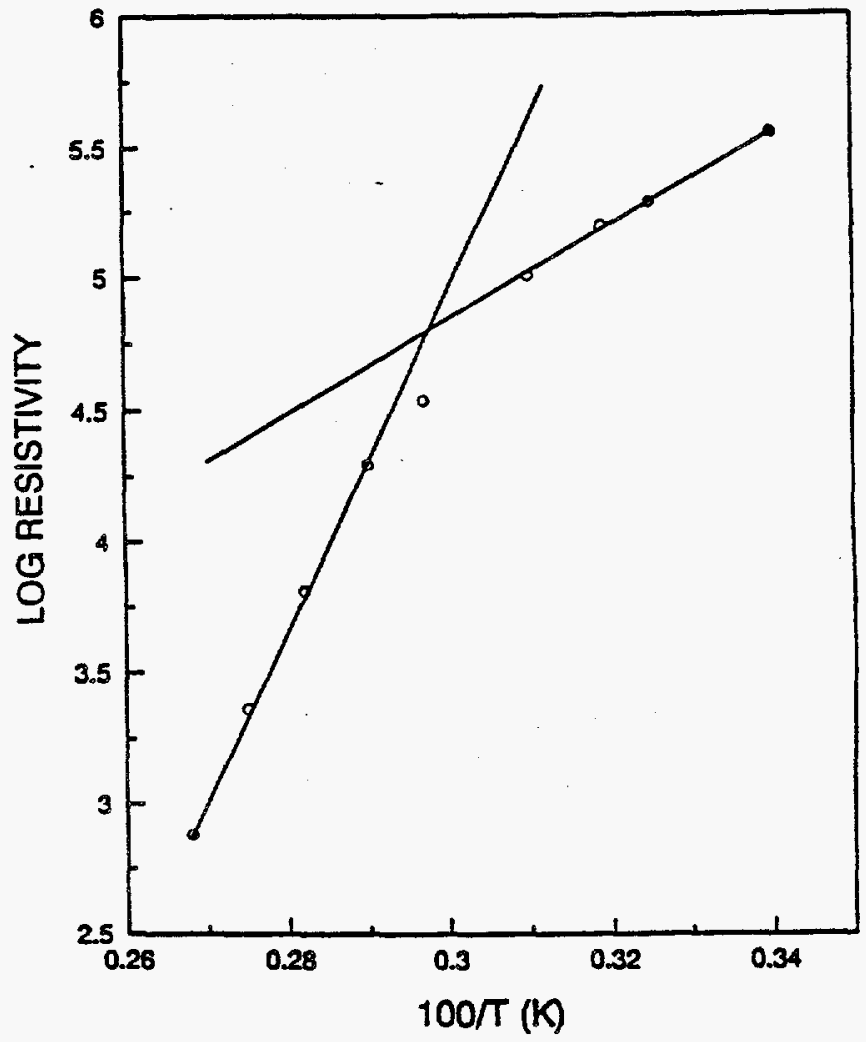

Figure 4-7 Lateral resistivity of an As-doped $\mathrm{ZnTe}$ film as a function of temperature

most desireable. However, $\mathrm{SnO}_{2}$ is reactive towards the reaction mixture (DEZn and DIPTe) used for the deposition of $\mathrm{ZnTe}$, and $\mathrm{ZnO} / \mathrm{ZnTe}$ junctions show a very low photovoltage, about $50 \mathrm{mV}$, due probably to the large mismatch in electron affinity (the electron affinities of $\mathrm{ZnO}$ and $\mathrm{ZnTe}$ are 4.35 and $3.53 \mathrm{eV}$, respectively).

Thin film $\mathrm{ZnSe} / \mathrm{ZnTe}$ solar cells were prepared by the successive in-situ deposition of 0.1 $0.2 \mu \mathrm{m}$ of Al-doped $\mathrm{ZnSe}$ at $500^{\circ} \mathrm{C}, 2 \mu \mathrm{m}$ of As-doped $\mathrm{ZnTe}$ (about $10^{3} \mathrm{ohm}-\mathrm{cm}$ resistivity), and $0.1-0.2 \mu \mathrm{m}$ of $\mathrm{p}^{+}-\mathrm{ZnTe}\left(3-5 \mathrm{ohm}-\mathrm{cm}\right.$ resistivity) at $400^{\circ} \mathrm{C}$ on $\mathrm{n}^{+}-\mathrm{ZnO} /$ glass substrates. The $\mathrm{p}^{+}-\mathrm{ZnTe}$ film serves as an ohmic contact to $\mathrm{p}-\mathrm{ZnTe}$, and $\mathrm{Ni}$ contact was deposited on $\mathrm{p}^{+}-\mathrm{ZnTe}$ by electron beam evaporation. Mesas of about $0.3 \mathrm{~cm}^{2}$ area were isolated by masking with Teflon tapes and etching with a $\mathrm{Br}_{2}-\mathrm{CH}_{3} \mathrm{OH}$ solution. A Ga-In alloy was used as a contact to $\mathrm{ZnO}$. The current-voltage characteristics of the mesa structures were measured in the dark and under illumination with ELH lamps at 100 $\mathrm{mW} / \mathrm{cm}^{2}$. A typical dark characteristics is shown in Figure 4-10, where the saturation current density and diode quality factor are approximately $4 \times 10^{-10} \mathrm{~A} / \mathrm{cm}^{2}$ and 2.12 , respectively. The illuminated characteristics of a $\mathrm{ZnSe} / \mathrm{ZnTe}$ solar cell are shown in Fig. 4-11, where the open-circuit voltage and the short-circuit current density are approximately $713 \mathrm{mV}$ and $0.5 \mathrm{~mA} / \mathrm{cm}^{2}$, respectively. The observed photocurrent is only about $10 \%$ of the expected value even the window layer absorbs all the above bandgap radiation. The low photocurrent was also observed in thin film $\mathrm{Cd}_{0.7} \mathrm{Zn}_{0.3} \mathrm{~S} / \mathrm{ZnTe}$ solar cells prepared by the insitu deposition of $\mathrm{Cd}_{0.7} \mathrm{Zn}_{0.3} \mathrm{~S}, \mathrm{p}-\mathrm{ZnTe}$, and $\mathrm{p}^{+}-\mathrm{ZnTe}$ films on $\mathrm{SnO}_{2} \cdot \mathrm{F}$ /glass substrates. The 


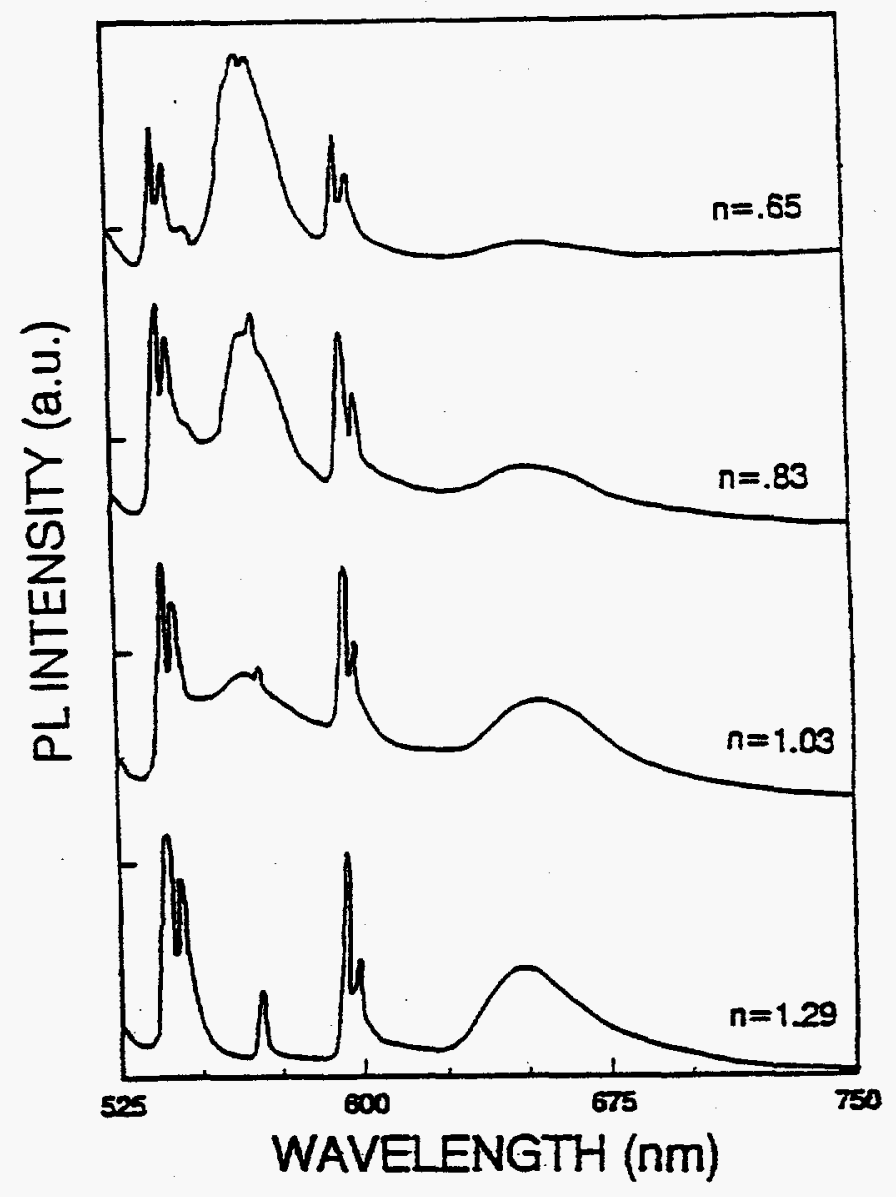

Figure 4-8 Photoluminescence spectra of $\mathrm{ZnTe}$ films at $4.2 \mathrm{~K}$ deposited at $350^{\circ} \mathrm{C}$ using various DEZn/DIPTe molar ratios in the reaction mixture

illuminated current-voltage characteristics of a $\mathrm{Cd}_{0.7} \mathrm{Zn}_{0.3} \mathrm{~S} / \mathrm{ZnTe}$ solar cell is also shown in Fig. 4-11. The low photocurrent and photovoltage in thin film $\mathrm{ZnTe}$ solar cells are due to the poor grain structure of $\mathrm{ZnTe}$ and high defect density at the TCS/ZnTe interface. 


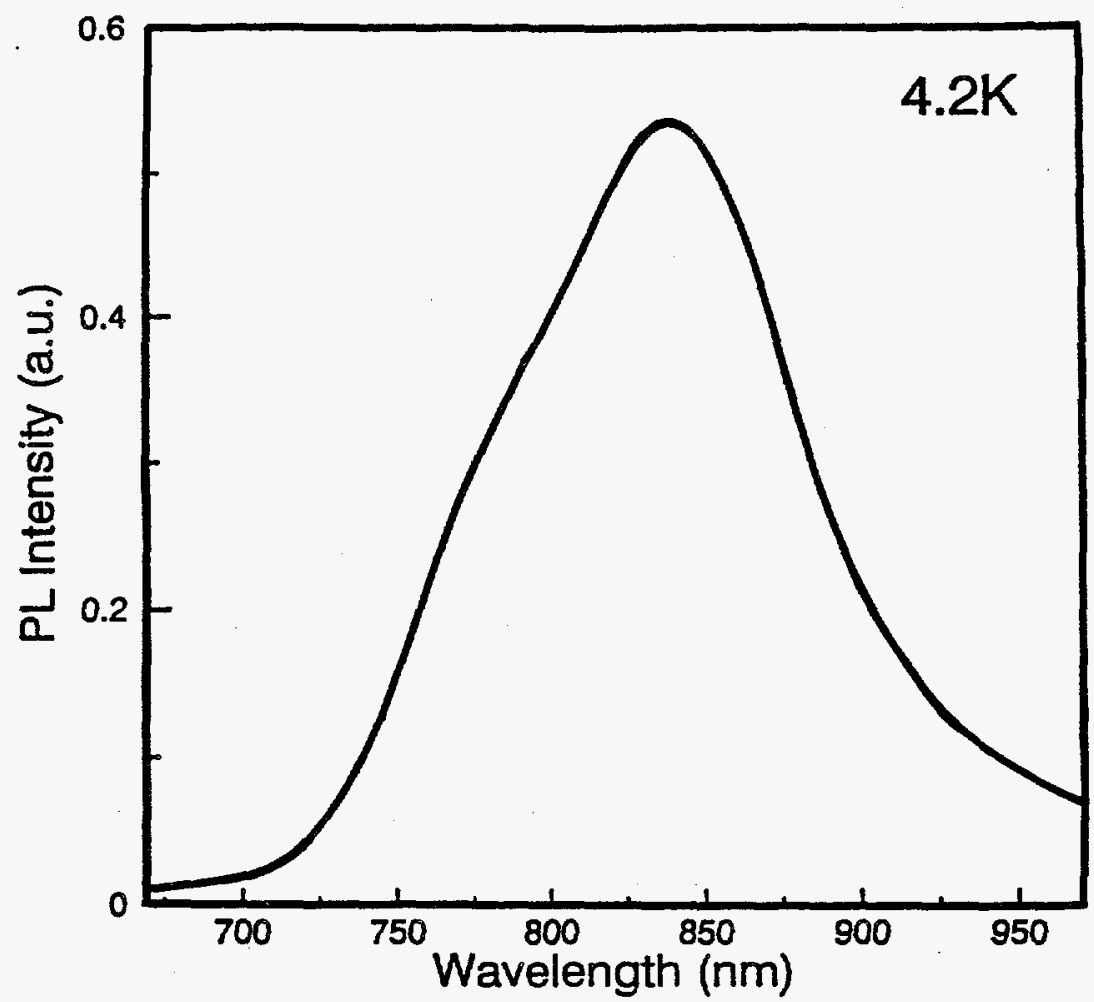

Figure 4-9 Photoluminescence spectrum of an As-doped ZnTe film at $4.2 \mathrm{~K}$

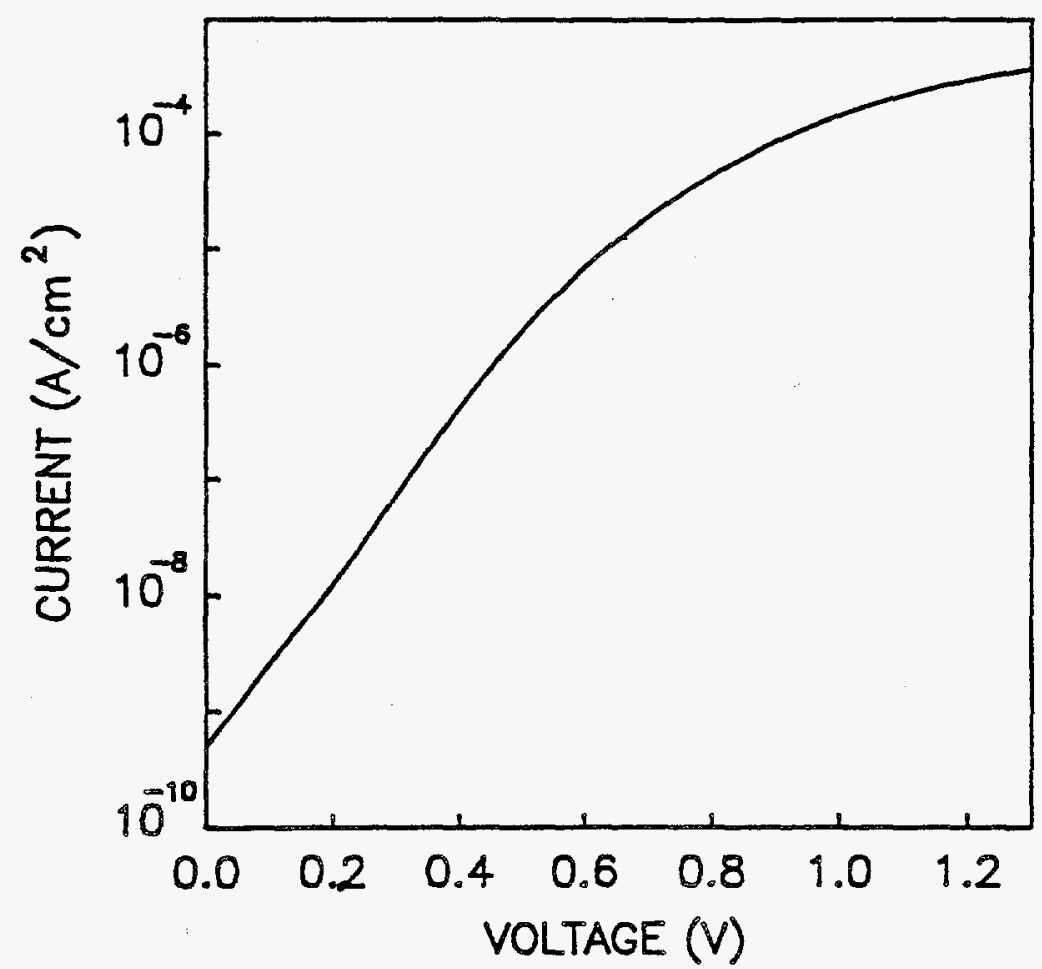

Figure 4-10 Dark current-voltage characteristics of a thin film $\mathrm{ZnSe} / \mathrm{ZnTe}$ solar cell 


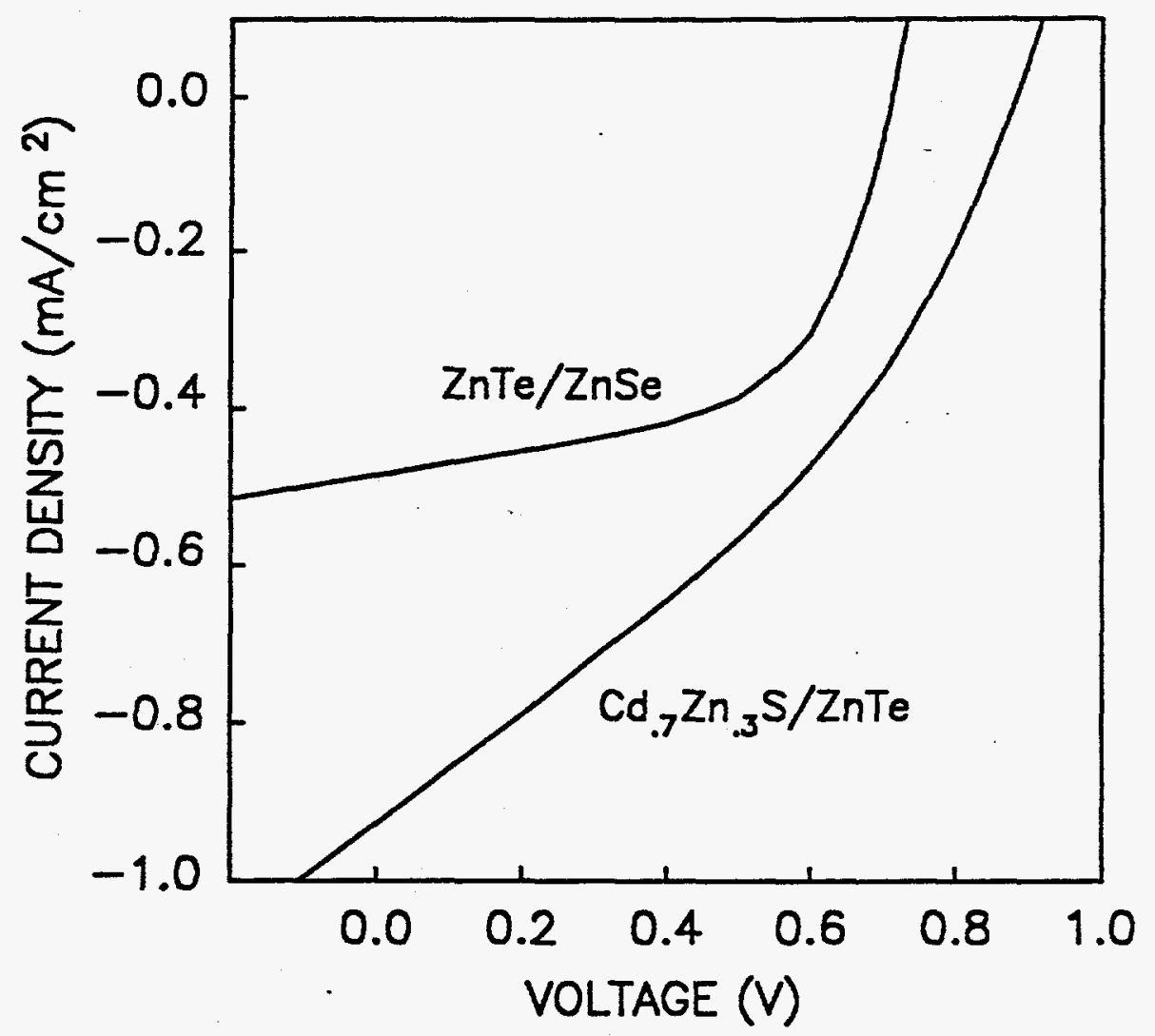

Figure 4-11 Current-voltage characteristics of thin film $\mathrm{ZnSe} / \mathrm{ZnTe}$ and $\mathrm{Cd}_{0.7} \mathrm{Zn}_{03} \mathrm{~S} / \mathrm{ZnTe}$ solar cells under illumination with $\mathrm{ELH}$ lamps at $100 \mathrm{~mW} / \mathrm{cm}^{2}$. 


\section{SECTION 5.0}

\section{CADMIUM ZINC TELLURIDE FILMS AND SOLAR CELLS}

The conversion efficiency of a single-junction polycrystalline thin film solar cell is presumably limited to $18 \%$. If two solar cells of direct gap semiconductors with appropriate bandgap energies are used in tandem, the overall conversion efficiency can be improved significantly. Two solar cells can be connected to form a two-terminal or four-terminal device. The four-terminal devices are more practical, since two separate external circuit loads are used and the photocurrents through each cell do not have to be the same. Thus, the match in thermal expansion coefficients of the two semiconductors and the formation of tunnel junctions, required in two-terminal devices, are not necessary. Consequently, a much larger selection of semiconductors is possible. The maximum conversion efficiency of four-terminal, single-crystalline cell tandem structures have been calculated to be $36.6 \%$ at AM1. Efficiencies of $25 \%$ can be expected from polycrystalline thin film four-terminal two-cell structures. The optimum bandgap energies for the upper and lower cells are 1.6 $1.8 \mathrm{eV}$ and $1.0-1.1 \mathrm{eV}$, respectively. The $\mathrm{CdZnS} / \mathrm{CuInSe}_{2}$ heterojunction cell (bandgap energy of CuInSe ${ }_{2}: 1.0 \mathrm{eV}$ ) is a promising candidate for the lower cell. The upper cell may be prepared from a number of solid solutions of UI-VI compounds. For example, CdTe and $\mathrm{ZnTe}(\mathrm{Eg}=2.25 \mathrm{eV}$ at $300 \mathrm{~K})$ form a continuous series of solid solutions, and the composition of cadmium zinc telluride $\left(\mathrm{Cd}_{1-x} \mathrm{Zn}_{\mathrm{z}} \mathrm{Te}\right)$ may be adjusted to yield the desired bandgap energy. Similarly, the bandgap energy of mercury zinc telluride $\left(\mathrm{Hg}_{1-x} \mathrm{Zn}_{\mathrm{x}} \mathrm{Te}\right)$ can also be controlled by its composition. The deposition and properties of thin films and solar cells of $\mathrm{Cd}_{1-x} \mathrm{Zn}_{x} \mathrm{Te}$ and $\mathrm{Hg}_{1-x} \mathrm{Zn}_{x} \mathrm{Te}$ have been investigated in this program.

The ternary system provides a tunable bandgap energy over the range of binary bandgaps; the bandgap energy of $\mathrm{Cd}_{1-x} \mathrm{Zn}_{\mathrm{x}} \mathrm{Te}$ has been determined as a function of composition by photoluminescence measurements[53]. The relation at $300 \mathrm{~K}$ is:

$$
\mathrm{Eg}(\mathrm{eV})=(1.510 \pm 0.005)+(0.606 \pm 0.010) x+(0.139 \pm 0.010) \mathrm{x}^{2}
$$

$\mathrm{Cd}_{1-\mathrm{x}} \mathrm{Zn}_{\mathrm{x}} \mathrm{Te}$ has many potential applications in solid state devices. For example, the addition of a few atomic percent of $\mathrm{ZnTe}$ to CdTe strengthens the bond in CdTe[54], and $\mathrm{Cd}_{1-x} \mathrm{Zn}_{x} \mathrm{Te}$ is better suited as a substrate for the epitaxial growth of mercury cadmium telluride. Also, $\mathrm{Cd}_{1-x} \mathrm{Zn}_{\mathrm{x}} \mathrm{Te}$ with bandgap energy of $1.65-1.75 \mathrm{eV}$ are promising candidates for the upper member of a two solar cell tandem structure.

Cadmium telluride can be doped to show both n- and p-type conductivity; however, ZnTe always exhibits p-type conductivity due to a high degree of self compensation of incorporated donors by native defects. Cd-rich $\mathrm{Cd}_{1-x} \mathrm{Zn}_{\mathrm{x}} \mathrm{Te}$ can be prepared in both $\mathrm{n}$ - and p-type forms; at $x>0.6$, only p-type material can be prepared. For example, Al-doped $\mathrm{Cd}_{1-\mathrm{x}} \mathrm{Zn}_{\mathrm{x}} \mathrm{Te}$ shows a sharp transition in conductivity at $\mathrm{x}>0.7$ and becomes high resistivity p-type at $x-0.75[55]$. Efficient visible luminescence from $\mathrm{Cd}_{1-x} \mathrm{Zn}_{\mathrm{x}} \mathrm{Te}$ junctions with emission peak at about $1.8 \mathrm{eV}$ has been observed[56]. 
Single crystals of $\mathrm{Cd}_{1-x} \mathrm{Zn}_{x} \mathrm{Te}$ with composition over a wide range have been grown from the melt. Epitaxial $\mathrm{Cd}_{1-x} \mathrm{Zn}_{\mathrm{x}} \mathrm{Te}$ films have been grown on $\mathrm{ZnTe}$ substrates from In and $\mathrm{Bi}$ solutions, and green-light emitting $\mathrm{n}-\mathrm{Cd}_{1-x} \mathrm{Zn}_{\mathbf{x}} \mathrm{Te} / \mathrm{p}-\mathrm{ZnTe}$ diodes have been produced[57]. Epitaxial $\mathrm{Cd}_{1-x} \mathrm{Zn}_{\mathrm{x}} \mathrm{Te}$ films have also been grown on single crystalline GaAs and InSb substrates by molecular beam epitaxy, and their structural and electrical properties investigated over a wide composition range[58,59]. High quality epitaxial $\mathrm{Cd}_{1-x} \mathrm{Zn}_{\mathbf{x}}$ Te films can be grown at compositions near the binaries. As the CdTe or ZnTe content exceeds about 10\%; however, the crystalline quality of the ternary degraded substantially, as shown by the $x$-ray rocking curve half-width, due possibly to phase separation.

Polycrystalline $\mathrm{Cd}_{1-x} \mathrm{Zn}_{\mathrm{x}} \mathrm{Te}$ films for tandem solar cells have received some attention recently. Thin films of $\mathrm{Cd}_{1-x} \mathrm{Zn}_{\mathrm{x}}$ Te with a bandgap energy of $1.7 \mathrm{eV}$ have been deposited on $\mathrm{CdS} / \mathrm{SnO}_{2} /$ glass substrates by the molecular beam technique using elemental sources[30,60]. The grown films have a uniform composition and sharp interfaces. However, solar cells processed by using the standard CdTe cell fabrication procedure (treatment with $\mathrm{CdCl}_{2}$ at $400^{\circ} \mathrm{C}$ in air) resulted in about $3.6 \%$ efficiency, high series resistance, and a bandgap energy reduction to $1.55 \mathrm{eV}$. Without the $\mathrm{CdCl}_{2}$ treatment, solar cells from $1.7 \mathrm{eV} \mathrm{Cd} d_{1-x} \mathrm{Zn}_{\mathrm{x}} \mathrm{Te}$ films had efficiencies of about $1 \%$. Polycrystalline $\mathrm{Cd}_{1-x} \mathrm{Zn}_{\mathrm{x}} \mathrm{Te}$ films of various stoichiometries have also been prepared by heating sequentially deposited thin layers of $\mathrm{Cd}, \mathrm{Zn}$, and $\mathrm{Te}$ on a substrate[61]. Small area $\mathrm{Cd}_{0.9} \mathrm{Zn}_{0.1} \mathrm{Te} / \mathrm{CdS}$ solar cells had a conversion efficiency of about $3 \%$.

Information on polycrystalline $\mathrm{Cd}_{1-x} \mathrm{Zn}_{\mathbf{x}} \mathrm{Te}$ films is very limited. In this program, $\mathrm{Cd}_{1-x} \mathrm{Zn}_{\mathbf{x}} \mathrm{Te}$ films have been deposited on glass and coated glass substrates by metalorganic chemical vapor deposition (MOCVD) with the objective of producing thin film solar cells suitable as the upper member of a two-cell tandem structure. The reaction of dimethylcadmium (DMCd), diethylzinc (DEZn), and diisopropyltellurium (DIPTe) in a hydrogen flow was used. The optical, electrical, and structural properties of these films have been investigated. The resistivity of $\mathrm{p}-\mathrm{Cd}_{0.7} \mathrm{Zn}_{0.3} \mathrm{Te}$ films has been controlled by using arsine as a dopant. Thin film $\mathrm{CdS} / \mathrm{Cd}_{0.7} \mathrm{Zn}_{0.3} \mathrm{Te}$ and $\mathrm{Cd}_{0.7} \mathrm{Zn}_{0.3} \mathrm{~S} / \mathrm{Cd}_{0.7} \mathrm{Zn}_{0.3} \mathrm{Te}$ junctions have been prepared and characterized.

\subsection{DEPOSITION PROCESS}

The apparatus for the MOCVD of $\mathrm{Cd}_{1-x} \mathrm{Zn}_{\mathrm{x}} \mathrm{Te}$ films has been shown schematically in Fig. 2-3. The metalorganics were introduced into the reaction tube, a fused silica tube of $5.5 \mathrm{~cm}$ $\mathrm{ID}$, by passing measured amounts of hydrogen through the liquids. Glass, $\mathrm{CdS} / \mathrm{SnO}_{2}: \mathrm{F} /$ glass, and $\mathrm{Cd}_{1-2} \mathrm{Zn}_{2} \mathrm{~S} / \mathrm{SnO}_{2}: \mathrm{F} /$ glass were used as substrates. The substrates were supported on a silicon carbide-coated graphite susceptor in the reaction tube, and the susceptor heated externally with an If generator. A thermocouple inserted into the interior of the susceptor was used to monitor the temperature of the substrates.

The important process parameters are the substrate temperature and the flow rates of hydrogen through DMCd, DEZn, DIPTe, and the reaction tube. The flow rates of the metalorganics determine the DMCd/DEZn and (DMCd + DEZn)/DIPTe molar ratios (referred to as II/VI ratio hereafter) in the reaction mixture. To simplify the large number 
of interrelated parameters, the substrate temperature was fixed at $400^{\circ} \mathrm{C}$, the temperature best suited for the MOCVD of CdTe and ZnTe films. The effects of the DMCd/DEZn and II/VI ratios on the properties of $\mathrm{Cd}_{1-x} \mathrm{Zn}_{x} \mathrm{Te}$ films were then evaluated.

Adherent films of $\mathrm{Cd}_{1-x} \mathrm{Zn}_{x} \mathrm{Te}$ have been deposited on glass and $\mathrm{SnO}_{2}: \mathrm{F} /$ glass substrates at $400^{\circ} \mathrm{C}$, where the vapor pressures of $\mathrm{CdTe}$ and $\mathrm{ZnTe}$ are negligible. At a fixed substrate temperature of $400^{\circ} \mathrm{C}$, the deposition rate of $\mathrm{Cd}_{1-x} \mathrm{Zn}_{x} \mathrm{Te}$ films depends on the composition and flow rate of the reaction mixture. The flow rates of DMCd, DEZn, and DIPTe were $(1.2-4.5) \times 10^{-5},(0.64-3.2) \times 10^{-5}$, and $(2.7-4.9) \times 10^{-5} \mathrm{moles} / \mathrm{min}$, respectively, and the flow rate of $\mathrm{H}_{2}$ was $4-4.5 \mathrm{l} / \mathrm{min}$. The deposition rate, $2-4 \mu \mathrm{m} / \mathrm{hr}$, was found to decrease with decreasing $\mathrm{DMCd} / \mathrm{DEZn}$ ratio in the reaction mixture.

\section{PROPERTIES}

The $\mathrm{Cd}_{1 . x} \mathrm{Zn}_{\mathrm{x}} \mathrm{Te}$ films deposited on glass and coated glass substrates at $400^{\circ} \mathrm{C}$ over a wide range of gas phase composition are all polycrystalline. The grain size is $0.2-0.4 \mu \mathrm{m}$, considerably smaller than the grain size in MOCVD CdTe films.

The crystallinity and composition of deposited films were determined by the $x$-ray diffraction technique. CdTe and $\mathrm{ZnTe}$ crystalize in the zincblende structure with lattice parameters of 6.481 and $6.101 \AA$, respectively. Polycrystalline CdTe powder of random orientations is known to show three strong diffraction peaks associated with $\{111\},\{220\}$, and $\{311\}$ reflections with $d$ values of $3.742,2.290$, and $2.945 \AA$, and relative intensities of 100,62 , and 28 , respectively. Polycrystalline $\mathrm{ZnTe}$ powder of random orientation is also known to show three strong diffraction peaks associated with $\{111\},\{220\}$, and $\{311\}$ reflections with $d$ values of $3.523,2.159$, and $1.840 \AA$, and relative intensities of 100,85 , and 35 , respectively. Since the lattice parameter of $\mathrm{Cd}_{1-x} \mathrm{Zn}_{\mathrm{x}} \mathrm{Te}$ films follows the Vegard's law, the composition of $\mathrm{Cd}_{1-x} \mathrm{Zn}_{\mathrm{x}} \mathrm{Te}$ films can be determined from the $\mathrm{d}$ values of the diffraction peaks. Figure 5-1 shows the diffraction spectrum of a $\mathrm{Cd}_{1-x} \mathrm{Zn}_{x}$ Te films obtained by using $\mathrm{CuK} \alpha$ radiation, where only one diffraction peak with a $2 \theta$ value of $24.43^{\circ}$ corresponding to a $d$ value of $3.640 \AA$ is present. The absence of diffraction peaks associated with CdTe and $\mathrm{ZnTe}$ indicates that this film is a single phase material. The absence of $\{220\}$ and $\{311\}$ reflections suggests that this film has a very strong $\{111\}$ preferred orientation. The composition of the film deduced from the $d$ value corresponds to $\mathrm{Cd}_{0.53} \mathrm{Zn}_{0.47} \mathrm{Te}$.

The bandgap energy of $\mathrm{Cd}_{1-\alpha} \mathrm{Zn}_{\mathbf{x}} \mathrm{Te}$ films at room temperature was determined by optical absorption measurements and junction photovoltage (JPV) spectroscopy. The optical bandgap energy was deduced from the linear plot of the square of the absorption coefficient, measured on a Cary $17 \mathrm{D}$ spectrophotometer, versus the photon energy near the band edge. Figure 5-2 shows the $\alpha^{2}$ versus the photo energy plot for several $\mathrm{Cd}_{1-x} \mathrm{Zn}_{\mathrm{x}} \mathrm{Te}$ films with different concentrations of $\mathrm{ZnTe}$, where the composition was analyzed by wavelength dispersive spectroscopy at the Solar Energy Research Institute. The measured bandgap energy - composition relation is shown in Fig. 5-3, where the previously established relation is shown as the solid line for comparison. The junction photovoltage spectroscopy is also convenient for determining the bandgap energy of $\mathrm{Cd}_{1-x} \mathrm{Zn}_{\mathrm{x}} \mathrm{Te}$ films deposited on CdS coated glass substrates. Graphite paste was applied to the surface of a $\mathrm{Cd}_{1-x} \mathrm{Zn}$ Te film to form a 


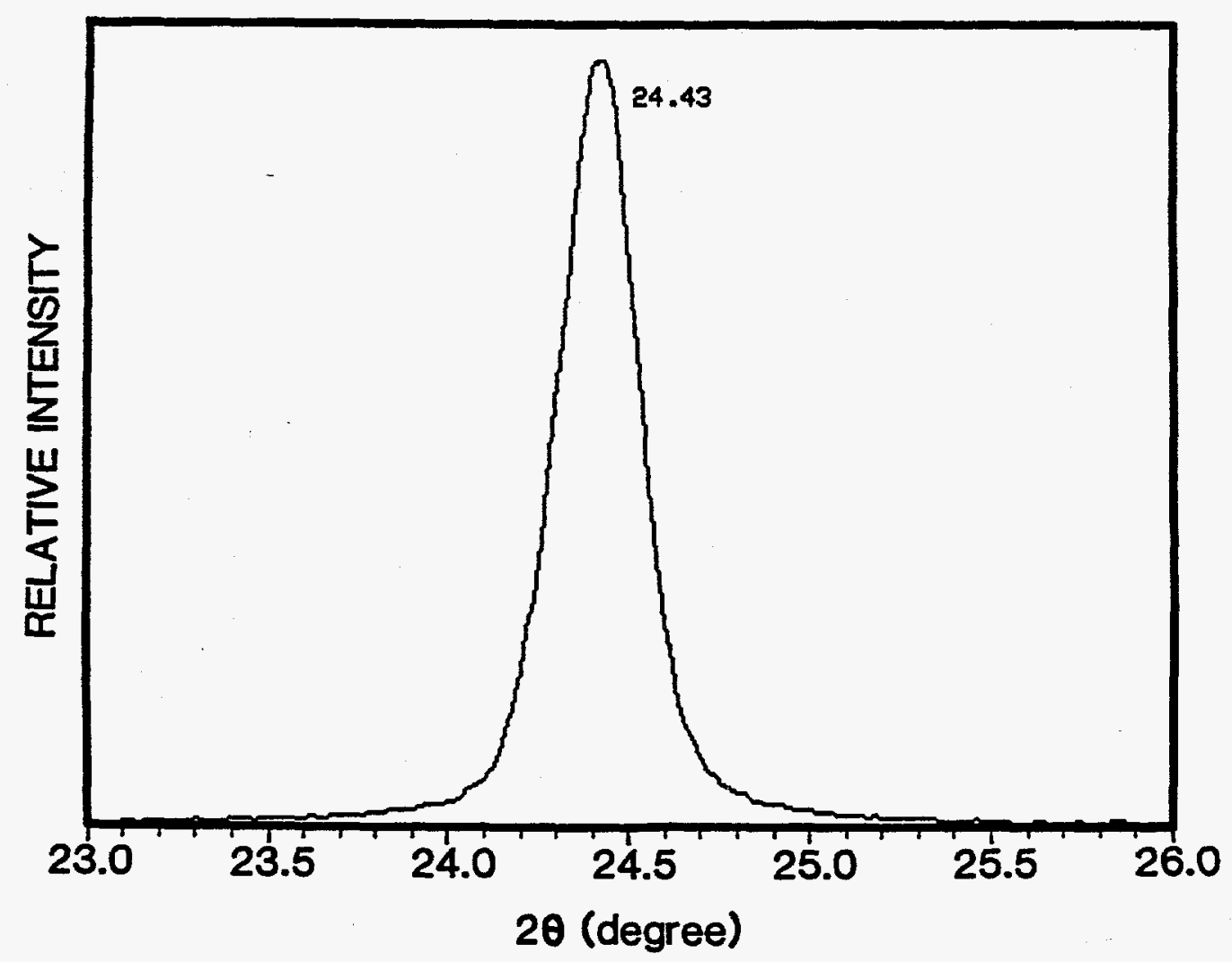

Figure 5-1 X-ray diffraction spectrum of a $\mathrm{Cd}_{0.53} \mathrm{Zn}_{207} \mathrm{Te}$ film.

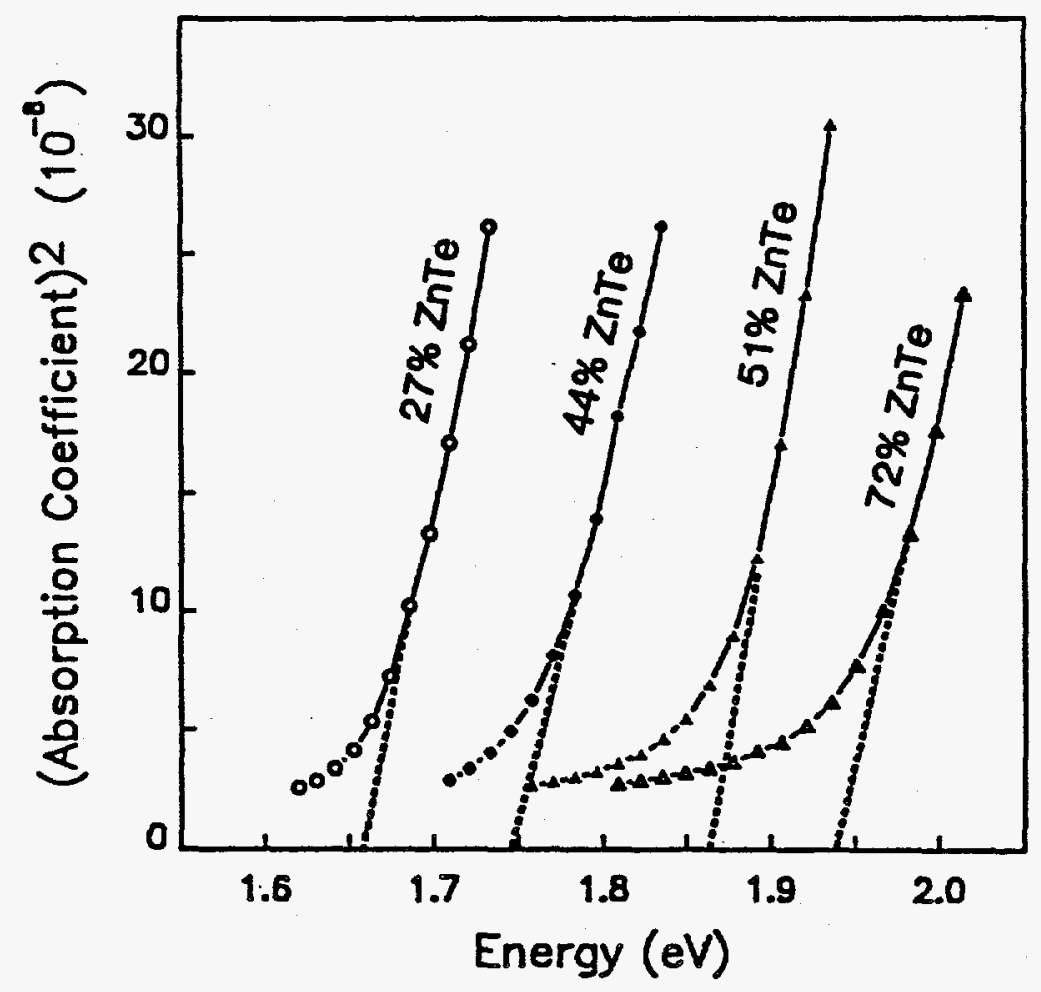

Figure 5-2 Optical absorption coefincients of $\mathrm{Cd}_{1-x} \mathrm{Zn}_{\mathbf{x}}$ Te films with different concentrations of $\mathrm{ZnTe}$. 


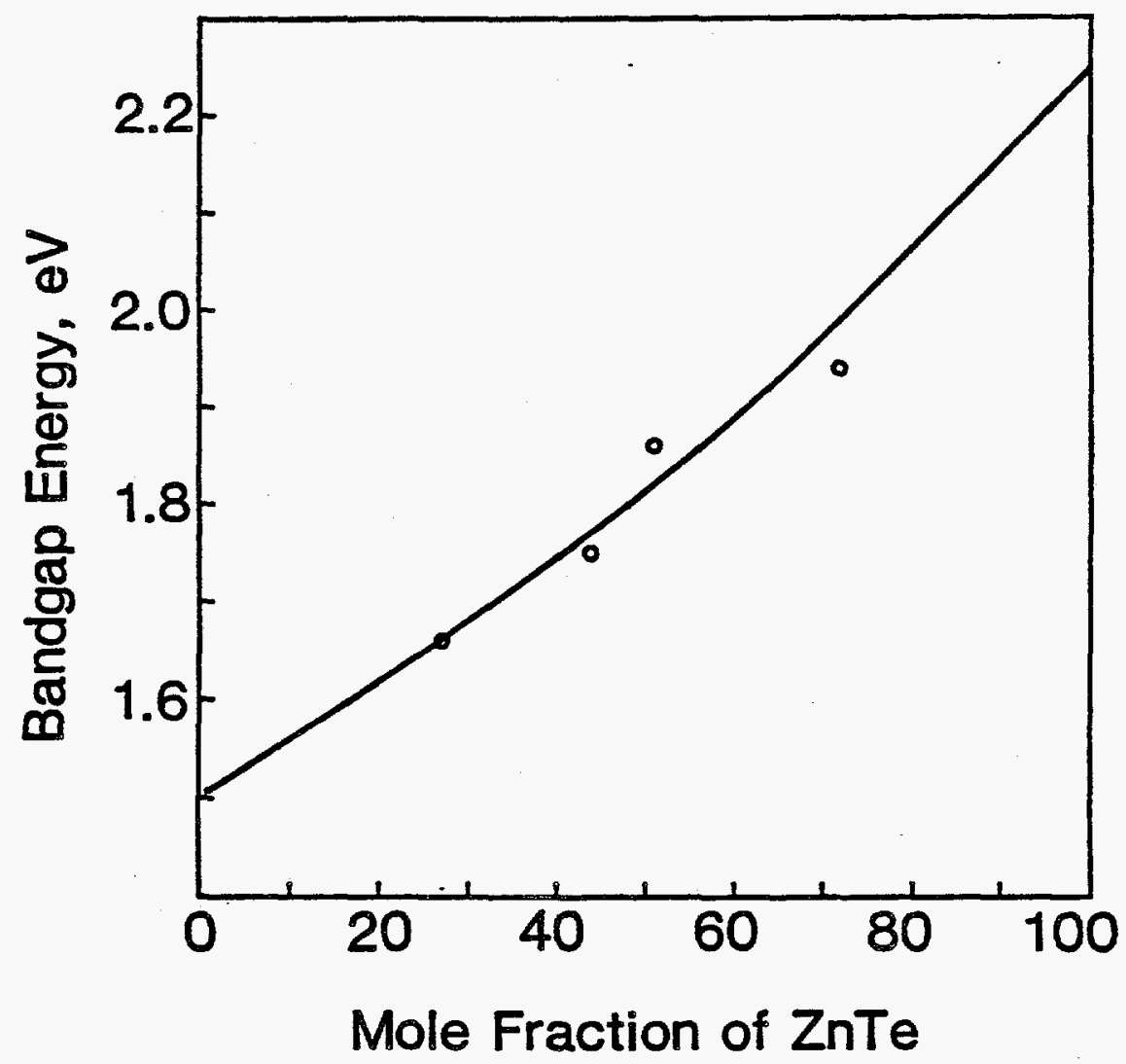

Figure 5-3 Bandgap energy - composition relation of $\mathrm{Cd}_{1-\mathrm{z}} \mathrm{Zn}_{\mathbf{x}} \mathrm{Te}$ films.

graphite $/ \mathrm{Cd}_{1-x} \mathrm{Zn}_{\mathrm{x}} \mathrm{Te} / \mathrm{CdS} / \mathrm{SnO}_{2} /$ glass structure. The junction photovoltage spectrum of the heterojunction was measured in the range of $500-1000 \mathrm{~nm}$ by illuminating the glass surface with a tungsten-halogen lamp. When the $\mathrm{Cd}_{1-x} \mathrm{Zn}_{x}$ Te film is of p-type conductivity, the $\mathrm{Cd}_{\mathrm{d}-\mathrm{x}} \mathrm{Zn}_{\mathrm{x}} \mathrm{Te} / \mathrm{CdS}$ junction is rectifying. The major portion of short wavelength radiation is absorbed in $\mathrm{Cd}_{\mathrm{l}-\mathrm{z}} \mathrm{Zn}_{\mathrm{x}} \mathrm{Te}$ near the junction, generating hole-electron pairs. As the wavelength of the incident radiation is increased, the generation of hole-electron pairs extends toward the graphite contact. The carriers generated within the depletion region are mostly collected to produce a photovoltage; however, the carriers generated outside the depletion region must diffuse to the depletion region to contribute to the photovoltage. Since the minority carrier diffusion length is most likely to be smaller than the absorption length, the carriers generated by the longer wavelength radiation may not be completely collected, and the photoresponse near the bandedge may decrease gradually. Figure 5.4 shows the junction photovoltage spectrum of a heterojunction with p-type $\mathrm{Cd}_{1-x} \mathrm{Zn}_{\mathrm{x}} \mathrm{Te}$, where the photoresponse drops off at about $730 \mathrm{~nm}$ corresponding to a bandgap energy of $1.7 \mathrm{eV}$. The gradual decrease of photoresponse near the bandedge is in contrast to the photovoltage spectra of CdTe films shown in Fig. 3-8, where the photoresponse cut-off is considerably more abrupt, implying the poorer quality of $\mathrm{Cd}_{1-x} \mathrm{Zn}_{\mathrm{x}} \mathrm{Te}$ films.

All $\mathrm{Cd}_{1-x} \mathrm{Zn}_{\mathrm{x}} \mathrm{Te}$ films deposited with no intentional doping are of $\mathrm{p}$-type conductivity. The lateral resistivity of $\mathrm{Cd}_{1-x} \mathrm{Zn}_{x} \mathrm{Te}$ films on glass substrates was measured by the conventional potential probe technique using graphite contacts. The dark lateral resistivity of all films 


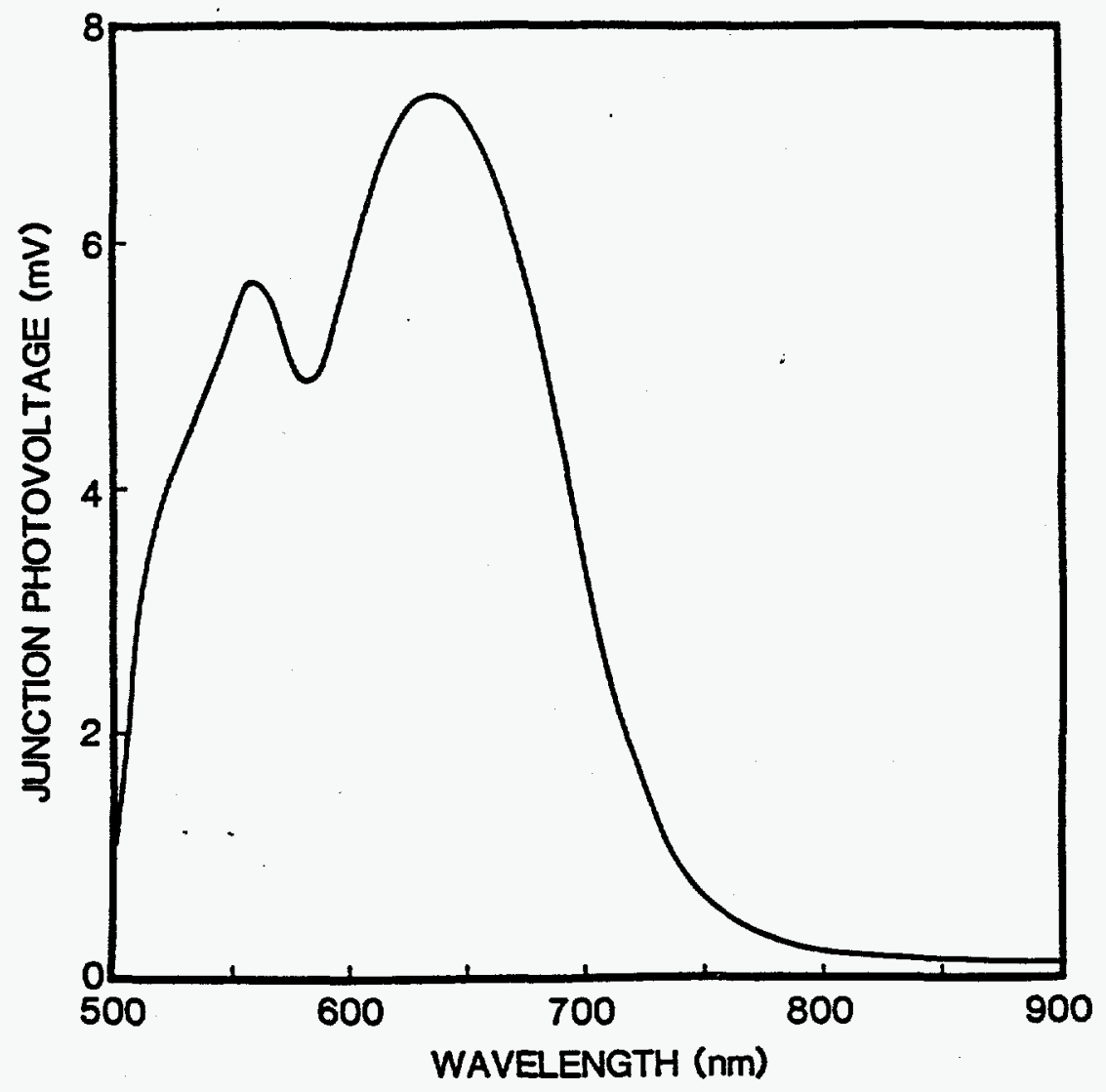

Figure 5-4 Junction photovoltage spectrum of a graphite/p-Cd $\mathrm{Cd}_{1-\mathrm{z}} \mathrm{Zn}_{\mathbf{x}} \mathrm{Te} /$ $\mathrm{CdS} / \mathrm{SnO}_{2} /$ glass structure

has been found to be $10^{7}-10^{8} \mathrm{ohm} \mathrm{cm}$, essentially independent of the composition of the film. To reduce the lateral resistivity of $\mathrm{Cd}_{1-x} \mathrm{Zn}_{x} \mathrm{Te}$ films, $\mathrm{AsH}_{3}$ was added to the reaction mixture during the deposition process. Since As occupies the Te site in the lattice, the incorporation of As should be facilitated by the presence of a high concentration of $\mathrm{Te}$ vacancies, i.e., by using a reaction mixture with a large II/VI molar ratio. Typically, II/VI molar ratios of 1.2-2.0 were used. Figure 5-5 shows the lateral resistivity of $\mathrm{Cd}_{0.8} \mathrm{Zn}_{0.2} \mathrm{Te}$ films as a function of $\mathrm{AsH}_{3} / \mathrm{DIPTe}$ molar ratio in the reaction mixture. The further addition of $\mathrm{AsH}_{3}$ does not reduce significantly the lateral resistivity. Under illumination with ELH lamps at $100 \mathrm{~mW} / \mathrm{cm}^{2}$, the lateral resistivity is reduced by a factor of 100 or more, also shown in Fig. 5-5. This reduction in resistivity may also be associated with the reduction of potential barriers at grain boundaries. The $\mathrm{Cd}_{1-x} \mathrm{Zn}_{\mathrm{x}} \mathrm{Te}$ films with higher $\mathrm{ZnTe}$ content can be more readily doped; As-doped $\mathrm{ZnTe}$ films deposited under similar conditions have resistivities as low as $10 \mathrm{ohm}-\mathrm{cm}$.

The composition or bandgap energy of $\mathrm{Cd}_{1-x} \mathrm{Zn}_{\mathrm{x}} \mathrm{Te}$ films depends strongly on the flow rates of hydrogen through DMCd, DEZn, DIPTe, and the reaction tube, or the DMCd/DEZn and II/VI molar ratios, during the deposition process. These ratios are important since DMCd and DEZn differ in stability and therefore the ease of telluride formation. At a fixed DMCd flow rate and a fixed $\Pi / V I$ ratio, the bandgap energy of $\mathrm{Cd}_{1-\mathrm{x}} \mathrm{Zn}_{\mathrm{x}} \mathrm{Te}$ film 


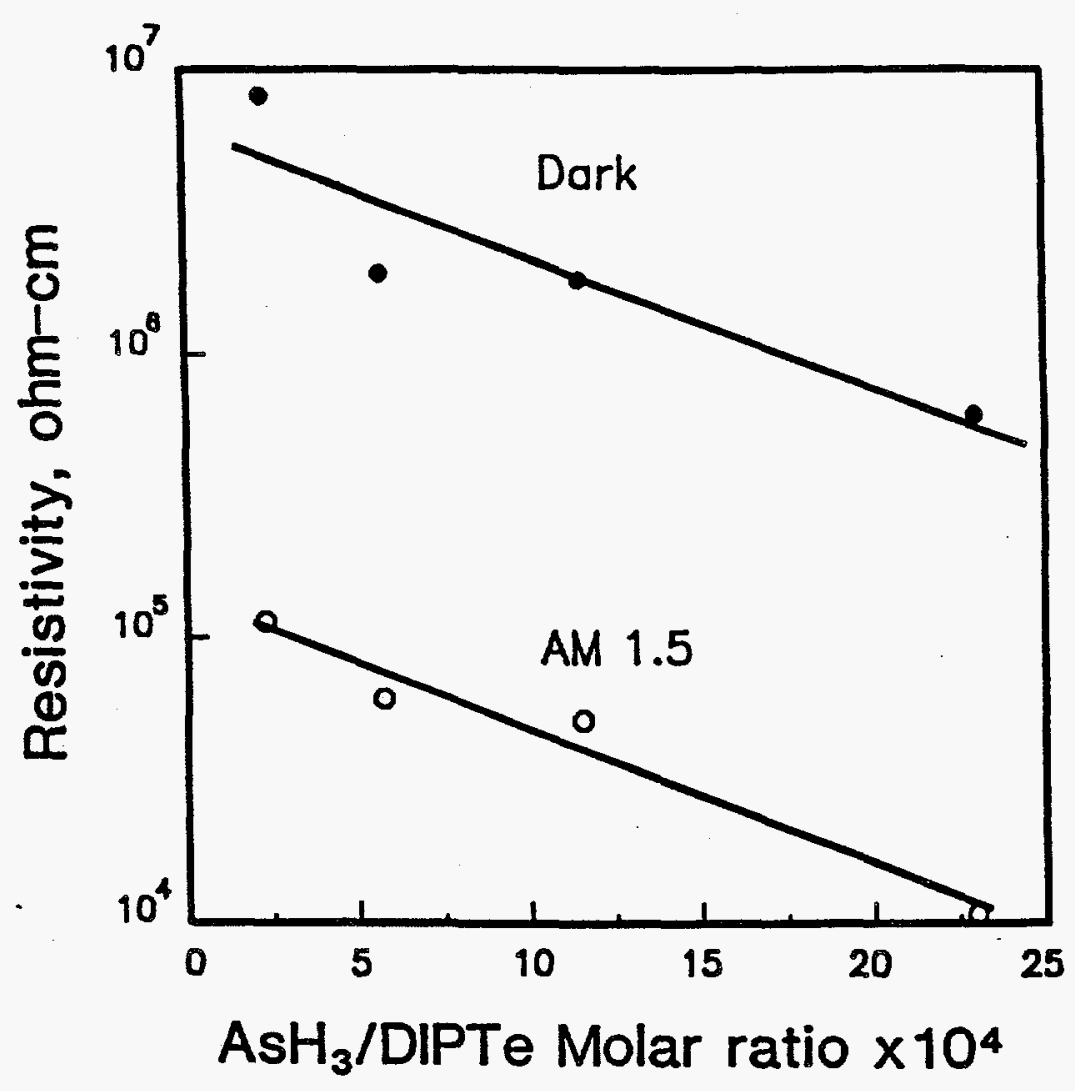

Figure 5-5 Lateral resistivity of $\mathrm{Cd}_{0,} \mathrm{Zn}_{02} \mathrm{Te}$ films as a function of $\mathrm{AsH}_{3}$ concentration in the reaction mixture.

increases with decreasing DMCd/DEZn ratio. Figure 5-6 shows the bandgap energy $\mathrm{DMCd} / \mathrm{DEZn}$ ratio relation when a DMCd flow rate of $2.2 \times 10^{-5} \mathrm{~mole} / \mathrm{min}$ and a II/VI ratio of 1.4 were used. The bandgap energy of the film can be varied in the range of 1.6 $1.8 \mathrm{eV}$ by adjusting the DMCd/DEZn ratio in the reaction mixture. These results indicate that $\mathrm{CdTe}$ is formed more readily than $\mathrm{ZnTe}$. A similar relation was observed when $\mathrm{Cd}_{1 \cdot x} \mathrm{Zn}_{\mathrm{x}} \mathrm{Te}$ films were deposited by using a fixed DMCd flow rate, a fixed DMCd/DEZn ratio, and varied II/VI ratios. Figure 5-7 shows the bandgap energy - II/VI ratio relation when a DMCd flow rate of $1.5 \times 10^{-5} \mathrm{~mole} / \mathrm{min}$ and a DMCd/DEZn ratio of 1.53 were used. The bandgap energy of the film can also be varied in the range of $1.6-1.8 \mathrm{eV}$ by adjusting the II/VI ratio in the reaction mixture.

\subsection{Solar Cells}

Thin film $\mathrm{Cd}_{1-x} \mathrm{Zn}_{\mathrm{x}}$ Te heterojunctions solar cells have been prepared by the successive in-situ depositions of $2-3 \mu \mathrm{m}$ of a $\mathrm{Cd}_{1-\mathrm{z}} \mathrm{Zn}$ Te film and $0.1 \cdot 0.2 \mu \mathrm{m}$ of a $\mathrm{p}^{+}-\mathrm{ZnTe}$ film on a $\mathrm{CdS} / \mathrm{SnO}_{2} /$ glass or $\mathrm{Cd}_{1-x} \mathrm{Zn}_{\mathrm{x}} \mathrm{S} / \mathrm{SnO}_{2} /$ glass substrate; the $\mathrm{p}^{+}-\mathrm{ZnTe}$ film was used as an ohmic contact to $\mathrm{Cd}_{1-\mathrm{z}} \mathrm{Zn}_{\mathrm{x}} \mathrm{Te}$, and $\mathrm{Ni}$ contact was deposited on $\mathrm{p}^{+}-\mathrm{ZnTe}$ by electron-beam evaporation. Mesa structures were isolated by masking with Teflon tape, etching with a $\mathrm{Br}_{2}$ $\mathrm{CH}_{3} \mathrm{OH}$ solution, rinsing with DI water, and drying at about $120^{\circ} \mathrm{C}$. A Ga-In alloy was used as the contact to $\mathrm{SnO}_{2}$. The current-voltage characteristics of the mesa structures were measured in the dark and under illumination with ELH lamps at $100 \mathrm{~mW} / \mathrm{cm}^{2}$. Most devices 


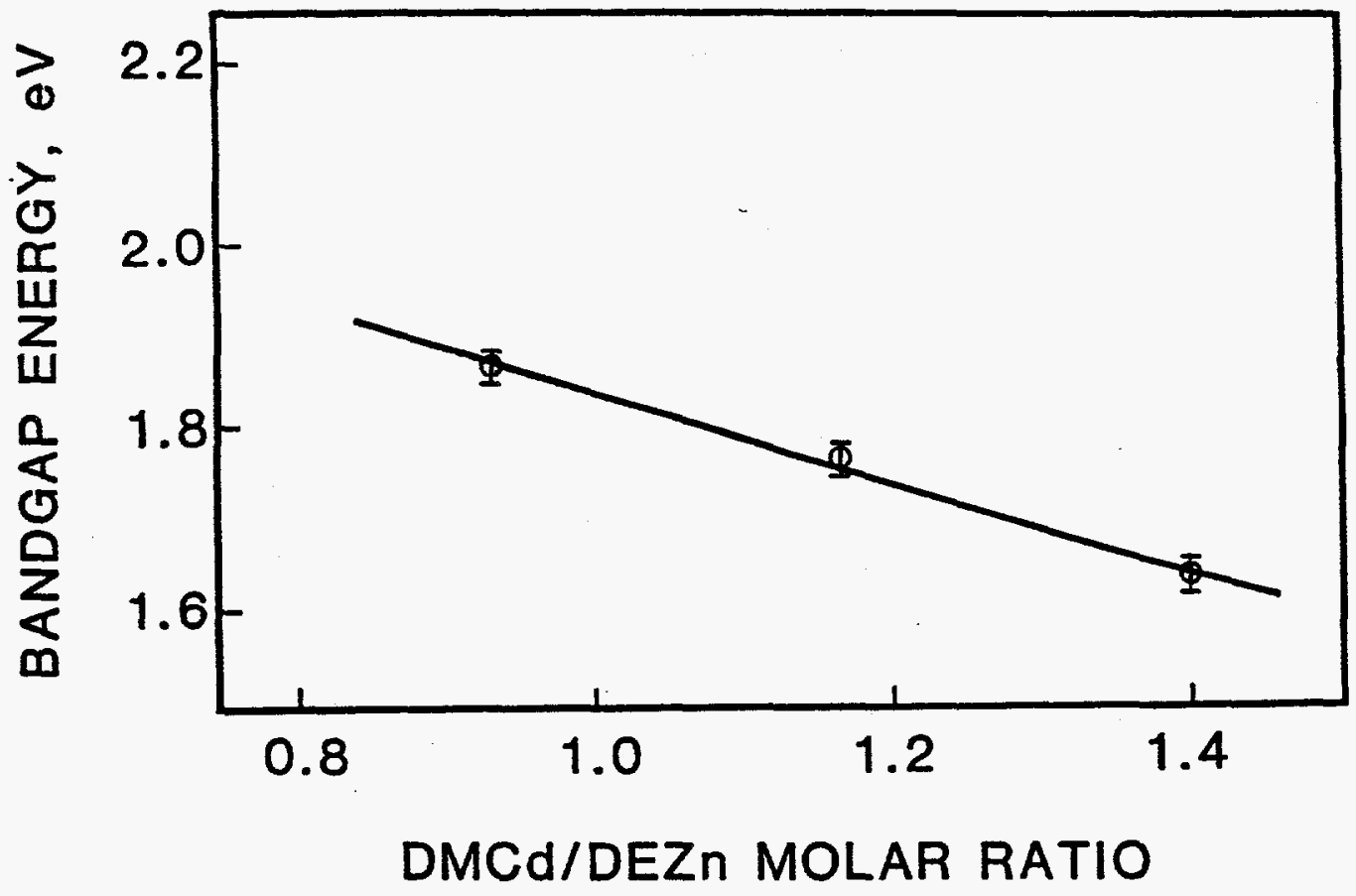

Figure 5-6 Bandgap energy of $\mathrm{Cd}_{1-x} \mathrm{Zn}_{\mathbf{2}}$ Te films as a function of DMCd/DEZn ratio in the reaction mixture using fixed DMCd flow rate and II/VI ratio.

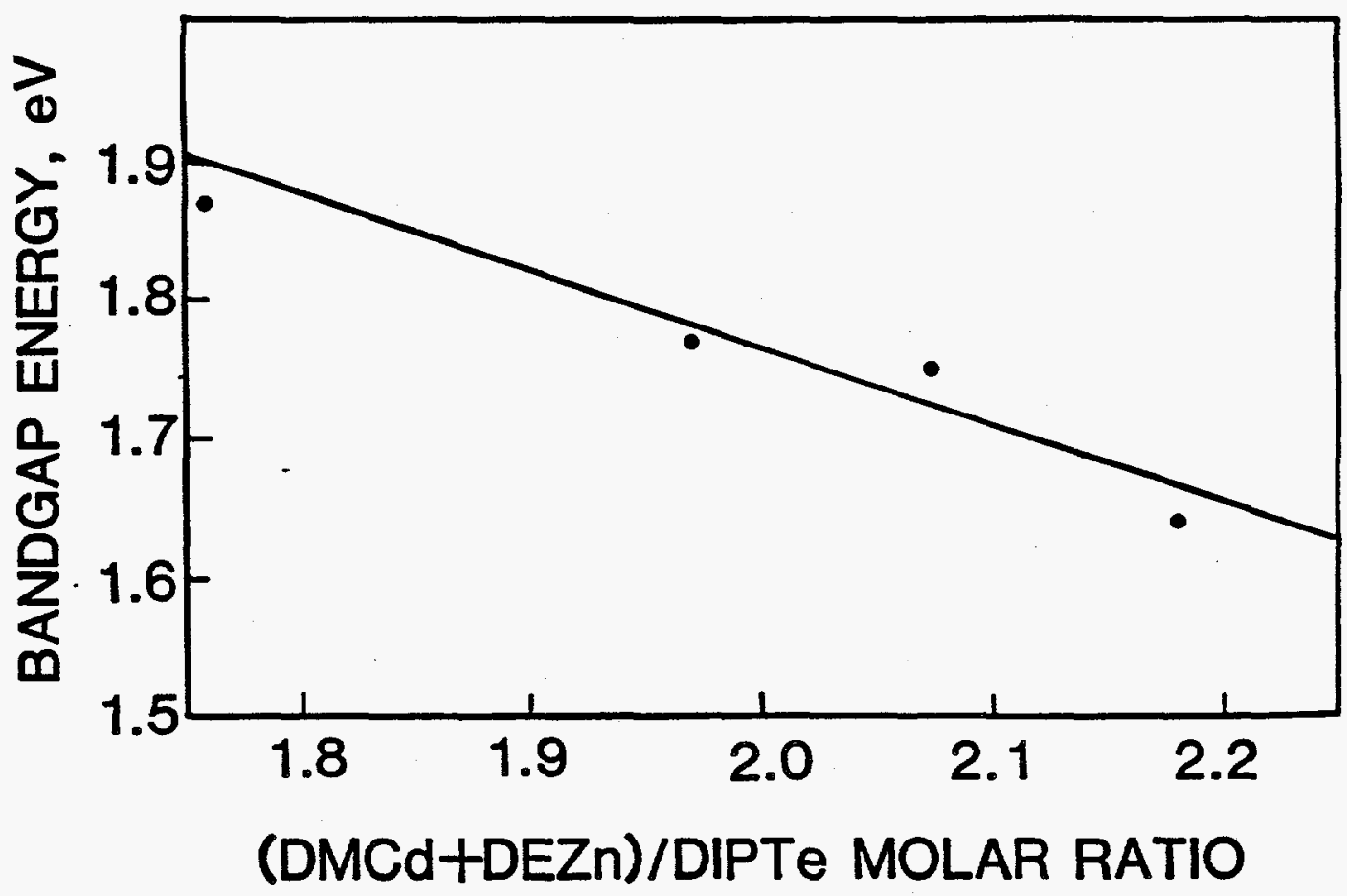

Figure 5-7 Bandgap energy of $\mathrm{Cd}_{1-x} \mathrm{Zn}_{2}$ Te films as a function of $\mathrm{II} / \mathrm{VI}$ ratio in the reaction mixture using fixed DMCd flow rate and DMCd/DEZn ratio. 
show low shunt resistance and high saturation current density ( about $10^{-8} \mathrm{~A} / \mathrm{cm}^{2}$ ), thus limiting the open-circuit voltage of thin film $\mathrm{Cd}_{1-x} \mathrm{Zn}_{x} \mathrm{Te} / \mathrm{CdS}$ solar cells to about 600 $\mathrm{mV}$. The short-circuit current density decreases with increasing bandgap energy of $\mathrm{Cd}_{1-x} \mathrm{Zn}_{\alpha} \mathrm{Te}$, about 6 and $2.5 \mathrm{~mA} / \mathrm{cm}^{2}$ for absorber bandgap energy of 1.65 and $1.75 \mathrm{eV}$, respectively. Assuming that $C d S$ absorbs all above bandgap radiation and that there are no current losses, the short-circuit current densities are 16.8 and $14 \mathrm{~mA} / \mathrm{cm}^{2}$, respectively, for absorber bandgap energy of 1.65 and $1.75 \mathrm{eV}$. The observed photocurrent is considerably less, and the current loss becomes more pronounced as the bandgap energy of the absorber increases. Since essentially all photocurrent is generated in the depletion region, the current loss is associated with the carrier recombination in the junction region and in $\mathrm{Cd}_{1-x} \mathrm{Zn}_{\mathrm{x}} \mathrm{Te}$ near the junction. The grains in $\mathrm{Cd}_{1-\mathrm{x}} \mathrm{Zn}_{\mathrm{x}} \mathrm{Te}$ films are of submicrometer dimensions and are highly defective due to the large difference in the lattice parameters of CdTe $\left(a_{0}=6.481 \AA\right)$ and $\mathrm{ZnTe}\left(\mathrm{a}_{0}=6.104 \AA\right)$; the intragrain defects are recombination centers. The poor microstructure of $\mathrm{Cd}_{1-x} \mathrm{Zn}_{\mathrm{x}}$ Te films is reflected in the shape of the junction photovoltage spectrum where the photoresponse near the band edge decreased gradually (Fig. 5-4). Further, the crystal quality of epitaxial $\mathrm{Cd}_{1-x} \mathrm{Zn}_{\mathrm{x}} \mathrm{Te}$ films has been shown to degrade as the CdTe or ZnTe content exceeds about $10 \%$ [58].

The illuminated characteristics of a thin film $\mathrm{Cd}_{0.7} \mathrm{Zn}_{0.3} \mathrm{~S} / \mathrm{Cd}_{0.75} \mathrm{Zn}_{0.25} \mathrm{Te}$ solar cell are shown in Fig. 5-8. The open-circuit voltage, short-circuit current density and fill factor are $665 \mathrm{mV}$, $8 \mathrm{~mA} / \mathrm{cm}^{2}$, and $42 \%$, respectively, corresponding to a conversion efficiency of $2.25 \%$. The photocurrent in thin film $\mathrm{Cd}_{0.7} \mathrm{Zn}_{0.3} \mathrm{~S} / \mathrm{Cd}_{\mathrm{I}-\mathrm{x}} \mathrm{Zn}_{\mathbf{x}} \mathrm{Te}$ solar cells can be increased by reducing the

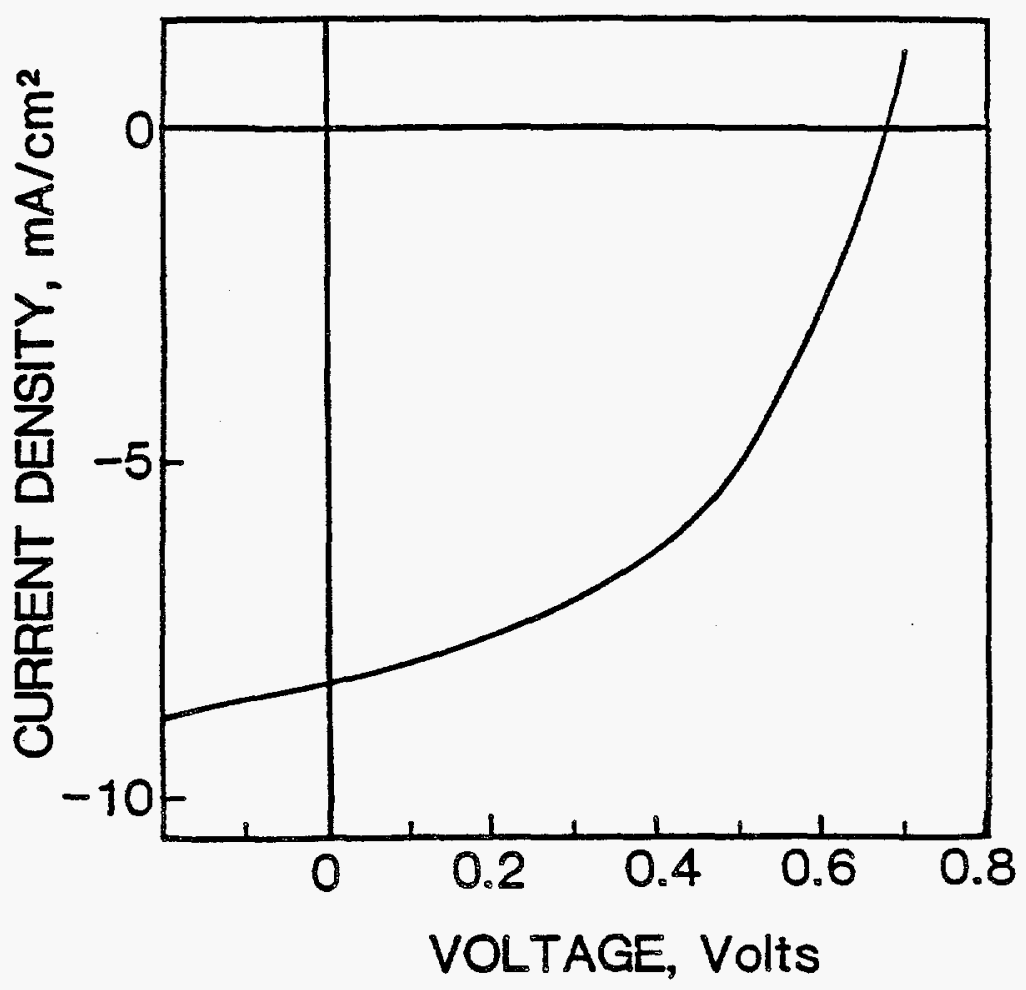

Figure 5-8 Illuminated current-voltage characteristics of a thin film $\mathrm{Cd}_{\mathbf{0 . 7 5}} \mathbf{Z n}_{\mathbf{0 . 2 5}} \mathrm{Te}$ $(\mathrm{Eg}=1.65 \mathrm{eV}) / \mathrm{Cd}_{0,7} \mathrm{Zn}_{0,3} \mathrm{~S}(\mathrm{Eg}=2.8 \mathrm{eV})$ solar cell. 
thickness of $\mathrm{Cd}_{1-x} \mathrm{Zn}_{\mathrm{x}} \mathrm{Te}$ to $0.2 \mu \mathrm{m}$ and by using $\mathrm{CdTe}$ as the major portion of the absorber. Figure 5-9 shows the illuminated current-voltage characteristics of a thin film.

$\mathrm{CdTe} / \mathrm{Cd}_{0.7} \mathrm{Zn}_{0.3} \mathrm{Te} / \mathrm{Cd}_{0.7} \mathrm{Zn}_{0.3} \mathrm{~S}$ solar cell where the open-circuit voltage, short-circuit current density, and fill factor are $0.627 \mathrm{~V}, 20.6 \mathrm{~mA} / \mathrm{cm}^{2}$, and $55 \%$, respectively, corresponding to a conversion efficiency of $7.1 \%$. The photocurrent of this device is about three times of that from a $\mathrm{Cd}_{0.7} \mathrm{Zn}_{0.3} \mathrm{~S} / \mathrm{Cd}_{0.7} \mathrm{Zn}_{0.3} \mathrm{Te}$ solar cell, again indicating that the low photocurrent in the latter is due to the poor microstructure in the $\mathrm{Cd}_{1-\alpha} \mathrm{Zn}_{\mathbf{x}} \mathrm{Te}$ film.

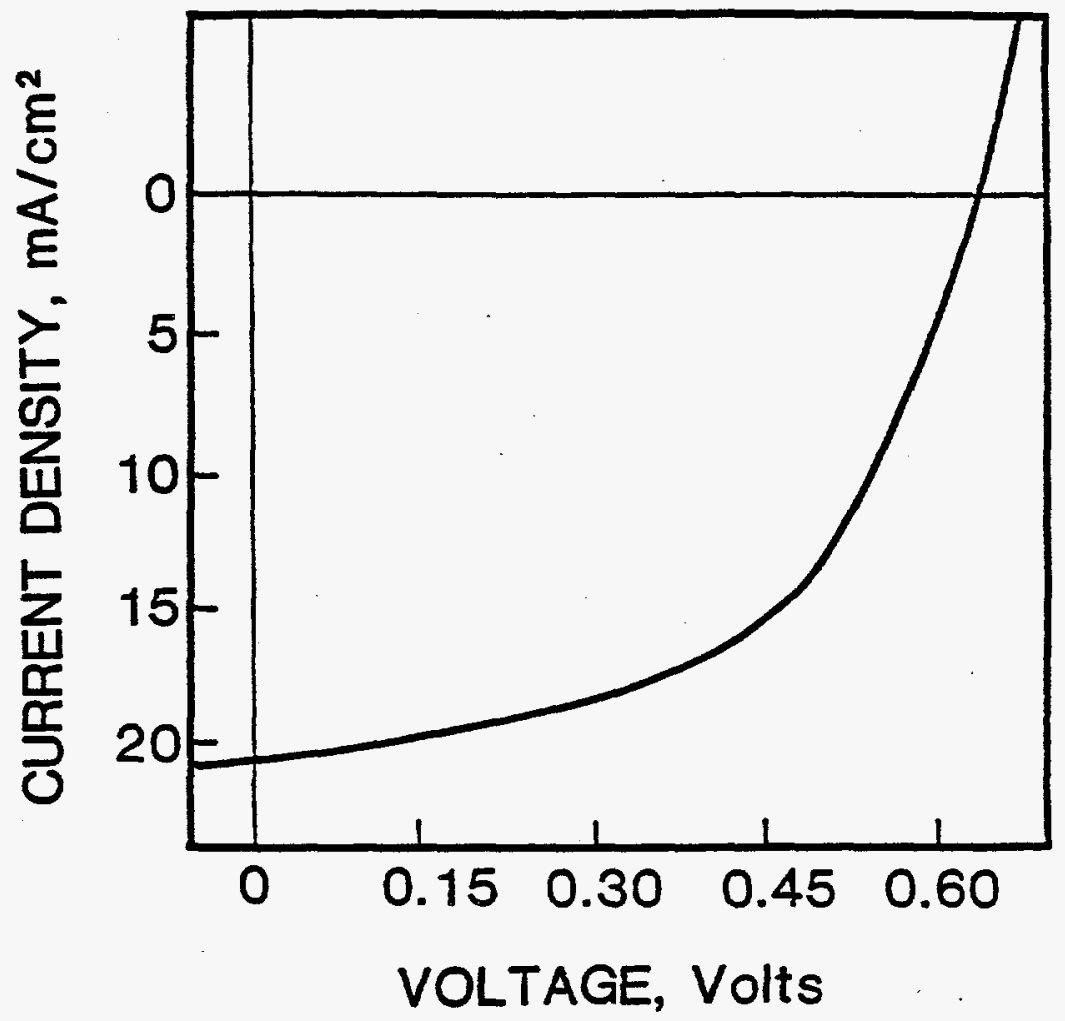

Figure 5-9 Illuminated current-voltage characteristics of a thin film $\mathrm{CdTe} /$ $\mathrm{Cd}_{0.7} \mathrm{Zn}_{0,3} \mathrm{Te} / \mathrm{Cd}_{0,7} \mathrm{Zn}_{0,3} \mathrm{~S}$ solar cell. 


\section{SECTION 6.0}

\section{MERCURY ZINC TELLURIDE FILMS AND SOLAR CELLS}

Mercury telluride, a semimetal, forms solid solutions with other group IIB tellurides: $\mathrm{Hg}_{1-x} \mathrm{Cd}_{x} \mathrm{Te}$ and $\mathrm{Hg}_{1-x} \mathrm{Zn}_{\mathrm{x}} \mathrm{Te}$. The $\mathrm{Hg}_{1-x} \mathrm{Cd}_{\mathrm{x}} \mathrm{Te}$ system has been extensively studied since the similarity in the lattice parameters of $\mathrm{HgTe}$ and $\mathrm{CdTe}$ facilitates the material growth process. The development of improved techniques for better control of crystallinity and homogeneity has contributed to the success of using $\mathrm{Hg}_{1-x} \mathrm{Cd}_{\mathrm{x}} \mathrm{Te}$ for infrared detectors over a wide spectral range. The $\mathrm{Hg}_{1-x} \mathrm{Zn}_{\mathbf{x}}$ Te system has been under study in the recent years. Bulk crystals of $\mathrm{Hg}_{0.85} \mathrm{Zn}_{0.15} \mathrm{Te}$ have been grown by the travelling heater method using tellurium as a solvent; this material was found to have a higher hardness than $\mathrm{Hg}_{1-x} \mathrm{Cd}_{x} \mathrm{Te}$ [62]. The higher bonding strength in $\mathrm{Hg}_{1-x} \mathrm{Zn}_{\mathrm{x}} \mathrm{Te}$ has prompted further investigations on the epitaxial growth and properties of $\mathrm{Hg}_{1-x} \mathrm{Zn}_{\mathrm{x}} \mathrm{Te}$ films. Epitaxial layers of $\mathrm{Hg}_{0.84} \mathrm{Zn}_{0.16} \mathrm{Te}$ and $\mathrm{Hg}_{0.77} \mathrm{Zn}_{0.23} \mathrm{Te}$ have been grown on CdTe substrates by liquid phase epitaxy from a Te solution of $\mathrm{Hg}$ and $\mathrm{ZnTe}$ [63]; their optical and electrical properties were found to be similar to those of $\mathrm{p}-\mathrm{Hg}_{1-x} \mathrm{Cd}_{x} \mathrm{Te}$. Epitaxial $\mathrm{Hg}_{1-x} \mathrm{Zn}_{\mathrm{x}} \mathrm{Te}$ films with properties comparable to high quality $\mathrm{Hg}_{1-x} \mathrm{Cd}_{x} \mathrm{Te}$ of the same cut-off frequency have also been grown on GaAs substrates by molecular beam epitaxy[64].

While epitaxial $\mathrm{HgTe}$ films have been grown on CdTe substrates by MOCVD using $\mathrm{Hg}$ and DMTe[65] or DMHg and DETe[66], the MOCVD of $\mathrm{Hg}_{1-z} \mathrm{Zn}_{\mathrm{x}} \mathrm{Te}$ is little known. In this program, the reaction of $\mathrm{Hg}, \mathrm{DMZn}$, and DIPTe has been used for the deposition of $\mathrm{Hg}_{1-x} \mathrm{Zn}_{x}$ Te films. The deposition of $\mathrm{Hg}_{1-\mathrm{x}} \mathrm{Zn}_{\mathbf{r}} \mathrm{Te}$ films is complicated by (1) the large difference in reactivity and stability of $\mathrm{HgTe}$ and $\mathrm{ZnTe}$, and (2) the high partial pressure of $\mathrm{Hg}$ over $\mathrm{Hg}_{1-x} \mathrm{Zn}_{x} \mathrm{Te}$ [67]. For example, the vapor pressure of $\mathrm{Hg}$ over $\mathrm{Hg}_{0.3} \mathrm{Zn}_{0.7} \mathrm{Te}$ has been estimated to be $1 \mathrm{~atm}$ and $0.1 \mathrm{~atm}$ at $630^{\circ} \mathrm{C}$ and $250^{\circ} \mathrm{C}$, respectively. Thus, the deposition of $\mathrm{Hg}_{1-x} \mathrm{Zn}_{\mathrm{x}} \mathrm{Te}$ films should be carried out at low temperatures to minimize the dissociation of $\mathrm{Hg}_{1-2} \mathrm{Zn}_{\mathrm{x}} \mathrm{Te}$. However, the deposition rate decreases exponentially with decreasing substrate temperature. A compromise must therefore be made.

The bandgap energy of $\mathrm{Hg}_{1-x} \mathrm{Zn}_{\mathrm{x}} \mathrm{Te}$ films is determined by several interrelated parameters including the substrate temperature, the partial pressure of $\mathrm{Hg}$ in the reaction chamber, and the DIPTe/DMZn molar ratio in the reaction mixture. Figure 6-1 shows the bandgap energy of $\mathrm{Hg}_{1-x} \mathrm{Zn}_{\mathrm{x}} \mathrm{Te}$ films as a function of substrate temperature in a series of experiments where the partial pressure of $\mathrm{Hg}$ and the DIPTe/DMZn molar ratio were maintained at 0.022 atm and 5.2, respectively (the wall of the reaction chamber must be kept at $195^{\circ} \mathrm{C}$ or above to avoid the condensation of $\mathrm{Hg}$ ). The increase in bandgap energy with increasing temperature is expected, since at a fixed $\mathrm{Hg}$ partial pressure, the $\mathrm{HgTe}$ content in $\mathrm{Hg}_{1-x} \mathrm{Zn}_{\mathbf{x}} \mathrm{Te}$ decreases with increasing temperature.

At a given substrate temperature, the bandgap energy of $\mathrm{Hg}_{1-x} \mathrm{Zn}_{\mathbf{x}} \mathrm{Te}$ films may also be varied by varying the DIPTe/DMZn molar ratio in the reaction mixture. Using a $\mathrm{Hg}$ partial pressure of $0.022 \mathrm{~atm}$ in the reaction chamber and a substrate temperature of $375^{\circ} \mathrm{C}$, the bandgap energy of $\mathrm{Hg}_{1 \cdot x} \mathrm{Zn}_{\mathrm{x}} \mathrm{Te}$ can be adjusted in the range of $1.55-1.95 \mathrm{eV}$ by varying the DIPTe/DMZn molar ratio, as shown in Fig. 6-2. This is due to the difference in the ease 


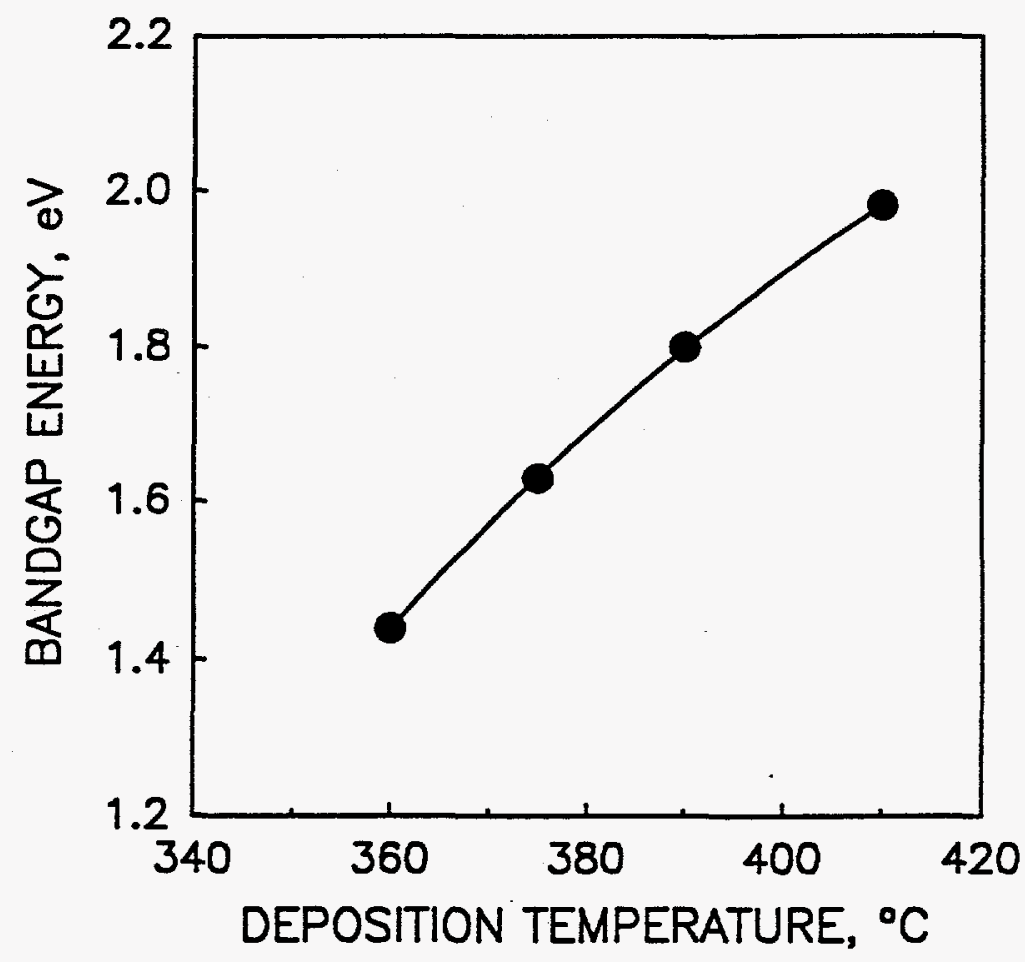

Figure 6-1 Bandgap energy of $\mathrm{Hg}_{1-x} \mathrm{Zn}_{\mathbf{x}} \mathrm{Te}$ as a function of substrate temperature.

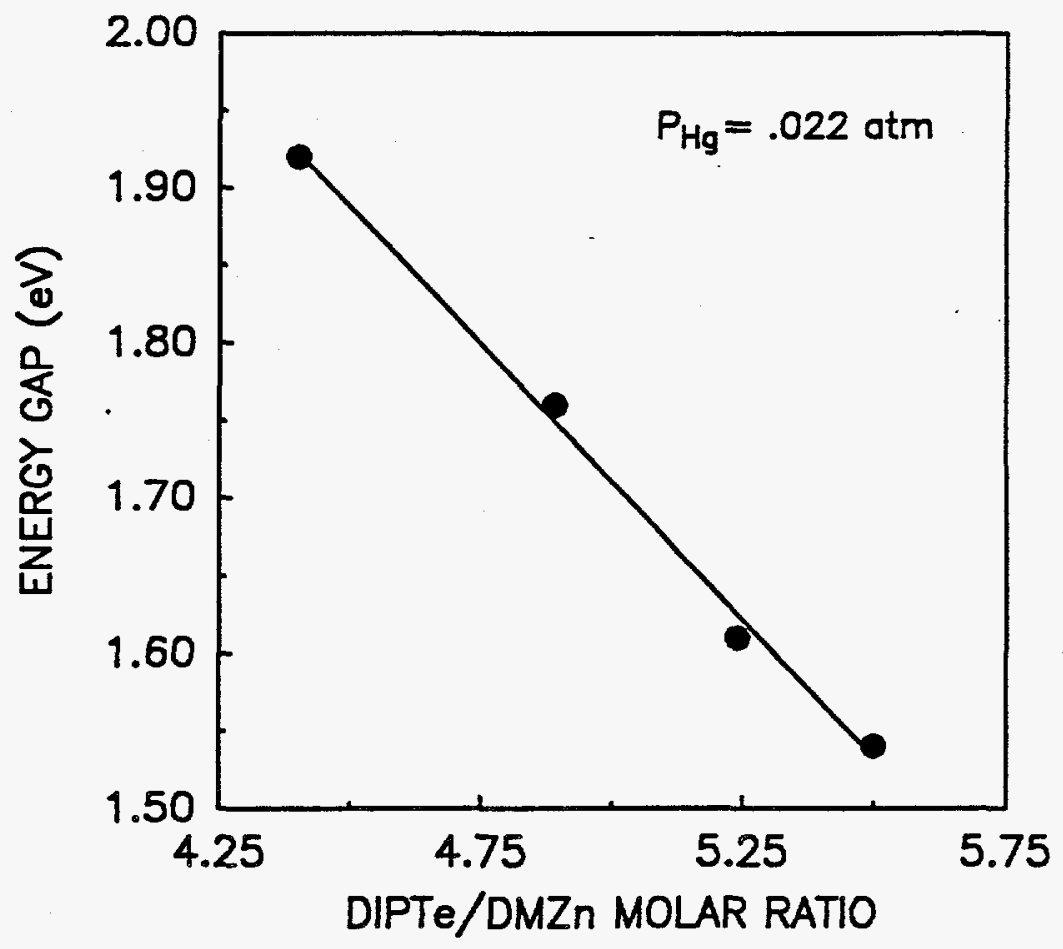

Figure 6-2 Bandgap energy of $\mathrm{Hg}_{1-x} \mathrm{Zn}_{\mathbf{2}}$ Te as a function of DIPTe/DMZn molar ratio in the reaction mixture. 
of formation of $\mathrm{HgTe}$ and $\mathrm{ZnTe}$. As the DIPTe/DMZn molar ratio increases, the $\mathrm{Hg} / \mathrm{DMZn}$ ratio also increases, resulting in a higher HgTe content, or lower bandgap energy of the resulting film.

All $\mathrm{Hg}_{1-x} \mathrm{Zn}_{\mathrm{x}} \mathrm{Te}$ films with bandgap energy of $1.55-1.95 \mathrm{eV}$ deposited at $375^{\circ} \mathrm{C}$ with a $\mathrm{Hg}$ pressure of $0.022 \mathrm{~atm}$ are of p-type conductivity. The lateral resistivity of these films on glass substrates were measured in the dark and under illumination with ELH lamps at 100 $\mathrm{mW} / \mathrm{cm}^{2}$ by the potential probe technique. The results are shown in Fig. 6-3. Since the bandgap energy decreases with increasing DIPTe/DMZn molar ratio, the resistivity of $\mathrm{Hg}_{1-x} \mathrm{Zn}_{\mathbf{x}} \mathrm{Te}$ films decreases as the HgTe content increases, as expected. The photoconductivity ratio also increases with increasing $\mathrm{HgTe}$ content in $\mathrm{Hg}_{1-x} \mathrm{Zn}_{\mathbf{x}} \mathrm{Te}$.

Since the $\mathrm{Hg}_{1-2} \mathrm{Zn}, \mathrm{Te}$ films deposited without intentional doping are of high resistivity, $\mathrm{AsH}_{3}$ was used as a dopant. Figure 6-4 shows the dark resistivity of $\mathrm{Hg}_{0.25} \mathrm{Zn}_{0.75} \mathrm{Te}(\mathrm{Eg}=1.65 \mathrm{eV})$ films as a function of $\mathrm{AsH}_{3}$ concentration in the reaction mixture, the deposition was also carried out at $375^{\circ} \mathrm{C}$ with a $\mathrm{Hg}$ pressure of $0.022 \mathrm{~atm}$.

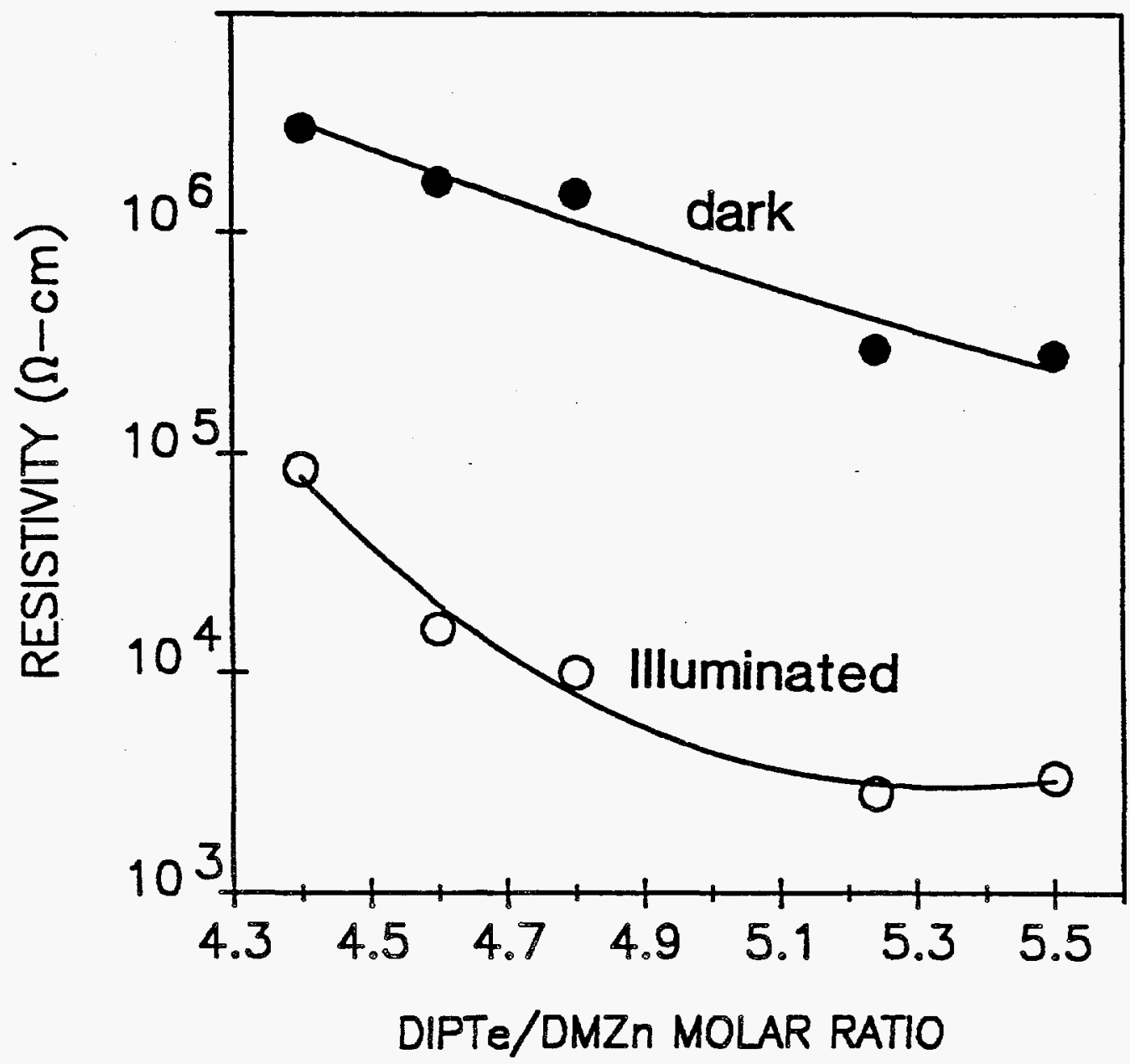

Figure 6-3 Lateral resistivity of $\mathrm{Hg}_{1-x_{2}} \mathrm{Zn}_{\mathrm{x}} \mathrm{Te}$ films on glass substrates in the dark and under illumination with ELH lamps at $100 \mathrm{~mW} / \mathrm{cm}^{2}$. 


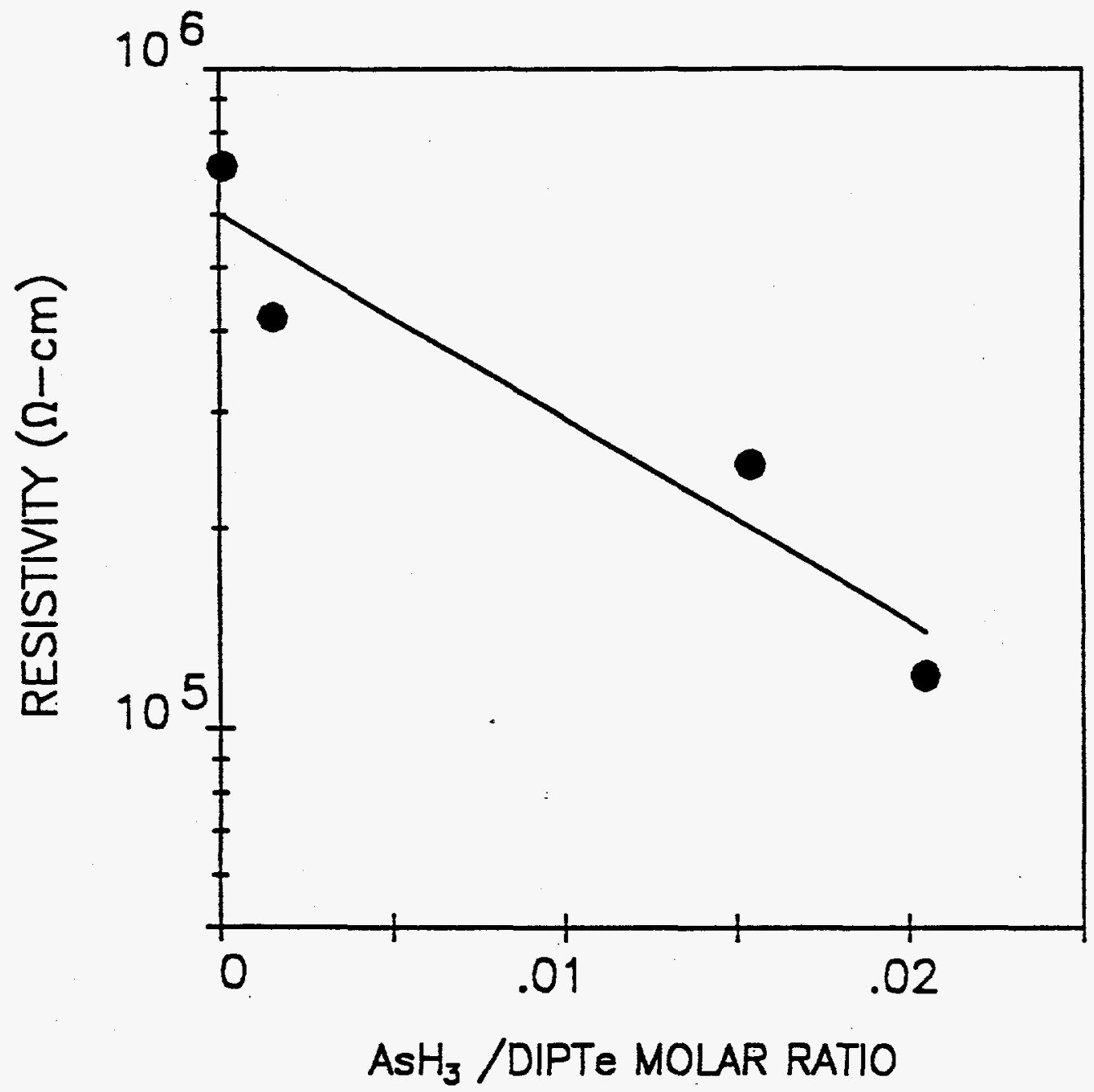

Figure 6-4 Dark resistivity of $\mathrm{Hg}_{0.25} \mathrm{Zn}_{0.75} \mathrm{Te}$ films as a function of $\mathrm{AsH}_{3}$ concentration in the reaction mixture.

Several thin film $\mathrm{Hg}_{1-x} \mathrm{Zn}_{x}$ Te solar cells were made by using Al-doped $\mathrm{Cd}_{0.7} \mathrm{Zn}_{0.3} \mathrm{~S}$ films deposited on $\mathrm{SnO}_{2}: \mathrm{F} /$ glass as substrates. The absorber was deposited at $375^{\circ} \mathrm{C}$ under a $\mathrm{Hg}$ pressure of $0.022 \mathrm{~atm}$. Figure 6-5 shows the current-voltage characteristics of a thin film $\mathrm{Hg} \mathrm{g}_{0.2} \mathrm{Zn}_{0.75} \mathrm{Te} / \mathrm{Cd}_{0.7} \mathrm{Zn}_{0.3} \mathrm{~S}$ solar cell under illumination with $\mathrm{ELH}$ lamps at $100 \mathrm{~mW} / \mathrm{cm}^{2}$. The low photocurrent, about $4.5 \mathrm{~mA} / \mathrm{cm}^{2}$, is related to the defects at the interface and in the grains of the $\mathrm{Hg}_{0.25} \mathrm{Zn}_{0.75} \mathrm{Te}$ film near the junction. However, definitive conclusions cannot be made from this limited study, and further work is required. 


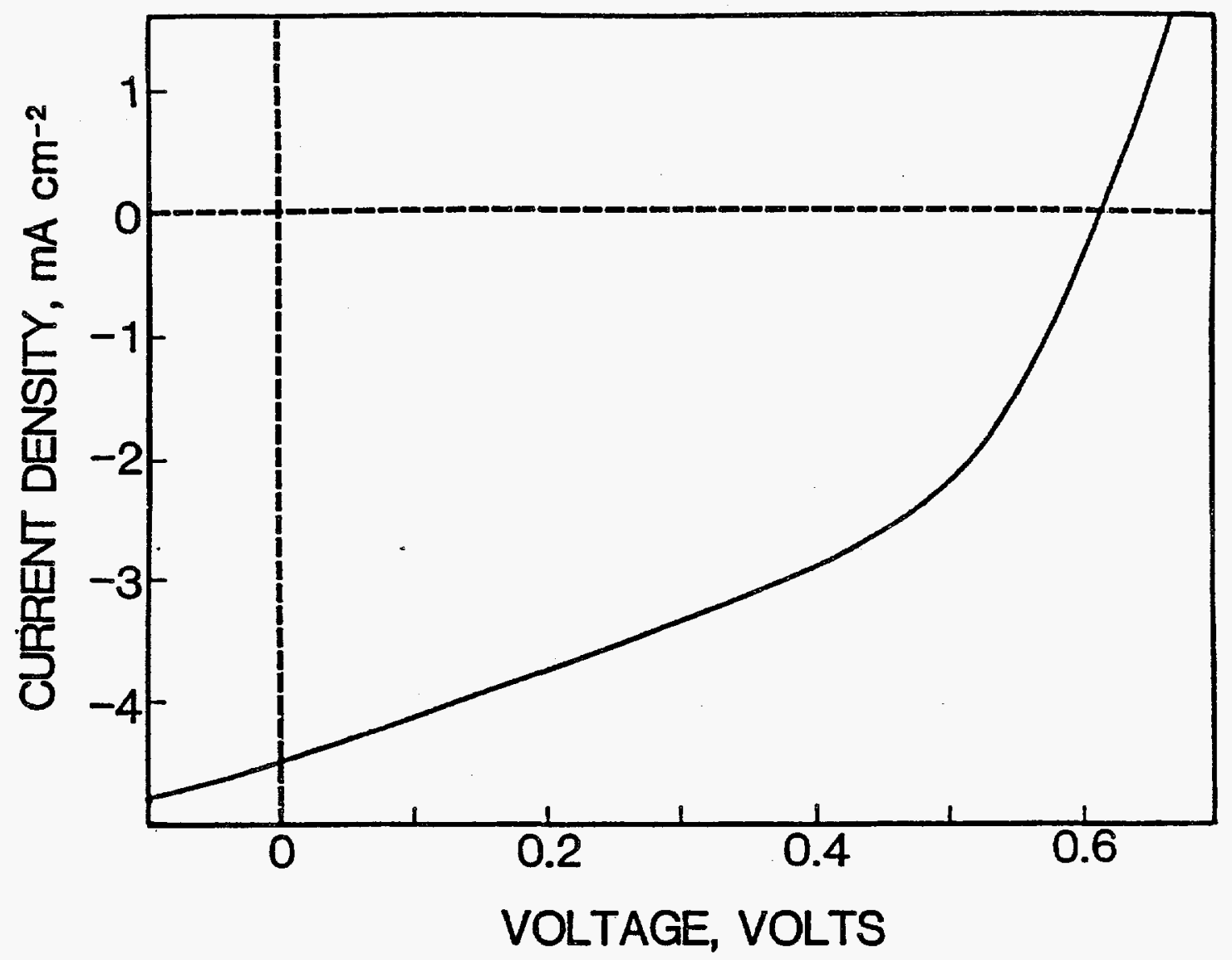

Figure 6-5 Illuminated current-voltage characteristics of a thin film $\mathrm{Hg}_{0.25} \mathrm{Zn}_{\text {a.95 }} \mathrm{Te} / \mathrm{Cd}_{0.7} \mathrm{Zn}_{\mathbf{0 . 3}} \mathrm{S}$ solar cell. 


\section{SECTION 7.0}

\section{CONCLUSIONS}

- Solution growth is a versatile technique for the deposition of device-quality CdS films.

- Close-spaced sublimation is well-suited for the high rate deposition of device quality CdTe films.

- The use of solution-grown CdS films and CSS CdTe films has demonstrated high efficiency thin film CdS/CdTe solar cells.

- $\quad \mathrm{CdS}$ is best suited for efficient CdTe solar cells. $\mathrm{ZnO} / \mathrm{CdTe}, \mathrm{ZnTe} / \mathrm{CdTe}$, and $\mathrm{SnO}_{2} / \mathrm{CdTe}$ junctions all show low photovoltage.

- MOCVD is a flexible technique for the deposition of TCS (window material) films of controlled properties, such as $\mathrm{Cd}_{1-x} \mathrm{Zn}_{2} \mathrm{~S}, \mathrm{ZnSe}, \mathrm{ZnO}$, and $\mathrm{SnO}_{2}$, at low temperatures.

- MOCVD of CdTe films has the advantage that $\mathrm{n}$ - and p-type films can be deposited at relatively low temperatures by intrinsic or extrinsic doping. However, the asdeposited films show poor microstructure and poor photovoltaic characteristics. The $\mathrm{CdCl}_{2}$ treatment enhances the grain growth and dramatically improves the solar cell characteristics.

- MOCVD is a convenient technique for the deposition of thin films of II-VI ternary compounds, such as cadmium zinc telluride and mercury zinc telluride. The grain growth techniques must be developed for these compounds to demonstrate their potential.

- The cost of metalorganic compounds has been increasing during the past three years. The cost reduction by a factor of 50 or more, required to meet the cost goals of the National Photovoltaic Program, is highly unlikely in the near future. 


\section{SECTION 8.0}

\section{DIRECTIONS FOR FUTURE RESEARCH}

The feasibility of using solution-grown CdS and CSS CdTe for efficient thin film CdS/CdTe solar cells has been established. The major elements of the device, CdS, CdTe, ohmic contact, and the two interfaces, are better understood. There appears to be considerable room for improvements; $18 \%$ efficiency should be achievable in $2-3$ years. The following tasks should be included in future research programs.

- Optimization of the deposition process to yield large grain (10 $\mu \mathrm{m}$ for example) CaTe films.

- Development of grain enhancement techniques for $\mathrm{CdTe}$ films (the $\mathrm{CdCl}_{2}$ treatment is not effective for large grain films).

- Characterization of the CdS/CdTe interface and grain boundaries by various analytical techniques at NREL.

- Passivation of grain boundaries in CdTe films.

- Optimization of contact material to p-CdTe for stability and reproducibility.

- Reduction of optical reflection at various interfaces. 
SECTION 9.0

\section{REFERENCES}

[1] N.R. Pavaskar, C.A. Menezes, and A.P.B. Sinha, "Photoconductive Films by a Chemical Bath Deposition Process," J. Electrochem. Soc., 124, 763 (1977).

[2] R.L. Call, N.K. Jaber, K. Seshan, and J.R. Whyte, Jr., "Structural and Electronic Properties of Three Aqueous-Deposited Films: CdS, CdO, ZnO, for Semiconductor and Photovoltaic Applications," Solar Energy Materials, 2, 373 (1980).

[3] I. Kaur, D.K. Pandya, and K.L. Chopra, "Growth Kinetics and Polymorphism of Chemically Deposited CdS Films," J. Electrochem. Soc., 127, 943 (1980).

[4] A. Mondal, T.K. Chaudhuri, and P. Pramanik, "Deposition of Cadmium Chalcogenide Thin Films by a Solution Growth Technique using Triethanolamine as a Complexing Agent," Solar Energy Materials, I, 431 (1983)

[5] WJ. Danaher, LE. Lyons, and G.C. Morris, "Some Properties of Thin Films of Chemically Deposited Cadmium Sulfide," Solar Energy Materials, 12, 137 (1985).

[6] Ting L. Chu, "Thin Film Cadmium Telluride, Zinc Telluride, and Mercury Zinc Telluride Solar Cells," Annual Technical Report, NREL Subcontract XI-8-18091-1, July 1989.

[7] L.C. Burton, B. Baron, T.L. Hench, and J.D. Meakin, "Formation and Characterization of $(\mathrm{CdZn}) \mathrm{S}$ Films and $(\mathrm{CdZn}) \mathrm{S} / \mathrm{Cu}_{2} \mathrm{~S}$ Heterojunctions," $\mathrm{J}$. Electronic Materials, Z, 159 (1978).

[8] T.M. Razykov, "Physical Properties of $\mathrm{Zn}_{x} \mathrm{Cd}_{1-x} \mathrm{~S}$ Films Fabricated by CVD for Use in Solar Cells," Solar Energy Materials, 12, 233 (1985).

[9] N. Romeo, G. Sberveglieri, and L. Tarricone, "Low Resistivity ZnCdS Films for Use as Windows in Heterojunction Solar Cells," Appl. Phys. Lett., 32, 807 (1978).

[10] G.K. Padam, G.L. Malhorta, and S.V.M. Rao, "Studies on Solution-Grown Thin Films of $\mathrm{Zn}_{\mathrm{x}} \mathrm{Cd}_{1-\mathrm{x}} \mathrm{S},{ }^{,} \mathrm{J}$. Appl. Phys. 63, 770 (1988).

[11] A.L Fahrenbruch, J. Aranovich, F. Courreges, T. Chynoweth, and R.H. Bube, "Recent Investigation of Metal Oxide/CdTe Heterojunction Solar Cells," Conference Record of the 13th IEEE Photovoltaic Specialists Conference, p.281 (1978).

[12] S.K. Ghandhi and R.J. Field, "Highly Oriented Zinc Oxide Films Grown by the Oxidation of Diethylzinc," Appl. Phys. Lett. 37, 449 (1980). 
[13] S. Oda, H. Tokunaga, N. Kitajama, J. Hanna, I. Shimizu, and H. Kokado, "Highly Oriented ZnO Films Prepared by MOCVD from Diethylzinc and Alcohols," Џap. J. Appl. Phys. 24, 1607 (1985).

[14] J. Hu and R.G. Gordon, Textured Fluorine-Doped ZnO Films by Atmospheric Pressure Chemical Vapor Deposition," Solar Cells, 30, 437 (1991).

[15] K. Mitchell, C. Eberspacher, J. Ermer, and D. Pier, "Single and Tandem Junction CuInSe $_{2}$ Cell and Module Technology," Conference Record of the 20th IEEE Photovoltaic Specialists Conference, p.1384 (1988).

[16] S.G. Parker and J.E. Pinnell, "Growth and Properties of ZnSe Crystals by Chemical Transport," Trans, Met. Soc. AIME, 245, 451 (1969).

[17] H.J. Hovel and A.G. Milnes, The Epitaxy of ZnSe on Ge, GaAs, and ZnSe by an $\mathrm{HCl}$ Close-Spaced Transport Process," J. Electrochem, Soc., 116, 843 (1969).

[18] M. Aven and W. Garwacki, "Synthesis and Transport Properties of ZnSe-ZnTe Mixed Crystals in n- and p-type Form," Appl. Phys. Lett. 5, 160 (1964).

[19] W.M. Yim and EJ. Stofko, "Vapor-Phase Epitaxial Growth and Some Properties of ZnSe, ZnS, and CdS," J.Electrochem. Soc. 112, 381 (1972).

[20] T. Matsumoto and T. Ishida, "Chemical Vapor Deposition of Zinc Chalcogenides Using Elemental Source Materials," I. Crystal Growth, 67, 135 (1984).

[21] J.M. Pawlikowski, "Preparation and Characterization of Close-Spaced Vapor Transport Thin Films of ZnSe for Heterojunction Solar Cells," Thin Solid Films, 127. 9 (1985).

[22] S. Sritharom, K.A. Jones, and K.M. Motyl, "The MOCVD Growth of ZnSe Using $\mathrm{Me}_{2} \mathrm{Zn}, \mathrm{H}_{2} \mathrm{Se}$, and $\mathrm{SeEt}_{2}$," J.Crystal Growth, 68, 656 (1984).

[23] H. Ando, H. Inuzuka, M. Konagai, and K. Takahashi, "Photoenhanced Metalorganic Chemical Vapor Deposition of ZnSe Films Using Diethylzinc and Dimethylselenide," J. Appl. Phys, 58, 802 (1985).

[24] T. Yogokawa, M. Ogura, and T. Kajiwara, "High Quality ZnSe Films Grown by Low Pressure Metalorganic Vapor Phase Epitaxy Using Methylalkyls," Appl. Phys. Lett., 50, 1065 (1987).

[25] H. Kukimoto, "MOCVD Growth and Doping of ZnSe and Related II-VI Materials," in MRS Symposium Proc. 161, 91 (1990).

[26] A. Taike, M. Migita, and H. Yamamoto, "P-type Conductivity Control of ZnSe Highly Doped with Nitrogen by Metalorganic Molecular Beam Epitaxy," Appl, Phys. Lett., 55, 1989 (1990). 
[27] K. Mochizuki and M. Takakusaki, "Growth of In-Doped $\mathrm{ZnS}_{\mathrm{x}} \mathrm{Se}_{1-\mathrm{x}}$ Single Crystals," Phys. Stat. Sol., (a) 94,243 (1986).

[28] See, for instance, R.H. Bube, "Photoconductivity of Solids," John Wiley \& Sons, New York, p.404 (1967).

[29] A. Noulri, R.J. Stirn, P.V. Meyers, and C.H. Lin, "High Efficiency CdTe Thin Film Solar Cells Using Metalorganic Chemical Vapor Deposition Technique," L. Vac. Sci. Technol., A Z 883 (1989).

[30] A. Rohtagi, S.A. Ringel, R. Sudharsanan, P.V. Meyers, C.H. Lin, and V. Ramanathan, "Investigation of Polycrystalline CdZnTe, CdMnTe, and CdTe Films for Photovoltaic Applications," Solar Cells, 27, 219 (1989).

[31] T.L. Chu, Shirley S. Chu, Y. Pauleau, K. Murthy, and E.D. Stokes,"Cadmium Telluride Films on Foreign Substrates," J. Appl. Phys. 54, 398 (1983).

[32] T.L. Chu, Shirley S. Chu, F. Friszt, H.A. Naseem, and R. Stawski, "Deposition and Characterization of p-Type Cadmium Telluride Films," L. Appl. Phys, 58, 1349 (1985).

[33] C.W. Tang and F. Vazan, "Effect of Oxygen on the Photoluminescence of CdS/CdTe Thin Films," I. Appl, Phys, 55, 3886 (1984).

[34] C.H. Wang, K.Y. Cheng, and S.J. Yang, "Photoluminescence in CdTe Grown on GaAs by Metalorganic Chemical Vapor Deposition," Appl. Phys. Lett., 46, 962 (1985).

[35] Z.C. Feng, M.J. Bevan, W.J. Choyke, and S.V. Krishnaswamy, "A Photoluminescence Comparison on CdTe Thin Films Grown by Molecular Beam Epitaxy and Metalorganic Chemical Vapor Deposition," J. Appl. Phys, 64, 2595 (1988).

[36] Z.C. Feng, M.G. Burke, and W.J. Choyke, "Structure Defect Related Donor-Bound Exciton Spectra in CdTe Epitaxial Films," Appl. Phys. Lett., 53, 128 (1988).

[37] J.M. Wrobel, J.J. Dubowski, and P. Bella, "Photoluminescence of Gallium Impurity in Cadmium Telluride," J. Vac. Sci. Technol. A7, 338 (1989).

[38] T. L. Chu, Shirley S. Chu, and S. T. Ang, "Electrical Properties of CdS/CdTe Heterojunctions," J. Appl. Phys., 64, 1233 (1988).

[39] N. Nakayama, H. Matsumoto, K. Yamaguchi, S. Ikegami, and Y. Hioki, "Ceramic Thin Film CdTe Solar Cell," Jap. J. Appl. Phys., 15, 2281 (1976).

[40] N. Nakayama, H. Matsumoto, A. Nakano, S. Ikegami, H. Uda, and T. Yamashita, "Screen Printed Thin Film CdS/CdTe Solar Cell," Jap. J. Appl. Phys, 19, 703 (1980). 
[41] P.V. Meyers, C.H. Liu, and T.J. Frey, "Heterojunction P-i-N Photovoltaic Cell," U.S. Patent 4, 710, 589.

[42] Y.K. Jun and H.B. Im, "Effect of Thickness and Sintering Conditions of CdS Films on the Photovoltaic Properties of CdS/CdTe Solar Cells," J. Electrochem. Soc. 135, 1658 (1988).

[43] S.A. Ringel, A.W. Smith, M.H. MacDougal, and A. Rohtagi, "The Effects of $\mathrm{CdCl}_{2}$ on Electronic Properties of Molecular-Beam Epitaxially Grown CdTe/CdS Heterojunction Solar Cells," J. Appl, Phys, 70, 881 (1991).

[44] Zh.R. Panosyan, "Radiation Recombination in Cadmium Telluride Crystals," in Proceedings of the P. IV. Lebedev Physics Institute, Vol 68, "Radiation Recombination in Semiconductor Crystals, " D.V. Skobeltsyn, Consultant Bureau, New York (1975).

[45] T.L. Chu, Thin Film Cadmium Telluride Solar Cells by Two Chemical Vapor Deposition Techniques," Solar Cells 23, 31 (1988).

[46] T.L. Chu, Shirley S. Chu, F. Firszt, and C. Herrington, "Deposition and Properties of Zinc Telluride and Cadmium Zinc Telluride Films," L.Apol. Phys., 59, 1259 (1986).

[47] F. Buch, A.L Fahrenbuch, and R.H. Bube, "Photovoltaic Properties of Five II-VI Heterojunctions," J. Appl. Phys. 48, 1596 (1977)。

[48] B. Cockayne and P.J. Wright, "Metalorganic Chemical Vapor Deposition of Wide Band Gap II-VI Compounds," L. Cryst. Growth, 68. 223 (1984).

[49] SJ.C. Irvine, J.B. Mullin, D.J. Robbins, and J.L Gasper, "A Study of UV Absorption Spectra and Photolysis of Some Group II and Group VI Alkyls," J. Electrochem. Soc. 132, 968 (1985).

[50] BJ. Morris, "Photochemical Organometallic Vapor Phase Epitaxy of Mercury Cadmium Telluride," Appl. Phys, Lett. 48, 867 (1986).

[51] J.B. Mullin and S.C. Irvine, "Ultraviolet Assisted Growth of II-VI Compounds," L Vac. Sci. Technol, A4, 700 (1986).

[52] I.S. Athwal and R.K. Bedi, "Electron Transport in Zinc Telluride Films," L. Appl, Phys., 64, 6345 (1988).

[53] D. J. Olego, J. P. Faurie, S. Sivananthan, and P. M. Raccah, "Optoelectronic Properties of $\mathrm{Cd}_{1-x} \mathrm{Zn}_{\mathbf{x}} \mathrm{Te}$ Films Grown by Molecular Beam Epitaxy on GaAs Substrates," Appl, Phys, Lett. 47, 1172 (1985). 
[54] S. Q. Qadri, E. F. Skelton, A. W. Webb, and J. Kennedy, "Evidence for Bond Strengthening in $\mathrm{Cd}_{1-x} \mathrm{Zn}_{x} \mathrm{Te}(\mathrm{x}=0.04)$," Appl, Phys. Lett. 45, 257 (1985).

[55] F. F. Morehead and G. Mandel, "Self-Compensation Limited Conductivity in Binary Semiconductors. IV, $\mathrm{n}-\mathrm{Zn}_{\mathrm{x}} \mathrm{Cd}_{1-\mathrm{x}} \mathrm{Te},{ }^{\mathrm{Phys}}, \mathrm{Rev}_{\mathrm{w}}, 137, \mathrm{~A} 294$ (1964).

[56] F. F. Morehead and G. Mandel, "Efficient, Visible Electroluminescence from p-n Junctions in $\mathrm{Zn}_{x} \mathrm{Cd}_{1-x} \mathrm{Te}$," Appl. Phys, Lett., 5,53 (1965).

[57] A. Kanamori, T. Ota, and K. Takahashi, "Liquid-Phase Epitaxial Growth of ZnTe and $\mathrm{Zn}_{1-x} \mathrm{Cd}_{\mathrm{x}} \mathrm{Te}$," J. Electrochem. Soc., 122,1117 (1975).

[58] S. B. Quadri and J. H. Dinan, "X-ray Determination of Dislocation Density in Epitaxial ZnCdTe," Appl. Phys. Lett. 47, 1066 (1985).

[59] R. D. Feldman, R. F. Austin, A. H. Dayem, and E. H. Westerwick, "Growth of $\mathrm{Cd}_{1-}$ $\mathrm{Zn}_{\mathbf{x}}$ Te by Molecular Beam Epitaxy," Appl. Phys. Lett. 49,797 (1986).

[60] S. A. Ringel, R. Sudharsanan, A. Rohtagi and W. B. Carter, "A Study of Polycrystalline Cd (Zn, Mn) Te/CdS Films and Interfaces," L. Electronic Materials, 19. 259 (1990).

[61] B. M. Basol, V. K. Kapur, and M. L. Ferris, "Low-Cost Technique for Preparing Cd C $_{1}$ $\mathrm{Zn}_{\mathrm{x}}$ Te Films and Solar Cells," L. Appl. Phys, 66, 1816 (1989).

[62] R. Triboulet, A. Lasbley, B. Toulouse, and R. Granger, "Growth and Characterization of Bulk HgZnTe Crystals," J. Crystal Growth, 79, 695 (1986).

[63] A. Sher, D. Eger, and A. Zemel, "Mercury Zinc Telluride, A New Narrow-Gap Semiconductor," Appl. Phys. Lett. 46, 59 (1985).

[64] S. Sivanathan, X. Chu, M. Boukerche, and J. P. Faurie, "Growth of $\mathrm{Hg}_{1-x} \mathrm{Zn}_{\mathrm{x}} \mathrm{Te}$ by Molecular Beam Epitaxy on GaAs (100) Substrates," Appl. Phys. Lett., 47, 1291 (1985).

[65] T. F. Kuech and J. O. McCaldin, "Low Temperature CVD Growth of Epitaxial HgTe on CdTe, " J. Electrochem. Soc., 128, 1142 (1981).

[66] C. H. Wang, P. Y. Lu, and L. M. Williams, "Epitaxial Growth of HgTe by Precracking Metalorganic Mercury and Tellurium Compounds," Appl. Phys. Lett., 48, 1085 (1986).

[67] K. T. Chen, Y. G. Sha, and R. F. Brebrick, "Partial Pressures of $\mathrm{Hg}$ and $\mathrm{Te}_{2}$ over $\left(\mathrm{Hg}_{1-x} \mathrm{Zn}_{\mathrm{x}}\right)_{1-\mathrm{y}} \mathrm{Te}$, Solid Solutions," L. Vac. Sci. Technol, A8, 1086 (1990). 


\section{SECTION 10.0}

\section{PUBLICATIONS AND PRESENTATIONS}

\subsection{Conference Presentations}

"Mercury Telluride as an Ohmic Contact to Efficient Thin Film Cadmium Telluride Solar Cells," presented at the 20th IEEE Photovoltaic Specialists Conference, Las Vegas, NV, September 26-30, 1988.

"Zinc Telluride Films for Photonic Devices," presented at the 176th Electrochemical Society Meeting, Hollywood, FL, October 15-20, 1989.

"Thin Film Cadmium Telluride Solar Cells," presented at the U.S. Department of Energy, Office of Conservation and Renewable Energy Program Review of Photovoltaic Research, Denver, CO, November 14, 1989.

Transparent Conducting Semiconductor/Zinc Telluride Heterojunctions by MOCVD," presented at the March 1990 Meeting of the American Physical Society, Anaheim, CA, March 12-16, 1990.

"Thin Film CdTe Homojunctions by MOCVD," presented at the 21st IEEE Photovoltaic Specialists Conference, Orlando, FL, May 21-25, 1990.

"MOCVD Cadmium Telluride and Zinc Telluride Films for Photovoltaic Devices," presented at the 2nd International Conference on Electronic Materials, Materials Research Society, Newark, NJ, September 17-19, 1990.

"CdTe and Alloys by CSS and MOCVD," presented at the SERI PV AR\&D 10th Review Meeting, Lakewood, CO, October 23-25, 1990.

"Films and Junctions of Cadmium Zinc Telluride and Mercury Zinc Telluride by MOCVD," presented at the 5th Biennial Workshop on Organometallic Vapor Phase Epitaxy, Panama City Beach, FL, April 14-17, 1991.

"Cadmium Zinc Telluride Films by Metalorganic Chemical Vapor Deposition," presented at the 5th International SAMPE Electronic Materials and Processes Conference, Los Angeles, CA, June 18-20, 1991.

"High Efficiency Thin Film CdS/CdTe Heterojunction Solar Cells," presented at the 5th International Conference on II-VI Compounds, Okayama, Japan, September 8-13, 1991. 
"High Efficiency CdS/CdTe Solar Cells from Solution-Grown CdS Films," presented at the 22nd IEEE Photovoltaic Specialists Conference, Las Vegas, NV, October 7-11, 1991.

"Cadmium Zinc Sulfide Films for Heterojunction Devices," presented at the 22nd IEEE Photovoltaic Specialists Conference, Las Vegas, NV, October 7-11, 1991.

\subsection{Refereed Publications}

T.L. Chu, Shirley S. Chu, and S.T. Ang, "Electrical Properties of CdS/CdTe Heterojunctions," \. Appl. Phys., 64, 1223 (1988).

T.L. Chu, "Cadmium Telluride Solar Cells," Chapter 3 in Current Topics in Photovoltaics, Academic Press, pp 235-300 (1988).

T.L. Chu and Shirley S. Chu, "Degenerate Cadmium Oxide Films for Electronic Devices," J. Electronic Mater. 19, 1003 (1990).

T.L. Chu, Shirley S. Chu, C. Ferekides, J. Britt, C.Q. Wu, G. Chen, and N. Schultz, "Thin Films of II-VI Compounds and Alloys," Solar Cells, 30, 123 (1991).

T.L. Chu, Shirley S. Chu, J. Britt, C. Ferekides, and C.Q. Wu, "Zinc Telluride Films by Photoenhanced Metalorganic Chemical Vapor Deposition," J. Electronic Mater, 20, 483 (1991).

T.L. Chu, Shirley S. Chu, C. Ferekides, J. Britt, and C.Q. Wu, "Cadmium Telluride Films by Metalorganic Chemical Vapor Deposition," L. Appl. Phys., 69, 7651 (1991).

T.L. Chu, Shirley S. Chu, J. Britt, and C. Ferekides, "Cadmium Zinc Sulfide Films and Heterojunctions," L. Appl, Phys, 70, 2688 (1991).

T.L. Chu, Shirley S. Chu, C. Ferekides, C. Q. Wu, J. Britt, and C. Wang, "13.4\% Efficient Thin Film CdS/CdTe Solar Cells," J. Appl. Phys, 70, December 1991.

T.L. Chu, Shirley S. Chu, G. Chen, J. Britt, C. Ferekides, and C.Q. Wu, "Zinc Selenide Films and Heterojunctions," L. Appl. Phys., 1992.

T.L. Chu, Shirley S. Chu, C. Ferekides, J. Britt, and C.Q. Wu, "Thin Film Junctions of Cadmium Telluride by Metalorganic Chemical Vapor Deposition," submitted for publication.

T.L Chu, Shirley S. Chu, C. Ferekides, and J. Britt, "Films and Junctions of Cadmium Zinc Telluride," submitted for publication. 
T.L. Chu, Shirley S. Chu, N. Schultz, and C. Wang, "Solution-Grown Cadmium Sulfide Films for Photovoltaic Devices," submitted for publication.

\subsection{Conference Proceedings}

T.L. Chu, Shirley S. Chu, K.D. Han, and M. Mantravadi, "Mercury Telluride as an Ohmic Contact to Efficient Thin Film Cadmium Telluride Solar Cells, ${ }^{\text {" Conference }}$ Record of the 20th IEEE Photovoltaic Specialists Conference, pp 1422-1425 (1988).

T.L. Chu, Shirley S. Chu, C. Ferekides, J. Britt, and C.Q. Wu, "MOCVD Cadmium Telluride and Zinc Telluride Films for Photovoltaic Devices," Proceedings of the 2nd International Conference on Electronic Materials, Materials Research Society, pp 345-350 (1990).

T.L Chu, Shirley S. Chu, C. Ferekides, J. Britt, and C.Q. Wu, "Thin Film CdTe Homojunctions by MOCVD," Conference Record of the 21st IEEE Photovoltaic Specialists Conference, pp 777-781 (1990).

T.L. Chu, Shirley S. Chu, C. Ferekides, J. Britt, and C.Q. Wu, "Cadmium Zinc Telluride Films by Metalorganic Chemical Vapor Deposition," Proceedings of the 5th International SAMPE Electronic Materials and Processes Conference, 


\section{SECTION 11.0}

\section{STUDENTS AND ASSOCIATES SUPPORTED}

1. Jeffrey S. Britt, "Thin Films and Solar Cells of Zinc Telluride and Mercury Zinc Telluride," Ph.D., December 1991.

2. Chris S. Ferekides, Thin Film and Solar Cells of Cadmium Telluride and Cadmium Zinc Telluride," Ph.D., December 1991.

3. Gang Chen, "Zinc Selenide Films for Photovoltaic Devices," M.S., December 1991.

4. Neal Schultz, "Cadmium Sulfide Films and Heterojunction Devices," M.S., December 1991.

5. Chong Q. Wu, "Properties of CdTe Films Deposited by Close-Spaced Sublimination," M.S., December 1991.

6. Sam Kadamani, graduate student, 1988-89.

7. Chu H. Wang, Visiting Scholar, 1991.

8. Min K. Song ( $\mathrm{Ph} . \mathrm{D}$., Stevens Institute of Technology), Research Associate, 1988.

9. Bae H. Tsing (Ph.D., University of Illinois), Research Associate, 1988. 


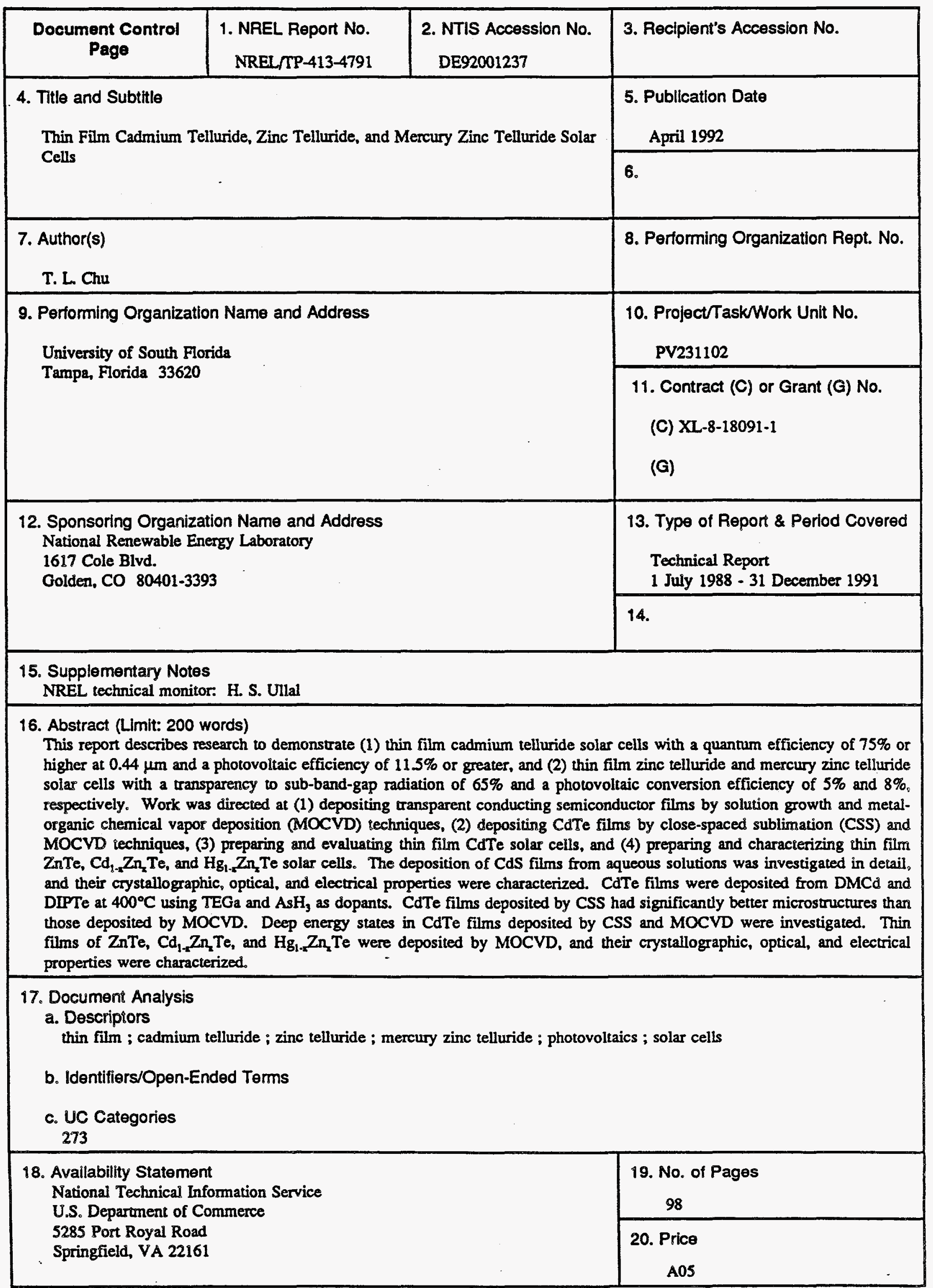

Form No. 0069E (6-30-87) 